orml

OAK RIDGE

NATIONAL

LABORATORY

LockuEg

\title{
Advanced Control Room Design Review Guidelines: Integration of the NUREG-0700 Guidelines and Development of New Human- System Interface Guidelines
}

Richard J. Carter

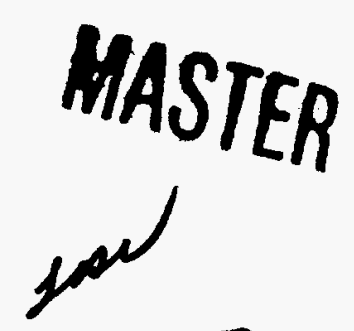

DISTRIBUTION OF THIS DOCUMENT IS UNLIMITED 
This report has been reproduced directly from the best available copy.

Available to DOE and DOE contractors from the Office of Scientific and Technical Information, P. O. Box 62, Oak Ridge, TN 37831; prices available from (423) 576-8401, FTS 626-8401.

Available to the public from the National Technical Information Service, U.S. Department of Commerce, 5285 Port Royal Road, Springfield, VA 22161.

This report was prepared as an account of work sponsored by an agency of the United States Government. Neither the United States Government nor any agency thereof, nor any of their employees, makes any warranty, express or implied, or assumes any legal liability or responsibility for the accuracy, completeness, or usefulness of any information, apparatus, product, or process disclosed, or represents that its use would not infringe privately owned rights. Reference herein to any specific commercial product, process, or service by trade name, trademark, manufacturer, or otherwise, does not necessarily constitute or imply its endorsement, recommendation, or favoring by the United States Government or any agency thereof. The views and opinions of authors expressed herein do not necessarily state or reflect those of the United States Government of any agency thereof. 
Computer Science and Mathematics Division

\title{
ADVANCED CONTROL ROOM DESIGN REVIEW GUIDELINES: INTEGRATION OF THE NUREG-0700 GUIDELINES AND DEVELOPMENT OF NEW HUMAN- SYSTEM INTERFACE GUIDELINES
}

\author{
Richard J. Carter \\ Human Systems Research Group \\ Cognitive and Information Sciences Section \\ Computer Science and Mathematics Division
}

July 1997

Research sponsored by the

U.S. Nuclear Regulatory Commission

Office of Nuclear Regulatory Research

Division of Systems Research

COTR: Jerry A. Wachtel

under U.S. Department of Energy Interagency Agreement 40-550-75

NRC FIN B0852

Prepared by the

OAK RIDGE NATIONAL LABORATORY

Oak Ridge, Tennessee 37831

managed by

LOCKHEED MARTIN ENERGY RESEARCH CORPORATION

for the

DEPARTMENT OF ENERGY

under contract number DE-AC05-960R22464 
ABSTRACT $\ldots \ldots \ldots \ldots \ldots \ldots \ldots \ldots \ldots \ldots \ldots \ldots \ldots \ldots \ldots \ldots \ldots \ldots \ldots$

ACRONYMS AND ABBREVIATIONS $\ldots \ldots \ldots \ldots \ldots \ldots \ldots \ldots \ldots \ldots \ldots$ ix

EXECUTIVE SUMMARY $\ldots \ldots \ldots \ldots \ldots \ldots \ldots \ldots \ldots \ldots \ldots \ldots \ldots \ldots \ldots \ldots$

1. INTRODUCTION $\ldots \ldots \ldots \ldots \ldots \ldots \ldots \ldots \ldots \ldots \ldots \ldots \ldots \ldots \ldots \ldots \ldots$

2. BACKGROUND .............................. 6

2.1 SUMMARY OF PRIOR EFFORTS $\ldots \ldots \ldots \ldots \ldots \ldots \ldots \ldots \ldots \ldots$

2.2 OVERVIEW OF THE NUREG-0700 GUIDELINES .......... 7

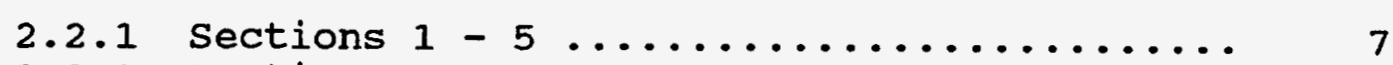

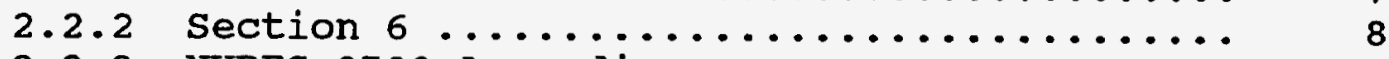

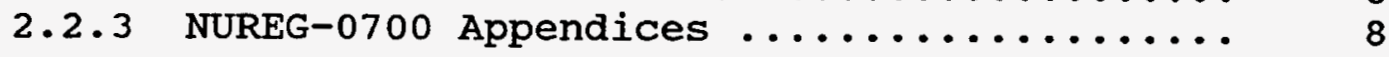

2.3 OVERVIEW OF THE ACRDR GUIDELINES ............. 9

3. INTEGRATE NUREG-0700 GUIDELINES INTO THE ACRDR

GUIDELINES ............................. 13

3.1 SUBTASK 9 A $\ldots \ldots \ldots \ldots \ldots \ldots \ldots \ldots \ldots \ldots \ldots \ldots \ldots \ldots \ldots \ldots$

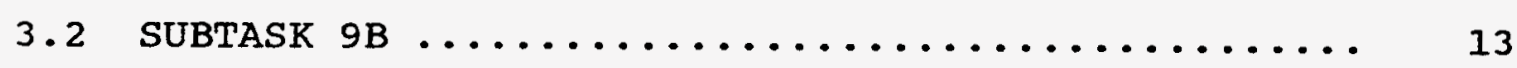

3.2 .1 objective ...................... 13

3.2 .2 Evaluation of sections $1-5$ of $\ldots \ldots \ldots \ldots$

3.2 .3 Evaluation of Section 6 of $\ldots \ldots \ldots \ldots \ldots \ldots$

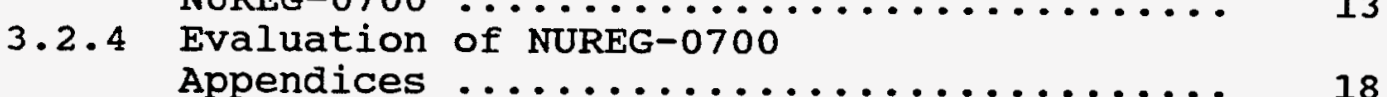

3.3 SUBTASK $9 \mathrm{C} \ldots \ldots \ldots \ldots \ldots \ldots \ldots \ldots \ldots \ldots \ldots \ldots \ldots \ldots . \ldots \ldots$

3.3 .1 Objectives ........................ 19

3.3 .2 Industry Human Factors Engineering

3.3 .3 Review of sections $i-5$ of $\ldots \ldots \ldots \ldots . \ldots \ldots$

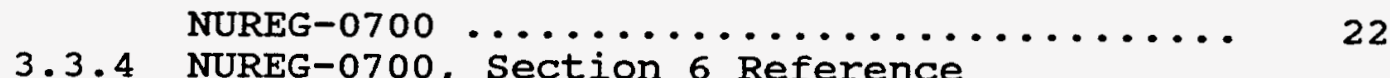

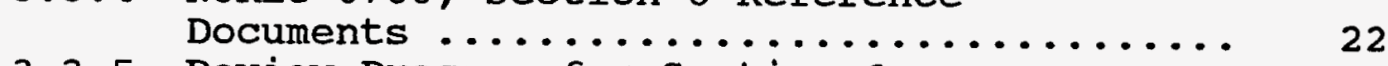

3.3 .5 Review Process for section $6 \ldots \ldots \ldots \ldots . \ldots . \ldots . \ldots 22$

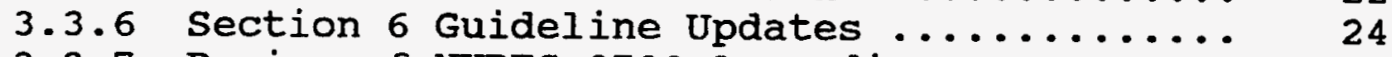

3.3 .7 Review of NUREG-0700 Appendices ......... 24 
TABLE OF CONTENTS (Continued)

Page

3.3.8 Miscellaneous Suggestions ........... 25

4. ASSESS NEW GUIDELINES DEVELOPMENT NEEDS TO

ENHANCE THE ACRDR GUIDELINES $\ldots \ldots \ldots \ldots \ldots \ldots \ldots \ldots \ldots .28$

4.1 SUBTASK $10 A \ldots \ldots \ldots \ldots \ldots \ldots \ldots \ldots \ldots \ldots \ldots \ldots \ldots \ldots \ldots \ldots \ldots, 28$

4.1 .1 Objective $\ldots \ldots \ldots \ldots \ldots \ldots \ldots \ldots \ldots \ldots \ldots \ldots \ldots \ldots$

4.1.2 Identification of Human-System

4.1.3 Description of Selected Human-

System Interface Categories .......... 30

4.2 SUBTASK $10 \mathrm{~B} \ldots \ldots \ldots \ldots \ldots \ldots \ldots \ldots \ldots \ldots \ldots \ldots \ldots \ldots \ldots \ldots \ldots$

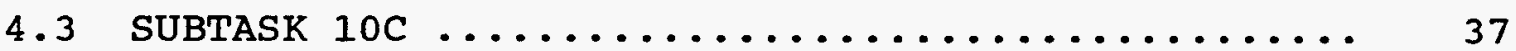

4.3 .1 Objective................... 37

4.3.2 Review of the FIN L1317 Secondary and

Tertiary sources $\ldots \ldots \ldots \ldots \ldots \ldots \ldots \ldots .6 \ldots$

4.3.3 Review of Additional Recent Human-

Computer Interaction Books and

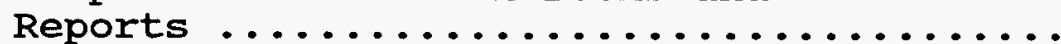

4.3.4 Review of Basic and Applied Technical Journals ............... 41

4.3.5 Review of Human-Computer Interaction Conference Proceedings ...... 42

4.3.6 Review of Library Data Bases ........... 43

4.3.7 Review of the Human-Computer Interaction Bibliography ........... 45

4.3.8 Review of Human-Computer Interaction Standards Working

Groups $\ldots \ldots \ldots \ldots \ldots \ldots \ldots \ldots \ldots \ldots$.

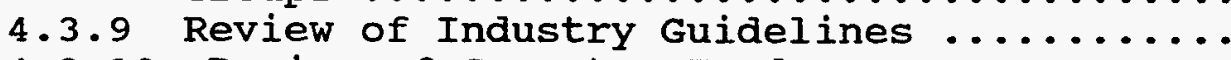

4.3.10 Review of Computer Trade Magazines and Journals ............ 50

4.3.11 Human-System Interface Categories

and Available Sources ............. 52

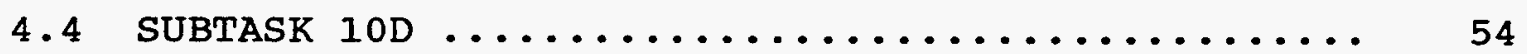

4.4 .1 Objectives ................... 54

4.4.2 Amount of Time and Level of Effort ...... 54

5. CONVERT EXISTING PRIMARY SOURCE GUIDELINES

DOCUMENTS INTO A FORM AND FORMAT COMPATIBLE WITH

NUCLEAR INDUSTRY NEEDS $\ldots \ldots \ldots \ldots \ldots \ldots \ldots \ldots \ldots \ldots$ 


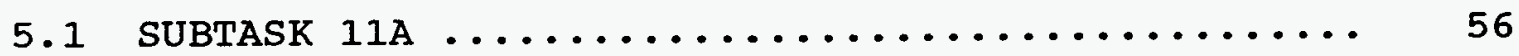

5.1 .1 objectives ...................... 56

5.1.2 Identification of NPP Control

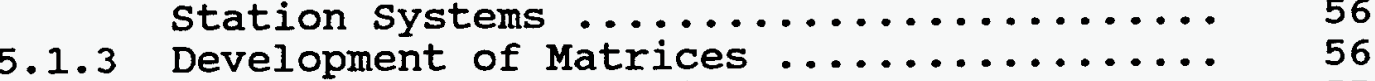

5.1 .4 NUREG-0700 Deficiencies .............. 57

5.2 SUBTASK 11 B $\ldots \ldots \ldots \ldots \ldots \ldots \ldots \ldots \ldots \ldots \ldots \ldots \ldots$

5.2 .1 objective $\ldots \ldots \ldots \ldots \ldots \ldots \ldots \ldots \ldots \ldots \ldots \ldots \ldots$

5.2.2 Modification Audit and Tracking

Systems Used by other Human

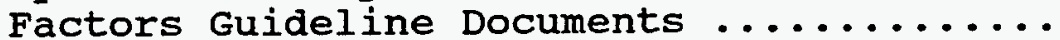

5.2.3 Other Options for the Guideline

Modification Audit and Tracking

system ......................... 59

5.2.4 Summary of the options for the

Audit and Tracking System ............. 60

5.2.5 Derived Guideline Modification

Audit and Tracking System ............. 60

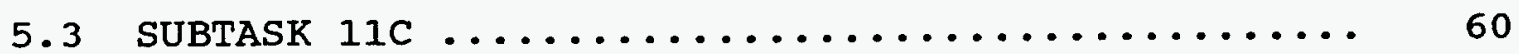

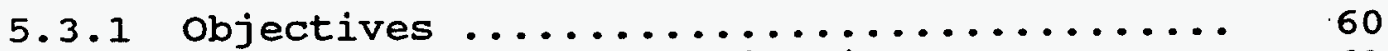

5.3 .2 Review of the ACRDR Guidelines ......... 61

6. DEVELOP ACRDR GUIDELINES FOR SELECTED ADVANCED

CONTROL/DISPIAY TECHNOLOGIES ................... 62

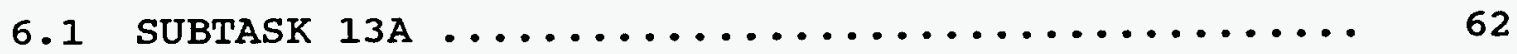

6.1 .1 objectives ....................... 62

6.1 .2 Overview of subtask specific ACRDR $\ldots \ldots \ldots \ldots . \ldots \ldots$

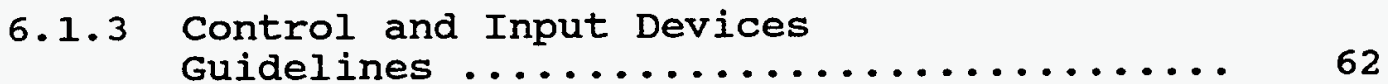

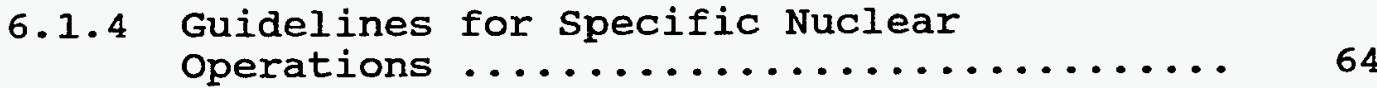

6.2 SUBTASK $13 \mathrm{~B} \ldots \ldots \ldots \ldots \ldots \ldots \ldots \ldots \ldots \ldots \ldots \ldots \ldots \ldots \ldots$

7. CONCLUSIONS................................ 65

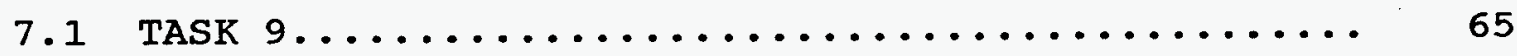

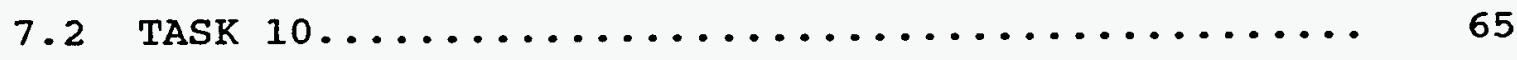


Page

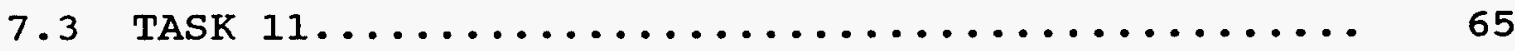

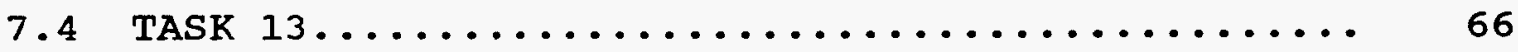

7.5 GENERAL COMMENTS..................... 66

REFERENCES $\ldots \ldots \ldots \ldots \ldots \ldots \ldots \ldots \ldots \ldots \ldots \ldots \ldots \ldots \ldots \ldots \ldots \ldots \ldots \ldots$

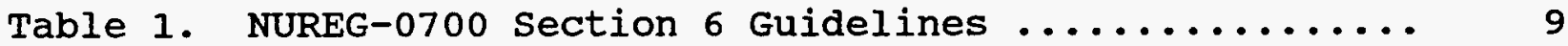

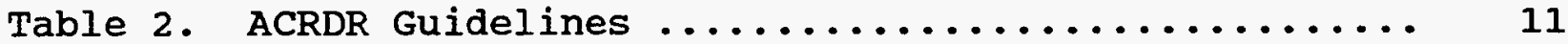

Table 3. Human Factors Guidelines by Baseline Documents .. 23

Table 4. Control and Input Device Guidelines .......... 63

Figure 1. Approach to the development of new advanced

control room design review guidelines ........ 38

APPENDIX A: TITLES AND ALPHA-NUMERIC DESIGNATIONS OF THE NUREG-0700 SECTION 6 CONTROL-RROM HUMAN

FACTORS ENGINEERING GUIDELINES ........... 83

APPENDIX B: AN OUTLINE OF THE ACRDR GUIDELINES ......... 109

APPENDIX C: CONTROL-ROOM HUMAN FACTORS ENGINEERING

GUIDELINES UPDATES ..................

APPENDIX D: DIAGRAMS TO BE INCORPORATED IN THE NUREG-0700

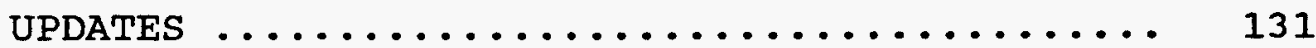

APPENDIX E: GUIDELINE BY CONTROL STATION SYSTEM MATRICES ............................. 134

APPENDIX F: NUMBERS AND TITLES OF THE MODIFIED ACRDR GUIDELINES ......................

APPENDIX G: ACRDR GUIDELINES FOR CONTROL AND INPUT DEVICES .......................

APPENDIX H: ACRDR GUIDELINES FOR SPECIFIC NUCLEAR OPERATIONS $\ldots \ldots \ldots \ldots \ldots \ldots \ldots \ldots \ldots \ldots \ldots \ldots$ 


\begin{abstract}
This report documents the work conducted in four tasks of the Nuclear Regulatory Commission (NRC) project entitled "Review Criteria for Human Factors Aspects of Advanced Controls and Instrumentation". The purpose of the first task was to integrate the applicable sections of NUREG-0700 into the advanced control room design review (ACRDR) guidelines to ensure that all applicable guidelines are together in one document and conveniently accessible to users. The primary objective of the second task was to formulate a strategy for the development of new ACRDR guidelines that have not otherwise been identified. The main focus of the third task was to modify the individual ACRDR guidelines generated to date to ensure that they are suitable for the intended nuclear power plant (NPP) control station system application. The goal of the fourth task was to develop human factors guidelines for two human-system interface categories that are missing from the current ACRDR guidelines document. During the first task those areas in NUREG-0700 that are not addressed by the ACRDR guidelines document were identified, the areas were subsequently reviewed against six recent industry human factors engineering review guidelines, and the NUREG-0700 guidelines were updated as necessary. In the second task 13 general categories of human-system interface guidelines that are either missing from or not adequately addressed by the ACRDR document were discovered, an approach was derived for the development of new ACRDR guidelines, a preliminary assessment of the available sources that may be useful in the creation of new guidelines and their applicability to the identified humansystem interface categories was performed, and an estimate was made of the amount of time and level of effort required to complete the development of needed new ACRDR guidelines. During the third task those NPP control station systems to which the NUREG-0700 and ACRDR guidelines apply were identified, matrices of such applicability were developed to support the needs of the NRC inspectors and reviewers, a guideline modification audit and tracking system was designed, and the ACRDR guidelines were reviewed and modified where appropriate to ensure that their language is applicable to the nuclear industry. In the fourth task control and input device guidelines were generated and human factors guidelines for specific nuclear operations were drafted.
\end{abstract}




\section{ACRONYMS AND ABBREVIATIONS}

ACM - Association for Computing Machinery

ACRDR - advanced control room design review

AFSC - Air Force Systems Command

ANS - American Nuclear Society

ANSI - American National Standards Institute

ASHRAE - American Society of Heating, Refrigeration, and Air-Conditioning Engineers

BNL - Brookhaven National Laboratory

BSCTE - Bell System Center for Technical Education

BWR - boiling water reactor

CHI - computer-human interaction

CHSS - containment hydrogen sampling system

CRT - cathode-ray tube

DEC - Digital Equipment Corporation

DOD - Department of Defense

ECIS - emergency coolant injection system

EDGC - emergency diesel generator control

EPRI - Electric Power Research Institute

$\mathrm{HCI}$ - human-computer interaction

HFEB - Human Factors Engineering Branch

HFS - Human Factors Society

I\&C - instrumentation and controls

IBM - International Business Machines

IEEE - Institute of Electrical and Electronics Engineers

INPO - Institute of Nuclear Power Operations

INSPEC - Information Services for Physics, Electronics, and Computing

ISO - International Standards Organization

LC - liquid crystal

LED - light emitting diode

MCR - main control room

MIL-HDBK - military handbook

MIL-STD - military standard 


\section{ACRONYMS AND ABBREVIATIONS (Continued)}

N/A - not applicable

NASA - National Aeronautics and Space Administration

NP - nuclear power

NPP - nuclear power plant

NRC - Nuclear Regulatory Commission

NTIS - National Technical Information Service

ORNL - Oak Ridge National Laboratory

PWR - pressurized water reactor

RRSF - remote reactor shutdown facility

RRSS - remote reactor scram system

RWMC - radiation waste monitoring and control

SID - Society for Information Display

SIG - special interest group

SPDS - safety parameter display system

TECOM - Test and Evaluation Command

UCI - user computer interaction

U.S. - United States

U.S.A. - United States of America

VDT - visual display terminal

VDU - visual display unit

VES - vital electrical system 


\title{
ADVANCED CONTROL ROOM DESIGN REVIEW GUIDELINES:
}

\author{
INTEGRATION OF THE NUREG-0700 GUIDELINES AND DEVELOPMENT \\ OF NEW HUMAN-SYSTEM INTERFACE GUIDELINES
}

\author{
Richard J. Carter \\ Computer Science and Mathematics Division
}

Oak Ridge National Laboratory

EXECUTIVE SUMMARY

NUREG-0700 contains guidelines for the review of analog hard-wired operator interfaces. This guidance has been useful in performing control room design reviews to identify and correct design deficiencies. The document has six main sections and five appendices. Section 6 of NUREG0700 contains detailed guidelines for reviewing the human factors suitability of control-room features. These guidelines provide the baseline for evaluating the human factors quality of specific control-room design components. The section is divided into nine primary areas: control-room workspace, communications, annunciator warning systems, controls, visual displays, labels and location aids, process computers, panel layout, and control-display integration

In light of the rapid technological advances in digital technology which have taken place in the 11 years since the publication of NUREG-0700, the guidelines are no longer adequate to assess the rapidly changing human-system interfaces. As a result a research program has been initiated with Oak Ridge National Laboratory (ORNL) and Brookhaven National Laboratory (BNL), the purpose of which is to upgrade NUREG-0700.

A set of draft advanced control room design review (ACRDR) guidelines, based upon human factors principles and criteria, has been compiled in order to conduct human factors engineering reviews of advanced control room designs and advanced human-system interfaces which may be introduced in nuclear power plant (NPP) control rooms. The new guidelines are to serve as an aid to ensure that the human factors effectiveness established from a detailed control room design review is maintained in the conversion to digital technology. The ACRDR guidelines are divided into seven main sections: information display, operator input and control, alarms, operator aids, inter-personnel communication, information protection, and workstation design

ORNL conducted four tasks oriented towards supporting the ACRDR guidelines development effort. The purpose of the first task was to integrate the applicable sections of NUREG-0700 into the ACRDR guidelines to ensure that all applicable guidelines are together in one document and conveniently accessible to users. During the initial part of this task those areas in NUREG-0700 
that are not addressed by the draft ACRDR guidelines, but which are still applicable to advanced instrumentation and controls (I\&C) and operator interface systems, were identified. It was determined that sections 1 through 5 should be incorporated within the ACRDR guidelines in their entirety. Four of the five appendices should also be subsumed under the new guidelines. In addition, the other NUREG-0700 appendix, reference materials, should be modified as appropriate and included within the ACRDR guidelines.

Most of Section 6 remains appropriate for advanced control room technology, development, and design review. The process computers subsection has, however, become outdated due to the rapid change in technology. Much of the guidance in this subsection should be deleted from consideration for the ACRDR guidelines. The control-room human engineering guidelines in Section 6 of NUREG-0700, which are non-redundant with the ACRDR guidance, should be added to the new guidelines.

In the later part of the first task, the identified areas were reviewed against six recent industry human factors engineering review guidelines and the NUREG-0700 guidelines were updated as necessary. A number of additions and/or deletions were made to the control-room workspace, annunciator warning systems, controls, visual displays, and process computer subsections.

The primary objective of the second task was to formulate a strategy for the development of new ACRDR guidelines that have not otherwise been identified. During the first step 13 general categories of human-system interface guidelines that are either missing from or not adequately addressed by the ACRDR document were discovered. They include: visual display terminals (VDT), projection devices, three-dimensional and virtual displays, printers and plotters, user control and input devices, coding of information displays, user interface requirements for operator supervised automation, user interface requirements for intelligent operator decision aids, transaction dialogue, display control, visual display hardware guidelines, screen design, and guidelines specific to nuclear operations.

In the second step ORNL derived an approach for the development of new ACRDR guidelines that makes maximum use of the secondary and tertiary sources identified by BNL. It also includes the use of technical literature in basic and applied journals, conference proceedings, other relevant documents, and contact with researchers actively working in the field of human-computer interaction (HCI).

During the third step of the task, a preliminary assessment of the available sources that may be useful in the creation of new guidelines and their applicability to the identified human-system interface categories was performed. The preliminary assessment consisted of: a review of the secondary and tertiary sources; an evaluation of additional recent HCI books and reports; an examination of basic and applied technical journals; an analysis of proceedings from $\mathrm{HCI}$ related conferences; literature searches of library data bases; a downloading and an examination of the $\mathrm{HCI}$ Bibliography from Ohio State University; an assessment of documentation obtained from $\mathrm{HCI}$ standards working groups; a review of guidelines received from human factors personnel in the computer industry; and an evaluation of computer trade magazines and journals. 
ORNL determined that a majority of the secondary and tertiary sources have material which can be used as the bases for the development of new ACRDR guidelines. Very little of the rest of the $\mathrm{HCI}$ technical literature was however deemed relevant or pertinent for the design of guidelines for the missing human-system interface categories. It was decided that the advanced systems and technologies are currently either too immature or there is insufficient information available to prepare ACRDR guidelines for eight of the human-system interface categories. Estimates of the amount of time and the level of effort required to generate new guidelines were derived for the other five categories (i.e., printers and plotters, user control and input devices, user interface requirements for operator supervised automation, user interface requirements for intelligent operator decision aids, and guidelines specific to nuclear operations).

The main focus of the third task was to modify the individual ACRDR guidelines generated to date to ensure that they are suitable for the intended NPP control station system application. During the first phase of the task, nine control station systems (i.e., main control room [MCR], safety parameter display system [SPDS], remote reactor shutdown facility [RRSF], remote reactor scram system [RRSS], emergency diesel generator control [EDGC], vital electrical system [VES], emergency coolant injection system [ECIS], containment hydrogen sampling system [CHSS], and radiation waste monitoring and control [RWMC]) were identified which appear to be appropriate for ACRDR-type inspections. They were derived via a review of a number of technical documents, discussions with contractors who have conducted control room design reviews, and ORNL nuclear engineering staff expertise. Then those control station systems to which the NUREG-0700 and ACRDR guidelines apply were identified and matrices of such applicability were developed to support the needs of the NRC inspectors and reviewers. The matrices were constructed such that the human factors engineering guidelines are the rows and the control stations form the columns.

In the second phase of the third task, ORNL designed a guideline modification audit and tracking system, the purpose of which was to ensure that the original ACRDR human factors guidelines as developed by BNL could be compared with any changes proposed to be made and subsequently incorporated within the guidelines document. The system consists of the following components: the original text of each modified guideline, along with the proposed changes printed in boldface (suggested additions to the guideline narratives enclosed in brackets and recommended deletions shown with a shaded background); a list of the proposed modified guidelines by number and title; and both a hard copy and a computer diskette copy of the original guidelines, along with the modified/revised guidelines.

During the third phase the ACRDR guidelines document was reviewed, the guidelines were modified where appropriate to ensure that their language is applicable to the nuclear industry, and vague, inconsistent, and redundant human factors guidance, and typographical errors and word misspellings within the guidelines were identified.

The goal of the fourth task was to develop human factors guidelines for two human-system interface categories that are missing from the current ACRDR guidelines document. Control and input device guidelines were generated for 11 advanced technology devices: keyboards, 
trackballs, mice, joysticks, touch screens, light pens, graphic tablets, touch pads, multi-degree of freedom hand controllers, glove controllers, and eye controllers. Human factors guidelines were drafted for specific nuclear operations. Human-system interface guidelines were produced for three nuclear systems: SPDS, computerized annunciator system, and nuclear graphic display.

ORNL recommends that human factors guidelines be developed for three human-system interface categories: printers and plotters, user interface requirements for operator supervised automation, and user interface requirements for intelligent operator decision aids. 


\section{INTRODUCTION}

This technical report documents the work conducted in Task 9 ("Integrate NUREG-0700 Guidelines into the ACRDR Guidelines"), Task 10 ("Assess New Guidelines Development Needs to Enhance the ACRDR Guidelines"), Task 11 ("Convert Existing Primary Source Guidelines Documents into a Form and Format Compatible with Nuclear Industry Needs"), and Task 13 ("Develop ACRDR Guidelines for Selected Advanced Control/Display Technologies") of the United States (U.S.) Nuclear Regulatory Commission (NRC), Office of Nuclear Regulatory Research project entitled "Review Criteria for Human Factors Aspects of Advanced Controls and Instrumentation" (NRC FIN B0852).

The purpose of Task 9 was to integrate the applicable sections of NUREG-0700 (Human Factors Engineering Branch [HFEB], 1981a) into the ACRDR guidelines being developed by BNL under NRC FIN L1317 to ensure that all applicable guidelines are together in one document and conveniently accessible to users. The primary objective of Task 10 was to formulate a strategy for the development of new ACRDR guidelines that have not otherwise been identified. The main focus of Task 11 was to modify the individual ACRDR guidelines generated to date by BNL, as required, to ensure that they are suitable for the intended NPP control station system application. This work was required because the present draft of the ACRDR guidelines document represents an amalgamation of guidelines originally developed for diverse, primarily non-nuclear, industries and applications. The goal of Task 13 was to develop human factors guidelines for two humansystem interface categories that are missing from the current ACRDR guidelines document prepared under NRC FIN L1317. The direction of the overall project is to contribute to the development and refinement of regulatory review guidelines for use in evaluating advanced I\&C systems in NPPs. 


\section{BACKGROUND}

\subsection{SUMMARY OF PRIOR EFFORTS}

Tasks one through eight and task 12 of this project were carried-out during fiscal years 1988, 1989 , and 1990. Tasks one through seven were directed towards surveying the nuclear industry with regard to their current, planned, and potential future uses of digital technology in NPP control rooms. The survey was conducted at five U.S. nuclear utilities, two advanced reactor vendors, four light water reactor vendors, four reactor facilities operated by National laboratories, the Canadian NPP vendor, and the principal Canadian nuclear utility. The survey found the U.S. nuclear industry to be quite interested in advanced I\&C, but very cautious in implementing such systems in nuclear facilities and power plants. There is an expectation among the utilities and the vendors that digital systems will increase reliability and safety, reduce the maintenance and surveillance needed, and be cost effective, and there is some actual experience supporting these expectations. (Carter and Uhrig, 1990)

Tasks one through seven were also aimed at identifying I\&C and human factors related issues. The $1 \& C$ issues include validation and verification, and configuration control. The primary human factors issues are:

- Is an advanced I\&C guideline equivalent to NUREG-0700 needed?

o What changes will there be in the role of the control room operator?

- The potential problem of information overload needs to be addressed.

- How should existing training technology be made applicable for advanced I\&C?

- How will operator acceptance and trust of advanced $I \& C$ be accomplished?

The primary objective of task eight was to identify the scope and type of control and monitoring tasks now performed by control-room operators in NPPs. Another purpose was to address the types of controls and safety systems needed to operate the plant. The final objective of task eight was to identify and categorize the type of information and displays/indicators required to monitor the performance of the control and safety systems. (Bovell, Carter, and Beck, 1997)

Task 12 was oriented towards the development of a program plan for regulatory research on expert systems. The plan includes a definition and description of expert systems and a discussion of how they differ from ordinary software. A short summary of the state-of-the-art of expert systems and current NRC-supported research projects in expert systems are provided. The plan also identifies and discusses regulatory issues associated with the use of expert systems in NPPs as derived from interviews with NRC management and staff members. In addition, it describes how current and anticipated research projects will resolve some of the identified issues and presents research programs needed to resolve the unaddressed issues. (Uhrig and Carter, 1989) 


\subsection{OVERVIEW OF THE NUREG-0700 GUIDELINES}

NUREG-0700 has six main sections and five appendices. They are as follows:

- Sections

- Introduction

- $\quad$ Planning phase

- Review phase

- Assessment and implementation

- Reports

- Control-room human engineering guidelines

- Appendices

- $\quad$ Reference materials

- $\quad$ Systems/operations design analysis techniques

- Control-room operating personnel interview protocol

- $\quad$ Photography guidelines

- $\quad$ Guidelines for environmental measurements

\subsubsection{Sections 1 - 5}

Section 1 (Introduction) describes the purpose, scope, and objectives of a control room design review. It also provides an overview of the design review process and discusses the design review in relationship to other human factors programs. Finally, the Introduction defines a number of terms which are used throughout the rest of the document.

Section 2 (Planning Phase) discusses management's responsibility during this preparatory phase of the control room design review and the selection of the design review team. In addition, it addresses the scheduling for the review tasks and subsequent assessment and implementation, and the systematic use of existing documents and the generation of new materials.

Section 3 (Review Phase) describes the six design review processes used to establish and apply benchmarks for identifying human factors engineering discrepancies of both completeness and human factors suitability. These processes include:

- A review of operating experience

- A review of system functions and an analysis of the tasks involved in control-room operator functions

o An inventory of control-room instrumentation and equipment

- An inventory of the human factors engineering acceptability of control-room components and environmental conditions 
- Verification of task performance capabilities

- Validation of control-room functions

Section 4 (Assessment and Implementation) covers the assessment and implementation processes. Assessment consists of an analysis of the human factors engineering discrepancies and selection of design improvements. The implementation process is comprised of the incorporation of enhancement and design alternative solutions.

Section 5 (Reports) addresses the generation and preparation of two reports, the program plan report and the detailed control-room design review report. A program plan report summarizes the selected approach to the control-room design review process. A detailed control-room design report synopsizes the overall review process, describes the identified human factors engineering discrepancies, discusses the control-room design improvements implemented during the course of the review, and identifies the proposed design improvements and their schedules for implementation.

\subsubsection{Section 6}

Section 6 (Control-Room Human Engineering Guidelines) of NUREG-0700 contains detailed guidelines for reviewing the human factors suitability of control-room features. These guidelines provide the baseline for evaluating the human factors quality of specific control-room design components. The section is divided into nine primary areas:

$\begin{array}{ll}0 & \text { Control-room workspace } \\ 0 & \text { Communications } \\ 0 & \text { Annunciator warning systems } \\ 0 & \text { Controls } \\ 0 & \text { Visual displays } \\ 0 & \text { Labels and location aids } \\ 0 & \text { Process computers } \\ 0 & \text { Panel layout } \\ 0 & \text { Control-display integration }\end{array}$

The areas and the number of control-room human factors engineering guidelines included in each area are listed in Table 1.

Each of the human factors engineering guidelines is identified by a number, letter, and title. The alpha-numeric designations and titles for each of the control-room guidelines are displayed in Appendix A.

\subsubsection{NUREG-0700 Appendices}

Appendix A (Reference Materials) has two parts, a Bibliography and a detailed Reference Matrix of the sources of the individual guidelines addressed in the Control-Room Human Engineering 
Table 1. NUREG-0700 Section 6 Guidelines

Area

Area Title

Number of

Number

Guidelines

6.1

6.2

6.3

6.4

6.5

6.6

6.7

6.8

6.9
Control-Room Workspace

Communications

41

Annunciator Warning Systems

52

Controls

63

Visual Displays

55

Labels and Location Aids

47

Process Computers

125

Panel Layout

20

Control-Display Integration

Guidelines section of the document. The bibliography includes references that may be useful in the performance of the control-room design review as well as those used in the preparation of NUREG-0700.

Appendix B (Systems/Operations Design Analysis Techniques) describes methods and tools useful in defining control-room design requirements. They include: function analysis, function allocation, verification of function allocation, and validation of system integration.

Appendix C (Control-Room Operating Personnel Interview Protocol) presents guidelines for operator interviews and selected interview questions. Appendix D (Photography Guidelines) discusses types and objectives of photographic support, panel-by-panel mosaic photographs, and discrepancy photographs. This appendix also exhibits specific guidance for picture taking. Appendix E (Guidelines for Environmental Measurements) has procedures for sound, lighting, humidity/temperature, and air velocity surveys.

\subsection{OVERVIEW OF. THE ACRDR GUIDELINES}

The ACRDR guidelines document being compiled by BNL is based upon seven primary source documents (i.e., Gilmore, Gertman, and Blackman, 1989; Human Factors Society [HFS], 1988; National Aeronautics and Space Administration [NASA], 1988, 1989; Smith and Mosier, 1986; and U.S. Department of Defense [DOD], 1989a, 1989b). 
Draft 2 of the ACRDR document is divided into seven main sections. They are as follows:

$\begin{array}{ll}\text { o } & \text { Information display } \\ \circ & \text { Operator input and control } \\ \circ & \text { Alarms } \\ \circ & \text { Operator aids } \\ \text { o } & \text { Inter-personnel communication } \\ \text { o } & \text { Information protection } \\ \text { o } & \text { Workstation design }\end{array}$

Information display is separated into four primary components: screen organization and layout, type of displays, display elements, and coding. There are five subsections under operator input and control: entering information, operator dialogue, display control, information manipulation, and system response time. The operator aids section is broken down into three areas: routine system messages and guidance, decision aids, and supervised automation. Inter-personnel communication has six subsections: preparing messages, addressing messages, initiating transmission, controlling transmission, and receiving messages. Information protection is partitioned into four segments: general, user identification, data access, and data transmission. Workstation design consists of display devices, control and input devices, workstation configuration, and control room configuration. The sections, subsections, and the number of ACRDR guidelines included in each subsection are listed in Table 2.

Each of the ACRDR guidelines consists of seven parts. They are:

$\begin{array}{ll}\circ & \text { Number } \\ \circ & \text { Title } \\ \circ & \text { Guidance } \\ \circ & \text { Comment } \\ \circ & \text { Assessment method } \\ \circ & \text { Source } \\ \circ & \text { Classification }\end{array}$

The number is an unique identification for each guideline and reflects the position of the guideline in the hierarchical structure of the overall document. The title is a short descriptor which indicates the subject of the guideline; guidance is narrative criteria. A comment is a further explanation, rationale, or example. Assessment method describes the data collection procedure for each guideline. The procedures include:

o Measurement (instruments or devices)

o Observations (visual and/or auditory observations)

o Interview (structured interview or questionnaire)

- Documentation review (specifies the review of applicable documentation including manufactures specifications, manuals, etc.)

o Operational review (a licenced reactor operator assessment) 
Table 2. ACRDR Guidelines

Section/

Section/Subsection Title

Number of

Subsection

Guidelines

Number

1

1.1

1.2

1.3

1.4

2

2.1

2.2

2.3

2.4

2.5

3

4

4.1

4.2

4.3

5

5.1

5.2

5.3

5.4

5.5

5.6

6

6.1

6.2

6.3

6.4

7

7.1

7.2

7.3

7.4
Information Display

Screen Organization and Layout $\quad 138$

Types of Displays

212

Display Elements

161

Coding

Operator Input and Control

183

Entering Information 308

Operator Dialogue $\quad 247$

Display Control 71

Information Manipulation $\quad 21$

System Response Time $\quad 18$

Alarms 4

Operator Aids

Routine System Messages and Guidance $\quad 152$

Decision Aids $\quad 55$

Supervised Automation 0

Inter-personnel Communication

General 11

Preparing Messages 15

Addressing Messages $\quad 13$

Initiating Transmission $\quad 13$

Controlling Transmission 9

Receiving Messages $\quad 19$

Information Protection

General 2

User Identification 9

Data Access $\quad 10$

Data Transmission 7

Workstation Design

Display Devices 124

Control and Input Devices $\quad 102$

Workstation Configuration 0

Control Room Configuration 4 
Source is the document(s) from which the guidance was obtained. Classification is the validity criteria upon which the guideline is based. The criteria can be either firm, tentative, or weak validity standards. A more detailed outline of the ACRDR guidelines is exhibited in Appendix B. 


\section{INTEGRATE NUREG-0700 GUIDELINES INTO THE ACRDR GUIDELINES}

\subsection{SUBTASK 9A}

The purpose of Subtask 9A was to hold a one-day orientation/kick-off meeting for this phase of the project. The meeting was held on December 19, 1990 at NRC headquarters in Bethesda, MD. Attendees consisted of the NRC project manager, BNL's principal investigator for NRC FIN L1317, and a representative of ORNL's project team. Topics discussed include: the most efficient method to integrate the NUREG-0700 guidelines into those being developed for the ACRDR; the development and status of the ACRDR guidelines and the computer-based electronic version of these guidelines; a format for subsequent revisions of the ACRDR guidelines document; and the work schedule for the two interrelated efforts.

\subsection{SUBTASK 9B}

\subsubsection{Objective}

The primary objective of Subtask 9B was to identify those areas in NUREG-0700 that are not addressed by draft 1 of the ACRDR guidelines document.

\subsubsection{Evaluation of Sections 1 - 5 of NUREG-0700}

ORNL analyzed both sets of guidelines (i.e., NUREG-0700 and ACRDR) and determined that the control-room design review process is not currently discussed by draft 1 of the ACRDR guidelines. As a result, it is suggested that Sections 1 through 5 (i.e., Introduction, Planning Phase, Review Phase, Assessment and Implementation, and Reports) of NUREG-0700 be included in their entirety within the ACRDR guidelines.

\subsubsection{Evaluation of Section 6 of NUREG-0700}

ORNL reviewed and evaluated the NUREG-0700 Control-Room Human Engineering Guidelines against the draft ACRDR guidelines. Many areas were identified that have not been adequately addressed by the new guidelines. These deficiencies are presented below in the same categorical taxonomy as that utilized in Section 6 of NUREG-0700.

\subsubsection{Control-Room Workspace}

Section 1.1 (Screen Organization and Layout) of the ACRDR guidelines covers areas that seem to be analogous to those presented in subsection 6.1.1 (General Layout) of NUREG-0700. The only duplication, however, between the two documents appears to be on the topic of Accessibility of Instrumentation and Equipment. NUREG-0700 guideline 6.1.1.1.a states that control-room instrumentation and equipment should include all controls and displays needed for detection of 
abnormal conditions, and bringing the plant to a safe shutdown condition, while ACRDR guideline 1.1.1-1 says that data needed for any transaction is displayed. It is recommended that these two guidelines be merged and the other six topics covered in the General Layout subsection be included within the ACRDR guidelines.

Subsection 6.1.2 (Work Station Design) of NUREG-0700 and Section 7 of the ACRDR guidelines have the same titles. Title similarity, however, is their only commonality. Some of the guidelines addressed within Section 7 seem to fit in with those in NUREG-0700; there is, however, no identical guideline presented by the two documents. It is suggested that all of the Work Station Design subsection be added to the ACRDR guidelines.

The two topics, Unit Integration and Interference, and Unit Mirror Imaging, described in subsection 6.1.3 (Multiunit Control Rooms) of NUREG-0700 are not covered by the ACRDR guidelines. The Multiunit Control Rooms subsection in its entirety should be subsumed under the ACRDR guidelines.

Subsection 6.1.4 (Emergency Equipment) of the NUREG-0700 is not addressed in the ACRDR guidelines. Section 7.3.2 (Support Equipment) of the ACRDR guidelines will probably fit in with the Emergency Equipment guidelines; however, at the present time Section 7.3.2 does not contain any guidelines. The Emergency Equipment subsection should, therefore, be incorporated within the ACRDR guidelines.

Both subsection 6.1.5 of NUREG-0700 and Section 7.3.4 of the ACRDR guidelines are entitled "Environment". The only common topic covered by the two sections is "glare" (NUREG-0700 guideline 6.1.5.3.f and ACRDR guidelines 7.3.4.1-1 and 7.3.4.1-2). The guidance provided by the two documents is different, but complementary. Some of NUREG-0700 sub-subsection 6.1.5.3 is, however, duplicated in Section 7.1.1.2 of the ACRDR guidelines which deals with cathode-ray tubes (CRT). Specifically, there is some replication in regards to "illumination". All of the NUREG-0700 Environment subsection, except for the topic of Illumination, should be added to the ACRDR guidelines. Illumination guidance not addressed in the ACRDR guidelines should also be extracted and incorporated within the new guidelines.

\subsubsection{Communications}

Subsection 6.2.1 (Voice Communication Systems) of NUREG-0700 deals with communication systems as do Sections 5 (Inter-operator Communication) and 7.1.2 (Audio and Voice Displays) of the ACRDR guidelines. There is, however, no redundancy between Section 5 and subsection 6.2.1. The ACRDR guidelines provide material on preparing, sending, monitoring, and receiving messages via computer transmission, while the NUREG-0700 guidelines cover human voice communication. Also, very little similarity exists between ACRDR Section 7.1.2 and the NUREG-0700 guidelines since most of Section 7.1.2 addresses audio and voice displays. There is, however, some redundancy between Section 7.1.2.4 (Speech Communication Equipment) and subsection 6.2.1. The Voice Communication Systems guidance which is not duplicated in Section 7.1.2 of the ACRDR guidelines should be subsumed under the new guidelines. 
Subsection 6.2.2 (Auditory Signal Systems) of NUREG-0700 is not replicated in ACRDR guidelines Section 5. In addition, little redundancy exists between ACRDR Section 7.1.2 and the NUREG-0700 guidelines. There is, however, some similarity between Section 7.1.2.2 (Nonspeech Audio Displays) and subsection 6.2.2. The Auditory Signal Systems guidance which is not duplicated in Section 7.1.2 of the ACRDR guidelines should be included in the new guidelines.

\subsubsection{Annunciator Warning Systems}

Section 6.3 of NUREG-0700 discusses human factors engineering guidance in regards to the annunciator warning system which is a specific display system in NPP control rooms. The annunciator warning system consists of a visual alarm tile subsystem, an auditory alert subsystem, and an operator response subsystem. Sections 1.1.5 (Message Areas) and 4.1 (Prompts, Alarms, and Messages) of the ACRDR guidelines address alarms and messages which are presented via computer-generated displays. There does not appear to be much similarity between the NUREG0700 and ACRDR guidance since information is provided via two different presentation modes. The Annunciator Warning Systems subsection should be added in its entirely to the ACRDR guidelines.

\subsubsection{Controls}

The two topics, General Principles and Prevention of Accidental Activation, described in subsection 6.4.1 (Selection of Controls) of NUREG-0700 are not currently covered by the ACRDR guidelines. The Selection of Controls subsection in its entirety should be subsumed under the ACRDR guidelines.

Sub-subsection 6.4.2.2 of subsection 6.4.2 (Design Principles) of NUREG-0700 and Section 1.3 of the ACRDR guidelines deal with coding. There is, however, no redundancy between these two sections because the ACRDR guidelines provide material on the coding of computer-generated displays, while NUREG-0700 covers the coding of controls. All of the Design Principles subsection should be incorporated within the ACRDR guidelines.

Subsections 6.4.3 (Pushbutton Control Specifications), 6.4.4 (Rotary Control Specifications), and 6.4.5 (Other Control Specifications) of NUREG-0700 and Section 7.2 (Control Devices) of the ACRDR guidelines present specifications for operator controls. There is, however, no duplication between these sections since the ACRDR guidelines address keyboards and direct manipulation controls, while the NUREG-0700 guidelines discuss pushbuttons, rotary controls, and switches. The Pushbutton, Rotary and Other Control Specifications subsections should be integrated within the ACRDR guidelines.

\subsubsection{Visual Displays}

The first five topics under NUREG-0700 subsection 6.5.1 (Principles of Display) are not presently addressed by the ACRDR guidelines. Sub-subsection 6.5.1.6 and ACRDR guidelines Section 1.3.3.3 both deal with color coding. There is some redundancy between these two areas. The 
Principles of Display subsection, except for the topic of Color Coding, should be added to the ACRDR guidelines. Only that color coding guidance not discussed in the ACRDR guidelines should be extracted and incorporated within the new guidelines.

Subsections 6.5.2 (Meters), 6.5.3 (Light Indicators), 6.5.4 (Graphic Recorders), and 6.5.5 (Miscellaneous Display Types) of NUREG-0700 and Section 7.1 (Display Devices) of the ACRDR guidelines provide guidance and specifications for operator displays. There is, however, no duplication between these sections since the ACRDR guidelines address visual display terminals, audio and voice displays, projection devices, printers, and plotters, while the NUREG0700 guidelines contain guidance on meters, light indicators, graphic recorders, and counters. The NUREG-0700 Meters, Light Indicators, Graphic Recorders, and Miscellaneous Display Types subsections should be included in the ACRDR guidelines.

\subsubsection{Labels and Location Aids}

The two topics, Need for Labeling and Hierarchical Scheme, described in subsection 6.6.1 (Labeling Principles) of NUREG-0700 are not presently addressed by the ACRDR guidelines. All of the Labeling Principles subsection should be subsumed under the ACRDR guidelines.

The last three topics included in subsection 6.6.2 (Label Location) of NUREG-0700 are not covered by the ACRDR guidelines. There is, however, some redundancy between sub-subsection 6.6.2.1 (Placement) and Section 1.2.4 (Labels) of the ACRDR guidelines. The Label Location subsection, except for Placement, should be incorporated within the ACRDR guidelines. The label placement guidance, which is not replicated in the ACRDR guidelines, should also be added to the new guidelines.

Five of the topics, Kinds of Information, Symbols, Brevity, Control Position Labeling, and Access Opening, Danger Warning, and Safety Instruction Labeling, presented in subsection 6.6.3 (Label Content) of NUREG-0700 are not included in the ACRDR guidelines. There appears, however, to be much duplication between the material described by sub-subsections 6.6.3.2, 6.6.3.3, 6.6.3.6, and 6.6.3.7, and Section 1.2.4 of the ACRDR guidelines. NUREG-0700 sub-subsections 6.6.3.1, 6.6.3.4, 6.6.3.5, 6.6.3.8, and 6.6.3.9 should be added to the ACRDR guidelines. The non-replicated human factors engineering guidance, covered by the four Label Content topics (i.e., Word Selection, Consistency, Similarity, and Functional Groups) which have a large amount of redundancy with the ACRDR guidelines, should also be subsumed under the new guidelines.

The two topics, Readability and Style, described in subsection 6.6.4 (Label Lettering) of NUREG0700 are not presently addressed by the ACRDR guidelines. All of the Labeling Lettering subsection should be incorporated within the ACRDR guidelines.

The two topics, Use and Control, discussed in subsection 6.6.5 (Use and Control of Temporary Labels) of NUREG-0700 are not currently covered by the ACRDR guidelines. The Use and Control of Temporary Labels subsection in its entirety should be subsumed under the ACRDR guidelines. 
NUREG-0700 subsection 6.6.6 (Location Aids) and the ACRDR guidelines contain much of the same guidance. Section 1.3.2 of the ACRDR guidelines (Text Coding) specifically deals with this topic. Only sub-subsection 6.6.6.1 is not duplicated in the new guidelines. NUREG-0700 subsubsection 6.6.6.2 and guidelines 1.1.3-8 (Demarcation of Groups), 1.2.3-28 (Grouping/Demarcating Information), and 1.1.4-12 (Window Demarcation) of the ACRDR guidelines discuss demarcation. Sub-subsection 6.6.6.3 and ACRDR guidelines Section 1.3.3.3 cover color. Sub-subsection 6.6.6.4 of NUREG-0700 and ACRDR Section 1.2.7 guidelines provide guidance on the use of mimics. It is ORNL's suggestion that only the non-redundant human factors engineering Location Aids guidance which is not presented in the current ACRDR guidelines should be incorporated within the new guidelines.

\subsubsection{Process Computers}

Section 6.7, when compared to the other sections of NUREG-0700, provides the most guidance on $\mathrm{HCl} /$ human-computer interface and advanced operator control and display technology. It also, however, has the most redundancy with the ACRDR guidelines. These points are discussed below. ORNL recommends that only the human factors engineering guidance in regards to Process Computers, which is not contained in the current ACRDR guidelines, should be integrated within the new guidelines.

NUREG-0700 subsection 6.7.1 (Computer Access) and Section 6 (Information Protection) of the ACRDR guidelines are involved with computer access. Sub-subsection 6.7.1.1 and ACRDR Section 6.2 (Computer Security) deal with software security. Sub-subsection 6.7.1.2 and Section 2.2 (Operator Dialogue) provide human factors engineering guidelines on operator/computer dialogue. Sub-subsection 6.7.1.3 and Section 4.1 (Prompts, Alarms, and Messages) address prompting. Sub-subsection 6.7.1.4 and Section 7.2.1 (Keyboards) cover computer keyboards. (There is, however, no guidance in draft 1 of the ACRDR guidelines.) Sub-subsections 6.7.1.5 and 6.7.1.6 and Section 7.2 (Control Devices) consist of guidelines for computer control devices. Sub-subsection 6.7.1.7 and Section 3.1 (System Response Time) are comprised of material on computer response time to operator queries. Sub-subsection 6.7.1.8 and Sections 4.2.5 (Job Aids) and 4.2.7 (On-Line Assistance) include guidelines on access aids.

Subsection 6.7.2 (CRT Displays and Printers) of NUREG-0700 and Section 7.1.1.2 of the ACRDR guidelines have similar titles and both address CRT visual displays. NUREG-0700 subsection 6.7.3 and ACRDR Section 7.1.4 are both entitled "Printers" and present human factors guidance for a number of different types of printers.

\subsubsection{Panel Layout}

NUREG-0700 subsections 6.8.1 (General Panel Layout) and 6.8.2 (Layout Arrangement Factors) and ACRDR guidelines Sections 1.1 (Screen Organization and Layout) and 1.2 (Information Format) deal with panel layout and arrangement. There is a small amount of redundancy between the human factors guidance in the two sets of guidelines. The NUREG-0700 guidance was generated for analog display panels consisting of meters, light indicators, graphic recorders, and 
switches and controls (e.g., pushbuttons, rotary controls, and switches) used in today's NPPs, while the ACRDR guidelines were created for state-of-the-art technology and advanced display and control devices. The General Panel Layout and Layout Arrangement Factors guidance which is not duplicated in the ACRDR guidelines should be integrated within the new guidelines.

Subsection 6.8.3 (Specific Panel Layout Design) of NUREG-0700 and Section 7 (Work Station Design) of the ACRDR guidelines address layout design. There is practically no duplication, however, between these two sections since the NUREG-0700 guidelines cover the design of panels consisting of analog operator displays and controls, while the ACRDR guidelines include material for the design of operator display consoles and the arrangement of information on computer-generated display devices. The non-redundant Specific Panel Layout Design guidance should be added to the ACRDR guidelines.

\subsubsection{Control-Display Integration}

Section 6.9 of NUREG-0700 and Section 3 of the ACRDR guidelines are both entitled "ControlDisplay Integration". The two sections seem, however, to be almost mutually independent. NUREG-0700 addresses the arrangement of operator control devices and displays on control panels, while the ACRDR guidelines cover the use of controls to input information into the computer via display devices.

The two topics, Single Control and Display Pairs, and Multiple Controls or Displays, described in subsection 6.9.1 (Basic Control-Display Relationships) of NUREG-0700 are not currently covered by the ACRDR guidelines. The Basic Control-Display Relationships subsection in its entirety should be subsumed under the new guidelines.

The three topics, Location and Arrangement of Control-Display Groups, Single Panel Arrangements, and Controls and Displays in Separate Planes, presented in NUREG-0700 subsection 6.9.2 (Groups of Controls and Displays) are not addressed by the ACRDR guidelines. All of the Groups of Controls and Displays subsection should be incorporated within the ACRDR guidelines.

One of the three items (i.e., display response time lag) in sub-subsection 6.9.3.1 and all of subsubsection 6.9.3.2 in NUREG-0700's subsection 6.9.3 (Dynamic Control-Display Relationships) have redundancy with material in Section 3 (Control/Display Integration) of the ACRDR guidelines. The two items (rotary controls and linear controls) under the topic entitled "General Movement Relationships" and other Dynamic Control-Display Relationships subsection topics, which are not duplicated in the ACRDR guidelines, should be added to the new guidelines.

\subsubsection{Evaluation of NUREG-0700 Appendices}

ORNL conducted an assessment and comparison of the NUREG-0700 appendices with draft 1 of the ACRDR guidelines. The results of these efforts are discussed in the following paragraphs. 


\subsubsection{Reference Materials}

A number of references were used in preparing draft 1 of the ACRDR guidelines. They are identified and described in the FIN L1317 Task 1 and 2 letter reports (BNL and Carlow Associates, 1989, 1990). There is, however, no reference section presently included as part of the new guidelines. Even if there was, there would still be no duplication between these documents and the references used in generating NUREG-0700. The entire NUREG-0700 Bibliography, along the references utilized in preparing the ACRDR guidelines, should be integrated within the new guidelines.

The Reference Material appendix exhibits a detailed Reference Matrix of the sources of the individual guidelines addressed in Section 6 of NUREG-0700. The ACRDR guidelines also identify the source(s) from which a particular guideline was prepared; however, it does so in a different manner. Each ACRDR guideline includes a source field as part of the guideline. This field shows the source(s) from which the guideline was obtained.

It was decided, during the Subtask 9A kickoff meeting at NRC headquarters, that the baseline for subsequent changes to the NUREG-0700 guidelines would be the existing document.

(Modifications to NUREG-0700 were accomplished during Subtask 9C). Thus each guideline should initially be coded with a letter designating that it was derived from NUREG-0700. If any modification is made to a guideline, its letter should be changed to one identifying a new source document.

It is suggested that the NUREG-0700 guidelines Reference Material Matrix be dropped and not added to the new guidelines. It is recommended that the way in which NUREG-0700 identifies its reference sources be changed to reflect the format used with the ACRDR guidelines.

\subsubsection{Systems/Operations Design Analysis Techniques, Control- Room Operating Personnel Interview Protocol, Photography Guidelines, and Guidelines for Environmental Measurements}

The last four appendices of NUREG-0700 were previously described. They cover design analysis techniques, interview protocol, photography, and environmental measurements. Material in these appendices is not replicated within the ACRDR guidelines. As a result, they should be included in the new guidelines.

\subsection{SUBTASK 9C}

\subsubsection{Objectives}

There were three primary objectives for Subtask 9C. They include: 
- To review the NUREG-0700 areas that are not addressed by draft 1 of the ACRDR guidelines, as identified in Subtask 9B, against recent industry human factors engineering review guidelines.

- To update the NUREG-0700 guidelines as necessary.

- To identify any required changes to the ACRDR guidelines document.

\subsubsection{Industry Human Factors Engineering Review Guidelines}

The NUREG-0700 areas that were not addressed by draft 1 of the ACRDR guidelines were reviewed against six industry human factors engineering review guidelines (i.e., HFS, 1988; Kinkade and Anderson, 1984; NASA, 1989; Sanders and McCormick, 1987; and U.S. DOD, 1981a, 1989b). Each of the review guidelines is briefly described below.

\subsubsection{HFS, 1988}

The American National Standard for Human Factors Engineering of VDT Workstations specifies conditions that have been established as representing acceptable human factors engineering principles and practices in the design of VDTs, associated equipment, and VDT environments. The HFS document was written for those VDT applications described as text processing, data entry, and data inquiry. The first four sections of the standard deal with the purpose and scope of the guidance, conformance to the document, and other standards cited by the document. The titles of Sections 5 through 10 are:

$\begin{array}{ll}\text { o } & \text { Working Environment } \\ \text { o } & \text { Visual Display } \\ \text { o } & \text { Keyboard } \\ \text { o } & \text { Furniture } \\ \text { o } & \text { Measurement Techniques } \\ \text { o } & \text { Cited References }\end{array}$

\subsubsection{Kinkade and Anderson, 1984}

The Human Factors Guide for NPP Control Room Development provides a framework for the systematic application of human factors principles and criteria during the progressive stages of NPP control-room development. It presents both general and specific guidelines for integrating features that improve operator reliability into personnel-plant interface designs. The document also summarizes the state-of-the-art for human factors planning, analysis, design, and evaluation efforts related to plant developments. The guide was tailored to meet the specific needs of the power industry and is intended to inform utility, architect-engineering, and nuclear steam supply system managers, as well as other plant development team participants, of what can be done to help insure that human capabilities are not exceeded by personnel-plant interface designs.

Chapter 1 of the document identifies relationships between plant development phases and human factors applications, and presents step-by-step guidelines for structuring a human factors 
engineering program plan. Chapter 2 presents a recommended approach to describing and analyzing plant functions and systems as well as operator tasks. Chapter 3 provides guidance for control-room layout, moderation of environmental conditions, and provisions for habitability. Chapter 4 provides recommendations for defining instrument types, arranging them on available panel surfaces, and establishing labeling, demarcation, and coding conventions. Chapter 5 addresses alarm and annunciator system design specifications and recommends ways to establish a coherent, consistent rationale for alerting and informing personnel about deviant plant conditions requiring operator action. Chapter 6 describes preferred display and control instrument design features that are compatible with personnel expectancies and reflect accepted human factors principles and criteria. Chapter 7 provides guidelines for supporting the design of an integrated communications system. A checklist summarizing the human factors principles and criteria addressed is provided for each chapter.

\subsubsection{NASA, 1989}

The Man-Systems Integration Standards supply specific user information to ensure proper integration of the man-system interface requirements with those of other disciplines. They also provide concise design considerations, design requirements, and design examples.

The NASA document has 14 sections; they are entitled as follows:

$\begin{array}{ll}\circ & \text { Introduction } \\ \circ & \text { General Requirements } \\ \circ & \text { Anthropometry and Biomechanics } \\ \circ & \text { Human Performance Capabilities } \\ \circ & \text { Natural and Induced Environments } \\ \circ & \text { Crew Safety } \\ \circ & \text { Health Management } \\ \circ & \text { Architecture } \\ \circ & \text { Workstations } \\ \circ & \text { Activity Centers } \\ \circ & \text { Hardware and Equipment } \\ \circ & \text { Design for Maintainability } \\ \circ & \text { Facility Management } \\ \circ & \text { Extravehicular Activity }\end{array}$

\subsubsection{The Other Three Guidelines}

The other three industry human factors engineering review guidelines are updated versions of earlier documents. Sanders and McCormick's book (1987) is the sixth edition of McCormick's well known human factors engineering textbook by the same title. Human Factors Engineering Design for Army Materiel (Military handbook [MIL-HDBK] 759A; U.S. DOD, 1981a) is the revised version of MIL-HDBK-759 (U.S. DOD, 1975); Human Engineering Design Criteria for Military Systems, Equipment, and Facilities (Military standard [MIL-STD] 1472D; U.S. DOD, 
1989b) is an updated issue of the previous four MIL-STD-1472 standards. All three of these review guidelines were utilized as baseline documents during the generation of NUREG-0700 (see Section 3.3.4 below).

\subsubsection{Review of Sections 1 - 5 of NUREG-0700}

ORNL analyzed the six industry human factors engineering review guidelines and determined that the control room design review process is not covered in any of the recent guidelines. As a result, it is suggested that no revisions should be made to Sections 1 through 5 (i.e., Introduction, Planning Phase, Review Phase, Assessment and Implementation, and Reports) of NUREG-700.

\subsubsection{NUREG-0700, Section 6 Reference Documents}

The control-room human factors engineering guidelines in Section 6 of NUREG-0700 were constructed based upon 27 source documents (i.e., American Society of Heating, Refrigeration, and Air-Conditioning Engineers [ASHRAE], 1977; Baumeister, 1978; Bell System Center for Technical Education [BSCTE]; Dreyfuss, 1967; Engel and Granda, 1975; Gould, 1968; Institute of Nuclear Power Operations [INPO], 1980, 1981; Kaufman, 1981; Kelly, 1972; Kubokawa, Woodson, and Selby, 1969; McCormick, 1976; Meister and Sullivan, 1969; Miller, 1968; Parker and West, 1973; Psychological Research Associates, 1959; Ramsey and Atwood, 1979; Seminara, Eckert, Seidenstein, Gonzalez, and Stempson, 1980; Seminara, Gonzalez, and Parsons, 1977; Shurtleff, 1980; Smith, 1979; U.S. Air Force Systems Command [AFSC], 1980; U.S. DOD, 1974, 1975; Van Cott and Kinkade, 1972; Vartabedian, 1971; and Woodson and Conover, 1964).

About half of the human factors engineering guidelines are also based upon what is referred to in Appendix A to NUREG-0700 as "NRC, Office of Nuclear Reactor Regulation, HFEB Preferred Practices". In discussions with the NRC project manager, it was determined that these preferred practices are not a written set of material that can be followed closely, but rather an undocumented group of procedures, methods, and techniques that the NRC inspectors/ reviewers utilize and/or look for during control-room design reviews. Apparently, prior to and/or during the generation of the NUREG-0700 guidance, the developers of the guidelines had a number of discussions with the HFEB evaluators/reviewers during which the preferred practices were described and discussed. Subsequently, this material was used by the developers to derive the Control-Room Human Factors Engineering Guidelines.

A breakdown of the control-room human factors guidelines by baseline document(s) used in their generation is exhibited in Table 3. The total amount exceeds the number of guidelines in Section 6 of NUREG-0700 since more than one source reference was utilized during the preparation of many of the guidelines.

\subsubsection{Review Process for Section 6}

Each of the guidelines and exhibits in Section 6 of NUREG-0700 was reviewed against one or more of the six industry human factors engineering review guidelines. The Guideline Reference 
Matrix which is subsection A.2 of Appendix A to NUREG-0700 provided the blueprint for the review. This matrix presents the control-room human factors engineering guidelines (rows) by reference documents (columns). In the cells of the matrix are displayed the page number of the reference document from which the guidance was extracted.

Table 3. Human Factors Guidelines by Baseline Documents

$\underline{\text { Source Document }}$

Number of Guidelines for Which the Source Was Used as a Baseline Document

ASHRAE (1977)

Baumeister (1978)

BSCTE

Dreyfuss (1967)

Engel \& Granda (1975)

Gould (1968)

INPO (1980)

INPO (1981)

Kaufman (1981)

Kelly (1972)

Kubokawa et al. (1969)

McCormick (1976)

Meister \& Sullivan (1969)

Miller (1968)

Parker \& West (1973)

Psychological Research (1959)

Ramsey \& Atwood (1979)

Seminara et al. (1977)

Seminara et al. (1980)

Shurtleff (1980)

Smith (1979)

U.S. AFSC (1980)

U.S. DOD (1974)

U.S. DOD (1975)

Van Cott \& Kinkade (1972)

Vartabedian (1.971)

Woodson \& Conover (1964)

HFEB Preferred Practices 
NUREG-0700 guidelines and exhibits, designed using a source document which has been superseded by a new one, were reviewed against the new set of guidance. Guidelines generated based upon MIL-STD-1472B were examined against the guidance in MIL-STD-1472D. Guidance prepared using MIL-HDBK-759 as a reference was compared with the material in MILHDBK-759A. Guidelines derived from the fourth edition of McCormick's book were evaluated against Sanders and McCormick's sixth edition. The nuclear-related human factors engineering guidance adapted from the two Seminara et al. and two INPO documents was assessed through a review of Kinkade and Anderson.

In regards to the control-room guidelines which were developed via the HFEB Preferred Practices, the following process was followed. First, the NRC project manager asked the Office of Nuclear Reactor Regulation's HFEB whether there have been any changes to the NRC inspector preferred practices; the Branch responded that if there have been, they have not been documented. Second, the material was evaluated against Kinkade and Anderson. Third, the guidelines were analyzed using the nuclear experience and technical expertise of the ORNL project team.

The Section 6 guidelines and exhibits which were generated using one or more of the other 19 source documents as a baseline were compared and contrasted with the industry human factors engineering guidelines as a whole. Individual guidelines were evaluated against each industry document one at a time.

\subsubsection{Section 6 Guideline Updates}

Subsequent to the review of the Section 6 guidance, NUREG- 0700 was revised where necessary in accordance with the industry human factors engineering review guidelines. Additions and/or deletions were made to the Control-Room Workspace, Annunciator Warning Systems, Controls, Visual Displays, and Process Computer subsections. The updates for the Control-Room Human Factors Engineering Guidelines are presented in Appendix C; they are listed in the same categorical taxonomy as that utilized in Section 6 of NUREG-0700. The source(s), upon which each guideline update is based, is identified.

\subsubsection{Review of NUREG-0700 Appendices}

ORNL conducted an assessment and comparison of the six industry human factors engineering review guidelines with the NUREG-0700 appendices areas identified in Subtask 9B. It was determined that the information within the five appendices is not addressed in any of the recent guidelines. As a result, it is suggested that no modifications be made to Appendices A through $\mathrm{E}$ (i.e., Reference Materials, Systems/Operations Design Analysis Techniques, Control-Room Operating Personnel Interview Protocol, Photography Guidelines, and Guidelines for Environmental Measurements) of NUREG-0700. 


\subsubsection{Miscellaneous Suggestions}

During ORNL's performance of Subtasks 9B and 9C, six miscellaneous suggestions were highlighted. The first deals with the addition of a reference section to the ACRDR guidelines and was described in section 3.2.4.1 of this report. The other five are presented and discussed below.

An inconsistency exists between the two sets of control-room human engineering guidelines in regards to their statement of the guidance. NUREG-0700 consistently uses the auxiliary word "should" in its guidelines. For instance, guideline 6.8.2.3.b states "layouts of repeated functions should not be mirror-imaged". This term gives the control-room evaluators some discretion in their review of the control room. They are allowed to determine whether something meets the guidance provided. The material shown in the ACRDR guidelines utilizes present-tense indicatives of the word "be", i.e., the terms "is" and "are". As an example, guideline 3.1.2 states "users are able to pace their data entry, rather than having the pace controlled by computer processing or external events". The guidance in the ACRDR guidelines appears to be definitive; it does not allow the evaluator any leeway. The guidelines present a "go"/"no-go" situation. A decision should be made as to which guidelines (i.e., either NUREG-0700 or ACRDR) should be modified.

NUREG-0700 uses a combination of numbers, letters, and capitalized word descriptors to designate specific guidelines; for instance, 6.7.2.1 CRT DISPLAY CHARACTERISTICS, $d$. LUMINANCE CONTRAST. The ACRDR guidelines utilize numbers and both small and capitalized letters to title and label its material; for example, 3.1 System Response Time, 3.1-4 Rough Cursor Positioning Time. This inconsistency between sets of guidelines needs to be rectified so that a thoroughly integrated document can be generated.

The ACRDR guidelines consist of ten parts. They are:

$\begin{array}{ll}\text { o } & \text { Section } \\ \text { o } & \text { Subsection } \\ \text { o } & \text { Grea } \\ \text { - } & \text { Guideline number } \\ \text { - } & \text { A narrative guideline } \\ \text { o } & \text { A further explanation, rationale, or examples (where appropriate) } \\ \text { o } & \text { Assessment method (i.e., the data collection procedure) } \\ \text { - } & \text { The sources from which the guideline was obtained } \\ \text { - } & \text { Whether the guideline is based upon firm, tentative, or weak validity criteria }\end{array}$

NUREG-0700 guidelines consist of the first six parts. They do not, however, have the last four parts. It is suggested that either the missing parts be added to the NUREG-0700 guidelines or the extra, inconsistent parts be deleted from the ACRDR guidelines. 
During the course of ORNL's review and evaluation of the two sets of guidelines, it became apparent that it would be more appropriate and much easier to integrate the ACRDR guidelines into the NUREG-0700 guidelines rather than vice versa. It would be more appropriate because much of NUREG-0700 seems to be directly applicable to advanced technology and advanced control rooms. It would be much easier since NUREG-0700 is broader in scope and, unlike the ACRDR guidelines, contains more than just the control-room human engineering guidelines.

NUREG-0700 has five other sections and five appendices. The NRC should reconsider current plans for the merging of the two sets of guidelines.

Since the NUREG-0700 human factors engineering guidelines which are not addressed by the present draft of the ACRDR guidelines are being updated, it seems appropriate to make changes to the guidance to reflect the suggestions of prior users of the NUREG-0700 guidance.

Individuals who have used the guidelines to evaluate control room design may have identified problem areas in the guidelines that should be rectified. Furthermore, they may have identified a number of inconsistencies, unclear verbiage, and/or redundancies that should be modified. In discussions with the NRC project manager it was determined, however, that no list of changes and suggestions currently exists.

In 1990, as part of the development process for the ACRDR guidelines, BNL conducted a study oriented towards identifying the use, issues, and problems associated with NUREG-0700. The areas covered included:

- Who have been the users of NUREG-0700?

- How have NRC inspectors used NUREG-0700 in the past, i.e., what applications has the document been used for?

- Have there been any problems in the use of NUREG-0700?

- How satisfactory is the structure/organization of the design review guidelines in NUREG-0700?

- What human factors guidelines documents other than NUREG-0700 are used in regulatory inspections or reviews? How do inspectors like the structure of these documents?

- Do you know of any automated or computer-based tools used for inspection/audit purposes?

- Are there operator interface technologies observed in plant inspection which NUREG-0700 does not adequately address?

- Do you know of any advanced operator technologies that will be in the control room or plant of the future that is not found in present-day plants?

- Do you have any recommendations on how a new control room review guideline can better meet their needs than NUREG-0700 and other existing guidelines?

Only the third question was directed at identifying recommended changes or improvements to the guidelines. It is, therefore, recommended that a survey of NRC inspectors/evaluators and industry personnel who have conducted control room design reviews be performed. The questions in the 
survey form should be aimed at identifying needed changes and improvements to the guidelines as a result of their use in the "real world". 


\section{ASSESS NEW GUIDELINES DEVELOPMENT NEEDS TO ENHANCE THE ACRDR GUIDELINES}

\subsection{SUBTASK 10A}

\subsubsection{Objective}

The objective of Subtask 10A was to identify categories of human-system interface guidelines that are missing from draft 1 of the ACRDR guidelines document prepared by BNL under FIN L1317, but which may be necessary for a complete document that will be able to serve the needs of NRC inspectors and reviewers.

\subsubsection{Identification of Human-System Interface Categories}

ORNL reviewed and evaluated draft 1 of the ACRDR guidelines document to assess the degree to which it incorporates a great majority of the prospective advanced systems and technologies which might be used in NPP control-room upgrades and/or in control rooms of the future. The ACRDR guidelines were also analyzed to determine whether there are sufficient human factors principles and criteria listed for each specific area covered within the guidelines document.

Thirteen general categories of human-system interface guidelines were subsequently identified that are either missing from, or not adequately addressed, by the prototype ACRDR document, but which may be necessary for an upgraded set of guidelines to serve the needs of NRC inspectors/reviewers. The categories include:

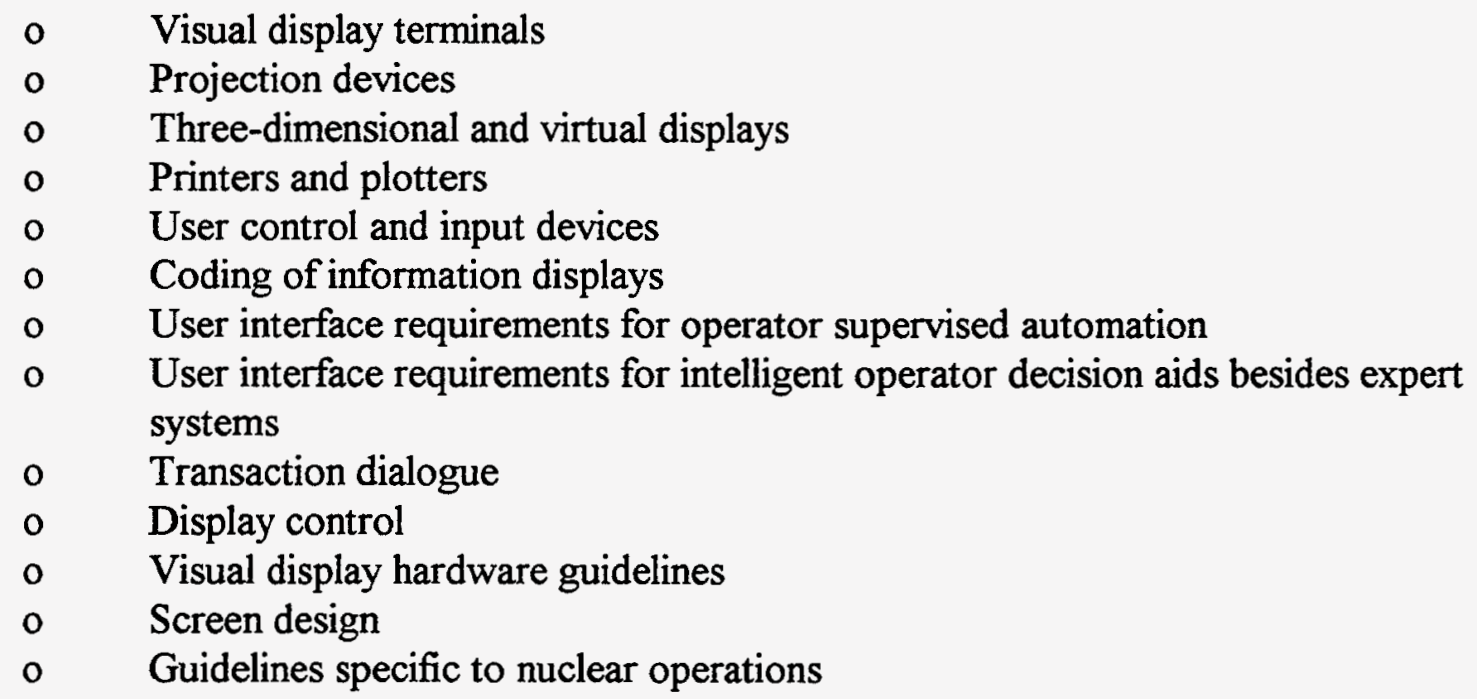

In regards to VDTs, human-system interface guidelines are either missing or enough are not provided for the following advanced technologies: 


$\begin{array}{ll}\text { - } & \text { Light emitting diodes (LED) } \\ \text { o } & \text { Plasma panels } \\ \text { o } & \text { Electroluminescence } \\ \text { o } & \text { Electrochromics } \\ \text { o } & \text { Electrophoretics } \\ \text { - } & \text { Liquid crystals (LC) } \\ \text { o } & \text { Large screen displays }\end{array}$

It was determined that there are insufficient interface guidelines to serve the needs of the NRC inspectors for two main types of printers (impact and nonimpact) and two primary kinds of plotters (pen and electrostatic).

Enough ACRDR guidelines have not been furnished for many user control and input devices. The devices include:

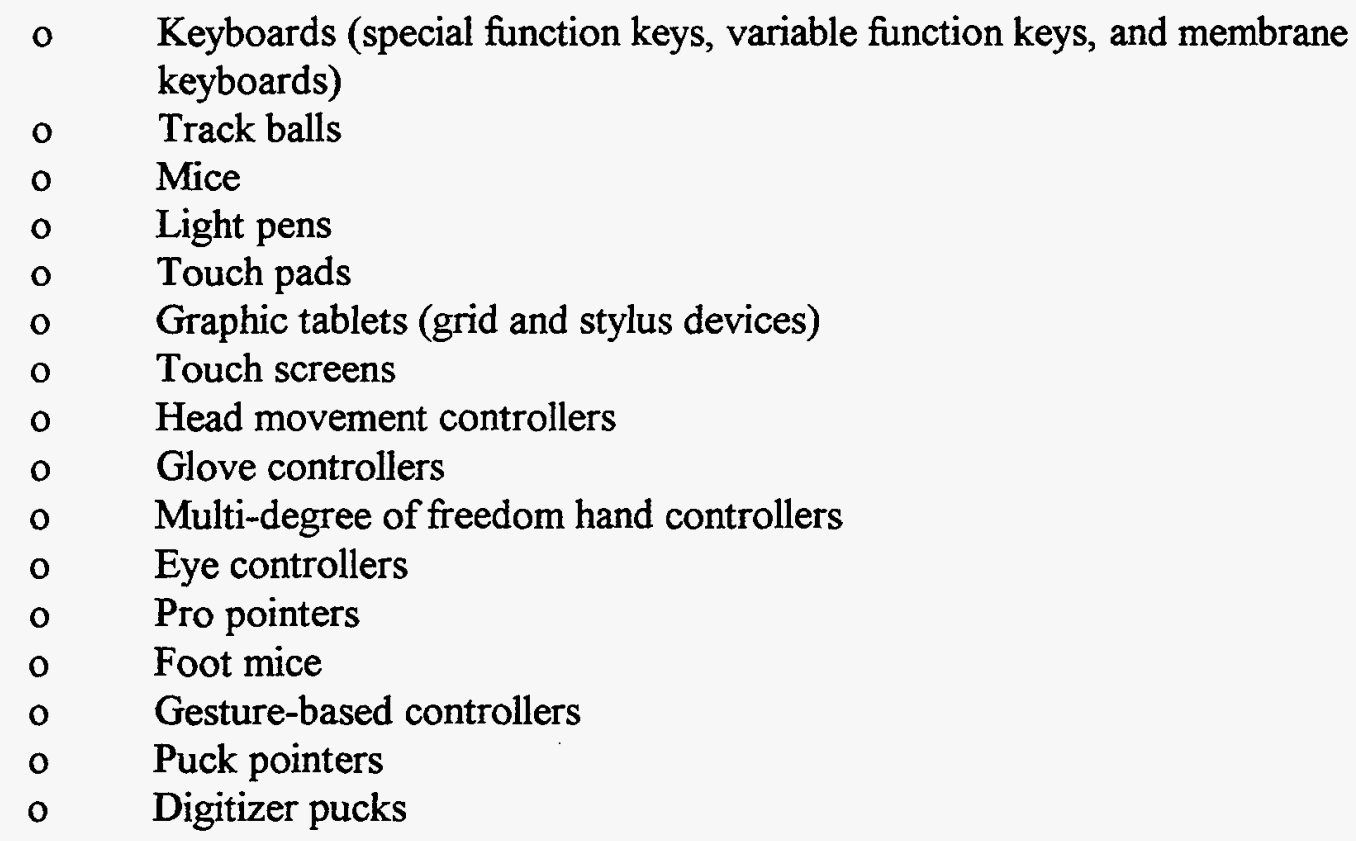

Human-system interface categories for the coding of information displays are deficient in the ACRDR guidelines document in three specific areas:
- Image reversal
- Lines
- Texture, focus, and motion

Under the domain of transaction dialogue, no guidelines are provided on natural language. Very few human factors guidelines were supplied in five areas of display control: 


$\begin{array}{ll}\text { o } & \text { Hypercard } \\ \text { o } & \text { Hypertext } \\ \text { o } & \text { Hypermedia } \\ \text { o } & \text { Pan and zoom } \\ \text { o } & \text { On-screen controls }\end{array}$

ORNL ascertained that visual display hardware guidelines are missing on the following topics:

$\begin{array}{ll}\text { o } & \text { Measurement of raster modulation for color displays } \\ \text { o } & \text { Determination of appropriate maximum character and background contrast ratio } \\ \text { o } & \text { Determination of polarity recommendations } \\ \text { o } & \text { Measurement of display resolution for color CRT and flat panel screens } \\ \text { o } & \text { A requirement for luminance uniformity (acceptable variation in luminance) } \\ \text { o } & \text { Selection and specification of suitable color coding metrics and color spaces } \\ \text { o } & \text { Character, line, and word spacing for displays } \\ \text { o } & \text { Flicker sensitivity } \\ \text { o } & \text { Image distortion }\end{array}$

There are six screen design areas that were not adequately addressed by draft 1 of the ACRDR guidelines. They include:
- Effects of highlighting and grouping techniques
- Effects of spatial relationships among elements
- Effects of graphics
o Effects of animation
o Effects of user characteristics
o Effects of task characteristics

\subsubsection{Description of Selected Human-System Interface Categories}

A number of the missing or inadequately addressed human-system interface categories are briefly described in the sections below.

\subsubsection{VDTs/Projection Devices}

LEDs display alphanumeric information which is typically gained from programmable logic controllers via a register output module. The diodes match this information to internally-stored messages to be displayed.

The plasma panel is an array of tiny neon bulbs. Each bulb can be put into an "on" (intensified) state or an "off" state, and it will remain in the prescribed state until the bulb is explicitly changed to the other. This memory property means that plasma panels need not be refreshed. There are two different types of panels, an alternating current and a direct current plasma panel. 
Electroluminescent displays consist of gridlike structures. Between the front and back panels is a thin layer of an electroluminescent material, such as zinc sulfide doped with manganese, that emits light when in a high electric field. A point on the panel is illuminated via a matrix-addressing scheme.

Electrophoretic displays use positively charged colored particles suspended in a solution of a contrasting color, sealed between two parallel, closely spaced plates that have matrix-addressing selection lines. A negative voltage on the front selection line and a positive voltage on the rear selection line pulls the colored particles toward the front plate, where they are seen instead of the colored liquid. Reversing the voltage pulls the particles toward the rear plate, so the colored liquid is seen.

There are two types of LC panels, an active and a nonactive matrix panel. Each panel consists of six layers. The front layer is a vertical polarizer plate. Next is a layer with thin grid wires electrodeposited on the surface adjoining the crystals. Next is a thin liquid-crystal layer, then a layer with horizontal grid wires on the surface next to the crystals, followed by a horizontal polarizer, and finally a reflector. The liquid-crystal material is comprised of long-line molecules.

Most large-screen displays use some form of CRT, in which the light from a small but very bright monochrome CRT is magnified and projected from a curved mirror. Color large-screen systems use three projectors with red, green, and blue filters.

There are two types of projection devices, a front projection and a back projection device. Projection devices generate magnified images of the surfaces of CRTs or use light valves to modulate the light from an internal source. In the most common approach, an electron gun traces an image on a thin oil film on a piece of glass. The electron charge causes the film to vary in thickness; a negatively charged area of the film is "stretched out," as the electrons repel one another, causing the film to become thinner. Light from the high-intensity source is directed at the glass, and is refracted in different directions because of the variation in the thickness of the oil film.

\subsubsection{Three-Dimensional and Virtual Displays}

There are two varieties of three-dimensional displays, stereoscopic and holographic displays. Stereoscopic displays are those which have a separate image projected for each eye, wherein the brain fuses the two two-dimensional scenes into a three-dimensional one. This can be accomplished with two screens, one for each eye, or by using one screen which alternates right/left eye views and utilizes glasses or shutters to present the proper view to each eye. Fastacting LC display shutters are now available which permit such picture interchange.

Holographic displays are produced by focusing phased light on scene negatives which were exposed with laser light. This creates a three-dimensional image which is perceived as if one were actually "in the environment", without the need for glasses or shutters. "Hard-copy" versions of 
this technique have been used as cover illustrations on, for example, National Geographic magazines.

Virtual displays are "computer-generated" images which are displayed to the user/viewer. Computer-generated means that the image exists only within the computer memory or program. This is the visual component of a new technology called "virtual reality", in which the entire "world" of the user is computer generated and controlled. The user can "manipulate" the virtual world, but such a world does not actually exist physically for the user to sense. A corresponding reality may exist outside the computer into which the computer can pass actions generated by the user.

\subsubsection{Printers and Plotters}

Impact printers include both dot matrix and daisy wheel printers. Dot-matrix printers use a print head of from 7 to 24 pins, each of which can be individually fired, to strike a ribbon against the paper. The print head moves across the paper one step at a time, the paper is advanced one line, and the print head makes another pass across the paper.

There are four main types of nonimpact printers: laser, ink-jet, thermal transfer, and thermal sublimation dye transfer. Laser printers scan a laser beam across a positively charged rotating drum coated with selenium. The areas hit by the laser beam lose their charge, and the positive charge remains only where the copy is to be black. A negatively charged powdered toner adheres to the positive areas of the drum and is then transferred to blank paper to form the copy. Ink-jets printers spray cyan, magenta, yellow, and sometimes black ink onto paper. In most cases, the ink jets are mounted on a head in a printerlike mechanism. The print head moves across the page to draw one scan line, returns while the paper advances by one inter-scan line spacing, and draws the next scan line. Thermal transfer printers transfer pigments from colored wax paper to plain paper via finely spaced heating nibs. The wax paper and plain paper are drawn together over the strip of heating nibs, which are selectively heated to cause the pigment transfer. Thermal sublimation dye transfer printers work similarly to the thermal transfer printers, except the heating and dye transfer process permits 256 intensities each of cyan, magenta, and yellow to be transferred, creating highquality full-color images with a spatial resolution of 79 dots-per-centimeter.

Pen plotters move a pen over a piece of paper in a random, vector-drawing style. In drawing a line, the pen is positioned at the start of the line, lowered to the paper, moved in a straight path to the endpoint of the line, raised, and moved to the start of the next line. There are two basic varieties of pen plotters (flatbed and drum). The flatbed plotter moves the pen in $x$ and $y$ directions on a sheet of paper spread out on a table and held down by electrostatic charge, by vacuum, or simply by being stretched tightly. A carriage moves longitudinally over the table. On the carriage is a pen mount moving latitudinally along the carriage; the pen can be raised and lowered. In contrast, the drum plotter moves the paper along one axis and the pen along the other axis. Typically, the paper is stretched tightly across a drum. Pins on the drum engage prepunched holes in the paper to prevent slipping. The drum can rotate both forward and 
backward. By contrast, many desk-top plotters move the paper back and forth between pinch rollers, while the pen moves across the paper.

The electrostatic plotter places a negative charge on those parts of the white paper that are to be black, and then flows positively charged black toner over the paper. The toner particles adhere to the paper where the charge has been deposited. The charge is placed on the paper one row at a time. The paper moves under a fine comb of electric contacts spaced horizontally. Each contact is either on (to impart a negative charge) or off (to impart no charge).

\subsubsection{User Control and Input Devices}

Track ball devices consist of a sphere suspended on low-friction bearings. The device is turned in place (usually by the hand) to control the position of a follower on an associated display. The motion of the track ball is sensed by potentiometers or shaft encoders. The ball does not return automatically to the point of origin; interfacing systems must provide this.

The mouse is a small handheld device that can be moved across any flat surface to control the position of a follower on an associated display. Mice differ in the number of buttons and in how relative motion is detected. The motion of the roller in the base of a mechanical mouse is converted to digital values that are used to determine the direction and magnitude of the movement. The optical mouse is used on a special pad having a grid of alternating light and dark lines. A LED on the bottom of the mouse directs a beam of light down onto the pad, from which it is reflected and sensed by detectors on the bottom of the mouse. As the mouse is moved, the reflected light beam is broken each time a dark line is crossed. The number of pulses so generated, which is equal to the number of lines crossed, are used to report mouse movements to the computer.

The light pen is a light-sensing device used primarily to indicate position on a display screen. The event caused when the light pen sees a light pulse on a display screen can be used to save the video controller's $\mathrm{x}$ and $\mathrm{y}$ registers and interrupt the computer.

Grid and stylus devices consist of a grid with a spatial layout that corresponds to that of the display. The grid senses the position of the stylus to control the position of a follower on the display. Most graphic tablets use an electrical sensing mechanism to determine the position of the stylus.

The touch-screen device is a control with a spatial layout that corresponds to that of the screen. It is activated by being touched and records the location of the touch. This control generally consists of a transparent surface attached directly to the face of a display screen and can be used for cursor control or to activate menu items.

A glove controller is a light weight glove-like device that transmits data records of arm, hand, shape, and position to a host computer. These data are provided by motion tracking sensors 
which transmit position and orientation of the hands as well as by flex sensing devices, usually located at finger joints, between fingers, and across the palm.

Eye controllers consist of an oculomotor and a magnetic field transducer. The controller is mounted in a helmet worn by an individual. The oculomotor monitors eye movements, while the transducer provides helmet position and attitude information. This information is integrated to determine the eye's line-of-sight.

The pro pointer fits into a space less than 0.387 centimeters square and can either stand alone or be integrated into a keyboard. The device has a handle approximately the size of a standard key on a keyboard. The pro pointer uses a LED and an optical sensor to generate $\mathrm{x}$ and $\mathrm{y}$ coordinates when the small handle is moved.

The foot mouse is a foot-operated cursor control device that consists of a metal pedal approximately 0.290 centimeters square. Its rubberized surface pivots so that a foot can depress the pedal at its top, bottom, left, or right edge. Edge press moves the display cursor one row or column in the selected direction.

The puck pointer combines the features of a mouse and a joystick. The device fits into a space approximately 0.258 centimeters square. Using a LED, the puck generates $\mathrm{x}$ and $\mathrm{y}$ coordinates through an optical sensor when a small handle placed in the center of the space is moved.

Digitizer pucks look something like a mouse with an installed optical sight. The device is used to enter into a computer the location of objects or text in hard-copy documents. A location is designated by positioning the puck's sight over the desired point on the document and then pressing one of the puck's buttons to send the spatial coordinates of the point to the attached computer.

\subsubsection{User Interface Requirements for Operator Supervised Automation and Intelligent Operator Aids}

It is not currently known how user interface requirements for supervised automation and operator aids will change in advanced NPP control rooms, but the role of the operator will most certainty be altered. In analog-instrumented control rooms, the operator is primarily response for "metering up", reviewing the analog displays, and operating the controls on the control-room panels. As a result of the introduction of advanced systems and technologies, the operator probably will be more of a supervisor whose primary duty will be monitoring. $\mathrm{He} / \mathrm{she}$ will also be interfacing with intelligent computer-driven operator aids. Plant functions will be performed more automatically than at present, and the operator will intervene and take over control of the situation only when he perceives a requirement to do so. The operator will function more as a manager and planner than at present. 


\subsubsection{Transaction Dialogue and Display Control}

Command languages are typically highly stylized and grammatically, very limited artificial languages. No natural language dialogue system has as yet been developed and used successfully with computers. In natural language dialogues, the user and the computer would communicate in a conversational manner, with both the user and computer able to use and comprehend a flexible set of terms containing many synonyms and a flexible syntax. The main constraints to a natural language system are the constraints of the language of the user.

Hypertext has been defined as computer-supported links within and between documents. It has also been described as a computer repository of information organized for access in ways that are analogous to the nonlinear access conventions used in printed information. Hypermedia is used to explicitly enlarge the hypertext concept to include other media, such as sound, video, and computer animation/simulation.

\subsubsection{Visual Display Hardware Guidelines}

The human-system interface category of visual display hardware guidelines is thoroughly addressed by Snyder (1989). A few of the subcategories are briefly described below.

A problem exists in the means of measuring raster modulation for color displays. A number of unanswered questions include the following. Should the modulation be measured with a single gun on? Or should it be measured with all three guns on, producing a "white" raster? At what luminance should it be measured? What aperture width and length should be used? How valid are such measurements in setting upper limits on raster modulation and are raster modulation requirements as meaningful for color shadow-mask displays? Do such measurements apply for all mask geometries?

It is assumed that performance improves with increasing contrast to no known maximum. There is, however, no scientific support for such a claim. Whether there is an upper limit to contrast that is needed, for example to avoid "floating" of characters against a nonvisible background, is a subject that should be pursued experimentally with variables such as space average luminance, character resolution, and character size held constant.

What polarity is acceptable? Positive contrast (characters on a dark background) leads to specular glare problems, while negative contrast increases sensitivity to flicker. Again, the experimental evidence is lacking for adequately controlled conditions.

Most lighting standards recommend that the luminance not vary more than $50 \%$ from the center of the display to the edges. There is, however, currently no suitable research that indicates this to be a safe or an adequate value, or that performance will not improve should this tolerance be tighter. 
Image distortion is the determination of the degree of distortion which is permissible in the image before a significant degree of human performance degradation occurs.

\subsubsection{Screen Design}

The human-system interface category of screen design is discussed by Tullis (1988). The subcategories are synopsized below.

The effects of a wide variety of highlighting and grouping techniques, such as reversed video, increased brightness, and graphical boundaries, are not as well understood as their extensive use might imply. Research is needed to understand each of these techniques, their interactions with each other, and their interactions with the spatial components of screen layouts.

The spatial relationships among the elements on a screen play an important role in determining how the user interprets the information. But we need a better understanding of the interpretations that users apply to various spatial relationships so that they can be used to best reflect the semantic relationships among the display elements.

Many aspects of the use of graphics are not well understood. Understanding how users process computer-generated graphics is as complex a problem as understanding visual perception itself. The key is to try to understand some of the important aspects of graphical displays, such as the situations where various types of graphical techniques yield the most effective display.

Very little is known about the use of animation as a screen design technique. However, such techniques as moving graphical objects on the screen or introducing other time-based changes in the appearance of the screen elements can clearly have a substantial impact on the user's interpretation of the display.

Very little is known about how the characteristics of users interact with the characteristics of screen displays. For example, what role, if any, does the user's age play in determining the effects of different screen formatting techniques? How does the user's perception of the screens for an application change as he or she changes from being a novice user to an experienced user?

The tasks that screens are used for are as varied as their users. A user may use a screen in very different ways at different times. Techniques for describing task characteristics need to be used to study the interactions of different kinds of tasks with different display characteristics.

\subsection{SUBTASK 10B}

The objective of Subtask 10B was to determine and recommend the most efficient approach to the development of new guidelines. ORNL designed an efficient approach to the development of new ACRDR guidelines. The recommended approach makes maximum use of the secondary and tertiary sources identified by BNL in FIN L1317. It also includes the use of technical literature in 
basic and applied journals, conference proceedings, other relevant documents, and contact with researchers actively working in the field of HCI. The approach to the development of new ACRDR guidelines is presented in a flow-chart manner in Figure 1.

\subsection{SUBTASK 10C}

\subsubsection{Objective}

The objective of Subtask 10C was to perform a preliminary assessment of the available sources, as identified in Subtask 10B, that may be useful in the development of new ACRDR guidelines and their applicability to the human-system interface categories identified in Subtask 10A.

Specifically, ORNL identified those categories of the human-system interface for which there are available secondary and/or tertiary sources which can be utilized; those which require a review of available basic and applied literature or other sources of information; and those for which the information is unavailable to serve as a basis of new guidelines development.

\subsubsection{Review of the FIN L1317 Secondary and Tertiary Sources}

BNL conducted a search of the human factors literature for input to the ACRDR guidelines; this review uncovered many applicable documents. The material was subdivided into two camps: seven primary source documents, which were subsequently used as references during the generation of the prototype guidelines, and other source material (i.e., secondary and tertiary sources) which was not utilized during the guidelines development process.

ORNL reviewed and evaluated the secondary and tertiary source documents (i.e., Apple Computer, 1987; Banks, Gertman, and Petersen, 1982; Banks, Gilmore, Blackman, and Gertman, 1983; Blackman, Gertman, and Gilmore, 1983; Blackman and Gilmore, 1984; Brown, 1988; Danchak, 1981; Dumas, 1988; Frey, Sides, Hunt, and Rouse, 1984; Galitz, 1989; Gertman, Blackman, Banks, and Petersen, 1982; Gilmore, 1985; Helander, 1988; HFEB, 1981b; Kinkade and Anderson, 1984; Lapinsky, Eckenrode, Goodman, and Correia, 1989; Meister, 1984; Mosier and Smith, 1986; Pankrantz, 1986; Perlman, 1989; Rankin, Rideout, Triggs, and Ames, 1985; Rouse, 1984a; Rupp, Mine, Wolbarsht, Andrew, and Hirsch, 1984; Salvendy, 1987; Shneiderman, 1987; Sidorsky, Parrish, Gates, and Munger, 1984; Smith and Mosier, 1984a; and U.S. DOD, 1981b, 1985).

Twenty of the 29 documents have material which can be used as the bases for the development of new guidelines. The applicability of the secondary and tertiary sources to the human-system interface categories is listed below.

o VDTs

$\begin{array}{ll}\text { - } & \text { LEDs - Meister } \\ \text { - } & \text { Plasma panels - Meister }\end{array}$




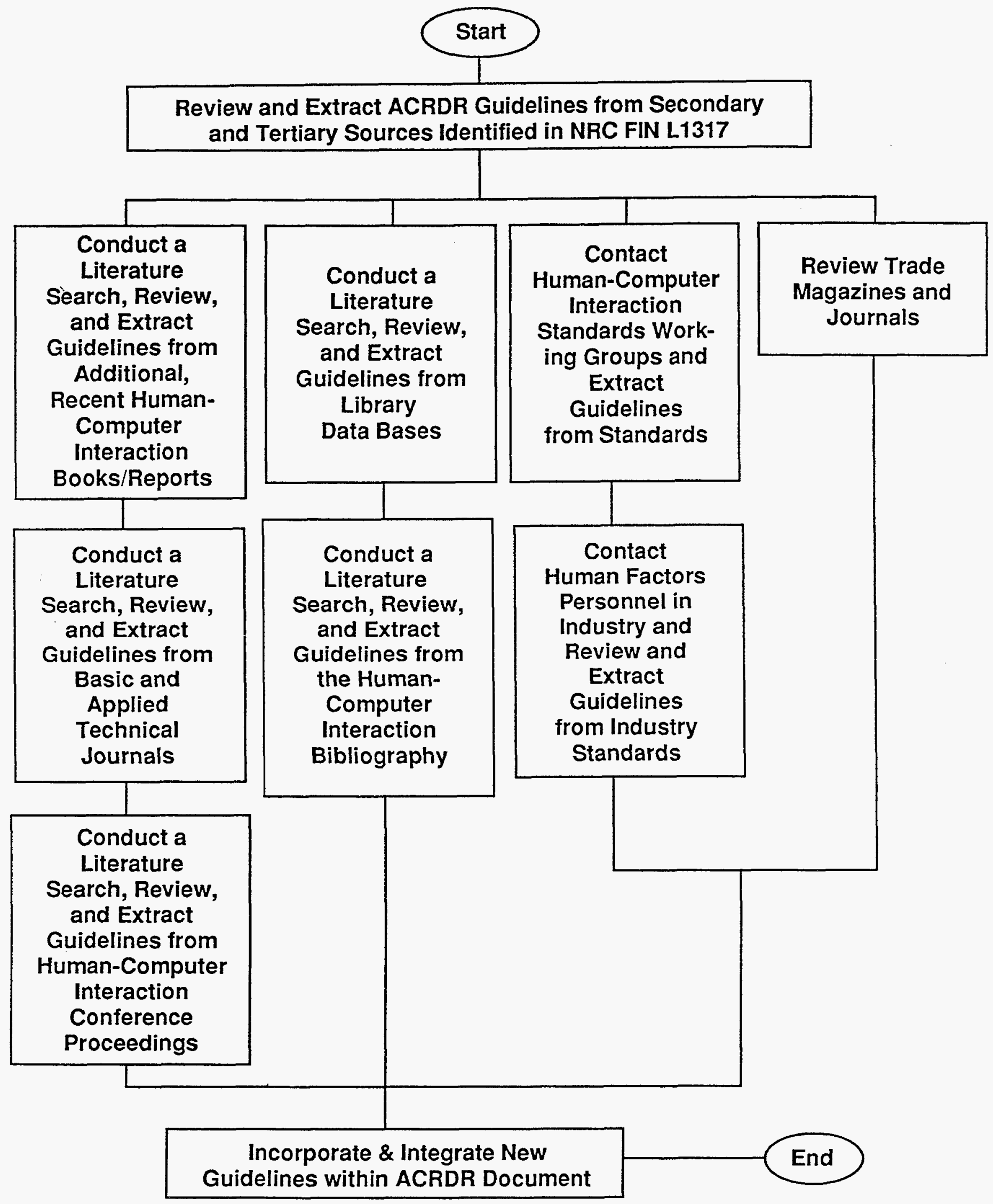

Figure 1. Approach to the development of new advanced control room design review guidelines. 
- $\quad$ Electroluminescence - Meister

- Electrochromics - Meister

- Electrophoretics - Meister

- LCs - Meister

- $\quad$ Large screen displays - Meister

- $\quad$ Projection devices - not applicable (N/A)

- Three-dimensional and virtual displays - N/A

o Printers and plotters

- Impact printers - N/A

- $\quad$ Nonimpact printers - N/A

- $\quad$ Pen plotters - N/A

- Electrostatic plotters - N/A

- User control and input devices

- $\quad$ Keyboards - Brown; Dumas; Gilmore; Helander; Rupp, Mine, Wolbarsht, Andrew, and Hirsch; Salvendy; and Shneiderman

- $\quad$ Track balls - Brown; Helander; Salvendy; and Shneiderman

- $\quad$ Mice - Brown; Helander; Salvendy; and Shneiderman

- Light pens - Brown; Helander; Salvendy; and Shneiderman

- Touch pads - Brown

- Graphic tablets - Helander; Salvendy; and Shneiderman

- Touch screens - Brown; Helander; Salvendy; and Shneiderman

- Head movement controllers - N/A

- $\quad$ Glove controllers - N/A

- $\quad$ Multi-degree of freedom hand controllers - N/A

- $\quad$ Eye controllers - Helander; and Salvendy

- Pro pointers - N/A

- $\quad$ Foot mice - N/A

- $\quad$ Gesture-based controllers - Salvendy

- $\quad$ Puck pointers - Salvendy

- Digitizer pucks - N/A

- $\quad$ Coding of information displays

- $\quad$ Image reversal - N/A

- $\quad$ Lines - N/A

- Texture, focus, and motion - N/A

- User interface requirements for operator supervised automation - Helander

- User interface requirements for intelligent operator aids - Helander; Rouse; and Salvendy 
- Natural language - Helander

- Display control

$$
\begin{array}{ll}
- & \text { Hypercard - N/A } \\
- & \text { Hypertext - N/A } \\
- & \text { Hypermedia - N/A } \\
- & \text { Pan and zoom - N/A } \\
\text { - } & \text { On-screen controls - N/A }
\end{array}
$$

- Visual display hardware guidelines

- Measurement of raster modulation for color displays - N/A

- Determination of appropriate maximum character and background contrast ratio - Meister

- Determination of polarity recommendations - Meister

- Measurement of display resolution for color CRT and flat panel screens Meister

- A requirement for luminance uniformity - Meister

- Selection and specification of suitable color coding metrics and color spaces - N/A

- $\quad$ Character, line, and word spacing for displays - Meister

- $\quad$ Flicker sensitivity - N/A

- Image distortion - N/A

- Screen design

- $\quad$ Effects of highlighting and grouping techniques - Banks, Gilmore, Blackman, and Gertman; Brown; Dumas; Frey, Sides, Hunt, and Rouse; and Sidorsky, Parrish, Gates, and Munger

- $\quad$ Effects of spatial relationships among elements - N/A

- $\quad$ Effects of graphics - N/A

- Effects of animation - N/A

- $\quad$ Effects of user characteristics - Frey, Sides, Hunt, and Rouse; and Helander

- $\quad$ Effects of task characteristics - N/A

o Guidelines specific to nuclear operations - Banks, Gertman, and Petersen; Blackman, Gertman, and Gilmore; Danchak; Gilmore; HFEB; Kinkade and Anderson; Lapinsky, Eckenrode, Goodman, and Correia; Pankrantz; and Rankin, Rideout, Triggs, and Ames 


\subsubsection{Review of Additional Recent Human-Computer Interaction Books and Reports}

ORNL examined and analyzed 26 other HCI books and reports (i.e., Badre and Shneiderman, 1984; Baecker and Buxton, 1987; Blackman, Gertman, Gilmore, and Ford, 1983; Card, Moran, and Newell, 1983; Christie, 1985; Foley, van Dam, Feiner, and Hughes, 1990; Galer, 1987; Gardiner and Christie, 1987; Glushko, 1991; Greeson, 1991; Hartson, 1985; Ivergard, 1989; Kantowitz and Sorkin, 1983; Koch and Schafer, 1986; Monk, 1989; Muratore, 1987; Norman and Draper, 1986; Pine, Schulz, Edman, Hanson, Evans, Gonzalez, Smith, and Seminara, 1982; Rouse, Kisner, Frey, and Rouse, 1984; Sanders and McCormick, 1987; Sime and Coombs, 1983; Smith and Green, 1980; Thomas and Schneider, 1986; Wickens, 1984; Wickens, Todd, and Seidler, 1989; and Wise, Culver, and Abi-Samra, 1987).

This literature was selected from material that: the ORNL project team had in their personal collections; the author of this report knew about but did not originally have; were cited in the secondary and tertiary sources; and were reviewed in the HFS Bulletin "reading" column.

Only six of the HCI books/reports have any relevant material for input into the development of new guidelines for the missing human-system interface categories. Badre and Shneiderman's book contains information on the effects of highlighting and grouping techniques on screen design. Ivergard has data which may be useful for the development of guidelines on user interface requirements for operator supervised automation, and guidelines specific to nuclear operations. Kantowitz and Sorkin, Monk, Norman and Draper, and Sanders and McCormick include material on user control and input devices. In addition, each of the four references has documentation on keyboards. All, except for Sanders and McCormick, have information on track balls, mice, and light pens. Monk also has data on touch pads, graphic tablets, and touch screens.

\subsubsection{Review of Basic and Applied Technical Journals}

ORNL examined and evaluated 15 basic and applied HCI related technical journals (i.e., Abstracts in Human-Computer Interaction, 1988 - 1989; Association for Computing Machinery [ACM] Computing Surveys, 1986 - 1991; ACM Transactions on Information Systems, 1985 - 1991; Communications of the ACM, 1985 - 1991; Ergonomics, 1987 -1991; Human-Computer Interaction, 1985 - 1991; Human Factors, 1980 - 1991; HFS Bulletin, 1980 - 1991; Institute of Electrical and Electronics Engineers [IEEE] Computer, 1985 - 1991; IEEE Computer Graphics and Applications, 1985 - 1991; IEEE Transactions on Systems, Man, and Cybernetics, 1987 1991; Interacting with Computers, 1989 - 1991; International Business Machines [IBM] Systems Journal, 1986 - 1991; International Journal of Human-Computer Interaction , 1989 - 1990; and International Journal of Man-Machine Studies, 1985 - 1991).

The journals were selected via the knowledge of the author and information presented in a book by Shneiderman (1987), which was identified above as a secondary/tertiary source. Some of the journals were reviewed for the past 12 years; others for only two years. 
Only two of the journals, Abstracts in Human-Computer Interaction and Human Factors, however, have any applicable articles. The issue of Abstracts in Human-Computer Interaction covering the literature of 1988 contains three related articles (i.e., Arnaut and Greenstein; Doran; and Goy). The first article includes material on user control and input devices, the second on track balls, and the third on mice.

The 1989 Human Factors journal has an article (i.e., Fisher and Tan) dealing with the effects of highlighting and grouping techniques on screen design; the 1988 volume has one article (i.e., Rouse) addressing user interface requirements for intelligent operator aids. Human Factors, 1987 includes two articles having material for the new guidelines (i.e., Eberts; Parasuraman). The first describes effects of task characteristics on screen design; the second presents information on user interface requirements for operator supervised automation. Each edition of the 1983 and 1981 Human Factors journal has a pertinent article (i.e., Isensee and Bennett, 1983; Fisk and Schneider, 1981). The 1983 article discusses flicker sensitivity; the 1981 article details user interface requirements for operator supervised automation.

\subsubsection{Review of Human-Computer Interaction Conference Proceedings}

ORNL reviewed and analyzed the proceedings from $24 \mathrm{HCI}$ related conferences (i.e., American Nuclear Society [ANS], 1990; ANS/European Nuclear Society, 1986; ACM Special Interest Group [SIG] on Computer-Human Interaction [CHI], 1986, 1987a, 1988a, 1989a, 1990a, 1991; HFS, 1982 - 1985, 1987, 1990 - 1991; IEEE, 1985, 1988a, 1989; International Federation for Information Processing, 1984; International Science, 1986; New York University, 1982; Society for Information Display [SID], 1990 - 1991; and United States of America [U.S.A.] - Japan, 1984).

The proceedings were chosen from conferences that the project team knew about, and from information presented in Shneiderman's book (1987) identified in Section 4.3.2. The majority of the proceedings are from conferences sponsored either by the ANS, ACM, HFS, IEEE, or SID.

Seven of the conference proceedings consist of papers which have applicability to the missing ACRDR guidelines human-system interface categories. Each of the proceedings from the 1990 and 1988 ACM SIGCHI Conferences includes a related paper. The 1990 paper (i.e., Brunner, Wittenburg, Williams, Sekine, Dahlgren, and Washco) describes natural language dialogue, while the 1988 paper (i.e., Brooks) addresses virtual displays. The proceedings from the 1990 HFS Annual Meeting has a paper (i.e., Snyder, Decker, Lloyd, and Dye) discussing the determination of polarity recommendations for visual display hardware. The proceedings from the 1988 IEEE Conference has a paper (i.e., Eckenrode, Lapinsky, and Ramirez) which contains input for the design of guidelines specific to nuclear operations. The proceedings from the 1986 International Science Conference includes a paper (i.e., Ahlstom and Lenman) dealing with keyboards, mice, and touch screens. The proceedings from the 1991 SID Symposium contains a paper (i.e., Rich) detailing the selection and specification of suitable color coding metrics and color spaces for visual display hardware. The proceedings from the 1984 U.S.A. - Japan Conference has a paper (i.e., Rouse, 1984b) which discusses user interface requirements for intelligent operator aids. 


\subsubsection{Review of Library Data Bases}

ORNL conducted a HCI literature review of two library data bases, the National Technical Information Service (NTIS) and Information Services for Physics, Electronics, and Computing (INSPEC). These data bases were selected based on an overview search of 86 science, technology, and computer-related data bases, and knowledge of the ORNL Library staff on data base content. The overview examination allowed a search to be carried out in all 86 data bases at one time to determine the suitability of the data bases for the topics of human factors and standards.

As a result of the preliminary search, the top four data bases were TRIS, NTIS, INSPEC, and COMPUTER ASAP. From this set, NTIS and INSPEC were chosen as the most relevant data bases. TRIS, a transportation data base, was not selected because the human factors related documents contained in it are associated primarily with automotive and other transportation applications. COMPUTER ASAP was not chosen because it is a full-text data base and one of the search terms (i.e., user interface) would very likely have retrieved a high percentage of irrelevant documents. In addition, the library staff knew from prior experience, that COMPUTER ASAP's orientation is toward popular computer literature, not research or scientific material.

NTIS and INSPEC were searched using the primary human-system interface categories as the key terms. These terms were crossed/mixed with the words "human factors and ergonomics" and "standard/guideline/recommendation". The findings from the data base searches are detailed in the paragraphs below.

\subsubsection{National Technical Information Service}

NTIS is produced by the National Technical Information Service of the U.S. Department of Commerce, the central source for the public sale and dissemination of U.S. governmentsponsored research. The data base is comprised of unclassified government-sponsored research, development, and engineering reports, as well as other analyses prepared by government agencies, their contractors, or grantees. Included in this coverage are federally generated machine-readable data files and software, U.S. government inventions available for licensing, federally generated translations, and reports prepared by non-U.S. governments and exchanged with federal agencies. An increasing proportion of the data base consists of unpublished material originating outside the U.S.

The number of articles identified as a result of the search of the NTIS data base are as follows:

- VDTs - 64 articles

o Projection devices -8 articles

- Three-dimensional and virtual displays -25 articles

- Printers and plotters -3 articles

- User control and input devices - 27 articles

- Coding of information displays - 9 articles 
- User interface requirements for operator supervised automation - None

- User interface requirements for intelligent operator aids/natural language - 56 articles

- Display control - 17 articles

- Visual display hardware guidelines - 15 articles

- Screen design - 15 articles

- Guidelines specific to nuclear operations -92 articles

Abstracts of all of the articles which were detected by the NTIS data base as prospective candidates for material for the missing ACRDR guidelines were reviewed and examined. Only three of the key terms uncovered potentially applicable articles.

The human-system interface category "VDTs" surfaced two articles which appear to have relevancy for the generation of guidelines specific to nuclear operations (i.e., Banks, Hunter, and Noviski, 1985; Venhuizen, 1983). The interface category "coding of information displays" revealed an article (i.e., International Atomic Energy Agency, 1987) which also seems to be pertinent for nuclear operations guidelines. The category "user control and input devices" identified three potential articles (i.e., Allen, 1990; NTIS, 1989; and Spacek, Gurstein, Robert, Rutenberg, and Thomas, 1988). The first and third articles have relevancy to the whole area of user control and input devices; the second appears to be pertinent to keyboards.

\subsubsection{Information Services for Physics, Electronics, and Computing}

INSPEC corresponds to the four Science Abstracts printed publications: Physics Abstracts, Electrical and Electronics Abstracts, Computer and Control Abstracts, and IT Focus: Update on Information Technology. The Science Abstracts family of journals began publication in 1898, and now forms the largest English-language data base in the fields of physics, electrical engineering, electronics, computers, control engineering, and information technology.

The number of articles identified as a result of the search of the INSPEC data base are as follows:

\begin{tabular}{|c|c|}
\hline o & VDTs - 283 articles \\
\hline o & Projection devices - 13 articles \\
\hline o & Three-dimensional and virtual displays -47 articles \\
\hline 0 & Printers and plotters - 46 articles \\
\hline o & User control and input devices - 147 articles \\
\hline o & Coding of information displays - 13 articles \\
\hline o & User interface requirements for operator supervised automation - 7 articles \\
\hline o & $\begin{array}{l}\text { User interface requirements for intelligent operator aids/natural language - } 78 \\
\text { articles }\end{array}$ \\
\hline 0 & Display control - 28 articles \\
\hline o & Visual display hardware guidelines - 38 articles \\
\hline o & Screen design -53 articles \\
\hline 0 & Guidelines specific to nuclear operations - 17 articles \\
\hline
\end{tabular}


Abstracts of all of the articles which were detected by the INSPEC data base as prospective candidates for material for the missing ACRDR guidelines were analyzed and evaluated. Four of the key terms uncovered potentially applicable articles.

The human-system interface category "VDTs" surfaced 15 articles (i.e., Beaton and DeVilbiss, 1989; Farrell, 1987; Gardner, 1989; Greeson, 1990; Institution of Electrical Engineers, 1986; Kokoschka, 1986; Long, 1984; Macdonald, 1990; Mollon and Cavonius, 1985; Reising and Mazur, 1990; Seamster, Baker, and Andrews, 1989; Taylor and Murch, 1986; Van Nes, 1986; Wickens, 1990; and Yingduo, Ostberg, and Lindstrom, 1990) which appear to have relevancy for the generation of human factors guidelines.

Greeson has relevancy for VDTs. Reising and Mazur, and Wickens has application for threedimensional displays. Gardner has pertinence for user control and input devices. The article by the Institution of Electrical Engineers can provide a basis for the design of guidelines specific to nuclear operations. The other 10 articles have input for the development of visual display hardware guidelines. Beaton and DeVilbiss, and Seamster, Baker, and Andrews contain material for the measurement of raster modulation for color displays. Kokoschka consists of data for the determination of appropriate maximum character and background contrast ratio. Yingduo, Ostberg, and Lindstrom includes information for the measurement of display resolution for color CRT and flat panel screens. Long, Macdonald, Mollon and Cavonius, Taylor and Murch, and Van Nes have material for the preparation of guidelines for the selection and specification of suitable color coding metrics and color spaces. Farrell contains details on flicker sensitivity.

The interface category "user control and input devices" uncovered five articles (i.e., Diehl and Apiki, 1989; Foote-Lennox, 1986; Koppa, 1986; Maguire, 1990; and Murray and Pappas, 1987) which may be appropriate for the development of ACRDR guidelines. Foote-Lennox and Maguire consist of information on user control and input devices in general. Koppa has data on track balls, Murray and Pappas on mice, and Diehl and Apiki on graphic tablets.

The category "visual display hardware guidelines" identified five prospective articles (i.e., Farrell, 1986; Fellmann, Brauninger, Gierer, and Grandjean, 1982; Otten, 1984; and Rogowitz, 1983, 1986). Fellmann, Brauninger, Gierer, and Grandjean has relevancy for VDTs. Otten has pertinency for user control and input devices. Farrell and both of the Rogowitz articles have application to the generation of visual display guidelines for flicker sensitivity.

"Screen design" revealed two articles (i.e, Reiber, 1990; Spoto and Babu, 1989) which appear to have relevancy. The first article has information on the effects of animation on screen design; the second on the effects of highlighting and grouping techniques.

\subsubsection{Review of the Human-Computer Interaction Bibliography}

Ohio State University is currently developing the $\mathrm{HCI}$ Bibliography, which is a computer-based free-access online extended bibliography of the HCI literature. The basic goal of this design project is to put a bibliography for most of $\mathrm{HCI}$ on the screens of all researchers and developers in 
the field through anonymous file transfer protocol access, mail servers, and Macintosh and IBMcompatible DOS floppy disks. When the project is completed a data base of several thousand bibliographic records will be available.

According to Gary Perlman at Ohio State, who is the project director, the primary reason for compiling the HCI Bibliography is to improve the accessibility of information used as a resource for research and development. Online access is a major step in that direction because it allows keyword searching in selected fields of records. Full-text versions of records (i.e., abstracts and tables of contents) provide auxiliary targets for search, and additional information to help a researcher decide if the original source (e.g., journal, book, proceedings) should be approached. Although some abstracted information is available from a few commercial sources, the expense of access and the low quality of user interfaces make them unattractive to many researchers, particularly students. One unfortunate result is the duplication of effort by researchers to create their own online bibliographies. The HCI Bibliography addresses these issues by being noncommercial, providing free-access to its information bases, and by performing basic research to produce better tools for accessing extended bibliographic information.

The HCI Bibliography is to contain most publications on HCI dating back to 1980; for publications before 1980, Ohio State will be more selective. The publications to be compiled include leading journals in $\mathrm{HCI}$, major conference proceedings, and selected publications from other sources. At first, Ohio State sought donations of any bibliographic information, but a large collection of multiple-format overlapping records presented problems. Their current strategy is to gather complete sets from published units like books, journals, and conference proceedings.

In addition to common summary information such as keywords and abstracts, many records will include tables of contents of section headings. Another extension that will allow interesting hypertext access is that records will eventually include a section containing the identifiers of referenced publications.

In May, 1991 the Bibliography was very limited. It consisted of only three HCI books (i.e., Baecker and Buxton, 1987; Helander, 1988; and Salvendy, 1987). It also had just four basic and applied technical journals (i.e., ACM Transactions on Information Systems, 1985 - 1991; HumanComputer Interaction, 1985 - 1991; Interacting with Computers, 1989 - 1991; and International Journal of Human-Computer Interaction, 1989 - 1990). In addition, the Bibliography contained only 16 conference proceedings (i.e., ACM SIGCHI, $1982-1983,1985$ - 1986, 1987a, b, 1988a, b, c, 1989a, b, 1990a, b, 1991; European Conference on Hypertext, 1990; and International Federation for Information Processing, 1984).

A great majority of what was in the HCI Bibliography data base in 1991 was analyzed during other stages of Subtask 10C. ORNL had previously reviewed the three books and four journals (see Sections 4.3.2, 4.3.3, and 4.3.4). Seven of the conference proceedings had also been evaluated (see Section 4.3.5). ORNL examined the other nine conference proceedings and determined that none of them contain papers which have applicability to the missing humansystem interface categories. 


\subsubsection{Review of Human-Computer Interaction Standards Working Groups}

There are currently three working groups, one international and the other two in the U.S., which are developing $\mathrm{HCI}$ related standards. They include:

$\begin{array}{ll}\text { - The International Standards Organization (ISO) } \\ \text { - The SID } \\ \text { o } & \text { The HFS }\end{array}$

The efforts of each group are described below.

\subsubsection{International Standards Organization}

The ISO is working on Standard 9241, "Ergonomic Requirements for Office Work with Visual Display Devices". According to James Williams of Bell Communications Research in Piscataway, $\mathrm{NJ}$, who is the chair of the U.S. technical advisory group to technical committee 159 , subcommittee 4, which is preparing the Standard, ISO 9241 is intended to cover visual displays, regardless of the display process employed. To date, work on the ISO 9241 Standard has only addressed CRT display systems; nothing has been done on the various non-CRT displays. Two other individuals whom the project team contacted (i.e., James Greeson of IBM, Research Triangle, NC, and Philip Krzyzkowski of the Army's Electronics Technology and Devices Laboratory, Fort Monmouth, NJ) both agreed and indicated that the effort on standards for flatpanel technology "is weak".

ISO 9241, when it is completed, will consist of many parts. They include:
o Part 1: General introduction
- Part 2: Guidance on task requirements
- Part 3: Visual display requirements
o Part 4: Keyboard requirements
- Part 5: Workstation layout and postural requirements
o Part 6: Environmental requirements
- Part 7: Display requirements with reflections
- $\quad$ Part 8: Requirements for displayed colors
- Part 9: Requirements for non-keyboard input devices
- Part 10: Dialogue principles
- Part 11: Usability statements
- Part 12: Presentation of information
- Part 13: User guidance
- Part 14: Menu dialogues
- Part 15: Command dialogues
- Part 16: Direct manipulation dialogues
- Part 17: Form-filling dialogues 
- Part 18: Question and answer dialogues

- Part 19: Natural language dialogues

The 19 parts are currently in various stages of development. The stages range between those which have become international standards (Parts 1 and 2) and those on which work has not as yet commenced (Parts 17, 18, and 19).

\subsubsection{Society for Information Display}

The SID's work in the area of HCI standards has focused primarily on CRT displays. They have recently, however, put together a group of Society members to generate draft guidelines for flatpanel display technologies. According to Peter Keller of Tektronix, Incorporated in Beaverton, $\mathrm{OR}$, who is the chair of the group, their efforts have just been initiated. He indicated that there is a proposal from the National Imaging Display Laboratory for the design of standards which has been distributed to group members. The first official meeting was held in May 1991 at the SDD international symposium.

\subsubsection{Human Factors Society}

The HFS assembled a HCI standards committee in 1987. At the HFS annual meeting of the same year, the committee presented a draft proposal for the development of standards. The standards committee serves as the American National Standards Institute (ANSI) authorized standards developing body for $\mathrm{HCI}$ standards and the U.S. technical advisory group to ISO technical committee 159 , subcommittee 4 , working group 5 . The standards committee is currently developing standards for:

- Dialogue techniques (including menus, commands, forms, and direct manipulation) o Information presentation (including text, graphics, sound, and voice)

o User guidance (including system messages, status information, feedback, prompts, error handling, and help)

- Window-based interaction

- The design process for developing successful $\mathrm{HCI}$

No official release of documentation, as yet, has been made by the committee.

ORNL reviewed and evaluated the efforts of the three HCI standards working groups. It was determined that there is very little, if anything, that can be used at the present time from these developments to form the bases for the generation of ACRDR guidelines for the missing humansystem interface categories.

\subsubsection{Review of Industry Guidelines}

Three of the computer hardware, software, and user input device organizations which ORNL 
contacted had in-house human factors guidelines for specific advanced technology. The organizations include:

$\begin{array}{ll}\text { - } & \text { IBM } \\ \text { - } & \text { Digital Equipment Corporation (DEC) } \\ \text { - } & \text { Microsoft }\end{array}$

The materials are discussed in the following paragraphs.

\subsubsection{International Business Machines}

James Greeson of IBM in Research Triangle, NC provided a pre-publication copy of IBM's Corporate Standards for "Design of Visual Display Products, Workstation Ergonomics". This manuscript is an updated version of a document by Rupp, Mine, Wolbarsht, Andrew, and Hirsch (1984) which was identified earlier in Section 4.3.2 as a secondary/tertiary source. The IBM standards are intended for all types of displays, both CRT and non-CRT. In this document, certain sections are marked as being only for CRTs, but there is nothing which is oriented directly to discrete-pixel displays. Some of the material is however adaptable (the same problem as with ISO 9241 discussed above). A brief section at the end of the report deals with keyboard standards.

ORNL examined the IBM material and determined that it appears to be applicable to plasma panels, LCs, large screen displays, and keyboards. In addition, it seems to be pertinent to the coding of information displays. The documentation supplied by IBM also looks as if it is relevant for seven of the subareas under visual display hardware guidelines. They include:

- Measurement of raster modulation for color displays

o Determination of appropriate maximum character and background contrast ratio

- Determination of polarity recommendations

- Measurement of display resolution for color CRT and flat panel screens

- A requirement for luminance uniformity

o Character, line, and word spacing for displays

o $\quad$ Flicker sensitivity

\subsubsection{Digital Equipment Corporation}

DEC uses OSF/Motife and DECwindows as their advanced interface. Chauncey Wilson from DEC in Nashua, NH furnished a set of in-house human factors guidelines. ORNL analyzed this material and decided that it deals primarily with the user interface. The set of guidelines however does not appear to be as well-developed as IBM's and does not have data which can used as a basis for the generation of missing ACRDR guidelines. 


\subsubsection{Microsoft}

Marshall McClintock of Microsoft in Redmond, WA supplied human factors test information from the evaluation of their new mouse. ORNL reviewed the documentation, and determined that it details the various designs that were tested, and provides the methodology for testing, raw data, summaries of the tests, and relevant conclusions. The conclusions show the error data and subject preferences associated with the various designs evaluated, and clearly portrays why Microsoft chose the final design. The material will probably be useful in the preparation of missing guidelines for the mouse.

\subsubsection{Review of Computer Trade Magazines and Journals}

ORNL compiled a number of computer trade publications from February to May, 1991. These were subsequently reviewed and analyzed. The publications include the following trade magazines and joumals:

$\begin{array}{ll}\text { o } & \text { PC Week } \\ \text { o } & \text { Mac World } \\ \text { o } & \text { PC World } \\ \text { o } & \text { NASA Tech Briefs } \\ 0 & \text { Military \& Aerospace Electronics } \\ \text { o } & \text { Government Computer News } \\ \text { o } & \text { Several IEEE publications }\end{array}$

The purpose of the assessment was to ascertain the introduction of new technology and significant upgrades to existing technology, which might create a future need for additional NRC human factors guidelines regarding such technology. Information was derived from both articles and advertisements, and pertains to both visual display and user control and input device technologies.

\subsubsection{VDTS}

Color is now available in LC flat panel screens which rivals that available in CRT displays. However, the cautions discussed previously in the standards working groups section are applicable to the use of CRT standards for discrete-pixel display technologies. As laptop machines make greater inroads into the personal computer market and workplace, the various flat-panel technologies will become more prevalent due to their lower power consumption and lighter weight.

Toshiba has announced some new monitors which boast totally flat screens and $1280 \times 1024$ pixel resolution. They also have a variety of both horizontal and vertical scanning frequencies which will make the monitors adaptable to any application around the world. In addition, Toshiba has a "crisp" looking active-matrix thin-transistor LC color screen on their new "portable" (7.71 kilograms) machine. 
There are several LC-based color overhead projection systems newly on the market. NView Corporation has a device they call the ViewFrame Spectra. It has a range of 4096 colors in a thin-film transistor active matrix LC device. According to a PC Week (May 6, 1991) article, the device provides near-CRT display capabilities.

In Focus Systems, Incorporated advertised (PC Week, February 25, 1991) a lightweight LiteShow II which organizes personal computer-based presentations and can be coupled with its PC Viewer LC- projection panel. Such a device can display any personal computer-based information in color on a large screen. This system has 256 colors in a $640 \times 480$ quality resolution (standard broadcast television quality).

High-definition television is currently being tested in Japan, and is being debated in Congress and the television industry in the U.S. High-definition television provides a more "ergonomically" compatible viewing environment, with a screen that is more horizontally oriented. Furthermore, it has a much higher quality television picture and has less flicker. There are a number of problems yet to be worked out for this technology (such as how to accommodate the much higher bandwidth required for broadcast), but, in closed-circuit settings, it should be available in the next few years.

\subsubsection{User Control and Input Devices}

Microsoft and other companies have introduced a mouse substitute which, for now, is intended to clip onto the end of the keyboard of laptop portable machines, giving them mouse-like capabilities without requiring desk-top space to operate the device. Microsoft calls their system the "BallPoint Mouse" (PC Week, March 11, 1991); Logitech named theirs the "TrackMan Portable" (PC Week, March 25, 1991). The new mice appear to be substitutes for the current versions. The devices have a higher dot resolution, and slightly different placement of the buttons than the current mouse. At present, human factors testing material on the BallPoint Mouse is not available from Microsoft. ORNL's contact at Microsoft indicated that such information would probably be available in about six months. Eventually, this system might replace the standard wire-connected mouse which requires desk top space for use.

Another new mouse design is the MousePen, which was advertised in PC Week (May 20, 1991). This device appears to be a small mouse-like device with a pen-like handle. It is gripped in the fingers like a writing stylus, but used like a mouse for pointing. The same standards for a mouse would probably apply to this device.

A new joystick adaptation, called the "ICONtroller", is advertised by Suncom Technologies. This is an additional "desktopless" mouse device substitute, consisting of a joystick and four buttons. Intended for laptop portables, it attaches to the end of the keyboard, like the BallPoint mouse discussed above.

Data entry devices are basically keyboard devices. The new development, seen only in a picture of a keyboard, is a "tilt-pad" device with an associated switch which permits the tilt-pad to function 
either as the four-arrow keys of a standard personal computer style keyboard, or as a pointing device analogous to a mouse or joystick.

\subsubsection{Human-System Interface Categories and Available Sources}

This section recapitulates the human-system interface categories by the number of applicable sources identified during ORNL's review, examination, and evaluation of the HCI technical literature. The matrix-like listing is as follows:

o VDTs

- LEDs - 1 source

- $\quad$ Plasma panels - 2 sources

- $\quad$ Electroluminescence - 1 source

- Electrochromics - 1 source

- Electrophoretics - 1 source

- $\quad$ LCs -2 sources

- $\quad$ Large screen displays -2 sources

- $\quad$ Projection devices - None

o Three-dimensional displays - 2 sources

o Virtual displays - 1 source

o $\quad$ Printers and plotters

- Impact printers - None

- $\quad$ Nonimpact printers - None

- $\quad$ Pen plotters - None

- $\quad$ Electrostatic plotters - None

o User control and input devices

- $\quad$ Keyboards - 14 sources

- $\quad$ Track balls - 9 sources

- $\quad$ Mice - 11 sources

- $\quad$ Light pens - 7 sources

- Touch pads - 2 sources

- Graphic tablets - 5 sources

- $\quad$ Touch screens - 6 sources

- Head movement controllers - None

- Glove controllers - None

- $\quad$ Multi-degree of freedom hand controllers - None

- $\quad$ Eye controllers - 2 sources

- Pro pointers - None

- $\quad$ Foot mice - None 
- $\quad$ Gesture-based controllers - 1 source

- $\quad$ Puck pointers - 1 source

- Digitizer pucks - None

- Coding of information displays

- Image reversal - 1 source

- $\quad$ Lines - 1 source

- $\quad$ Texture, focus, and motion - 1 source

- User interface requirements for operator supervised automation - 4 sources

o User interface requirements for intelligent operator aids - 5 sources

- Transaction dialogue

- Natural language - 2 sources

- Display control

- $\quad$ Hypercard - None

- $\quad$ Hypertext - None

- $\quad$ Hypermedia - None

- $\quad$ Pan and zoom - None

- On-screen controls - None

- Visual display hardware guidelines

- Measurement of raster modulation for color displays - 3 sources

- Determination of appropriate maximum character and background contrast ratio - 3 sources

- Determination of polarity recommendations - 3 sources

- $\quad$ Measurement of display resolution for color CRT and flat panel screens - 3 sources

- A requirement for luminance uniformity - 2 sources

- $\quad$ Selection and specification of suitable color coding metrics and color spaces - 6 sources

- $\quad$ Character, line, and word spacing for displays - 2 sources

- $\quad$ Flicker sensitivity -5 sources

- Image distortion - None

- Screen design

- $\quad$ Effects of highlighting and grouping techniques -8 sources

- $\quad$ Effects of spatial relationships among elements - None

- $\quad$ Effects of graphics - None 
- $\quad$ Effects of animation - 1 source

- Effects of user characteristics - 2 sources

- Effects of task characteristics - 1 source

- Guidelines specific to nuclear operations - 15 sources

\subsection{SUBTASK D}

\subsubsection{Objectives}

The primary objective of Subtask 10D was to prepare a technical letter report describing the results of the work performed in Subtasks 10A through 10C. The letter report was generated and submitted to the NRC in June, 1991. A secondary objective of the subtask was to estimate the amount of time and level of effort required to complete the development of needed new ACRDR guidelines.

\subsubsection{Amount of Time and Level of Effort}

ORNL determined that there is not enough available information to serve as a basis for the design of guidelines for the missing human-system interface categories of VDTs and projection devices. There are two main reasons for this conclusion. First, there is very little literature currently available with which to create the guidelines. This situation could change when the $\mathrm{HCI}$ standards working groups complete their assigned tasks. The second reason is that the VDT and projection device technologies are somewhat immature and not yet state-of-the-art.

It was also ascertained that there is insufficient technical literature available with which to generate human factors guidelines for three-dimensional and virtual displays, a number of user control and input devices (i.e., touch pads, head movement controllers, glove controllers, multidegree of freedom hand controllers, eye controllers, pro pointers, foot mice, gesture-based controllers, puck pointers, and digitizer pucks), coding of information displays, transaction dialogue, and display control. The lack of sufficient material for three-dimensional and virtual displays, the user control and input devices, and natural language transaction dialogue is primarily due to the fact that these advanced technologies are quite new and are not fully developed. The reason for deficient documentation in regards to the human-system interface categories dealing with coding of information (image reversal, lines, and texture, focus, and motion) and display control (hypercard, hypertext, hypermedia, pan and zoom, and on-screen display) is that very few human factors related books, reports, papers, and articles have been written on these topic areas.

ORNL concluded as a result of a review of the published technical literature that there is currently not enough experimental research and substantially open-literature publications in the areas of visual display hardware and screen design human-system interfaces to prepare ACRDR guidelines. 
Printing and plotting devices have been in existence for quite a few years, however, there was no pertinent $\mathrm{HCI}$ literature uncovered during the preliminary assessment concerning these technologies. Even though there appears to be no published human factors guidelines and standards, ORNL believes that ACRDR guidelines could be developed. More specifically, the baseline from which the design effort would commence would be printer and plotter literature received from manufacturers and developers. It is estimated that the effort would require one person working full-time for two months to prepare the needed guidelines for NRC inspectors and reviewers.

For six of the user control and input devices (i.e., keyboards, track balls, mice, light pens, graphic tablets, and touch screens) many sources were identified during the literature review. These materials would provide the bases for the creation of a set of new guidelines. ORNL postulates that roughly two-person months would be required to complete the work.

Although only four documents having relevant material for the development of user interface requirements for operator supervised automation were discovered during the literature review and evaluation, ORNL has determined that it is feasible to expect that ACRDR guidelines could be designed for the human interface requirements and human factors concerns related to supervised automation. The effort would include discussions with NPP control-room operators and I\&C engineers. Given the knowledge and expertise of the ORNL project team in this area, it is estimated that around three person-months of work would be needed to generate the human factors guidelines for this human-system interface category.

Five excellent sources for user interface requirements for intelligent operator decision aids were identified during ORNL's preliminary assessment. These would be the building blocks upon which the human-system interface guidelines would be developed. About two person-months of effort would be required to complete the preparation of the needed human factors guidance.

Fifteen documents were unearthed with which guidelines specific to nuclear operations could be created. The work would consist of generating guidelines from these books, reports, and papers. No further literature review would be conducted. It is projected that it would take approximately two months for one person to review, extrapolate, collate, and develop guidance from these documents. 
5. CONVERT EXISTING PRIMARY SOURCE GUIDELINES DOCUMENTS INTO A FORM AND FORMAT COMPATIBLE WITH NUCLEAR INDUSTRY NEEDS

\subsection{SUBTASK 11A}

\subsubsection{Objectives}

The objectives of Subtask 11A were to identify those NPP control station systems to which the individual NUREG-0700 and ACRDR guidelines apply and to develop matrices of such applicability to support the needs of the NRC inspectors and reviewers and to assist them in preparing for and/or conducting an inspection.

\subsubsection{Identification of NPP Control Station Systems}

Nine NPP control station systems were derived which appear to be appropriate for ACRDR-type inspections. They include:

$\begin{array}{ll}\circ & \text { MCR } \\ \circ & \text { SPDS } \\ 0 & \text { RRSF } \\ 0 & \text { RRSS } \\ \circ & \text { EDGC } \\ \text { o } & \text { VES } \\ \text { o } & \text { ECIS } \\ \text { - } & \text { CHSS } \\ \text { o } & \text { RWMC }\end{array}$

These control station systems were gleaned via a review of a number of technical documents, discussions with contractors who have conducted control-room design reviews, and ORNL nuclear engineering staff expertise. The documents consist of: Bovell, Carter, and Beck (1997); Bovell, Carter, Gunnon, and Stewart (1987); Carter and Uhrig (1990); Hartley, Levy, and Fecht (1984); Laughery and Carter (1986); and Seminara (1988). Contractors contacted include Monterey Technologies, Concord Associates, and General Physics.

\subsubsection{Development of Matrices}

Individual NUREG-0700 and ACRDR guidelines were evaluated against the nine NPP control station systems one at a time. All of the sections in NUREG-0700 and the first draft of the ACRDR guidelines document were analyzed. During the review process, a conservative approach was taken in order to ensure that appropriate guidelines were not accidently excluded. Also this approach will allow NRC inspectors to modify each set of guidelines for a control station evaluation dependent upon what advanced technology is present at a specific nuclear site. 
Subsequent to the guideline-control station evaluation, two matrices were constructed. The human factors engineering guidelines formed the rows; the control station systems constituted the columns of the matrices. An X was placed in a cell of a matrix if the specific guideline may be applicable to the control station system. The two guideline by control station system matrices are presented in Appendix E.

\subsubsection{NUREG-0700 Deficiencies}

During ORNL's performance of Subtask 11A, it was determined that NUREG-0700 is deficient in two areas when it is applied to NPP control station systems instead of the main control room. First, the document does not adequately address the human factors design criteria for manually controlled valves. Second, NUREG-0700 does not cover the design requirements of control stations that are subject to extreme environmental conditions. It is recommended that guidelines on these two topics be added to the combined NUREG-0700/ACRDR document.

\subsection{SUBTASK 11B}

\subsubsection{Objective}

The objective of Subtask 11B was to develop a guideline modification audit and tracking system. The purpose of the audit and tracking system was to ensure that the original ACRDR human factors guidelines as developed by BNL could be compared with any changes proposed to be made and subsequently incorporated within the ACRDR guidelines in Subtask 11C.

\subsubsection{Modification Audit and Tracking Systems Used by Other Human Factors Guideline Documents}

All of the primary source documents, which were utilized during the generation of the ACRDR guidelines, were reviewed in regards to their use of a guideline modification audit and tracking system. This effort was undertaken because it was hoped that maybe an established audit and tracking system already existed and a new guideline modification system would not have to be prepared. In worst case, it was anticipated that information could be gleaned from this material which could be used as a baseline during the development of the guideline modification audit and tracking system for this project.

As a result of the document review, it was determined that two of the sets of guidelines (i.e., NASA, 1989; U.S. DOD, 1989b) have made use of a guideline modification audit and tracking system of some sort. Revision A of the Man-Systems Integration Standards employed an audit and tracking system which is very simple. The first eight pages of volume I of that document list: new paragraphs that were added, paragraph number changes, paragraphs that were deleted, and paragraphs that were combined or divided to make new paragraphs. In regards to paragraphs that were either added or deleted, the paragraph number and name are presented in chronological order. On the two pages which address paragraph number changes, the original paragraph 
number is listed first, followed by the revision A paragraph number. In the case of the NASA document paragraphs that were combined to make new paragraphs, the original paragraph numbers are shown on the left-hand side of the page and the new paragraph number(s) on the right side. Paragraphs that were divided to make new paragraphs are identified by the original paragraph number; the new paragraph numbers come immediately after that.

The B, C, and D versions of ML-STD-1472 (U.S. DOD, 1974, 1981c, 1989b) do not discuss the use of a guideline modification audit and tracking system. In order to determine whether and where changes were made from one edition to the next, one must compare the different versions. If one reviews the notices to the $\mathrm{B}$ and $\mathrm{C}$ editions, however, he can readily determine that the authors of this set of guidelines did in fact implement a modification tracking system. As an example, item 1 on page 1 of notice 2 to MIL-STD-1472C states "the following pages of MLSTD-1472C have been revised and supersede the pages listed". This statement is followed by a list which exhibits the new page numbers and the dates on which the pages were approved, and then the superseded page numbers and the dates on which these pages became effective. Item 2 on page 2 of notice 2 informs the holder of MLL-STD-1472C to "make pen and ink changes". For instance, sub-item ' $n$ ' said "insert asterisk in minimum clearance around stick block; delete asterisk from maximum clearance around stick block" in Figure 18 on page 105. The notices to the $B$ version also had another ingredient which was apparently dropped in the notices to version C. That is, the new pages which were part of the notice packages for MIL-STD-1472B had solid black lines in the right-hand margins identifying the proposed changes.

Gerald Chaikin, who was responsible for incorporating changes within MIL-STD-1472, was contacted. The purpose of the phone discussion was to make inquiries in regards to his use of a guideline modification audit and tracking system. Chaikin remarked that he has a modification audit trail of the revisions which were incorporated within the B, C, and D editions of MIL-STD1472. He exclaimed that the modifications that were made to the original version of MIL-STD1472 were sent to an U.S. Army records holding center and subsequently lost. Chaikin stated that, since MIL-STD-1472A, he has kept track of where the changes were made, who suggested the revisions, and what the bases for the modifications were. Chaikin finally commented that he is now just beginning to put all of his hand-written notes onto computer disk.

The other five primary source documents have not implemented or employed an audit and tracking system of any kind. Three sets of guidelines (i.e., Gilmore, Gertman, and Blackman, 1989; HFS, 1988: and NASA, 1988) have not required the use of such a system since they have not as yet been modified. The fourth (i.e., Smith and Mosier, 1986), even though its guidelines are a revision and extension of a previous compilation of design guidelines (i.e., Smith and Mosier, 1984b), did not apply a guideline modification audit and tracking system during their revision process. In a discussion that ORNL had with Jane Mosier, she said that this was due to a couple of reasons. Mosier noted that Mitre Corporation did not utilize a tracking system because the modified set of guidelines superseded the earlier edition. She commented that Mitre was not, therefore, concerned with providing an audit trail from the older to the newer version. (As a sideline, Mosier noted that she is almost certain that there is commercial software available for generating an audit and tracking system which might be applicable to guideline modifications. 
Mosier could not, however, identify any of them by name.) The fifth document (i.e., DOD, 1989a), although it is also a revised set of human factors guidelines, did not utilize an audit and tracking system because the modifications and changes from the earlier to the later version were quite extensive and in many areas new human factors guidelines had to be created.

It was concluded, as a result of a review of the primary source documents, that a well defined guideline modification audit and tracking system does not currently exist. It was decided that some of the methods and techniques used by the authors of the Man-Systems Integration Standards and MIL-STD-1472 would be considered as candidates for the ACRDR guidelines modification audit and tracking system. At the very minimum, they would be the baseline from which the development of the audit and tracking system would originate.

\subsubsection{Other Options for the Guideline Modification Audit and Tracking System}

Besides the procedures used by the two human factors guidelines documents, there are a few other techniques, identified by ORNL, which could be used as part of the guideline modification audit and tracking system. The methods are briefly described below.

The ANS working group for ANSI standard 3.5 in their draft revision C (1981) to the document exhibited the original text on the left-hand side of the page and the same text, along with the proposed changes, on the right side. This option provides a direct comparison of the old and new lines of text.

The U.S. Army Test and Evaluation Command (TECOM) during the revision process of their Test Operations Procedures for Human Factors Engineering (1983) in the late 1970s underlined proposed word changes to its test procedures. Text which was suggested for deletion was not highlighted, but new words were. This is the same method that was used in identifying draft guideline updates to NUREG-0700 in Subtask 9C.

The HFS, when it proposed changes to its bylaws in 1988, took the TECOM procedure one step further. The Society provided all of the original text and printed suggested changes in boldface. Proposed additions were enclosed in brackets; recommended deletions were lined out. The advantage of this technique over the other is that both additions and deletions can be shown at the same time.

A capitalized or small letter could be added either to the end of the ACRDR guideline number or at the end of the guideline narrative. This letter would identify that the guideline has been modified. Examples of the two cases are as follows:

o "2.1.1-1 Data Entered Only Once" could be changed to "2.1.1-1A Data Entered Only Once".

- $\quad$ "A user should need to enter any particular data only once, and the computer should access those data if needed for the same task or for different tasks" could be changed to "A user should need to enter any particular data only once, and the 
computer should access those data if needed for the same task or for different tasks" (A).

An " $A$ " would signify that this is the first revision to the guideline. A " $B$ " would denote that the guideline has been modified twice, a "C" three times, and so on.

\subsubsection{Summary of the Options for the Modification Audit and Tracking System}

ORNL weeded through all of the options presented above and determined that there are a number of viable techniques which seem appropriate for this project's guideline modification audit and tracking system. They include:

- $\quad$ Provide a proposed list of modified guidelines by number and title.

o Keep either a hard copy or computer diskette copy of the original guideline along with the modified/revised guideline.

o Make pen and ink changes on the pages of the original guidelines.

o Put solid black lines in the right-hand margins of the guideline page identifying where the proposed changes are to be made.

- Print the original text of the guidelines on the left-hand side of the page and the same text, along with the proposed changes, on the right side.

- Underline the proposed word changes in the modified guidelines.

- Provide all of the original text and print the proposed changes in boldface. Put additions in brackets; line out recommended deletions.

- Add a letter to either the end of the number of the ACRDR guideline or at the end of the guideline narrative.

\subsubsection{Derived Guideline Modification Audit and Tracking System}

The guideline modification audit and tracking system that was derived and used in Subtask 11C consists of a combination of three options identified in Section 5.2.4. It is as follows:

- The original text of each modified guideline, along with the proposed changes printed in boldface, is provided. Suggested additions to the guideline narratives are enclosed in brackets ([ ]); recommended deletions are shown with a shaded background.

- A list of the proposed modified guidelines by number and title is also furnished.

- Both a hard copy and a computer diskette copy of the original guideline, along with the modified/revised guideline, was kept. The hard copy version is being submitted as part of this final report.

\subsection{SUBTASK $11 C$}

\subsubsection{Objectives}


The objectives of Subtask $11 \mathrm{C}$ were:

o To review draft 2 of the ACRDR guidelines document.

o To modify the guidelines where appropriate to ensure that their language is applicable to the nuclear industry.

- To identify vague, inconsistent, and redundant human factors guidance, and typographical errors and word misspellings within the guidelines.

Care was taken to ensure that the semantics of the human factors guidelines, and thus their validity, was not modified.

\subsubsection{Review of the ACRDR Guidelines}

Draft 2 of the ACRDR guidelines document which was developed by BNL was evaluated. The review process proceeded in a chronological fashion with the section 1 guidelines being reviewed first, the section 2 guidelines next, and so on. Within a particular section, each guideline was reviewed one at a time in an orderly manner. Areas where the guidelines might be changed for applicability to the nuclear industry were noted. Vague, inconsistent, and redundant human factors guidelines were also identified. In addition, guidelines having typographical errors and word misspellings were highlighted. A list of the modified guidelines by number and title is presemted in Appendix F. 


\section{DEVELOP ACRDR GUIDELINES FOR SELECTED ADVANCED CONTROL/DISPLAY TECHNOLOGIES}

\subsection{SUBTASK 13A}

\subsubsection{Objectives}

The objectives of Subtask 13A were to: generate draft ACRDR guidelines for the human-system interface category entitled "control and input devices", and design draft human factors guidelines for specific nuclear operations.

\subsubsection{Overview of Subtask Specific ACRDR Guidelines}

Section 7 of draft 2 of the ACRDR guidelines document has a subsection (Subsection 7.2) which addresses control and input devices. It currently provides only a limited set of human factors guidelines for advanced technology devices. Subsection 7.2 covers: keyboards, trackballs, mice, joysticks, touch screens, light pens, graphic tablets (grid and stylus devices), touch pads, multidegree of freedom hand controllers, glove controllers, eye controllers, and head movement controllers. The breakdown of the number of human-system interface guidelines by control/input device is presented in Table 4. Draft 2 of the ACRDR guidelines document does not have any guidelines which are specific to particular nuclear operations.

\subsubsection{Control and Input Devices Guidelines}

ORNL generated additional human factors guidelines for 11 advanced technology control and input devices. The devices include: keyboards, trackballs, mice, joysticks, touch screens, light pens, graphic tablets, touch pads, multi-degree of freedom hand controllers, glove controllers, and eye controllers. The human-system interface guidelines were derived from the seven primary source documents used during the development of the ACRDR guidelines document (i.e., Gilmore, Gertman, and Blackman, 1989; HFS, 1988; NASA, 1988, 1989; Smith and Mosier, 1986; and U.S. DOD, 1989a, 1989b). The material identified during the preliminary assessment of available sources in Subtask 10C (i.e., Ahlstom and Lenman, 1986; Allen, 1990; Arnaut and Greenstein, 1988; Brown, 1988; Diehl and Apiki, 1989; Doran, 1988; Dumas, 1988; FooteLennox, 1986; Gardner, 1989; Gilmore, 1985; Greeson, 1988; Goy, 1988; Helander, 1988; Kantowitz and Sorkin, 1983; Koppa, 1986; Maguire, 1990; Microsoft, 1988; Monk, 1989; Murray and Pappas, 1987; NTIS, 1989; Norman and Draper, 1986; Otten, 1984; Rupp, Mine, Wolbarsht, Andrew, and Hirsch, 1984; Salvendy, 1987; Sanders and McCormick, 1987; Shneiderman, 1987; and Spacek, Gurstein, Robert, Rutenberg, and Thomas, 1988), along with other documentation (i.e., Sherr, 1988) which surfaced since the review in Task 10, was also utilized during the creation of new ACRDR guidelines. 
Control/Input Device and

Major Guideline Titles
Number of

Guidelines

Keyboards

General

30

Special Function Keys

11

Displacement

Membrane

Direct Manipulation Controls

General

Trackballs

5

Mice

Joysticks

Force (Isometric) Joysticks

7

Displacement (Isotonic) Joysticks

7

Direct Pointing Controllers

General

2

Touch Screens 9

Light Pens 5

Graphic Tablets - Grid and Stylus Devices 3

Touch Pads 0

Other Controllers

General

Multi-Degree of Freedom Hand Controllers 0

Glove Controllers $\quad 0$

Eye Controllers 0

Head Movement Controllers $\quad 0$

Controllers

The ACRDR guidelines for the human-system interface category entitled "control and input devices" are exhibited in Appendix G 


\subsubsection{Guidelines for Specific Nuclear Operations}

ORNL designed human factors guidelines for specific nuclear operations. Human-system interface guidelines were produced for three nuclear systems. They include: SPDSs, computerized annunciator systems, and nuclear graphic displays. The new ACRDR guidelines were derived from the material identified during the preliminary assessment of available sources in Subtask 10C (i.e., Banks, Gertman, and Petersen, 1982; Banks, Hunter, and Noviski, 1985; Blackman, Gertman, and Gilmore, 1983; Danchak, 1981; Eckenrode, Lapinsky, and Ramirez, 1988; Gilmore, 1985; HFEB, 1981b; Institution of Electrical Engineers, 1986; International Atomic Energy Agency, 1987; Ivergard, 1989; Kinkade and Anderson, 1984; Lapinsky, Eckenrode, Goodman, and Correia, 1989; Pankrantz, 1986; Rankin, Rideout, Triggs, and Ames, 1985; and Venhuizen, 1983), along with a number of other sources which surfaced since the review in Task 10 (i.e., Banks, 1980; Division of Human Factors Safety, 1981, 1982; IEEE, 1988b, c; and Petersen, Banks, and Gertman, 1982). The ACRDR guidelines for specific nuclear operations are displayed in Appendix $\mathrm{H}$.

\subsection{SUBTASK 13B}

After approval of the two sets of draft human-system interface guidelines by the NRC project manager, ORNL modified the guidelines as necessary and prepared them in both hard copy and electronic form. These human factors guidelines were subsequently delivered to the NRC in formats compatible with those of the ACRDR guidelines developed under FIN L1317 and in accordance with the format agreed upon during the coordination meeting in Subtask 9A. 


\section{CONCLUSIONS}

\subsection{TASK 9}

The areas in NUREG-0700 that are not addressed by the draft ACRDR guidelines, but which are still applicable to advanced I\&C and operator interface systems, were identified. The NUREG0700 guidelines were reviewed against six recent industry human factors engineering review guidelines and the NUREG-0700 guidance was updated as necessary. Additions and/or deletions were made to the Control-Room Workspace, Annunciator Warning Systems, Controls, Visual Displays, and Process Computer subsections of Sections 6 . The applicable sections of NUREG0700 were integrated into the ACRDR guidelines to ensure that all applicable guidelines are together in one document and conveniently accessible to users.

\subsection{TASK 10}

General categories of human-system interface guidelines that are either missing from or not adequately addressed by the ACRDR document were discovered. They include: VDTs, projection devices, three-dimensional and virtual displays, printers and plotters, user control and input devices, coding of information displays, user interface requirements for operator supervised automation, user interface requirements for intelligent operator decision aids, transaction dialogue, display control, visual display hardware guidelines, screen design, and guidelines specific to nuclear operations.

A strategy for the development of new ACRDR guidelines that have not otherwise been identified was formulated. The derived approach makes maximum use of the secondary and tertiary sources identified during the generation of the ACRDR guidelines. It also includes the use of technical literature in basic and applied journals, conference proceedings, other relevant documents, and contact with researchers actively working in the field of HCI. A preliminary assessment of the available sources that may be useful in the creation of new guidelines and their applicability to the identified human-system interface categories was subsequently performed.

Estimates of the amount of time and the level of effort required to generate new ACRDR guidelines for five of the human-system interface categories (i.e., printers and plotters, user control and input devices, user interface requirements for operator supervised automation, user interface requirements for intelligent operator decision aids, and guidelines specific to nuclear operations) were generated.

\subsection{TASK 11}

Nine NPP control station systems were derived which appear to be appropriate for ACRDR-type inspections. The control station systems to which the NUREG-0700 and ACRDR guidelines 
apply were identified and matrices of such applicability were developed to support the needs of the NRC inspectors and reviewers.

A guideline modification audit and tracking system, the purpose of which was to ensure that the original ACRDR human factors guidelines could be compared with any changes proposed to be made and subsequently incorporated within the guidelines document, was designed. The ACRDR guidelines document was reviewed and the guidelines were modified where appropriate to ensure that their language is applicable to the nuclear industry. Vague, inconsistent, and redundant human factors guidance, and typographical errors and word misspellings within the guidelines were also identified.

\subsection{TASK 13}

Human factors guidelines were developed for two human-system interface categories that are missing from the current ACRDR guidelines document. Control and input device guidelines were prepared for keyboards, trackballs, mice, joysticks, touch screens, light pens, graphic tablets, touch pads, multi-degree of freedom hand controllers, glove controllers, and eye controllers. Human factors guidelines were drafted for specific nuclear operations. Human-system interface guidelines were produced for SPDSs, computerized annunciator systems, and nuclear graphic displays.

\subsection{GENERAL COMMENTS}

ORNL recommends that human factors guidelines be developed for three human-system interface categories: printers and plotters, user interface requirements for operator supervised automation, and user interface requirements for intelligent operator decision aids.

A number of potential problems/recommendations were identified during ORNL's performance of the four tasks. They include: a reference section should be added to the ACRDR guidelines; an inconsistency exists between the two sets of control-room human engineering guidelines in regards to their statement of guidance; NUREG-0700 and the ACRDR document use different types of decriptors to designate specific guidelines; the two sets of guidelines do not consist of the same number of parts; it would be more appropriate and much easier to integrate the ACRDR guidelines into the NUREG-0700 guidelines rather than vice versa; changes should be made to the ACRDR guidelines to reflect the suggestions of prior users of the NUREG-0700 guidance; NUREG-0700 does not adequately address the human factors design criteria for manually controlled valves; and the NUREG-0700 document does not cover the design requirements of control stations that are subject to extreme environmental conditions. The identified concerns should be reviewed and appropriate resolutions should be identified. 


\section{REFERENCES}

Abstracts in Human-Computer Interaction (1988 - 1989). Lawrence, KS: Allen Press.

Ahlstom, B. and S. Lenman (1986). Touch screen, cursor keys, and mouse interaction.

Proceedings of the International Science 1st Conference on Work with Display Units, 831-837.

Allen, H. W. (1990). A Human Factors Review of Data Entry Devices (SAND90-0795).

Albuquerque, NM: Sandia National Laboratory.

American Nuclear Society (1990). Proceedings of the Topical Meeting on Advances in Human Factors Research on Man/Computer Interactions: Nuclear and Beyond. La Grange Park, IL.

American Nuclear Society and European Nuclear Society (1986). Proceedings of the Topical Meeting on Advances in Human Factors in Nuclear Power Systems. La Grange Park, IL.

American Nuclear Society Working Group (1981). American National Standard 3.5, Nuclear Power Plant Simulators for Use in Operator Training (Draft revision C). La Grange Park, Il.

American Society of Heating, Refrigeration, and Air-Conditioning Engineers (1977). Handbook and Product Directory, 1977 Fundamentals. New York, NY.

Apple Computer (1987). Human Interface Guidelines: The Apple Desktop Interface. Reading, MA: Addison-Wesley Publishing Company.

Arnaut, L. Y. and J. S. Greenstein (1988). Human factors considerations in the design and selection of computer input devices. In S. Sherr (Ed.), Input Devices. Boston, MA: Academic Press.

Association for Computing Machinery Computing Surveys (1986 -1991). New York, NY.

Association for Computing Machinery Special Interest Group on Computer-Human Interaction (1982 - 1983, 1985 - 1986, 1987a, 1988a, 1989a, 1990a, 1991). Proceedings of the 1st, 2nd, 3rd, 4th, 5th, 6th, 7th, 8th, and 9th Conferences on Human Factors in Computing Systems. New York, NY.

Association for Computing Machinery Special Interest Group on Computer-Human Interaction (1988b, 1990b). Proceedings of the 1st and 2nd Conferences on Computer-Supported Cooperative Work. New York, NY.

Association for Computing Machinery Special Interest Group on Computer-Human Interaction (1987b, 1989b). Proceedings of the 1st and 2nd Conferences on Hypertext. New York, NY. 
Association for Computing Machinery Special Interest Group on Computer-Human Interaction (1988c). Proceedings of the 1st Conference on Document Processing Systems. New York, NY.

Association for Computing Machinery Transactions on Information Systems. (1985 - 1991). New York, NY.

Badre, A. and B. Shneiderman (1984). Directions in Human/Computer Interaction. Norwood, NJ: Ablex Publishing Corporation.

Baecker, R. M. and W. A. S. Buxton (1987). Readings in Human-Computer Interaction: A Multidisciplinary Approach. San Mateo, CA: Morgan Kaufmann Publishers, Incorporated.

Banks, W. W. (1980). Some Suggestions for Human Engineering Design Guidelines Relating to CRT Displays and Software Development (SD-D-80-002). Idaho Falls, ID: EG\&G Idaho, Incorporated.

Banks, W. W., D. I. Gertman, and R. J. Petersen (1982). Human Engineering Design Considerations for Cathode Ray Tube-Generated Displays (NUREG/CR-2496). Washington, D.C.: U.S. Nuclear Regulatory Commission.

Banks, W. W., W. E. Gilmore, H. S. Blackman, and D. I. Gertman (1983). Human Engineering Design Considerations for Cathode Ray Tube-Generated Displays, Volume II (NUREG/CR3003). Washington, D.C.: U.S. Nuclear Regulatory Commission.

Banks, W. W, S. L. Hunter, and O. J. Noviski (1985). Human Factors Engineering: Display Development Guidelines (UCDD-20560). Livermore, CA: Lawrence Livermore National Laboratory.

Baumeister, T. (1978). Marks' Standard Handbook for Mechanical Engineers (8th Ed.). New York, NY: McGraw-Hill Publishing Company.

Beaton, R. J. and C. A. DeVilbiss (1989). Assessment method for the ANSI/HFS 100-1988 guideline on display jitter. Proceedings of the Society for Information Display International Symposium, Seminar, and Exhibition, 216-219.

Bell System Center for Technical Education. Telecommunications Transmission Engineering (Volume 1). Piscataway, NJ.

Blackman, H. S., D. I. Gertman, and W. E. Gilmore (1983). CRT Display Evaluation: The Checklist Evaluation of CRT-Generated Displays (NUREG/CR-3557). Washington, D.C.: U.S. Nuclear Regulatory Commission. 
Blackman, H.S., D. I. Gertman, W. E. Gilmore, and R. E. Ford (1983). Noninteractive Simulation Evaluation of CRT-Generated Displays (NUREG/CR-3556). Washington, D.C.: U.S. Nuclear Regulatory Commission.

Blackman, H. S. and W. E. Gilmore (1984). Interactive Simulator Evaluation for CRT-Generated Displays (NUREG/CR-3767). Washington, D.C.: U.S. Nuclear Regulatory Commission.

Bovell, C. R., R. J. Carter, and M. G. Beck (1997). Nuclear Power Plant Control Room Operator Control and Monitoring Tasks (ORNL/TM-11726). Oak Ridge, TN: Oak Ridge National Laboratory.

Bovell, C. R., R. J. Carter, F. G. Gunnon, and G. B. Stewart (1987). BWR and PWR Off-normal Event Descriptions (NUREG-1291). Washington, D.C.: U.S. Nuclear Regulatory Commission.

Brookhaven National Laboratory and Carlow Associates Incorporated (1990). Task 2 Letter Report: Review and Application of Existing Guidelines to NPP Control Rooms. Upton, NY.

Brookhaven National Laboratory and Carlow Associates Incorporated (1989). Task 1 Letter Report: Identification of Existing Guidelines. Upton, NY.

Brooks, F. P., Jr. (1988). Grasping reality through illusion: Interactive graphics servicing science. Proceedings of the Association for Computing Machinery Special Interest Group on Computer-Human Interaction 6th Conference on Human Factors in Computing Systems, 1-11.

Brown, C. M. (1988). Human-Computer Interface Design Guidelines. Norwood, NJ: Ablex Publishing Corporation.

Brunner, H., K. Wittenburg, M. Williams, Y. Sekine, S. Dahlgren, and P. Washco (1990). A snapshot of natural language interfaces. Proceedings of the Association for Computing Machinery Special Interest Group on Computer-Human Interaction 8th Conference on Human Factors in Computing Systems, 53-55.

Card, S. K., T. P. Moran, and A. Newell (1983). The Psychology of Human-Computer Interaction. Hillsdale, NJ: Lawrence Erlbaum Associates, Publishers.

Carter, R. J. and R. E. Uhrig (1990). Human Factors Issues Associated with Advanced Instrumentation and Control Technologies in Nuclear Plants (NUREG/CR-5439). Washington, D.C.: U.S. Nuclear Regulatory Commission.

Christie, B. (1985). Human Factors of the User-System Interface. New York, NY: North Holland

Communications of the Association for Computing Machinery (1985 -1991). New York, NY. 
Danchak, M. M. (1981). Techniques for Displaying Multivariate Data on Cathode Ray Tubes with Applications to Nuclear Process Control (NUREG/CR-1994). Washington, D.C.: U.S. Nuclear Regulatory Commission.

Diehl, S. and S. Apiki (1989). Product focus: Digitizing tablets and graphic details. BYTE, 14(1), 162-166, 168-172, 174.

Division of Human Factors Safety (1982). Clarification of TMI Action Plan Requirements: Requirements for Emergency Response Capability (NUREG-0737, supplement 1). Washington, D.C.: U.S. Nuclear Regulatory Commission.

Division of Human Factors Safety (1981). Evaluation Criteria for Detailed Control Room Design Review (NUREG-0801). Washington, D.C.: U.S. Nuclear Regulatory Commission.

Doran, D. (1988). Trackballs and joysticks. In S. Sherr (Ed.), Input Devices. Boston, MA: Academic Press.

Dreyfuss, H. (1967). The Measure of Man. New York, NY: Whitney Library of Congress.

Dumas, J. S. (1988). Designing User Interfaces for Software. Englewood Cliffs, NJ: Prentice Hall.

Eberts, R. E. (1987). Internal models, tracking strategies, and dual-task performance. Human Factors, 29(4), 407-420.

Eckenrode, R. J., G. W. Lapinsky, Jr., and R. G. Ramirez (1988). Lessons learned from the NRC review of the SPDS. Proceedings of the Institute of Electrical and Electronics Engineers 4th Conference on Human Factors and Power Plants, 198-200.

Engel, S. E. and R. E. Granda (1975). Guidelines for Man/Display Interface (TR 00, 2720). Poughkeepsie, NY: International Business Machines Poughkeepsie Laboratory.

Ergonomics (1987 - 1991). New York, NY: Taylor and Francis.

European Conference on Hypertext (1990). Proceedings of the Conference. Cambridge, England: Cambridge University Press.

Farrell, J. E. (1987). Predicting flicker thresholds for visual displays. Proceedings of the Society for Information Display International Symposium, Seminar, and Exhibition, 18-21.

Farrell, J. E. (1986). An analytical method for predicting perceived flicker. Behaviour and Information Technology, 5(4), 349-358. 
Fellmann, T., U. Brauninger, R. Gierer, and E. Grandjean (1982). An ergonomic evaluation of VDTs. Behavior and Information Technology, 1(1), 69-80.

Fisher, D. L. and K. C. Tan (1989). Visual displays: The highlighting paradox. Human Factors, 31(1), $17-30$.

Fisk, A. D. and W. Schneider (1981). Control and automatic processing during tasks requiring sustained attention: A new approach to vigilance. Human Factors, 23(6), 737-750.

Foley, J. D., A. van Dam, S. K. Feiner, and J. F. Hughes (1990). Computer Graphics: Principles and Practice (2nd Ed.). Reading, MA: Addison-Wesley Publishing Company.

Foote-Lennox, T. (1986). Ergonomic guidelines for computerized user interfaces. Proceedings of the Institute of Electrical and Electronics Engineers Computer Standards Conference, 38-41.

New York, NY: Institute of Electrical and Electronics Engineers.

Frey, P. R., W. H. Sides, Jr., R. M. Hunt, and W. B. Rouse (1984). Computer-Generated Display System Guidelines, Volume 1: Display Design (EPRI NP-3701). Palo Alto, CA: Electric Power Research Institute.

Galer, I, (1987). Applied Ergonomics Handbook. Boston, MA: Butterworths.

Galitz, W. O. (1989). Handbook of Screen Format Design (3rd Ed.). Wellesley, MA: QED Information Sciences, Incorporated.

Gardiner, M. M. and B. Christie (1987). Applying Cognitive Psychology to User-Interface Design. New York, NY: John Wiley and Sons.

Gardner, L. (1989). Sorting out industrial operator interfaces. Instrumentation and Control Systems, 62(5), 31-34.

Gertman, D. I., H. S. Blackman, W. W. Banks, and R. J. Petersen (1982). CRT Display Evaluation: The Multidimensional Rating of CRT-Generated Displays (NUREG/CR-2942). Washington, D.C.: U.S. Nuclear Regulatory Commission.

Gilmore, W. E. (1985). Human Engineering Guidelines for the Evaluation and Assessment of Video Display Units (NUREG/CR-4227). Washington, D.C.: U.S. Nuclear Regulatory Commission.

Gilmore, W. E., D. I. Gertman, and H. S. Blackman (1989). User-Computer Interface in Process Control: A Human Factors Engineering Handbook. Boston MA: Academic Press. 
Glushko, R. J. (1991). Hypertext: Prospects and Problems for Crew System Design (CSERIAC SOAR-90-22). Wright-Patterson Air Force Base, OH: Crew System Ergonomics Information Analysis Center.

Gould, G. D. (1968). Visual factors in the design of computer-controlled CRT displays. Human Factors, 10(4).

Goy, C. (1988). Mice. In S. Sherr (Ed.), Input Devices. Boston, MA: Academic Press.

Greeson, J. C., Jr. (1991). A Critical Review of Standards for Flat Panel Display Systems (SPIE Code 37 08). Research Triangle Park, NC: International Business Machines.

Greeson, J. C., Jr. (1990). International standards challenge flat-panel displays. Information Display, 6(7-8), 14-15, 20.

Hartley, C. S., I. S. Levy, and B. A. Fecht (1984). Potential Human Factors Deficiencies in the Design of Local Control Stations and Operator Interfaces in Nuclear Power Plants (NUREG/CR3696). Washington, D.C.: U.S. Nuclear Regulatory Commission.

Hartson, H. R. (1985). Advances in Human-Computer Interaction. Norwood, NJ: Ablex Publishing Corporation.

Helander, M. (1988). Handbook of Human-Computer Interaction. New York, NY: NorthHolland.

Human-Computer Interaction (1985 - 1991). Hillsdale, NJ: Lawrence Erlbaum Associates, Publishers.

Human Factors (1980 - 1991). Santa Monica, CA: The Human Factors Society.

Human Factors Engineering Branch (1981a). Guidelines for Control Room Design Reviews (NUREG-0700). Washington D.C.: U.S. Nuclear Regulatory Commission.

Human Factors Engineering Branch (1981b). Human Factors Acceptance Criteria for the Safety Parameter Display System (NUREG-0835). Washington D.C.: ' U.S. Nuclear Regulatory Commission.

Human Factors Society $(1982$ - 1985, 1987, 1990 - 1991). Proceedings of the 26th, 27th, 28th, 29th, 31st, 34th, and 35th Annual Meetings. Santa Monica, CA.

Human Factors Society (1988). American National Standard for Human Factors Engineering of Visual Display Terminal Workstations (ANSI/HFS 100). Santa Monica, CA.

Human Factors Society Bulletin (1980 - 1991). Santa Monica, CA: The Human Factors Society. 
Institute of Electrical and Electronics Engineers (1989). Proceedings of the 3rd International Conference on Human-Computer Interaction. New York, NY: Elsevier Science Publishing Company Incorporated.

Institute of Electrical and Electronics Engineers $(1985,1988 \mathrm{a})$. Proceedings of the 3rd and 4th Conferences on Human Factors and Power Plants. New York, NY.

Institute of Electrical and Electronics Engineers (1988b). Guide for the Application of Human Factors Engineering to Systems, Equipment, and Facilities of Nuclear Power Generating Stations (Std 1023). New York, NY.

Institute of Electrical and Electronics Engineers (1988c). Guide to Evaluation of Man-Machine Performance in Nuclear Power Generating Station Control Rooms and Other Peripheries (Std 845). New York, NY.

Institute of Electrical and Electronics Engineers Computer (1985 -1991). New York, NY.

Institute of Electrical and Electronics Engineers Computer Graphics and Applications (1985 1991). New York, NY.

Institute of Electrical and Electronics Engineers Transactions on Systems, Man, and Cybernetics (1987 - 1991). New York, NY.

Institute of Nuclear Power Operations (1981). February 25th Memo. Atlanta, GA.

Institute of Nuclear Power Operations (1980). Draft Human Engineering Deficiency Checklist for Control Room Evaluation. Atlanta, GA.

Institution of Electrical Engineers (1986). Colloquium on Developments in the Man-Machine Interface in Power Stations (Digest 86/043). Stevenage, Herts, United Kingdom.

Interacting with Computers (1989 - 1991). Boston, MA: Butterworth-Heinemann, Ltd.

International Atomic Energy Agency (1987). Improving Nuclear Power Plant Safety through Operator Aids. Guidelines for Selecting Operator Aids (IAEA-TECDOC-444). Vienna, Austria.

International Business Machines Systems Journal (1986 - 1991). Endicott, NY.

International Federation for Information Processing (1984). Proceedings of the 1st Conference on Human-Computer Interaction -Interact ' 84 . New York, NY: North-Holland.

International Journal of Human-Computer Interaction (1989 - 1990). Norwood, NJ: Ablex Publishing Corporation. 
International Journal of Man-Machine Studies (1985 - 1991). New York, NY: Academic Press.

International Science (1986). Proceedings of the 1st Conference on Work with Display Units. New York, NY: North Holland.

Isensee, S. H. and C. A. Bennett (1983). The perception of flicker and glare on computer CRT displays. Human Factors, 25(1), 177-184.

Ivergard, T. (1989). Handbook of Control Room Design and Ergonomics. New York, NY: Taylor and Francis

Kantowitz, B. H. and R. D. Sorkin (1983). Human Factors: Understanding People-System Relationships. New York, NY: John Wiley and Sons.

Kaufman, J. E. (1981). Illuminating Engineering Handbook (1981 application volume). New York, NY: Illuminating Engineering Society of America.

Kelly, K. L. (1972). Twenty-two colors of maximum contrast. In I. M. Nimeroff(Ed.), Precision Measurement and Calibration: Selected National Bureau of Standards Papers on Colorimetry (Special Publication 300). Gaithersburg, MD: National Bureau of Standards.

Kinkade, R. G. and J. Anderson (1984) - Human Factors Guide for Nuclear Power Plant Control Room Development (EPRI NP-3659). Palo Alto, CA: Electric Power Research Institute.

Koch, H. and R. Schafer (1986). West German standards for display work stations. Displays, Technology and Applications, 7(2), 73-77.

Kokoschka, S. (1986). Visibility aspects of VDUs in terms of contrast and luminance. Behaviour and Information Technology, 5(4) 309-333.

Koppa, R. J. (1986). UCI guidelines research for keyboards and function keys. Proceedings of the Texas A\&M University Symposium on Human Factors in Management Information Systems. College Station Texas: Texas A\&M University.

Kubokawa, C., W. Woodson, and P. Selby (1969). Databook for Human Factors Engineers. Moffett Field, CA: National Aeronautics and Space Administration Research Center.

Lapinsky, G. W., Jr., R. J. Eckenrode, P. C. Goodman, and R. P. Correia (1989). A Status Report Regarding Industry Implementation of Safety Parameter Display Systems (NUREG1342). Washington, D.C.: U.S. Nuclear Regulatory Commission.

Laughery, K. R. and R. J. Carter (1986). Nuclear Power Plant Simulation Facility Evaluation Methodology (NUREG/CR-4188). Washington, D.C.: U.S. Nuclear Regulatory Commission. 
Long, T. (1984). Human factors principles for the design of computer colour graphics displays. British Telecom Technology Journal, 2(3), 5-14.

Macdonald, L. W. (1990). Using colour effectively in displays for computer-human interface. Displays, Technology, and Applications, 11(3), 129-141.

Maguire, M. C. (1990). A review of human factors guidelines and techniques for the design of graphical human-computer interfaces. In J. Preece and L. Keller (Eds.), Human-computer Interaction. Englewood Cliffs, NJ: Prentice Hall Incorporated.

McCormick, E. J. (1976). Human Factors in Engineering and Design (4th Ed.). New York, NY: McGraw-Hill Publishing Company.

Meister, D. (1984). Human Engineering Data Base for Design and Selection of Cathode Ray Tube and Other Display Systems (NPRDC TR 84-51). San Diego, CA: U.S. Navy Personnel Research and Development Center.

Meister, D. and D. J. Sullivan (1969). Guide to Human Engineering Design for Visual Displays. Goleta, CA: Bunker-Ramo Corporation.

Miller, R. B. (1968). Response time in man-computer conversational transactions. Proceedings of the Spring Joint Computer Conference.

Mollon, J. D. and C. R. Cavonius (1985). Derivation of a uniform colour space from discriminative reaction times (CRT displays). International Conference on Colour in Information Technology and Visual Displays, 27-31.

Monk, A. (1989). Fundamentals of Human-Computer Interaction. New York, NY: Academic Press.

Mosier, J. N. and S. L. Smith (1986). Application of guidelines for designing user interface software. Behaviour and Information Technology, 5(1), 39-46.

Muratore, D. A. (1987). Human Performance Aspects of Cursor Control Devices (WP-6321). Bedford, MA: The Mitre Corporation.

Murray, W. H. and C. H. Pappas (1987). Pick of the little (mice). BYTE, 12(6), 238, 240-242.

National Aeronautics and Space Administration (1989). Man-Systems Integration Standards (STD-3000, Revision A). Houston, TX: Lyndon B. Johnson Space Center.

National Aeronautics and Space Administration (1988). Space Station Freedom Program Human-Computer Interface Guide (USE-1000, Version 2.1). Houston, TX: Lyndon B. Johnson Space Center. 
National Technical Information Service (1989). Computer Keyboards: Design, Selection, and Evaluation (PB89-861561). Springfield, VA.

New York University (1982). Proceedings of the Symposium on User Interfaces. Norwood, NJ: Ablex Publishing Corporation.

Norman, D. A. and S. W. Draper (1986). User Centered System Design. Hillsdale, NJ: Lawrence Erlbaum Associates Publishers.

Otten, K. W. (1984). Information tools: Hardware and software ergonomics determine user acceptance and productivity. Journal of Information and Image Management, April, 19-35.

Pankrantz, D. (1986). Graphic Display Development Methodology, Volume 1: Theory (EPRI NP-4874). Palo Alto, CA: Electric Power Research Institute.

Parasuraman, R. (1987). Human-computer monitoring. Human Factors, 29(6), 695-706.

Parker, J. F., Jr. and V. R. West (1973). Bioastronautics Data Book (2nd Ed.). Washington, DC: National Aeronautics and Space Administration.

Perlman, G. (1989). The checklist method of applying guidelines to design and evaluation. Proceedings of the INTERFACE Conference.

Petersen, R. J., W. W. Banks, and D. I. Gertman (1982). Performance-based evaluation of graphic displays for nuclear power plant control rooms. Proceedings of the Association for Computing Machinery Special Interest Group on Computer-Human Interaction 1st Conference on Human Factors in Computing Systems, 182-189.

Pine, S. M., K. A. Schulz, T. R. Edman, T. G. Hanson, T. G. Evans, W. Gonzalez, D. Smith, and J. Seminara (1982). Human Engineering Guide for Enhancing Nuclear Control Rooms (EPRI NP-2411). Palo Alto, CA: Electric Power Research Institute.

Psychological Research Associates (1959). Human Factors Principles and Specifications in the Design of Ground Support Equipment. Anaheim, CA.

Ramsey, H. R. and M. E. Atwood (1979). Human Factors in Computer Systems: A Review of the Literature (SAI-79-111-DEN). La Jolla, CA: Science Applications Incorporated.

Rankin, W. L., T. B. Rideout, T. J. Triggs, and K. R. Ames (1985). Computerized Annunciator Systems (NUREG/CR-3987). Washington, D.C.: U.S. Nuclear Regulatory Commission.

Reiber, L. P. (1990). Animation in computer-based instruction. Educational Technology, Research and Development, 38(1), 77-86. 
Reising, J. M. and K. M. Mazur (1990). 3-D displays for cockpits: Where they payoff. Proceedings of the International Society for Optical Engineering, 35-43.

Rich, D. C. (1991). Standardized methods for characterizing the color of visual display units. Proceedings of the Society for Information Display International Symposium, Seminar, and Exhibition, 652-653.

Rogowitz, B. E. (1986). A practical guide to flicker measurement: using the flicker-matching technique. Behaviour and Information Technology, 5(4), 359-373.

Rogowitz, B. E. (1983). Flicker matching: A technique for measuring the perceived flicker on a VDT. Proceedings of the Society for Information Display International Symposium, Seminar, and Exhibition, 172-173.

Rouse, W. B. (1988). Adaptive aiding for human/computer control. Human Factors, 30(4), 431444.

Rouse, W. B. (1984a). Computer-Generated Display System Guidelines, Volume 2: Developing an Evaluation Plan (EPRI NP-3701). Palo Alto, CA: Electric Power Research Institute.

Rouse, W. B. (1984b). Design and evaluation of computer-based decision support systems. Proceedings of the United States of America - Japan 1st Conference on Human-Computer Interaction, 229-246.

Rouse, W. B., R. A. Kisner, P. R. Frey, and S. H. Rouse (1984). A Method for Analytical Evaluation of Computer-Based Decision Aids (NUREG/CR-3655). Washington, D.C.: U.S. Nuclear Regulatory Commission.

Rupp, B., G. Mine, M. L. Wolbarsht, I. Andrew, and R. S. Hirsch (1984). Human Factors of Workstations with Visual Displays (3rd Ed.). San Jose, CA: International Business Machines Human Factors Center.

Salvendy, G. (1987). Handbook of Human Factors. New York, NY: John Wiley and Sons.

Sanders, M. S. and E. J. McCormick (1987). Human Factors in Engineering and Design (6th Ed.). New York NY: McGraw-Hill Publishing Company.

Seamster, T., C. Baker, and P. J. Andrews (1989). Tactical symbology for visual displays: The standardization process. Proceedings of the Human Factors Society 33rd Annual Meeting, 10941098.

Seminara, J. L. (1988). Control-room Deficiencies, Remedial Options, and Human Factors Research Needs (EPRI NP-5975). Palo Alto, CA: Electric Power Research Institute. 
Seminara, J. L, S. Eckert, S. Seidenstein, W. Gonzalez, and R. Stempson (1980). Human Factors Methods for Nuclear Control Room Design. Volume 3: Human Factors Methods for Conventional Control Board Design (EPRI NP-1118). Palo Alto, CA: Electric Power Research Institute.

Seminara, J.L, W. Gonzalez, and S. Parsons (1977). Human Factors Review of Nuclear Power Plant Control Room Design (EPRI NP-309). Palo Alto, CA: Electric Power Research Institute.

Sherr, S. (1988). Input Devices. Boston, MA: Academic Press.

Shneiderman, B. (1987). Designing the User Interface: Strategies for Effective HumanComputer Interaction. Reading, MA: Addison-Wesley Publishing Company.

Shurtleff, D. A. (1980). How to Make Displays Legible. Lexington, MA: Human Interface Design.

Sidorsky, R. C., R. N. Parrish, J. L. Gates, and S. J. Munger (1984). Design Guidelines for User Transactions with Battlefield Automation (ARI research product 84-08). Alexandria, VA: U.S. Army Research Institute for the Behavioral and Social Sciences.

Sime, M. E. and M. J. Coombs (1983). Designing for Human-Computer Communication. Orlando, FL: Academic Press.

Smith, H. L. and T. R. G. Green (1980). Human Interaction with Computers. New York, NY: Academic Press.

Smith, S. L. (1979). Letter size and legibility. Human Factors, 21(6), 661-670.

Smith, S. L. and J. N. Mosier (1986). Guidelines for Designing User Interface Software (ESDTR-86-278). Bedford, MA: The Mitre Corporation.

Smith, S. L. and J. N. Mosier (1984a). A Design Evaluation Checklist for Interface Software (ESD-TR-84-358). Bedford, MA: The Mitre Corporation.

Smith, S. L. and J. N. Mosier (1984b). Design Guidelines for User-System Interface Software (ESD-TR-84-190). Bedford, MA: The Mitre Corporation.

Snyder, H. L. (1989). What is missing in the ANSI VDT standard? Human Factors Society Visual Performance Technical Group Newsletter, 11(1), 2-5.

Snyder, H. L., J. J. Decker, C. J. C. Lloyd, and C. Dye (1990). Effect of image polarity on VDT task performance. Proceedings of the Human Factors Society 34th Annual Meeting, 1447-1451. 
Society for Information Display (1990 - 1991). Proceedings of the International Symposiums, Seminars, and Exhibitions. Playa del Ray, CA.

Spacek, J., M. Gurstein, J. M. Robert, U. Rutenberg, and H. Thomas (1988). Ergonomically Designed Workstation for Training of Electronic Systems Maintenance Technicians (TP8742E). Montreal, Quebec, Canada: Transportation Development Center.

Spoto, C. G. and A. J. G. Babu ((1989). Highlighting in alphanumeric displays: The efficacy of monochrome methods. Proceedings of the Human Factors Society 33rd Annual Meeting, 370374.

Taylor, J. M. and G. M. Murch (1986). The effective use of color in visual displays: Text and graphics applications. Color Research and Application, 11, S3-S10.

Thomas, J. C. and M. L. Schneider (1986). Human Factors in Computer Systems. Norwood, NJ: Ablex Publishing Company.

Tullis, T. S. (1988). Screen design. In M. Helander (Ed.), Handbook of Human-Computer Interaction. New York, NY: North-Holland.

Uhrig, R. E. and R. J. Carter (1989). Program Plan for Regulatory Research on Expert Systems (ORNL/NRC/LTR-89/5). Oak Ridge TN: Oak Ridge National Laboratory.

United States of America - Japan (1984). Proceedings of the 1st Conference on HumanComputer Interaction. New York: NY: Elsevier Science Publishing Company Incorporated.

U.S. Air Force Systems Command (1980). Design Handbook: Human Factors Engineering (AFSC DH 1-3). Wright-Patterson Air Force Base, $\mathrm{OH}$.

U.S. Army Test and Evaluation Command (1983). Test Operations Procedures for Human Factors Engineering (DRSTE-RP-702-100). Aberdeen Proving Ground, MD.

U.S. Department of Defense (1989a). Human Engineering Guidelines for Management Information Systems (MIL-HDBK-761A). Aberdeen Proving Ground, MD: U.S. Army Human Engineering Laboratory.

U.S. Department of Defense (1989b). Human Engineering Design Criteria for Military Systems, Equipment, and Facilities (MIL-STD-1472D). Aberdeen Proving Ground, MD: U.S. Army Human Engineering Laboratory.

U.S. Department of Defense (1985). Department of Defense Password Management Guideline. Huntsville, AL: U.S. Army Missile Command. 
U.S. Department of Defense (1981a). Human Factors Engineering Design for Army Materiel (MIL-HDBK-759A). Aberdeen Proving Ground, MD: U.S. Army Human Engineering Laboratory.

U.S. Department of Defense (1981b). Abbreviations for Use on Drawings, and in Specifications, Standards, and Guidelines. Huntsville, AL: U.S. Army Missile Command.

U.S. Department of Defense (1981c). Human Engineering Design Criteria for Military Systems, Equipment, and Facilities (MIL-STD-1472C). Aberdeen Proving Ground, MD: U.S. Army Human Engineering Laboratory.

U.S. Department of Defense (1975). Human Factors Engineering Design for Army Materiel (MIL-HDBK-759). Aberdeen Proving Ground, MD: U.S. Army Human Engineering Laboratory.

U.S. Department of Defense (1974). Human Engineering Design Criteria for Military Systems, Equipment, and Facilities (MIL-STD-1472B). Aberdeen Proving Ground, MD: U.S. Army Human Engineering Laboratory.

Van Cott, H. P. and R. G. Kinkade (1972). Human Engineering Guide to Equipment Design (Revised Ed.). Washington, D.C.: U.S. Government Printing Office.

Van Nes, F. L. (1986). Space colour and topography on visual display terminals. Behaviour and Information Technology, 5(2), 99-118.

Vartabedian, A. G. (1971). The effects of letter size, case, and generation method on CRT display search time. Human Factors, 13(4).

Venhuizen, J. R. (1983). A Method for Evaluating Operator Inputs to Digital Controllers (EGGM-17882). Idaho Falls, ID: EG\&G Idaho.

Wickens, C. D. (1990). Three-dimensional stereoscopic display implementation: Guidelines derived from human visual capabilities. Proceedings of the International Society for Optical Engineering, 2-11.

Wickens, C. D. (1984). Engineering Psychology and Human Performance. Columbus, OH: Charles E. Merrill Publishing Company.

Wickens, C. D., S. Todd, and K. Seidler (1989). Three-Dimensional Displays: Perception, Implementation, Applications (CSERIAC SOAR-89-01). Wright-Patterson Air Force Base, OH: Crew System Ergonomics Information Analysis Center. 
Wise, J. A., M. C. Culver, and N. C. Abi-Samra (1987). Display Design for Dispatch Control Centers in Electric Utilities: Handbook (EPRI EL-4960). Palo Alto, CA: Electric Power Research Institute.

Woodson, W. E. and D. W. Conover (1964). Human Engineering Guide for Equipment Designers (2nd Ed.). Berkeley, CA: University of California Press.

Yingduo, F., O. Ostberg, and B. Lindstrom (1990). MTFA as a measure for computer display screen image quality. Displays, Technology and Application, 11(4), 186-192. 
APPENDIX A:

TITLES AND ALPHA-NUMERIC DESIGNATIONS OF THE NUREG-0700 SECTION 6 CONTROL-ROOM HUMAN FACTORS ENGINEERING GUIDELINES 


\section{1 CONTROL ROOM WORKSPACE}

\subsubsection{General Layout}

6.1.1.1 Accessibility of Instrumentation/Equipment
a. Present in the Control Room
b. Arranged to Facilitate Coverage

Exhibit $6.1-1$

6.1.1.2 Consistency of Manning with Equipment Layout
a. Coverage
b. Utilization of Additional Personnel

6.1.1.3 Furniture and Equipment Layout
a. Viewing
b. Communications
c. Operator Access
d. Circulation Patterns
e. Operator Maneuvering space
f. Equipment-to-Opposing-Surface Distance
g. Openings

Exhibit 6.1-2

Exhibit 6.1-3

Exhibit 6.1-4

6.1.1.4 Document Organization and storage
a. Accessibility
b. Location Aids
c. Convenience of Use
d. Protection
e. Dedicated Sets of Procedures

6.1.1.5 Spare Parts, Operating Expendables, and Tools
a. Supply
b. Accessibility
c. Tools
d. Storage space
e. Coding
f. Inventory

6.1.1.6 Supervisor Access
a. Access
b. Communications 


\subsubsection{Nonessential Personnel Access}

\subsubsection{Work Station Design}

6.1.2.1 Anthropometric Basis for Equipment Dimensions

Exhibit $6.1-5$

\subsubsection{Stand-Up Console Dimensions}

a. Console Height to see over

b. Control Height

c. Benchboard Slope

d. Control Distance from the Front Edge of the Console

e. Display Positioning

f. Lateral Spread of Controls and Displays

g. Foot Room

Exhibit 6.1-6

Exhibit 6.1-7

Exhibit $6.1-8$

\subsubsection{Sit-Down Console Dimensions}
a. Console Height to See Over
b. Control Height
c. Benchboard Slope
d. Control Distance from the Front Edge of the Console
e. Display Positioning
f. Lateral Spread of Controls and Displays
g. Leg and Foot Room
h. Writing Space on Consoles

$$
\begin{aligned}
& \text { Exhibit } 6 \cdot 1-9 \\
& \text { Exhibit } 6 \cdot 1-10 \\
& \text { Exhibit } 6 \cdot 1-11 \\
& \text { Exhibit } 6 \cdot 1-12
\end{aligned}
$$

\subsubsection{Sit-Stand Work Stations}
a. Control and Display Positioning
b. Chair Height
c. Knee Room

\subsubsection{Vertical Panels}
a. Control Height
b. Display Height

Exhibit $6.1-13$

Exhibit 6.1-14 
6.1.2.6 Use of Procedures and other Reference Materials at Consoles

Exhibit 6.1-15

Exhibit 6.1-16

6.1.2.7 Desk Dimensions
a. Working space
b. Chair Positions
c. Operator comfort
d. Dimensions

Exhibit 6.1-17

Exhibit 6.1-18

6.1.2.8 Chairs
a. Mobility
b. Backrests
c. Armrests
d. Cushioning
e. Seat Area
f. Seat Adjustability
g. Footrests

Exhibit 6.1-19

Exhibit 6.1-20

\subsubsection{Multiunit Control Rooms}

6.1.3.1 Unit Integration and Interference

a. Equipment Arrangement

b. Senior operator Station

c. Sharing of Personnel

d. Sharing of Procedures

e. Shared Equipment

6.1.3.2 Unit Mirror Imaging

a. Dedicated Crews

b. Accentuate Differences

6.1.4 Emergency Equipment

6.1.4.1 Operator Protective Equipment
a. Types of Equipment
b. Anthropometry
c. Periodic Checks
d. Quantity 
e. Marking

f. Expendables

g. Accessibility

h. Training

i. Procedures

6.1.4.2 Fire, Radiation, and Rescue Equipment
a. Periodic Checks
b. Accessibility
c. Training
d. Procedures
e. Automatic Warning system

6.1.4.3 Emergency Equipment Storage
a. Proper storage
b. Access

6.1.5 Environment

6.1.5.1 Temperature and Humidity
a. Comfort Zone
b. Temperature Differential

Exhibit 6.1-21

6.1.5.2 Ventilation
a. Air Quantity
b. Air Velocity

6.1.5.3 Illumination
a. Levels
b. Uniformity
c. Supplemental Light
d. Task Area Luminance Ratio
e. Shadowing
f. Glare
g. Reflectance
h. Color

Exhibit $6 \cdot 1-22$
Exhibit $6 \cdot 1-23$
Exhibit $6 \cdot 1-24$
Exhibit $6 \cdot 1-25$

6.1.5.4 Emergency Lighting

a. Automatic Action 
b. Operability

c. Lighting Levels

6.1.5.5 Auditory Environment

a. Background Noise

b. Limit

c. Further Reductions

d. Noise Distractions

e. Reverberation Time and Sound Absorption

Exhibit $6.1-26$

6.1.5.6 Personal storage

a. Storage Locations

b. Storage suitability

6.1.5.7 Ambience and Comfort

a. Decor

b. Restroom and Eating Facilities

c. Rest Area/Lounge

\subsection{COMMUNICATIONS}

6.2.1 Voice Communication Systems

6.2.1.1 General Requirements for Voice Communication Systems

a. Instructions

b. Periodic Maintenance Tests

c. Emergency Messages

6.2.1.2 Conventional-Powered Telephone Systems
a. Frequency Response
b. Handsets
c. Switching Mechanism
d. Telephone Ringing
e. Announcing Use

6.2.1.3 Sound-Powered Telephone Systems
a. sound quality
b. Headsets
c. Ringing
d. Jack Provisions
e. Switching

6.2.1.4 Walkie-Talkie Radio Transceivers 

a. Sound Quality
b. Area Coverage
c. Packaging
d. Party Identification
e. Battery Replenishment

6.2.1.5 Fixed-Base UHF Transceivers
a. Signal Quality
b. Gain
c. Procedures

6.2.1.6 Announcing Systems
a. Intelligibility and coverage
b. Microphone Characteristics
c. Loudspeaker Location
d. Speech clarity
e. Loudspeaker volume
f. Priority

6.2.1.7 Point-to-Point Intercom Systems
a. Intelligibility
b. Gain Adjustment

6.2.1.8 Emergency Communications
a. Backup Equipment
b. Equipment Usability
c. Voice Communications with Masks

\subsubsection{Auditory Signal Systems}

6.2.2.1 Use of Auditory Signals
a. Dedicated Use
b. Localization
c. Selection

6.2.2.2 Signal Meaning

6.2.2.3 Auditory Coding Techniques
a. Distinctive coding
b. Pulse Coding
c. Frequency Change coding
d. Discrete Frequency coding
e. Coding by Intensity

6.2.2.4 Propagation of Signals 
a. Direction of sound

b. Audibility

6.2.2.5 Frequency

a. Range

b. Bandwidth

6.2.2.6 Signal Intensity

a. General
b. Comfort
c. Maximum Intensity

6.2.2.7 Reliability

a. Failure of Alarm circuitry

b. False Alarms

c. System Test

6.3 ANNUNCIATOR WARNING SYSTEMS

6.3.1 General System Characteristics

6.3.1.1 General System Design

Exhibit 6.3-1

Exhibit 6.3-2

6.3.1.2 Alarm Parameter Selection

a. Set Points

b. General Alarms

c. Multichannel or Shared Alarms

d. Multiunit Alarms

6.3.1.3 First Out Annunciators

a. Reactor system

b. Turbine-Generator system

c. Position

d. Application

6.3.1.4 Prioritization

a. Levels of Priority

b. Priority coding

Exhibit $6.3-3$

6.3.1.5 Cleared Alarms 

a. Auditory Signal
b. Visual Signal

\subsubsection{Auditory Alert Subsystem}

6.3.2.1 Signal Detection
a. Intensity
b. Control
c. Limits
d. Detection
e. Reset
f. Identification

6.3 .2 .2 coding
a. Localization
b. Prioritization

6.3.3 Visual Alarm Subsystems

6.3.3.1 Visual Annunciator Panels
a. Location
b. Labeling
c. Lamp Replacement
Exhibit $6 \cdot 3-4$

6.3.3.2 Visual Alarm Recognition and Identification
a. Flashing
b. Flash Rate
c. Flasher Failure
d. Contrast Detectability
e. "Dark" Annunciator Panels
f. Extended Duration Illumination

6.3.3.3 Arrangement of Visual Alarm Tiles
a. Matrix Organization
b. Functional Grouping
c. Labeling of Axes
d. Pattern Recognition
e. Out-of-Service Alarms
f. Blank Tiles

\subsubsection{Visual Tile Legends}
a. Unambiguous
b. Singularity
c. Specificity 
d. Abbreviations

6.3.3.5 Visual Tile Readability

a. Distance

b. Type style

c. Legend Contrast

d. Letter Dimensions and Spacing

6.3.4 Operator Response Subsystem

6.3.4.1 Controls
a. Silence
b. Acknowledge
c. Reset
d. Test

Exhibit $6 \cdot 3-5$

6.3.4.2 Control set Design

a. Positioning of Repetitive Groups

b. Control coding

c. Nondefeatable Controls

6.3.4.3 Annunciator Response Procedures

a. Availability

b. Indexing

6.4 CONTROLS

6.4.1 Selection of Controls

6.4.1.1 General Principles
a. Adequacy
b. Economy
c. Human Suitability
d. Compatibility with Emergency Gear
e. Durability

6.4.1.2 Prevention of Accidental Activation
a. Proper Location
b. Fixed Protective structures
c. Movable Covers or Guards
d. Interlocking Controls
e. Resistance to Movement
f. Sequential Activation
g. Choice of Action 
Exhibit 6.4-1

Exhibit 6.4-2

6.4.2 Design Principles

6.4.2.1 Direction of Movement

6.4.2.2 Coding of controls
a. Consistency
b. Location coding
c. Size coding
d. Shape coding
e. Rotating Knob Shape Options
f. Color coding
Exhibit 6.4-3
Exhibit 6.4-4
Exhibit 6.4-5
Exhibit 6.4-6

6.4.3 Pushbutton Control Specifications

6.4.3.1 Pushbutton Design Principles
a. Position
b. Indication of Activation
c. Pushbutton Surface

6.4.3.2 Round Pushbuttons

Exhibit 6.4-7

6.4.3.3 Legend Pushbuttons
a. Discriminability
b. Legend
c. Provision for Lamp Failure
d. Barriers
e. Legend Pushbutton Dimensions
Exhibit $6.4-8$

6.4.4 Rotary Control Specifications

6.4.4.1 Rotary Control Design Principles

a. Direction of Activation

b. Rotary Control shape coding

c. Coding specifications

$6.4 .4 .2 \mathrm{~J}$-Handles 


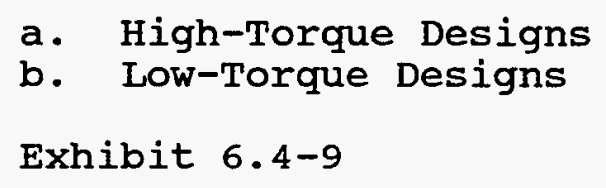

6.4.4.3 Key-operated Controls
a. Use
b. Teeth: Single Row
c. Teeth: Double Row
d. On-off orientation
e. Key Removal
f. Labeling
g. Key-Operated Control Dimensions

Exhibit 6.4-10

6.4.4.4 Continuous Adjustment Rotary Controls

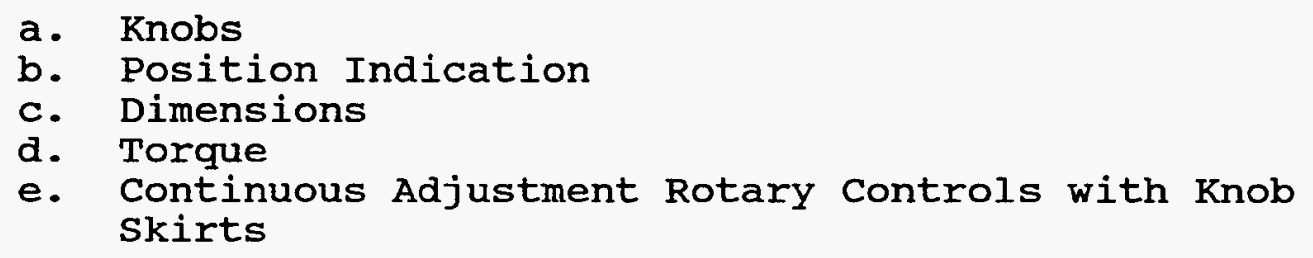

6.4.4.5 Rotary Selector Controls

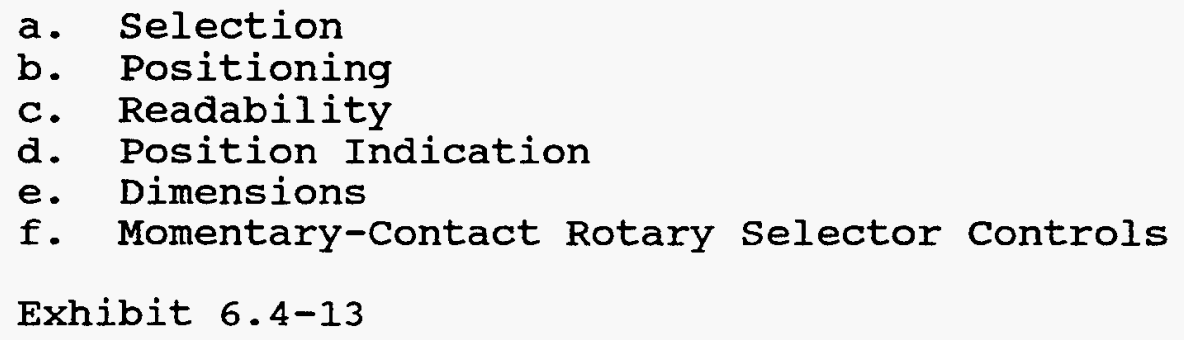

6.4.5.1 Thumbwheels
a. Visibility
b. Coding
c. Continuous Adjustment Thumbwheels
d. Discrete setting (stepped) Thumbwheels
Exhibit 6.4-14

6.4.5.2 Slide Switches 

a. Surface
b. Dimensions

Exhibit 6.4-15

6.4.5.3 Toggle Switches
a. Positioning
b. Feedback
c. Dimensions

Exhibit 6.4-16

6.4.5.4 Rocker Switches
a. Orientation
b. Indication of Activation
c. Resistance
d. Inadvertent Activation
e. Rocker Switch Dimensions
Exhibit 6.4-17

\subsection{VISUAL DISPLAYS}

\subsubsection{Principles of Display}

6.5.1.1 Information To Be Displayed
a. Task Analysis
b. Completeness of Information
c. Unnecessary Information
d. Redundancy
e. Demand Information Versus status Information
f. Display Failure

6.5.1.2 Usability of Displayed Values
a. Scale Selection
b. Elimination of operator Conversion
c. Percentage Indication
d. Scale Range
e. Scale size
f. Sensitivity

6.5.1.3 Readability
a. Character Height
b. Type style
c. Contrast
d. Character Dimensions and spacing
e. Characters for CRT Presentation 
Exhibit 6.5-1

Exhibit 6.5-2

6.5.1.4 Printing on the Display Face

a. Provision of Needed Message

b. Avoidance of Extraneous Items

c. Brevity

d. Abbreviations

e. Consistency with Procedures

f. Indication of Transformations Needed

6.5.1.5 Scale Marking

a. Use of Graduations

b. Graduation Height

c. Values Indicated by Unit Graduations

d. Scale compatibility

e. Linear vs. Logarithmic scales

f. Multiscale Indicators

Exhibit 6.5-3

Exhibit 6.5-4

Exhibit 6.5-5

Exhibit 6.5-6

6.5.1.6 Color coding

a. Redundancy

b. Number of Colors

c. Meaning of colors

d. Consistency of Meaning

e. Principles of Color Selection

Exhibit 6.5-7

\subsubsection{Meters}

6.5.2.1 Directionality of Movement and Numbering with FixedScale Moving-Pointer Meters
a. Circular scales
b. Vertical straight scales
c. Horizontal straight Scales

Exhibit $6.5-8$

Exhibit $6.5-9$

\subsubsection{Pointers}

a. Pointer Tip Form

b. Pointer Positioning Relative to scale 
c. Pointer Visibility

Exhibit $6.5-11$

6.5.2.3 Zone Marking

Exhibit $6 \cdot 5-12$

6.5.2.4 Orientation of Markings on Fixed-Scale Meters

a. Numerical orientation

b. Zero-Point orientation

c. End-Point Indication on Partial-Revolution Scales

Exhibit $6.5-13$

6.5.2.5 Moving-Scale Meters

6.5.3 Light Indicators

6.5.3.1 Characteristics and Problems of Light Indicators

a. Precautions to Assure Availability

b. Precautions to Assure Unambiguous Sensing by Operators

c. Precautions to Avoid Misinterpretation

d. Use as Alerting Indicators

6.5.3.2 Design and Use of Non-Legend Light Indicators

a. Identification of Meaning

b. Light Intensity

6.5.3.3 Design and Use of Legend Light Indicators

a. Visibility Factors

b. Legend Design

c. Distinguishability from Legend Pushbuttons

d. Color coding

\subsubsection{Graphic Recorders}

6.5.4.1 General Characteristics of Graphic Recorders
a. Quality of Expendable Materials
b. Scale compatibility
c. Scale Design
d. Paper Takeup and cutoff
e. Availability of Expendables
f. Ease of Routine Replenishment
g. Use
h. Placement of Recorders 
i. Paper-Speed Adjustability

j. Annotation

k. Visibility

6.5.4.2 Specific Recorder Types

a. Continuous Recorders

b. Discrete Recorders

6.5.5 Miscellaneous Display Types

6.5.5.1 Drum-Type Counters

a. Numerical Presentation Factors

b. Mounting

c. Drum Movement

Exhibit 6.5-14

Exhibit 6.5-15

6.5.5.2 Electronic Counters

a. Numerical Presentation Factors

b. Rate of Change

c. Contrast

6.6 LABELS AND LOCATION AIDS

6.6.1 Labeling Principles

6.6.1.1 Need for Labeling

6.6.1.2 Hierarchical Scheme

a. Ranking

b. Letter Gradations

Exhibit 6.6-1

6.6.2 Label Location

6.6.2.1 Placement
a. Normal Placement
b. Panel Labeling
c. Visibility Enhancement
d. Proximity
e. Labels on Controls
f. Adjacent Labels
Exhibit 6.6-2
Exhibit 6.6-3 
Exhibit $6.6-4$

6.6.2.2 Mounting

a. Integrity

b. Surface

6.6.2.3 Spatial Orientation

a. Horizontal orientation

b. Curved Patterns

Exhibit $6.6-5$

6.6.2.4 visibility
a. Other Information Sources
b. Concealment
c. Controls
d. cleaning

6.6.3 Label Content

6.6.3.1 Kinds of Information

a. Primary Function

b. Secondary Function

6.6.3.2 Word Selection
a. Intended Action
b. Clarity
c. Direct
d. Meaning
e. Technical Terms
f. Spelling

6.6.3.3 Consistency

a. Administrative Control
b. Internal Consistency
c. Consistency with Procedures

Exhibit $6.6-6$

6.6 .3 .4 symbols
a. Meaning
b. Distinguishability
c. Standard
d. Consistency
e. Roman Numerals 
6.6.3.5 Brevity

Exhibit 6.6-7

6.6.3.6 Similarity

Exhibit $6.6-8$

6.6.3.7 Functional Groups

a. Functional Relationship

b. Location

6.6.3.8 Control Position Labeling
a. Position
b. Direction
c. Visibility

6.6.3.9 Access Opening, Danger Warning, and Safety Instruction Labeling

a. Access opening Labels

b. Danger, Warning, and Safety Instruction Labels

6.6.4 Label Lettering

6.6.4.1 Readability

a. Character Height

b. Contrast

Exhibit 6.6-9

6.6.4.2 style
a. Character selection
b. Character Width
c. Stroke width
d. Spacing

6.6.5 Use and Control of Temporary Labels

6.6 .5 .1 Use
a. Necessity
b. Human Factors Practices
c. Visibility
d. Identification
e. Mounting
f. Obscuration
g. Activation 
h. Adjacent Devices

6.6 .5 .2 Control

a. Administrative Procedures

b. Review Procedures

6.6.6 Location Aids

6.6.6.1 Need for Location Aids

6.6.6.2 Demarcation
a. Use
b. Contrast
c. Permanence

6.6 .6 .3 Color

6.6.6.4 Use of Mimics
a. Color
b. Mimic Lines
c. Symbols

6.7 PROCESS COMPUTERS

6.7.1 Computer Access

6.7.1.1 Software security
a. Authorization
b. Secure Storage
c. Editing
d. Acknowledgment

6.7.1.2 Operator/Computer Dialogue
a. Language Characteristics
b. Entry Length
c. Abbreviations
d. Error Avoidance

6.7.1.3 Prompting and structuring
a. Operator Requests
b. Correction of Data
c. Mode/File Display
d. Specific Error correction
e. Entry File

6.7.1.4 Data Entry--Keyboards 


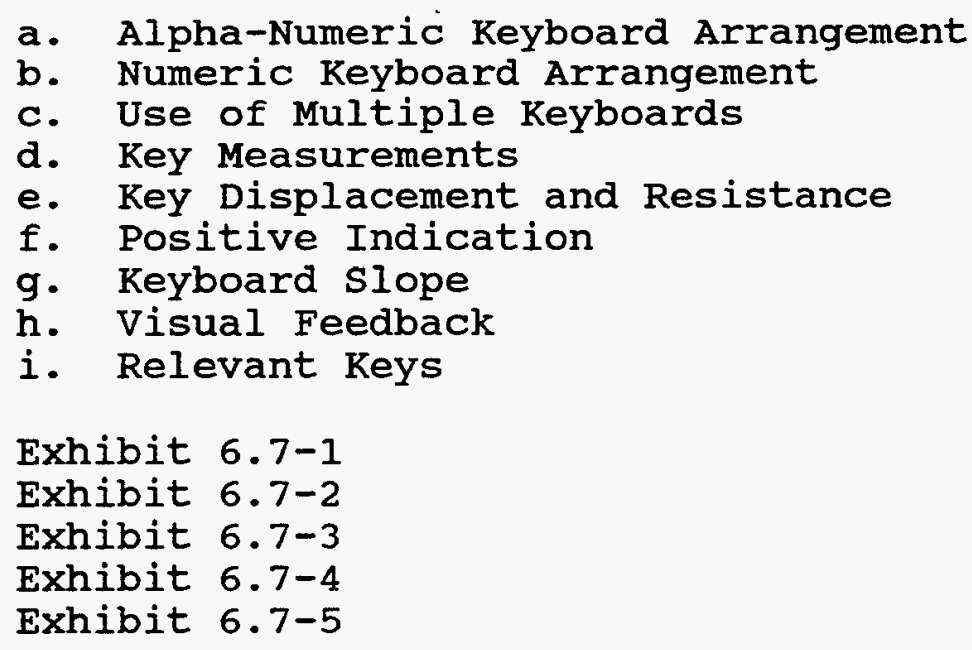

6.7.1.5 Computer Function Controls

a. Control Design

b. Labeling and Nomenclature

c. Master Control

d. Function Controls

6.7.1.6 Other Control Devices

a. Location

b. Speed

c. Accuracy

d. Displacement

6.7.1.7 Computer Response Time to Operator Queries

a. Maximum Response Time

b. Response Delay Messages

Exhibit $6.7-6$

6.7 .1 .8 Access Aids

a. Computer Systems Procedures

b. Data Point Indices

6.7.2 Cathode Ray Tube (CRT) Displays

6.7.2.1 CRT Display Characteristics
a. Readability
b. Reflected Glare-CRT
c. Screen Luminance
d. Luminance contrast
e. Geometric Distortion
f. Resolution 
g. Regeneration Rate

h. CRT Display Controls

6.7.2.2 Symbols and Characters

a. Symbol size

b. Alpha-Numeric Character set

c. Character width-to-Height Ratio

d. Stroke-Width-to-Character-Height Ratio

e. Graphics

f. Character and symbol separation

g. Character style (Font)

Exhibit 6.7-7

6.7.2.3 Operator-Display Relationships
a. Viewing Distance
b. Viewing Angle
c. Screen Location, seated operators
d. Screen Location, standing operators
e. Mounting in Consoles
f. Visibility of Data
Exhibit 6.7-8
Exhibit 6.7-9
Exhibit 6.7-10

6.7.2.4 Data Presentation Format
a. Usability of Data
b. Illustrations
c. Character Grouping
d. Maintenance of ordering
e. Presentation of Identical Data
f. Menu Designations
g. Lists
h. Tables and Graphs
i. Hyphenation
j. Alignment
k. Periods
1. Standardized Fields
m. Data Group Labeling
n. Label Placement
o. Label orientation
p. Label Highlighting
q. Option Labels

6.7.2.5 Screen Layout and structuring

a. Organization of Data

b. Location of Data Groups 
c. Demarcation of Data Subgroups

d. Use of Frequency Ranking

e. Alpha-Numeric Ranking

f. Separation of Paragraphs

g. Selection Designators

h. Page Designation

i. Continuous Numbering

j. Placement of Instructions

k. Urgent Messages

1. Use of Cursor

m. Screen Loading

n. Trend Plot Scales

6.7.2.6 Messages

a. Messages, General

b. Message Content

c. Use of Prompts

d. Content of Prompts

e. Prompt Information Sequence

f. Use of Error Messages

g. Error Correction Guidance

h. Error Correction Ease

i. System Status Feedback Messages

j. Selection Feedback

k. Delay Feedback

1. Activity Completion Feedback

6.7.2.7 Graphic Coding and Highlighting

a. Use of Highlighting

b. Consistent Approach

c. Contrast Enhancement

d. Flicker or Blinking

e. Blink Rates

f. Inverse Video

g. Use of Graphic coding

h. Graphic Code Consistency

i. Geometric Shape coding

j. Number of symbols

k. Use of Color

1. Color Meanings

m. Red-Green Combinations

Exhibit $6.7-11$

\subsubsection{Multiple-Page Considerations}
a. Operator Memory
b. Audit Trail
c. Location References
d. Operator Control 
e. Location Consistency

6.7.3 Printers

6.7.3.1 Printer Characteristics

a. Printer Applications

b. Display Copies

c. Form of Printed Information

d. Printer speed

e. Printer operation

f. Print Copy Accessibility

6.7.3.2 Alarm Messages

a. Alarm Records

b. Alarm Sequence

c. Operator-Requested Printout

d. Alarm Identification

e. Alarm Discrimination

f. Consistent Terminology

6.7.3.3 Graph and Table Requirements

a. Shape of Function

b. Interpolation

c. Grids

d. Tables

6.8 PANEL LAYOUT

6.8.1 General Panel Layout

6.8.1.1 Assigning Panel Contents

a. Grouping by Task sequence

b. Grouping by system Function

c. Grouping by Importance and Frequency of Use

6.8.1.2 Effective Panel Layout

6.8.1.3 Enhancing Recognition and Identification

a. Spacing

b. Demarcation

c. Color Shading

d. Emergency Controls

Exhibit $6.8-1$

6.8.2 Layout Arrangement Factors 
6.8.2.1 Sequence, Frequency of Use, and Functional Considerations
a. Sequence
b. Frequency of Use
c. Functional Considerations

6.8.2.2 Logical Arrangement and Layout

a. Order and Labeling

b. Other Expectations

6.8.2.3 Layout Consistency

a. Repeated Functions

b. Mirror-Imaging

6.8.2.4 Standardization

a. Panel to Panel standardization

b. Simulator-to-Control Room Standardization

6.8.3 Specific Panel Layout Design

6.8.3.1 Separation of Controls
a. Access
b. Inadvertent Actuation
c. Simultaneous Actuation

Exhibit 6.8-2

Exhibit 6.8-3

6.8.3.2 Strings or clusters of similar components
a. Orientation
b. String Length
c. Number of Components
d. Large Matrices

Exhibit $6.8-4$

Exhibit $6.8-5$

Exhibit $6.8-6$

6.8.3.3 Mirror-Imaging

6.9 CONTROL-DISPLAY INTEGRATION

6.9.1 Basic Control-Display Relationships

6.9.1.1 Single Control and Display Pairs 

a. Proximity
b. Obscuration
c. Association

Exhibit 6.9-1

6.9.1.2 Multiple Controls or Displays
a. Multiple Controls, Single Display
b. Single Control, Multiple Displays
c. Display Selectors

Exhibit 6.9-2

6.9.2 Groups of Controls and Displays

6.9.2.1 Location and Arrangement of Control-Display Groups
a. Functional Integrity
b. Sequence of Use

6.9.2.2 Single Panel Arrangements
a. Display Above Each Control
b. Controls and Displays in Rows
c. Multi-Row Displays with single-Row Controls
d. Consistent Practice
e. Control/Display Packages
Exhibit 6.9-3
Exhibit 6.9-4
Exhibit 6.9-5

6.9.2.3 Controls and Displays in Separate Planes

a. Separated Controls and Displays
b. Facing Panels

Exhibit 6.9-6

6.9.3 Dynamic Control-Display Relationships

6.9.3.1 General Movement Relationships
a. Rotary Controls
b. Linear Controls
c. Display Response Time Lag

6.9.3.2 Control-Display Ratio
a. Controls
b. Displays 
c. Excess Precision

d. Feedback 
APPENDIX B:

AN OUTLINE OF THE ACRDR GUIDELINES

109 


\subsection{INFORMATION DISPIAY}

1.1 Screen Organization and Layout

1.1.1 General

1.1.2 Multiple Pages

1.1.3 Grouping

1.1.4 Windows

1.1.4.1 General

1.1.4.2 Display of Windows

1.1.4.3 Interacting with Windows

1.1.5 Message Areas

1.1.6 Command Areas

1.1.7 General Information Areas

1.2 Types of Displays

1.2.1 Tables and Lists

1.2.2 Data Forms

1.2 .3 Mimics

1.2.4 Graphics
$1 \cdot 2 \cdot 4 \cdot 1$
General
1.2.4.2 Flow Charts
1.2.4.3 Pictures and Diagrams
1.2.4.4 Maps and Situation Displays
1.2.4.5 Instrument Panels
1.2.4.6 Scaling
1.2.4.7 Curves and Line Graphs
1.2.4.8 Bar/Column Graphs and Histograms
1.2.4.9 Pie Charts
1.2.4.10 Scatterplots

1.3 Display Elements

1.3.1 General

1.3.2 cursor
1.3.2.1 General
1.3 .2 .2 Pointing cursors
1.3.2.3 Placeholder Cursors

1.3.3 Text, style, and Character

1.3.4 Labels

1.3.4.1 General 
1.3.4.2 Scaling, Graphs, Bar Charts and Histograms

1.3 .4 .3 windows

1.3.4.4 Display Control

1.3.4.5 Flow Charts

1.3.4.6 Functions Keys

1.3.4.7 Pictures, Drawings, Maps, and Situation Displays

1.3.4.8 Menus

1.3.4.9 Pie Charts

1.3.4.10 Tables

1.3.4.11 Data Entry

1.3.5 Icons

1.4 coding

1.4.1 General

1.4.2 Text coding

1.4.2.1 Abbreviations and Acronyms

1.4.2.2 Alphanumerics

1.4.2.3 Font

1.4.2.4 Enhancement/Highlighting

1.4.2.5 Underlining

1.4.3 Other coding

1.4.3.1 Auditory

1.4.3.2 Brightness

1.4 .3 .3 Color

1.4.3.4 Flashing/Blinking

1.4.3.5 Image Reversal

1.4.3.6 Line

1.4.3.7 Shape and Symbol

1.4 .3 .8 Size

1.4.3.9 Spatial/Position/Pattern/Location

1.4.3.10 Texture/Focus/Motion

2.0 OPERATOR INPUT AND CONTROL

2.1 Entering Information

2.1.1 General

2.1.2 Cursor Positioning and control

2.1.2.1 General

2.1.2.2 Controlling Cursor Movement

2.1.2.3 Automatic Cursor Placement

2.1.2.4 Cursor Control and Data Entry

2.1.2.5 Use of Multiple Cursors 
2.1.3 Text Entry and Editing

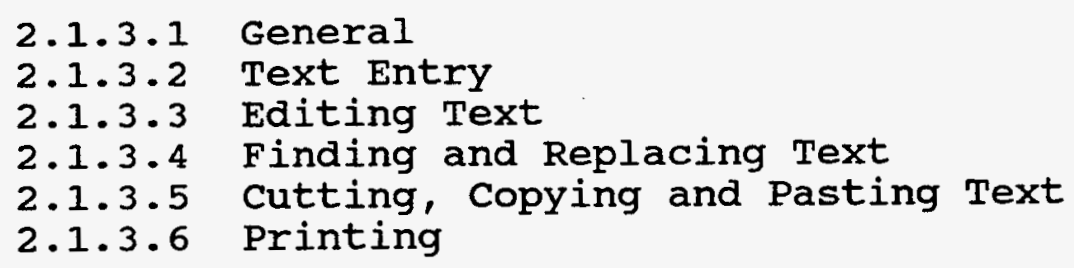

2.1.4 Form Entry

2.1.5 Tabular Data Entry

2.1.6 Speech Input

\subsubsection{Graphics Entry and Editing}
$2.1 \cdot 7 \cdot 1$
2.1 .7 .2
General
$2 \cdot 1 \cdot 7 \cdot 3$
Plotting Data Points
Drawing Lines and Figures

2.1.8 Data Validation

2.1.9 Error Prevention and Correction
$2 \cdot 1 \cdot 9 \cdot 1$
General
$2 \cdot 1 \cdot 9 \cdot 2$
2.1 .9 .3
Correcting Data/Command Entries
Confirming Entries
$2 \cdot 1 \cdot 9 \cdot 4$
Protecting Data

\subsection{Operator Dialogue}

2.2.1 General

2.2.2 Sequence Control

2.2.3 Transaction Selection

2.2.4 Transaction Interrupts

2.2.5 Transaction Dialogue

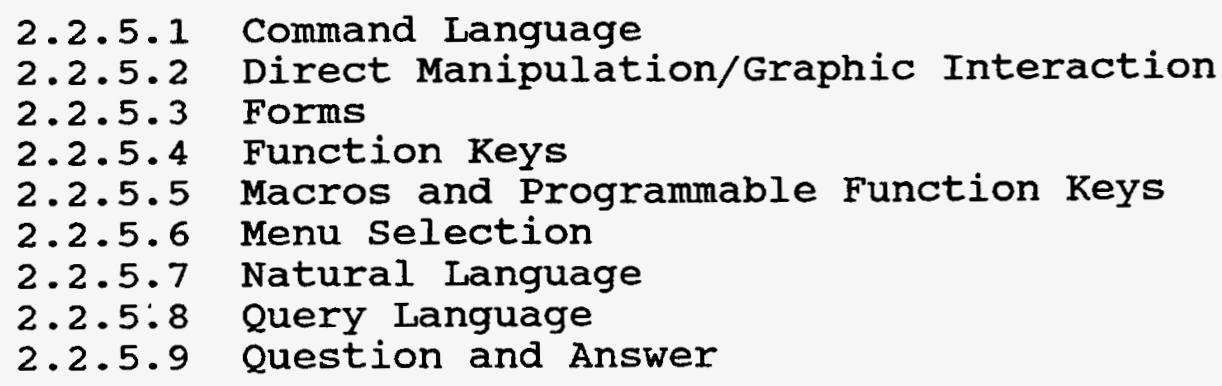

2.3 Display Control

2.3.1 Genera1

2.3.2 Display Freeze

2.3.3 Display selection 
2.3.4 Display Suppression

2.3.5 Display Update

2.3.6 Hypertext

2.3.7 Paging

2.3.8 Scrolling

2.3.9 Searching

2.3.10 on-screen Controls

2.4 Information Manipulation

2.4.1 Saving and Exiting Files

2.4.2 Temporary Editing Buffer

2.4.3 Excerpt File

2.4.4 Retrieval Buffer

2.4.5 Print Cue

2.5 System Response Time

3. 0 ALARMS

4.0 OPERATOR AIDS

4.1 Routine System Messages and Guidance

4.1.1 Prompts

4.1.2 Cautions and warnings

4.1.3 System Messages

4.1.4 Operator Guidance - General

4.1.5 Status Information

4.1.6 Routine Feedback

4.1.7 Error Feedback

4.1 .8 Job Aids

4.1.9 Operator Performance Monitoring

4.1.10 On-line Assistance

4.1.10.1 HELP

4.1.10.2 On-line Training

4.2 Decision Aids

4.2.1 Expert Systems

4.2.1.1 General

4.2.1.2 Dialog

4.2.1.3 Planning and Consultation

4.2.1.4 Expert System Display

4.2.1.5 Certainty Factors

4.2.1.6 Explanation Facilities

4.2.2 Other Decision Aids 
4.3 Supervised Automation

5. 0 INTER-PERSONNEL COMMUNICATION

5.1 General

5.2 Preparing Messages

5.3 Addressing Messages

5.4 Initiating Transmission

5.5 Controlling Transmission

5.6 Receiving Messages

6.0 INFORMATION PROTECTION

6.1 General

6.2 User Identification

6.3 Data Access

6.4 Data Transmission

7.0 WORKSTATION DESIGN

7.1 Display Devices

7.1.1 Visual Display Terminal

7.1.1.1 General

7.1.1.2 CRTS

7.1.1.3 Liquid Crystal

7.1.1.4 Plasma

7.1.1.5 Electrochemic

7.1.1.6 Electrophoretic

7.1.1.7 Electroluminescent

7.1 .1 .8 LEDS

7.1.1.9 Large Screen Displays

7.1.2 Projection Devices

7.1.2.1 Front Projection Devices

7.1.2.2 Rear Projection Devices

7.1.2.3 Large Screen Optical Projection Displays

7.1.3 Printers

7.1.3.1 General

7.1.3.2 Dot Matrix 


$$
\begin{array}{ll}
7.1 .3 .3 & \text { Laser } \\
7.1 .3 .4 & \text { Daisy Wheel } \\
7.1 .3 .5 & \text { Thermal } \\
7.1 .3 .6 & \text { Ink Jet }
\end{array}
$$

\subsubsection{Plotters}

7.1.5 Audio and Voice Displays

$$
\begin{array}{ll}
7.1 .5 .1 & \text { Speech } \\
7.1 .5 .2 & \text { Non-speech Audio Displays } \\
7.1 .5 .3 & \text { Control of Audio Displays } \\
7.1 .5 .4 & \text { Speech Communication Equipment }
\end{array}
$$

7.2 Control and Input Devices

7.2.1 Keyboards

7.2.1.1 General

7.2.1.2 Special Function Keys

7.2.1.3 Displacement

7.2.1.4 Membrane

7.2.2 Direct Manipulation Controls

7.2.2.1 General

7.2.2.2 Trackballs

7.2 .2 .3 Mice

7.2 .2 .4 Joysticks

7.2.2.4.1 Force (Isometric) Joysticks

7.2.2.4.2 Displacement (Isotonic) Joysticks

7.2.3 Direct Pointing Controllers

7.2.3.1 General

7.2.3.2 Touch Screen

7.2 .3 .3 Light Pen

7.2.3.4 Graphic Tablet - Grid and Stylus Devices

7.2.3.5 Touch Pad

7.2.4 Other Controllers

7.2.4.1 General

7.2.4.2 Multi-degree of Freedom Hand Controllers

7.2.4.3 Glove Controllers

7.2.4.4 Eye Controllers

7.2.4.5 Head Movement Controllers

7.3 Workstation Configuration

7.3.1 Workstation Integration 


\subsubsection{Support Devices}

7.4 Control Room Configuration

7.4.1 Environment

$$
\begin{array}{ll}
7.4 .1 .1 & \text { Glare } \\
7.4 .1 .2 & \text { Static }
\end{array}
$$




\begin{abstract}
APPENDIX C:
CONTROL-ROOM HUMAN FACTORS ENGINEERING GUIDELINES OPDATES
\end{abstract}




\subsection{Control-Room Workspace}

6.1.2 Work Station Design

6.1.2.1 Anthropometric Basis for Equipment Dimensions

$$
\text { Exhibit } 6.1-5
$$

- No changes are required to the data in the columns.

- The first source should, however, be changed to: MII-STD-1472D, Section 5.6, March 1989.

- In addition, the first sentence under note 1 should be modified as follows: MIL-STD-1472D gives separate values for male ground troops and aviators.

- Also, the first sentence in note 5 should be: These measurements are not given in MIL-STD1472D.

6.1.2.8 Chairs

e. Seat Area

- The seat width should be changed. The second sentence of the guideline should be: The seat should be at least 18 inches wide (ANSI/HFS 100).

f. Seat Adjustability

- The first sentence of the guidance should be modified. It should be as follows: For chairs at sit-down stations, seat height should generally be adjustable from 16 to 20.5 inches (ANSI/HFS 100).

Exhibit $6.1-19$

- The seat height adjustable should be modified. It should be 16" - 20.5".

- The seat width should be changed to 18" min (ANSI/HFS 100).

\subsubsection{Environment}

6.1.5.1 Temperature and Humidity

Exhibit $6.1-21$

- The first note under the figure should be modified. It should be as follows: 
ANSI/ASHRAE comfort standard 55-1981. (ANSI/HFS 100)

\subsubsection{Auditory Environment}

e. Reverberation Time and Sound Absorption

- The guidance should be modified as follows: The acoustical treatment of the control room should limit reverberation time to 1.2 seconds or less. (MIL-STD-1472D)

\subsection{Communications}

No updates to any of the guidelines in subsection 6.2 are required.

\subsection{Annunciator Warning systems}

6.3.3 Visual Alarm Subsystems

6.3.3.1 Visual Annunciator Panels

b. Labeling

- No changes are required to the first item in this guideline.

- The second item should, however, be modified. The guidance should be as follows: Panel identification labels should be designed so that they can be read easily and accurately when viewed from a central position within the primary operating area. (MIL-STD-1472D)

6.3.3.3 Arrangement of Visual Alarm Tiles

c. Labeling of Axes

- No changes are required to the first two items in this guideline.

- The third item should, however, be modified. The guidance should be as follows: coordinate designation labels should be designed so that they can be read easily and accurately as viewed from a central position within the primary operating area. (MIL-STD-1472D)

6.3.3.5 Visual Tile Readability

a. Distance 
- The first item in this guideline which deals with visual angle should be deleted. (MILSTD-1472D)

- The second item should remain unchanged.

\subsection{Controls}

\subsubsection{Design Principles}

\subsubsection{Coding of controls}

d. Shape coding

- The first three sentences of this guideline should remain unchanged.

- The last sentence should be modified and be as follows: control shapes should be identifiable both visually and tactually. (MIL-STD-1472D)

- The following should be added to the end of the guideline. When shape coding is used:

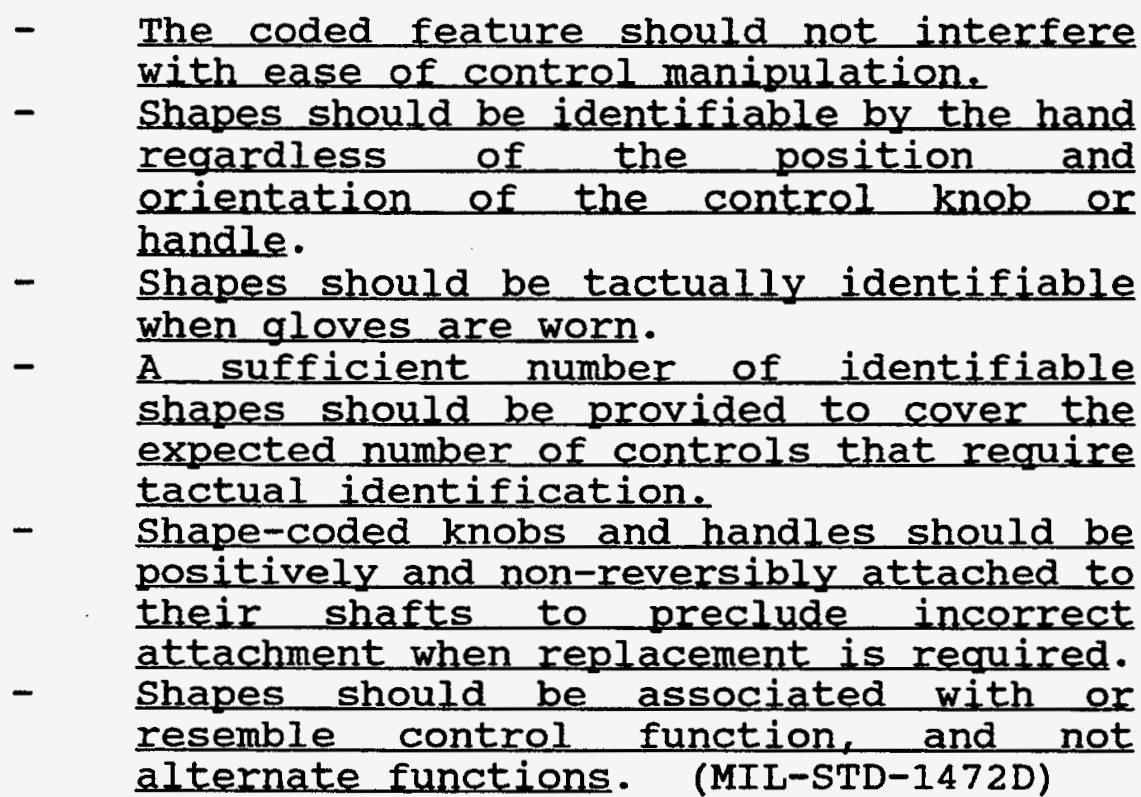

\subsubsection{Pushbutton Control Specifications}

6.4.3.2 Round Pushbuttons

Text

- Item a(1) should be changed to: Unguarded and nonrecessed pushbuttons: Minimum $\underline{0.375}$.

- Item $b$ should be modified as follows: 
Diameter (D), for thumb or palm operation (inches): Minimum 0.75 .

- Item $c$ should be divided into two and be as follows:

- c. Displacement (A), for fingertip operation (inches): Minimum 0.078 and

- d. Displacement (A), for thumb or palm operation (inches): Minimum 0.125 .

- Item d should be relabeled item e.

- Another item should added after item e. It should be as follows: $f$. Resistance (R), for thumb or palm operation (ounces): Minimum 10, Maximum 80. (MIL-STD-1472D)

Exhibit 6.4-7

- The table should be deleted and replaced in accordance with MIL-STD-1472D:

Dimensions

(inches)

Diameter

Fingertip Thumb

or

Palm

Operation Operation

D)
Resistance (R)

(ounces)

Fingertip Thumb

or

Palm

Operation Operation
Displacement

(A)

(inches)

Minimum

0.375

0.75

10

10

0.078

Fingertip Thumb or Palm

Maximum 1.0

40

80

0.25

1.5

\subsubsection{Legend Pushbuttons}

c. Provision for Lamp Failure

- The following should be added to the end of item (1): if the mean time between failure is less than 100,000 hours. (MIL-STD-1472D)

- No changes should be made to items (2), (3), and $(4)$.

e. Legend Pushbutton Dimensions 
- Item (3) should have a maximum value added to it. The value should be $\underline{0.25}$.

- The minimum value in item (4) should be modified. It should be 0.188 .

- The maximum resistance in item (5) should be changed to 60. (MIL-STD-1472D)

Exhibit 6.4-8

- The table should be changed in accordance with MIL-STD-1472D. The following modifications should be made.

- The * after barriers should be deleted.

- A * should appear after minimum size.

- A $\star \star *$ should be added after minimum displacement.

- Minimum Bd should be changed to 0.188 .

- Maximum resistance should be 60 .

- The following should be included in the notes section of the table.

- $\quad 0.625$ inches where switch is not depressed below the panel.

- ** 0.188 inches for positive position switches.

\subsubsection{Rotary Control Specifications}

6.4.4.2 J-Handles

a. High-Torque Designs

- Item (1) should be modified in accordance with EPRI NP-3659. It should be as follows:

- Handle length (L) (inches)

Minimum 4.0

Maximum 6.0

- Item (2) should be changed to reflect the guidance in EPRI NP-3659. The material should be:

- Clearance (C) (inches)

Minimum 1.25

Maximum 2.0

- Three new items as presented in EPRI NP-3659

should be added to the guideline. They are:

- Handle diameter (D) (inches) 


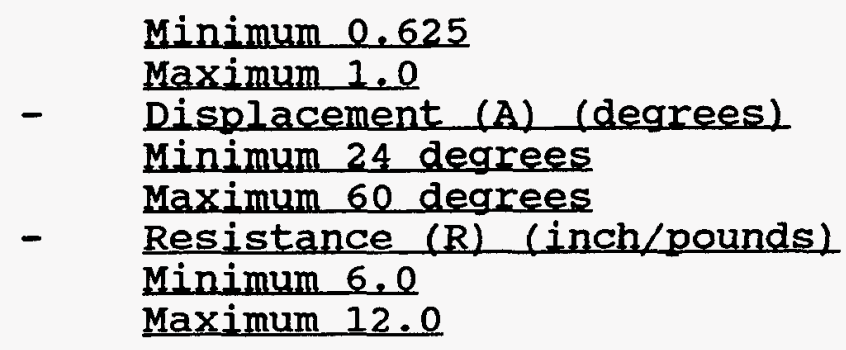

Exhibit 6.4-9

- The drawing should be deleted and replaced with the sketch from EPRI NP-3659. It is exhibited in Appendix D.

- The table should be modified in accordance with EPRI NP-3659 and be as follows:

\begin{tabular}{|c|c|c|c|c|c|}
\hline & Length & Clearance & Diameter & Displacement & Resistance \\
\hline & (inches) & (inches) & (inches) & (degrees) & $\begin{array}{l}\text { (inch/ } \\
\text { pounds) }\end{array}$ \\
\hline Minimum & 4.0 & 1.25 & 0.625 & 24 & 6 \\
\hline Maximum & 6.0 & 2.0 & 1.0 & 60 & 12 \\
\hline
\end{tabular}

6.4.4.3 Key-Operated Controls

c. Teeth: Double Row

- The guidance should be changed as follows: Keys with teeth on both edges, which fit the lock with either side up or forward, are preferred. (MIL-STD-1472D)

f. Labeling

- The guidance for labeling should not be changed.

- Another guideline should, however, be added between $f$. and $g$. and be entitled "Item Actuation". The guidance should be as follows: Actuation of an item by a key operated switch should be accomplished by turning the key clockwise from the vertical OFF position. (MIL-STD-1472D)

g. Key-Operated Control Dimensions 
- The minimum displacement in item (1) should be 30 degrees. (MIL-STD-1472D)

Exhibit $6.4-10$

- Minimum displacement should changed to 30 degrees. (MIL-STD-1472D)

6.4.4.5 Rotary Selector Controls

b. Positioning

- Item (4) should be deleted since it no longer appears in the current version of MIL-STD1472 .

Exhibit $6.4-13$

- No changes should be incorporated within the table.

- A modification should, however, be made to the ** item in the notes section. The following should be included at the end of the sentence: or when tactually ("blind") positioned controls are required. (MIL-STD-1472D)

\subsubsection{Other Control Specifications}

6.4.5.1 Thumbwheels

d. Discrete setting (stepped) Thumbwheels

- No changes should be made to item (1).

- A number of modifications as reflected in MILSTD-1472D should, however, be made to item

(2). They are as follows:

- Both values in subitem (a) should be changed. The minimum should be 1.125; the maximum 3.0.

- The minimum trough distance in subitem (b) should be 0.438 .

- The minimum width in subitem (c) should be 0.125 .

Exhibit 6.4-14

- Some of the minimum values in the figure are incorrect. The entries should be as follows: $1.125,0.438,0.125,0.125$, and 6.0. (MIISTD-1472D) 


\subsubsection{Slide Switches}

Guidelines

- Four new guidelines as detailed in MIL-STD$1472 \mathrm{D}$ should be added to this section. They should be as follows:

- DETENTS--Detents should be provided for each slide switch setting.

- posITIONING-To minimize the possibility of inadvertent activation or setting between control positions, slide switches should have an elastic resistance that increases as the control is moved and drops as the switch snaps into position. The slide switch should not be capable of stopping between positions.

- ORIENTATION--Slide switches should be vertically oriented. Horizontal orientation or actuation slide switches should be employed only for compatibility with the controlled function or equipment location.

- POSITIVE INDICATION--slide switches involving more than two positions should be designed to provide positive indication of control setting, preferably a pointer located on the left side of the slide handle.

b. Dimensions

- The letter "b" should be changed to $\mathrm{f}$.

o Items (1) and (2) should be deleted and replaced with the following guidance from MILSTD-1472D.

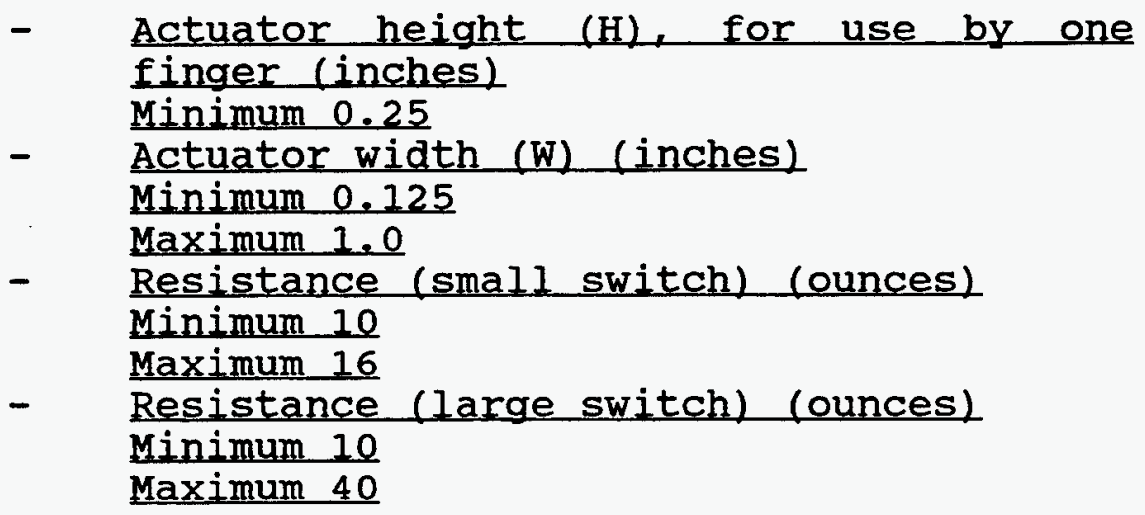


Exhibit $6.4-15$

- The drawing should be omitted and the sketch from MIL-STD-1472D should be substituted in its place. The sketch is displayed in Appendix D.

- The table should be deleted and replaced in accordance with EPRI NP-3659. It should be as follows:

Dimensions

(inches)
Resistance

(ounces)
Actuator Height

(H)
Actuator width
Small

Switch
Large

Switch

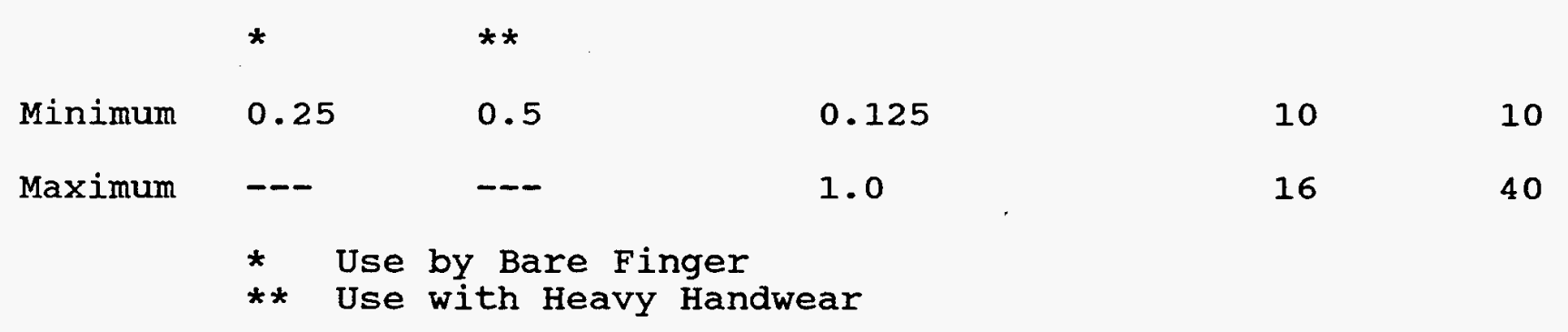

\subsubsection{Toggle Switches}

c. Dimensions

o No changes to items (1), (2), (3), and (4).

- The maximum displacement in item (5) should be changed to 80 degrees.

- In item (6) the minimum and maximum displacement values should be modified. They should be 17 and 40 degrees, respectively. (MIL-STD-1472D)

Exhibit $6.4-16$

- Three of the five displacement values in the figure should be changed. The two position values should be 30 and 80 ; the displacement values for three-position toggle switches should be 17,40 , and 25 . 
- The ** item in the notes section should be modified as follows: ** Use with Heavy Handwear. (MIL-STD-1472D)

6.4.5.4 Rocker Switches

e. Rocker Switch Dimensions

- A new item in accordance with MIL-STD-1472D and EPRI NP-3659 should be added. It should be as follows:

- Length (IL) (inches)

Minimum 0.5

Maximum 0.75

- Item (1) should be modified as specified in MIL-STD-1472D. The minimum width should be $\underline{0.25}$.

- Items (2), (3), and (4) should be renumbered (3) through (5).

Exhibit $6 \cdot 4-17$

- The figure should be changed to incorporate a length dimension. A sketch shown in Appendix $D$ identifies where this measurement should be placed.

- The top part of the table should be modified to reflect MIL-STD-1472D and EPRI NP-3659. This part of the table should be as follows:

\section{Dimensions}

(inches)
Resistance

(ounces)

Width (W) Length (L)

Minimum

0.25

$\underline{0.5}$

10

Maximum

1.5

$\underline{0.75}$

40

\subsection{Visual Displays}

6.5.1 Principles of Display

$$
\text { 6.5.1.3 Readability }
$$

a. Character Height 
- This guideline should be deleted since MILSTD-1472D no longer talks about visual angle.

e. Characters for CRT Presentation

- Title - The title of this guidance should be changed to CHARACTERS FOR VISUAL DISPLAY TERMINAL PRESENTATION since the CRT portion of NUREG-0700 is being expanded to include other types of visual display terminals.

- Text - The text should be modified as follows: Recommended character styles for visual display terminal use are presented in section 6.7 , Guideline $\mathrm{xxxx}$.

\subsubsection{Color coding}

Introductory Text

- The acronym CRTs in the first paragraph should be changed to visual display terminals since the CRT portion of NUREG-0700 is being expanded to include other types of visual display terminals.

d. Consistency of Meaning

- The acronym CRTs in item (2) should be changed to visual display terminals since the CRT portion of NUREG-0700 is being expanded to include other types of visual display terminals.

Exhibit $6.5-7$

- In accordance with the bibliography section of NUREG-0700, the reference line should be changed from Kelly, 1965 to Kelly, 1972.

\subsubsection{Meters}

6.5.2.1 Directionality of Movement and Numbering with FixedScale Moving-Pointer Meters

Exhibit $6.5-10$

- There is a typographical error in the title of the figure. The title should be "Direction of numbering and pointer movement for horizontal fixed scales".

6.5.4 Graphic Recorders 
6.5.4.1 General Characteristics of Graphic Recorders Introductory Text

- The verb has been left out of the third sentence. It is proposed that the sentence read as follows: Discrete recorders provide time-phase recording of a number of input channels, plotting them in sequence.

\subsubsection{Miscellaneous Display Types}

6.5.5.1 Drum-Type Counters

a. Numerical Presentation Factors

- The guidance in item (5) should be modified to be in accordance with EPRI NP-3659. It should read as follows: (5) DRUM FINISH--The surface of the drums and surrounding areas should have a dull matte finish to minimize glare.

\subsubsection{Electronic Counters}

b. Rate of Change

- The guideline should be changed to reflect the guidance in EPRI NP-3659. The text should be: b. RATE OF CHANGE--Numerals should not follow each other faster than one per second when the operator is expected to read the numerals consecutively.

c. Contrast

- The guidance should be modified as specified in EPRI NP-3659. It should be: c. CONTRAST-Character-to-background contrast ratio should be between 5:1 minimum and 15:1 preferred.

\subsection{Labels and Location Aids}

No updates to any of the guidelines in subsection 6.6 are required.

\subsection{Process Computers}

\subsubsection{Computer Access}

6.7.1.4 Data Entry--Keyboards 
Exhibit $6.7-5$

- The angle of the preferred slope should be changed. The optimum slope should be 17-18 degrees instead of 16-17 degrees. (MIL-STD1472D)

\subsubsection{Computer Function Controls}

Introductory Text

- The end of the first sentence should be changed from CRT parameters, etc. to visual display terminal parameters, etc. since there are many different types of display devices which are covered in the advanced control room design review guidelines.

c. Master Control

- The two places in this guideline where the term "CRT" is used should be modified. The phrase "visual display terminal" should be substituted in its place.

\subsection{Panel Layout}

No updates to any of the guidelines in subsection 6.8 are required.

6.9 Control-Display Integration

No updates to any of the guidelines in subsection 6.9 are required. 
APPENDIX D:

DIAGRAMS TO BE INCORPORATED IN THE NUREG-0700 UPDATES 


\section{HIGH TORQUE HAND OPERATED ROTARY}

SELECTOR SWITCH - J HANDLE

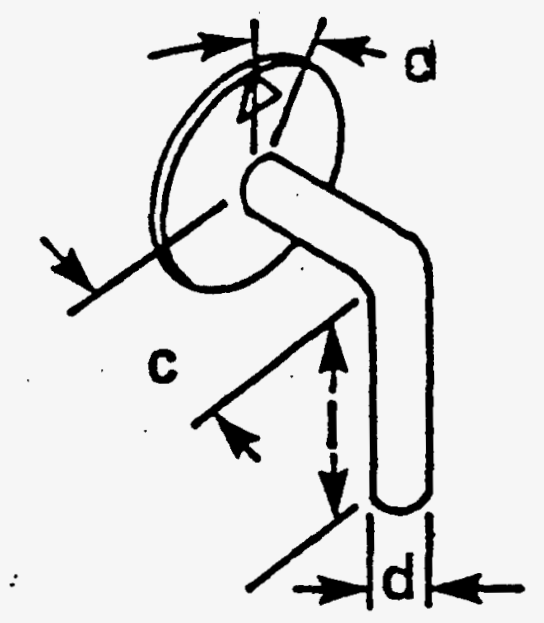

Sketch for Exhibit 6.4-9

\section{SLIDING SWITCH}

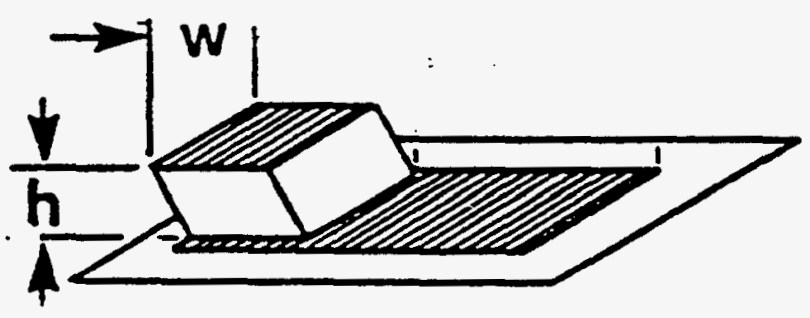

Sketch for Exhibit 6.4-15 


\section{ROCKER SWITCH}

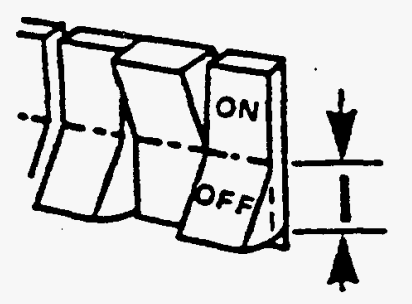

Sketch for Exhibit 6.4-17 
APPENDIX E:

GUIDELINE BY CONTROL STATION SYSTEM MATRICES 


\section{HUMAN FACTORS \\ ENGINEERING GUIDELINES}

section $\quad$ Title
MCR SPDS RRSF RRSS EDGC VES ECIS CHSB RWMC

\section{Number}

\section{NUREG-0700}

2. PLANNING PHASE

$\begin{array}{lllllllll}\mathrm{X} & \mathrm{X} & \mathrm{X} & \mathrm{X} & \mathrm{X} & \mathrm{X} & \mathrm{X} & \mathrm{X} & \mathrm{X}\end{array}$

3. REVIEW PHASE

4. ASSESSMENT AND IMPLEMENTATION

$\begin{array}{lllllllllll}x & x & x & x & x & x & x & x & x\end{array}$

$\begin{array}{llllllllll}x & x & x & x & x & x & x & x & x\end{array}$

5. REPORTS

$\begin{array}{lllllllll}\mathrm{X} & \mathrm{x} & \mathrm{X} & \mathrm{X} & \mathrm{X} & \mathrm{x} & \mathrm{x} & \mathrm{x} & \mathrm{x}\end{array}$

6. CONTROL ROOM HUMAN ENGINEERING GUIDELINES

6.1 CONTROL ROOM WORKSPACE
6.1.1 General Layout
$6 \cdot 1 \cdot 1 \cdot 1$
Accessibility of Instrumentation/ Equipment

$\mathrm{x} \quad \mathrm{x}$
$6.1 \cdot 1 \cdot 2$
Consistency of
Manning with
Equipment Layout
$6 \cdot 1 \cdot 1 \cdot 3$
Furniture and
Equipment Layout
$6 \cdot 1 \cdot 1 \cdot 4$
Document
organization and
$\mathrm{X} \quad \mathrm{X} \quad \mathrm{X}$
storage
6.1.1.5 Spare Parts,
Operating
Expendables and
Tools
6.1 .1 .6
Supervisor Access
X X X
$6.1 \cdot 1 \cdot 7$
Nonessential
Personnel Access

$\begin{array}{lll}\mathrm{X} & \mathrm{x} & \mathrm{X} \\ \mathrm{x} & \mathrm{x} & \mathrm{x}\end{array}$

$\mathrm{X}$

$\mathrm{X}$ 
HUMAN FACTORS

ENGINEERING GUIDELINES

- - - - - - - - - - - - - - - - - -

section

Title

Number

6.1 .2

Work station

Design

$6 \cdot 1 \cdot 2 \cdot 1$

Anthropometric

Basis for

Equipment

Dimensions

$6 \cdot 1 \cdot 2 \cdot 2$

Stand-Up console

Dimensions

$6 \cdot 1 \cdot 2 \cdot 3$

Sit-Down Console
Dimensions

6.1 .2 .4

Sit-Stand work

stations

$6.1 \cdot 2 \cdot 5$

Vertical Panels

6.1 .2 .6

Use of Procedures

and other

Reference

Materials at

Consoles

6.1.2.7 Desk Dimensions

6.1.2.8 Chairs

$6 \cdot 1 \cdot 3$

Multiunit

Control Rooms

$6 \cdot 1 \cdot 3 \cdot 1$

Unit Integration

and Interference

6.1.3.2 Unit Mirror

Imaging

\section{1 .4}

Emergency

Equipment

\section{MCR SPDS RRSF RRSS EDGC VES ECIS CHSS RTMC}

$\mathrm{X}$
$\mathrm{X}$

$\mathrm{X}$

$\mathrm{X}$

$\mathrm{X} \quad \mathrm{X} \quad \mathrm{X}$

$\mathrm{X}$

$\mathrm{X} \quad \mathrm{X} \quad \mathrm{X}$

(n)

$\mathrm{x}-\mathrm{x}-\mathrm{x}-\mathrm{x}-\mathrm{x}-\mathrm{x}-\mathrm{x}-\mathrm{x}$

$x+x$

$\mathrm{X} \quad \mathrm{X} \quad \mathrm{X}$

$X$

$\mathrm{X}$ $\mathrm{x}$

$x$

$\mathrm{X}$

$\mathrm{X}$

$\mathrm{X}-\mathrm{x}$

$\mathrm{x} \quad \mathrm{X} \quad \mathrm{x}$ 


\section{section \\ Title}

Number

$\begin{array}{ll}6.1 .4 .1 & \text { Operator } \\ \text { Protective } \\ \text { Equipment }\end{array}$

6.1.4.2 Fire, Radiation, $\mathrm{X}$ and Rescue

Equipment

6.1.4.3 Emergency X

Equipment

Storage

6.1.5 Environment

6.1.5.1 Temperature $X \quad X \quad X$ and Humidity

6.1.5.2 Ventilation

6.1.5.3 Illumination

6.1.5.4 Emergency

Lighting

6.1.5.5 Auditory

Environment

6.1.5.6 Personal Storage $x$

6.1.5.7 Ambience and $x$

Comfort

6.2 COMMUNICATIONS

6.2.1 Voice Communication Systems
6.2 .1 .1
General
$\mathrm{x}$
$\begin{array}{lllllll}\mathrm{X} & \mathrm{X} & \mathrm{X} & \mathrm{X} & \mathrm{X} & \mathrm{X} & \mathrm{X}\end{array}$
Requirements
for Voice
Communication
Systems

$\mathrm{X} \quad \mathrm{X} \quad \mathrm{X}$

$\begin{array}{lllllllll}\mathrm{X} & \mathrm{X} & \mathrm{X} & \mathrm{X} & \mathrm{X} & \mathrm{X} & \mathrm{X} & \mathrm{X} & \mathrm{x}\end{array}$

$\begin{array}{llllllllllll}x & x & x & x & x & x & x & x & x\end{array}$ 
HUMAN FACTORS

ENGINEERING GUIDELINES

MCR SPDS RRSF RRSS EDGC VES ECIS CHSS RWMC

\section{section Title}

Number

\begin{tabular}{|c|c|c|c|c|c|c|c|c|c|c|}
\hline 6.2 .1 .2 & $\begin{array}{l}\text { Conventional- } \\
\text { Powered } \\
\text { Telephone systems }\end{array}$ & $\mathrm{x}$ & & $\mathrm{x}$ & $\mathrm{X}$ & $\mathrm{X}$ & $\mathrm{X}$ & $\mathrm{X}$ & $\mathrm{X}$ & $\mathrm{X}$ \\
\hline 6.2 .1 .3 & $\begin{array}{l}\text { Sound-Powered } \\
\text { Telephone Systems }\end{array}$ & $\mathrm{X}$ & & $\mathrm{X}$ & $\mathrm{X}$ & $\mathrm{X}$ & $\mathrm{X}$ & $\mathrm{X}$ & $\mathrm{X}$ & $\mathrm{X}$ \\
\hline 6.2 .1 .4 & $\begin{array}{l}\text { Walkie-Talkie } \\
\text { Radio } \\
\text { Transceivers }\end{array}$ & $\mathrm{X}$ & & $\mathrm{X}$ & $\mathrm{X}$ & & & & & \\
\hline $6.2 \cdot 1.5$ & $\begin{array}{l}\text { Fixed-Base UHF } \\
\text { Transceivers }\end{array}$ & $\mathrm{X}$ & & & & & & & & \\
\hline 6.2 .1 .6 & $\begin{array}{l}\text { Announcing } \\
\text { Systems }\end{array}$ & $\mathrm{X}$ & & $\mathrm{x}$ & $\mathrm{X}$ & $\mathrm{X}$ & $\mathrm{X}$ & $\mathrm{X}$ & $\mathrm{X}$ & $\mathrm{X}$ \\
\hline 6.2 .1 .7 & $\begin{array}{l}\text { Point-to-Point } \\
\text { Intercom systems }\end{array}$ & $\mathrm{X}$ & & $\mathrm{x}$ & $\mathrm{X}$ & $\mathrm{X}$ & $\mathrm{X}$ & $\mathrm{X}$ & $\mathrm{X}$ & $\mathrm{X}$ \\
\hline $6.2 \cdot 1.8$ & $\begin{array}{l}\text { Emergency } \\
\text { Communications }\end{array}$ & $\mathrm{X}$ & & $\mathrm{X}$ & $\mathrm{X}$ & $\mathrm{X}$ & $\mathrm{X}$ & $\mathrm{X}$ & $\mathrm{X}$ & $\mathrm{X}$ \\
\hline 6.2 .2 & $\begin{array}{l}\text { Auditory Signal } \\
\text { Systems }\end{array}$ & & & & & & & & & \\
\hline 6.2 .2 .1 & $\begin{array}{l}\text { Use of Auditory } \\
\text { Signals }\end{array}$ & $\mathrm{X}$ & $\mathrm{X}$ & $\mathrm{X}$ & & & $\mathrm{X}$ & & $\mathrm{X}$ & \\
\hline 6.2 .2 .2 & Signal Meaning & $\mathrm{X}$ & $\mathrm{X}$ & $\mathrm{x}$ & & & $\mathrm{X}$ & & & $X$ \\
\hline 6.2 .2 .3 & $\begin{array}{l}\text { Auditory Coding } \\
\text { Techniques }\end{array}$ & $\mathrm{X}$ & $X$ & $\mathrm{x}$ & & & $\mathrm{x}$ & & $\mathrm{X}$ & \\
\hline 6.2 .2 .4 & $\begin{array}{l}\text { Propagation of } \\
\text { Signals }\end{array}$ & $\mathrm{X}$ & $\mathrm{X}$ & $X$ & & & $\mathrm{x}$ & & $\mathrm{X}$ & \\
\hline 6.2 .2 .5 & Frequency & $\mathrm{X}$ & $\mathrm{X}$ & $\mathrm{X}$ & & & $\mathrm{X}$ & & & $x$ \\
\hline 6.2 .2 .6 & Signal Intensity & $\mathrm{X}$ & $\mathrm{X}$ & $\mathrm{X}$ & & & $\mathrm{X}$ & & $\mathrm{X}$ & \\
\hline 6.2 .2 .7 & Reliability & $X$ & $X$ & $X$ & & & $X$ & & $X$ & \\
\hline
\end{tabular}




\section{HUMAN FACTORS \\ ENGINEERING GUIDELINES

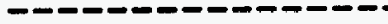 \\ section \\ Title \\ Number \\ 6.3 ANNUNCIATOR WARNING SYSTEMS}

MCR SPDS RRSF RRSS EDGC VES ECIS CHSS RWMC

6.3.1 General System Characteristics

6.3.1.1 General System $X$ Design

6.3 .1 .2

Alarm Parameter

$\mathrm{X}$

$\mathrm{X}$ Selection

$6 \cdot 3 \cdot 1 \cdot 3$

First out

$\mathrm{X}$

$\mathrm{X}$

Annunciators

$6 \cdot 3 \cdot 1 \cdot 4$

Prioritization

$\mathrm{X} \quad \mathrm{X}$

$6 \cdot 3 \cdot 1 \cdot 5$

Cleared Alarms

$\mathrm{X}$

$\mathrm{X}$

6.3 .2

Auditory Alert

Subsystem

6.3 .2 .1

Signal Detection

$\mathrm{X}$

$\mathrm{X}$

6.3.2.2 coding

$\mathrm{X}, \mathrm{x}$

$6 \cdot 3 \cdot 3$

Visual Alarm

Subsystems

$6 \cdot 3 \cdot 3 \cdot 1$

Visual

Annunciator

Panels
$6 \cdot 3 \cdot 3 \cdot 2$
Visual Alarm
Recognition and
$\mathrm{X} \quad \mathrm{X}$
Identification
$6 \cdot 3 \cdot 3 \cdot 3$
Arrangement of
$\mathrm{X}$
$\mathrm{X}$
Visual Alarm
Tiles 
HUMAN FACTORS ENGINEERING GUIDELINES
MCR SPDS RRSF RRSB EDGC VES ECIS CHSS RWMC

\section{section Title}

Number

\begin{tabular}{|c|c|c|}
\hline $6 \cdot 3 \cdot 3 \cdot 4$ & $\begin{array}{l}\text { Visual Tile } \\
\text { Legends }\end{array}$ & $\mathrm{X}$ \\
\hline $6 \cdot 3 \cdot 3 \cdot 5$ & $\begin{array}{l}\text { Visual Tile } \\
\text { Readability }\end{array}$ & $\mathrm{X}$ \\
\hline 6.3 .4 & $\begin{array}{l}\text { Operator } \\
\text { Response } \\
\text { Subsystem }\end{array}$ & \\
\hline 6.3 .4 .1 & Controls & $\mathrm{X}$ \\
\hline 6.3 .4 .2 & $\begin{array}{l}\text { Control set } \\
\text { Design }\end{array}$ & $\mathrm{X}$ \\
\hline 6.3 .4 .3 & $\begin{array}{l}\text { Annunciator } \\
\text { Response } \\
\text { Procedures }\end{array}$ & $\mathrm{X}$ \\
\hline
\end{tabular}

6.4 CONTROLS
6.4.1 Selection of Controls

6.4.1.1 General

Principles

6.4.1.2 Prevention of Accidental

$\mathrm{X}$

$X$

\section{$\mathrm{X}$}

$x$

Activation

$\begin{array}{ll}6.4 .2 & \text { Design } \\ & \text { Principles }\end{array}$

$\begin{array}{llllllllllllll}6.4 .2 .1 & \text { Direction of } & & X & X & X & X & X & X & X & X & X\end{array}$ Movement

$\begin{array}{llllllllll}X & X & X & X & X & X & X & X & X\end{array}$

$\begin{array}{llllllllll}\mathrm{X} & \mathrm{X} & \mathrm{X} & \mathrm{X} & \mathrm{X} & \mathrm{X} & \mathrm{X} & \mathrm{X} & \mathrm{X}\end{array}$
6.4.2.2 Coding of Controls

$\begin{array}{lllllllll}\mathrm{X} & \mathrm{X} & \mathrm{X} & \mathrm{X} & \mathrm{X} & \mathrm{X} & \mathrm{x} & \mathrm{X} & \mathrm{X}\end{array}$
6.4.3 Pushbutton Control Specifications


HUMAN FACTORS

ENGINEERING GUIDELINES

\section{section Title}

Number
$6.4 .3 .1 \quad$ Pushbutton

Principles

$\begin{array}{lllllllllllllll}6.4 .3 .2 & \text { Round Pushbuttons } & X & X & X & X & X & X & X & X & X\end{array}$

$\begin{array}{lllllllllllllll}6.4 .3 .3 & \text { Legend Pushbuttons } & X & X & X & X & X & X & X & X & x\end{array}$
$6 \cdot 4 \cdot 4$
Rotary control
Specifications

6.4.4.1 Rotary Control

Design

MCR SPDS RRSF RRSS EDGC VES ECIS CHSB RWMC

\begin{tabular}{|c|c|c|c|c|c|c|c|c|c|c|}
\hline 6.4 .4 .1 & $\begin{array}{l}\text { Rotary Control } \\
\text { Design } \\
\text { Principles }\end{array}$ & $\mathrm{X}$ & $\mathrm{X}$ & $\mathrm{X}$ & $\mathrm{X}$ & $\mathrm{X}$ & $\mathrm{X}$ & $\mathrm{X}$ & $\mathrm{x}$ & $\mathrm{x}$ \\
\hline 6.4 .4 .2 & J-Handles & $\mathrm{x}$ & & $\mathrm{X}$ & & & & & & \\
\hline $6.4 .4 \cdot 3$ & $\begin{array}{l}\text { Key-Operated } \\
\text { Controls }\end{array}$ & $\mathrm{X}$ & & $\mathrm{X}$ & & & & & & \\
\hline 6.4 .4 .4 & $\begin{array}{l}\text { Continuous } \\
\text { Adjustment } \\
\text { Rotary Controls }\end{array}$ & $\mathrm{X}$ & $\mathrm{X}$ & $\mathrm{X}$ & $\mathrm{x}$ & $\mathrm{X}$ & $\mathrm{X}$ & $\mathrm{X}$ & $\mathrm{X}$ & $\mathrm{x}$ \\
\hline 6.4 .4 .5 & $\begin{array}{l}\text { Rotary selector } \\
\text { Controls }\end{array}$ & $\mathrm{x}$ & $\mathrm{X}$ & $\mathrm{X}$ & $\mathrm{X}$ & $\mathrm{X}$ & $\mathrm{X}$ & $\mathrm{X}$ & $\mathrm{X}$ & $\mathrm{x}$ \\
\hline 6.4 .5 & $\begin{array}{l}\text { Other control } \\
\text { specifications }\end{array}$ & & & & & & & & & \\
\hline 6.4 .5 .1 & Thumbwheels & $\mathrm{x}$ & $\mathrm{x}$ & $\mathrm{x}$ & $\mathrm{X}$ & $\mathrm{X}$ & $\mathrm{X}$ & $x$ & $\mathrm{x}$ & $\mathrm{x}$ \\
\hline $6.4 \cdot 5.2$ & Slide Switches & $\mathrm{x}$ & $\mathrm{x}$ & $\mathrm{x}$ & $\mathrm{x}$ & $\mathrm{x}$ & $\mathrm{x}$ & $\mathrm{x}$ & $\mathrm{x}$ & $\mathrm{X}$ \\
\hline 6.4 .5 .3 & Toggle Switches & $\mathrm{x}$ & $\mathrm{x}$ & $\mathrm{x}$ & $\mathrm{x}$ & $\mathrm{x}$ & $\mathrm{x}$ & $\mathrm{x}$ & $\mathrm{x}$ & $\mathrm{X}$ \\
\hline 6.4 .5 .4 & Rocker Switches & $\mathrm{x}$ & $\mathrm{x}$ & $\mathrm{x}$ & $\mathrm{x}$ & $\mathrm{X}$ & $\mathrm{x}$ & $\mathrm{x}$ & $\mathrm{x}$ & $\mathrm{X}$ \\
\hline \multicolumn{11}{|c|}{6.5 VISUAL DISPLAYS } \\
\hline 6.5 .1 & $\begin{array}{l}\text { Principles of } \\
\text { Display }\end{array}$ & & & & & & & & & \\
\hline
\end{tabular}


HUMAN FACTORS

ENGINEERING GUIDELINES

\section{section}

Title

MCR SPDS RRSF RRSE EDGC VES ECIS CHSS RWMC

\section{Number}

\begin{tabular}{|c|c|c|c|c|c|c|c|c|c|c|}
\hline 6.5 .1 .1 & $\begin{array}{l}\text { Information To } \\
\text { Be Displayed }\end{array}$ & $\mathrm{x}$ & $\mathrm{x}$ & $\mathrm{x}$ & $\mathrm{x}$ & $\mathrm{x}$ & $\mathrm{x}$ & $\mathrm{x}$ & $\mathrm{x}$ & $\mathrm{x}$ \\
\hline 6.5 .1 .2 & $\begin{array}{l}\text { Usability of } \\
\text { Displayed Values }\end{array}$ & $\mathrm{x}$ & $\mathrm{x}$ & $\mathrm{x}$ & $\mathrm{x}$ & $\mathrm{X}$ & $\mathrm{X}$ & $\mathrm{X}$ & $\mathrm{x}$ & $\mathrm{x}$ \\
\hline 6.5 .1 .3 & Readability & $\mathrm{x}$ & $\mathrm{X}$ & $\mathrm{x}$ & $\mathrm{x}$ & $\mathrm{x}$ & $\mathrm{x}$ & $\mathrm{X}$ & $\mathrm{x}$ & $\mathrm{X}$ \\
\hline 6.5 .1 .4 & $\begin{array}{l}\text { Printing on the } \\
\text { Display Face }\end{array}$ & $\mathrm{x}$ & $\mathrm{x}$ & $\mathrm{X}$ & $\mathrm{x}$ & $\mathrm{x}$ & $\mathrm{x}$ & $\mathrm{x}$ & $\mathrm{x}$ & $\mathrm{x}$ \\
\hline 6.5 .1 .5 & Scale Marking & $\mathrm{x}$ & $\mathrm{x}$ & $\mathrm{x}$ & $\mathrm{x}$ & $\mathrm{x}$ & $\mathrm{x}$ & $\mathrm{x}$ & $\mathrm{x}$ & $\mathrm{x}$ \\
\hline 6.5 .1 .6 & Color Coding & $\mathrm{x}$ & $\mathrm{x}$ & $\mathrm{x}$ & $\mathrm{X}$ & $\mathrm{x}$ & $\mathrm{x}$ & $\mathrm{X}$ & $\mathrm{x}$ & $\mathrm{x}$ \\
\hline 6.5 .2 & Meters & & & & & & & & & \\
\hline 6.5 .2 .1 & $\begin{array}{l}\text { Directionality } \\
\text { of Movement and } \\
\text { Numbering with } \\
\text { Fixed-Scale } \\
\text { Moving-Pointer } \\
\text { Meters }\end{array}$ & $\mathrm{x}$ & $\mathrm{x}$ & $\mathrm{x}$ & $\mathrm{x}$ & $\mathrm{x}$ & $\mathrm{x}$ & $\mathrm{x}$ & $\mathrm{x}$ & $\mathrm{x}$ \\
\hline 6.5 .2 .2 & Pointers & $\mathrm{X}$ & $\mathrm{X}$ & $\mathrm{X}$ & $\mathrm{x}$ & $\mathrm{X}$ & $\mathrm{X}$ & $\mathrm{x}$ & $\mathrm{x}$ & $\mathrm{x}$ \\
\hline 6.5 .2 .3 & Zone Marking & $\mathrm{X}$ & $\mathrm{x}$ & $\mathrm{X}$ & $\mathrm{x}$ & $\mathrm{X}$ & $\mathrm{x}$ & $\mathrm{x}$ & $\mathrm{x}$ & $\mathrm{x}$ \\
\hline 6.5 .2 .4 & $\begin{array}{l}\text { Orientation of } \\
\text { Markings on } \\
\text { Fixed-scale } \\
\text { Meters }\end{array}$ & $\mathrm{x}$ & $\mathrm{X}$ & $\mathrm{x}$ & $\mathrm{x}$ & $\mathrm{x}$ & $\mathrm{x}$ & $\mathrm{x}$ & $\mathrm{x}$ & $\mathrm{x}$ \\
\hline $6.5 .2 \cdot 5$ & $\begin{array}{l}\text { Moving-Scale } \\
\text { Meters }\end{array}$ & $\mathrm{x}$ & $\mathrm{x}$ & $\mathrm{x}$ & $\mathrm{x}$ & $\mathrm{x}$ & $\mathrm{x}$ & $\mathrm{x}$ & $\mathrm{x}$ & $\mathrm{x}$ \\
\hline 6.5 .3 & Light Indicators & & & & & & & & & \\
\hline 6.5 .3 .1 & $\begin{array}{l}\text { Characteristics } \\
\text { and Problems of } \\
\text { Light Indicators }\end{array}$ & $\mathrm{x}$ & $\mathrm{x}$ & $\mathrm{x}$ & $\mathrm{x}$ & $\mathrm{x}$ & $\mathrm{x}$ & $\mathrm{x}$ & $\mathrm{x}$ & $\mathrm{x}$ \\
\hline
\end{tabular}


HUMAN FACTORS

ENGINEERING GUIDELINES

\section{section \\ Title}

Number

MCR SPDS RRSF RRSS EDGC VES ECIS CHSS RMC

\begin{tabular}{|c|c|c|c|c|c|c|c|c|c|c|}
\hline $6.5 \cdot 3.2$ & $\begin{array}{l}\text { Design and Use } \\
\text { of Non-Legend } \\
\text { Light Indicators }\end{array}$ & $\mathrm{X}$ & $\mathrm{X}$ & $\mathrm{X}$ & $\mathrm{X}$ & $\mathrm{X}$ & $\mathrm{X}$ & $\mathrm{X}$ & $\mathrm{X}$ & $\mathrm{X}$ \\
\hline $6.5 \cdot 3 \cdot 3$ & $\begin{array}{l}\text { Design and Use } \\
\text { of Legend Light } \\
\text { Indicators }\end{array}$ & $\mathrm{X}$ & $\mathrm{X}$ & $\mathrm{x}$ & $\mathrm{X}$ & $\mathrm{X}$ & $\mathrm{x}$ & $\mathrm{x}$ & $\mathrm{x}$ & $\mathrm{x}$ \\
\hline 6.5 .4 & Graphic Recorders & & & & & & & & & \\
\hline 6.5 .4 .1 & $\begin{array}{l}\text { General } \\
\text { Characteristics } \\
\text { of Graphic } \\
\text { Recorders }\end{array}$ & $\mathrm{X}$ & $\mathrm{x}$ & $\mathrm{x}$ & $\mathrm{X}$ & $\mathrm{x}$ & $\mathrm{X}$ & $\mathrm{X}$ & $\mathrm{X}$ & $\mathrm{x}$ \\
\hline 6.5 .4 .2 & $\begin{array}{l}\text { Specific } \\
\text { Recorder Types }\end{array}$ & $\mathrm{X}$ & $\mathrm{x}$ & $\mathrm{x}$ & $\mathrm{x}$ & $\mathrm{x}$ & $\mathrm{x}$ & $\mathrm{x}$ & $\mathrm{x}$ & $\mathrm{x}$ \\
\hline 6.5 .5 & $\begin{array}{l}\text { Miscellaneous } \\
\text { Display Types }\end{array}$ & & & & & & & & & \\
\hline $6.5 \cdot 5.1$ & $\begin{array}{l}\text { Drum-Type } \\
\text { Counters }\end{array}$ & $\mathrm{x}$ & $\mathrm{x}$ & $\mathrm{X}$ & $\mathrm{x}$ & $x$ & $\mathrm{x}$ & $\mathrm{x}$ & $\mathrm{X}$ & $\mathrm{x}$ \\
\hline 6.5 .5 .2 & $\begin{array}{l}\text { Electronic } \\
\text { counters }\end{array}$ & $\mathrm{X}$ & $x$ & $\mathrm{X}$ & $\mathrm{x}$ & $\mathrm{X}$ & $\mathrm{X}$ & $\mathrm{x}$ & $\mathrm{x}$ & $\mathrm{x}$ \\
\hline $\begin{array}{ll}6.6 \quad \mathrm{LAE} \\
\mathrm{LOC}\end{array}$ & $\begin{array}{l}\text { S AND } \\
\text { rION AIDS }\end{array}$ & & & & & & & & & \\
\hline 6.6 .1 & $\begin{array}{l}\text { Labeling } \\
\text { Principles }\end{array}$ & & & & & & & & & \\
\hline 6.6 .1 .1 & $\begin{array}{l}\text { Need for } \\
\text { Labeling }\end{array}$ & $\mathrm{X}$ & $\mathrm{X}$ & $\mathrm{X}$ & $\mathrm{X}$ & $\mathrm{X}$ & $\mathrm{x}$ & $\mathrm{X}$ & $x$ & $\mathrm{x}$ \\
\hline 6.6 .1 .2 & $\begin{array}{l}\text { Hierarchical } \\
\text { Scheme }\end{array}$ & $\mathrm{X}$ & $\mathrm{X}$ & $\mathrm{X}$ & $\mathrm{X}$ & $\mathrm{X}$ & $\mathrm{X}$ & $\mathrm{X}$ & $\mathrm{x}$ & $\mathrm{X}$ \\
\hline 6.6 .2 & Label Location & & & & & & & & & \\
\hline 6.6 .2 .1 & Placement & $\mathrm{X}$ & $X$ & $\mathrm{X}$ & $X$ & $\mathrm{X}$ & $\mathrm{X}$ & $X$ & $\mathrm{X}$ & $\mathrm{X}$ \\
\hline
\end{tabular}


HUMAN FACTORS

ENGINEERING GUIDELINES

--------

section

Title

MCR SPDS RRSF RRSS EDGC VES ECIS CHSS RWMC

\section{Number}

6.6.2.2 Mounting

6.6.2.3 Spatial

orientation

6.6.2.4 Visibility

6.6.3 Label content

6.6 .3 .1 Kinds of

Information

6.6.3.2 Word Selection

6.6.3.3 Consistency

6.6.3.4 Symbols

$6.6 .3 .5 \quad$ Brevity

6.6.3.6 similarity

6.6.3.7 Functional Groups

6.6.3.8 Control Position

Labeling

6.6.3.9 Access Opening, Danger Warning, and Safety

Instruction

Labeling

6.6 .4

Label Lettering

6.6.4.1 Readability

6.6.4.2 Style

$6 \cdot 6 \cdot 5$

Use and control

of Temporary

Labels

$\begin{array}{lllllllll}\mathrm{X} & \mathrm{X} & \mathrm{X} & \mathrm{X} & \mathrm{X} & \mathrm{X} & \mathrm{X} & \mathrm{X} & \mathrm{X}\end{array}$

$\begin{array}{llllllllll}\mathrm{X} & \mathrm{X} & \mathrm{X} & \mathrm{X} & \mathrm{X} & \mathrm{X} & \mathrm{X} & \mathrm{X} & \mathrm{X}\end{array}$

$\begin{array}{lllllllll}\mathrm{X} & \mathrm{X} & \mathrm{X} & \mathrm{X} & \mathrm{X} & \mathrm{X} & \mathrm{X} & \mathrm{X} & \mathrm{X}\end{array}$

$\begin{array}{llllllllll}\mathrm{X} & \mathrm{X} & \mathrm{X} & \mathrm{X} & \mathrm{X} & \mathrm{x} & \mathrm{x} & \mathrm{x} & \mathrm{x}\end{array}$

$\begin{array}{lllllllll}\mathrm{X} & \mathrm{X} & \mathrm{X} & \mathrm{X} & \mathrm{X} & \mathrm{X} & \mathrm{X} & \mathrm{x} & \mathrm{X}\end{array}$

$\begin{array}{lllllllll}X & x & x & x & x & x & x & x\end{array}$

$x \quad x \quad x \quad x \quad x \quad x \quad x \quad x$

$x \quad x \quad x \quad x \quad x \quad x \quad x \quad x$

$\begin{array}{llllllll} & x & x & x & x & x & x\end{array}$

$\begin{array}{llllllll} & x & x & x & x & x & x\end{array}$

$\begin{array}{llllllllll}x & x & x & x & x & x & x & x & x\end{array}$

$\begin{array}{llllllllll}\mathrm{X} & \mathrm{X} & \mathrm{X} & \mathrm{X} & \mathrm{X} & \mathrm{X} & \mathrm{X} & \mathrm{X} & \mathrm{X}\end{array}$

$\begin{array}{lllllllll}\mathrm{X} & \mathrm{X} & \mathrm{X} & \mathrm{X} & \mathrm{X} & \mathrm{X} & \mathrm{X} & \mathrm{X} & \mathrm{X}\end{array}$

$\begin{array}{llllllllll}\mathrm{X} & \mathrm{X} & \mathrm{X} & \mathrm{X} & \mathrm{X} & \mathrm{X} & \mathrm{X} & \mathrm{X} & \mathrm{X}\end{array}$ 
HUMAN FACTORS

ENGINEERING GUIDELINES
MCR SPDS RRSF RRSS EDGC VES ECIS CHSS RWMC

\section{Section Title}

Number

$\begin{array}{lllllllllll}6.6 .5 .1 & \text { Use } & \mathrm{X} & \mathrm{X} & \mathrm{X} & \mathrm{X} & \mathrm{X} & \mathrm{X} & \mathrm{X} & \mathrm{X} & \mathrm{X} \\ 6.6 .5 .2 & \text { Control } & \mathrm{X} & \mathrm{X} & \mathrm{X} & \mathrm{X} & \mathrm{X} & \mathrm{X} & \mathrm{X} & \mathrm{X} & \mathrm{x}\end{array}$

6.6.6 Location Aids

6.6.6.1 Need for $X$

Location Aids

6.6.6.2 Demarcation

$\begin{array}{llllllllll}\mathrm{X} & \mathrm{X} & \mathrm{X} & \mathrm{X} & \mathrm{X} & \mathrm{X} & \mathrm{X} & \mathrm{X} & \mathrm{X}\end{array}$

6.6.6.3 Color

$\begin{array}{lllllllllllllllll}\mathrm{X} & \mathrm{X} & \mathrm{X} & \mathrm{X} & \mathrm{X} & \mathrm{X} & \mathrm{X} & \mathrm{X} & \mathrm{X}\end{array}$

6.6.6.4 Use of Mimics

$\mathrm{X} \quad \mathrm{X}$

$\mathrm{X}$

$\mathrm{X}$

6.7 PROCESS COMPUTERS

6.7.1 Computer Access

6.7.1.1 Software security $x$

$\begin{array}{llllllllllllll}6.7 .1 .2 & \text { Operator/Computer } & X & X & X & X & X & X & X & X & X\end{array}$ Dialogue

6.7.1.3 Prompting and $\begin{array}{lllllllll}\mathrm{X} & \mathrm{X} & \mathrm{X} & \mathrm{X} & \mathrm{X} & \mathrm{X} & \mathrm{X} & \mathrm{X} & \mathrm{X}\end{array}$ structuring

6.7.1.4 Data Entry-Keyboards

6.7 .1 .5

Computer

Function Controls

6.7.1.6 Other Control Devices

$\begin{aligned} & 6.7 .1 .7 \text { Computer Response } \\ & \text { Time to operator }\end{aligned}$ Queries

$\begin{array}{lllllllll}X & X & X & X & X & X & X & X & X\end{array}$

$\begin{array}{lllllllll}X & X & X & X & X & X & X & X & X\end{array}$

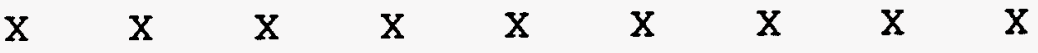

6.7.1.8 Access Aids

$\mathrm{X}$ 
HUMAN FACTORS

ENGINEERING GUIDELINES

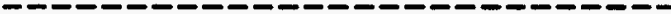

section

Title
MCR SPDS RRSF RRSS EDGC VES ECIS CHSS RWMC

\section{Number}

6.7 .2 Cathode Ray Tube

(CRT) Displays

6.7 .2 .1

CRT Display

Characteristics

6.7.2.2 Symbols and

Characteristics

6.7 .2 .3

Operator-Display

Relationships

$6 \cdot 7 \cdot 2 \cdot 4$

Data Presentation

Format

$6 \cdot 7 \cdot 2 \cdot 5$

Screen Layout and structuring

6.7.2.6 Messages

$6 \cdot 7 \cdot 2 \cdot 7$

Graphic coding and Highlighting

6.7.2.8 Multiple-Page Considerations

6.7 .3

Printers

$6 \cdot 7 \cdot 3 \cdot 1$

Printer

Characteristics

6.7 .3 .2

Alarm Messages

$\mathrm{X}$

$\mathrm{X} \quad \mathrm{X}$

$\mathrm{x} \quad \mathrm{x}$

$\mathrm{X}$

$\mathrm{X} \quad \mathrm{X}$

$\mathrm{X}$

$\mathrm{X}$

$\mathrm{X}$

$\mathrm{X}$

$\mathrm{X}$

$x$

$\mathrm{x}$

$\mathrm{X}$

$\mathrm{x} \quad \mathrm{x}$

$\mathrm{X} \quad \mathrm{X} \quad \mathrm{x}$ X

$\mathrm{x} \quad \mathrm{x}$

$\mathrm{x}$

$x$

$\mathrm{X}$

$\mathrm{X}$

$\mathrm{X}$

$\mathrm{x}$

$\mathrm{X}$

$x$

$\mathrm{X}$

$\mathrm{X}$

$\mathrm{X}$

$\mathrm{X}$

$\mathrm{X}$

$\mathrm{X}$

$\mathrm{X}$

$\mathrm{X}$

$\mathrm{X} \quad \mathrm{x}$

$\mathrm{x}$

$\mathrm{x}$

$\mathrm{x}$

$x$

$\mathrm{x}$

$x$

$\begin{array}{ccccccccc}\mathrm{X} & \mathrm{X} & \mathrm{X} & \mathrm{X} & \mathrm{X} & \mathrm{X} & \mathrm{X} & \mathrm{X} & \mathrm{x} \\ \mathrm{X} & \mathrm{X} & \mathrm{X} & \mathrm{X} & \mathrm{X} & \mathrm{X} & \mathrm{X} & \mathrm{X} & \mathrm{x}\end{array}$

$\begin{array}{lllllllll}\mathrm{X} & \mathrm{X} & \mathrm{X} & \mathrm{X} & \mathrm{X} & \mathrm{X} & \mathrm{X} & \mathrm{x} & \mathrm{x}\end{array}$

$6 \cdot 7 \cdot 3 \cdot 3$

Graph and Table

Requirements

$\mathrm{X} \quad \mathrm{X}$
6.8 PANEL LAYOUT
$6.8 \cdot 1$
General Panel
Layout 
HUMAN FACTORS

ENGINEERING GUIDELINES
Title

section

Number

6.8 .1 .1 Assigning Panel $\mathrm{X}$ Contents

6.8.1.2 Effective Panel $X$ Layout

6.8.1.3 Enhancing Recognition and $\mathrm{X}$ Identification

6.8 .2

Layout

Arrangement

Factors

$6 \cdot 8 \cdot 2 \cdot 1$

Sequence, Frequency of Use, $\mathrm{X} \quad \mathrm{X}$ and Functional Considerations

6.8.2.2 Logical

Arrangement and

$\mathrm{X}$

MCR SPDS RRSF RRSS EDGC VES ECIS CHSS RWMC

\begin{tabular}{|c|c|c|c|c|c|c|c|c|c|c|}
\hline (2) & $\begin{array}{l}\text { Frequency of Use, } \\
\text { and Functional } \\
\text { Considerations }\end{array}$ & 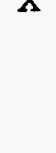 & 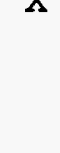 & 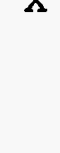 & 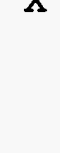 & 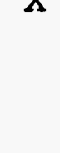 & 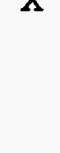 & & & \\
\hline 6.8 .2 .2 & $\begin{array}{l}\text { Logical } \\
\text { Arrangement and } \\
\text { Layout }\end{array}$ & $\mathrm{x}$ & $\mathrm{x}$ & $\mathrm{X}$ & $\mathrm{X}$ & $\mathrm{X}$ & $\mathrm{X}$ & $\mathrm{X}$ & $\mathrm{X}$ & $\mathrm{x}$ \\
\hline 6.8 .2 .3 & Layout Consistency & $\mathrm{X}$ & $\mathrm{X}$ & $\mathrm{X}$ & $\mathrm{X}$ & $\mathrm{X}$ & $\mathrm{X}$ & $\mathrm{X}$ & $\mathrm{X}$ & $\mathrm{x}$ \\
\hline 6.8 .2 .4 & standardization & $\mathrm{X}$ & & $\mathrm{X}$ & & & & & & \\
\hline $6.8 \cdot 3$ & $\begin{array}{l}\text { Specific Panel } \\
\text { Layout Design }\end{array}$ & & & & & & & & & \\
\hline $6.8 \cdot 3.1$ & $\begin{array}{l}\text { Separation of } \\
\text { Controls }\end{array}$ & $\mathrm{X}$ & $\mathrm{X}$ & $\mathrm{X}$ & $\mathrm{X}$ & $\mathrm{X}$ & $\mathrm{X}$ & $\mathrm{X}$ & $\mathrm{X}$ & $\mathrm{X}$ \\
\hline $6.8 \cdot 3 \cdot 2$ & $\begin{array}{l}\text { Strings or } \\
\text { clusters of } \\
\text { similar } \\
\text { Components }\end{array}$ & $\mathrm{X}$ & $\mathrm{X}$ & $\mathrm{X}$ & $\mathrm{X}$ & $\mathrm{X}$ & $\mathrm{X}$ & $\mathrm{X}$ & $\mathrm{X}$ & $\mathrm{x}$ \\
\hline $6 \cdot 8 \cdot 3 \cdot 3$ & Mirror-Imaging & $\mathrm{X}$ & & $\mathrm{X}$ & & & & & & \\
\hline $\begin{aligned} 6.9 & \text { CON } \\
& \text { INT }\end{aligned}$ & LL-DISPLAY & & & & & & & & & \\
\hline
\end{tabular}




\section{HUMAN FACTORS}

ENGINEERING GUIDELINES
MCR SPDS RRSF RRSS EDGC VES ECIS CHSS RWMC

section Title

Number

$6.9 .1 \quad$ Basic Control-

Display

Relationships

$\begin{array}{llllllllllllllll}6.9 .1 .1 & \text { Single control } & x & x & x & X & x & X & X & x & x\end{array}$ and Display Pairs

$\begin{array}{llllllllllllll}6.9 .1 .2 & \text { Multiple Controls } & X & X & X & X & X & X & X & X & X\end{array}$ or Displays

6.9.2 Groups of Controls

and Displays

6.9.2.1 Location and

Arrangement of

Control-Display

Groups

6.9.2.2 Single Panel

Arrangements

6.9.2.3 Controls and

Displays in

Separate Planes

6.9.3 Dynamic Control-

Display

Relationships

6.9 .3 .1 General Movement

Relationships

6.9.3.2 Control-Display

Ratio

$\begin{array}{llllllllll}\mathrm{X} & \mathrm{X} & \mathrm{X} & \mathrm{X} & \mathrm{X} & \mathrm{X} & \mathrm{X} & \mathrm{X} & \mathrm{X}\end{array}$

$\begin{array}{lllllllll}X & X & X & X & X & x & x & x & x\end{array}$

$\mathrm{X} \quad \mathrm{X}$

$\begin{array}{llllllllll} & X & X & X & X & X & X & X & X & X\end{array}$ 
HUMAN FACTORS

ENGINEERING GUIDELINES

Title

section

MCR SPDS RRSF RRSS EDGC VES ECIS CHSS RMMC

Number

\section{ACRDR GUIDELINES}

1. INFORMATION DISPLAY

1.1 Screen Organization and Layout

$\begin{array}{llllllllllllll}1.1 .1 & \text { General } & X & X & X & X & X & X & X & X & X\end{array}$

$\begin{array}{lllllllllllll}1.1 .2 & \text { Multiple Pages } & X & X & X & X & X & X & X & X & X\end{array}$

$\begin{array}{llllllllllllll}\text { 1.1.3 } & \text { Grouping } & X & X & X & X & X & X & X & X & X\end{array}$

$\begin{array}{lllllllllllll}1.1 .4 & \text { Windows } & X & X & X & X & X & X & X & X & X\end{array}$

$\begin{array}{llllllllllllll}1.1 .5 & \text { Message Areas } & X & X & X & X & X & X & X & X & X\end{array}$

$\begin{array}{lllllllllllllllll}1.1 .6 & \text { Command Areas } & X & X & X & X & X & X & X & X & X\end{array}$

$\begin{array}{lllllllllllllll}1.1 .7 & \text { General } & X & X & X & X & X & X & X & X & X\end{array}$

Information

Areas

1.2 Information Format

$\begin{array}{llllllllllllll}1.2 .1 & \text { Dynamic Displays } & \mathrm{X} & \mathrm{X} & \mathrm{X} & \mathrm{X} & \mathrm{X} & \mathrm{X} & \mathrm{X} & \mathrm{X} & \mathrm{X}\end{array}$

1.2.2 Cursor

1.2.2.1 General

$\begin{array}{llllllllll}\mathrm{X} & \mathrm{X} & \mathrm{X} & \mathrm{X} & \mathrm{X} & \mathrm{X} & \mathrm{X} & \mathrm{X} & \mathrm{X}\end{array}$

1.2.2.2 Shape and Type

$\begin{array}{lllllllll}\mathrm{X} & \mathrm{X} & \mathrm{X} & \mathrm{X} & \mathrm{X} & \mathrm{X} & \mathrm{X} & \mathrm{X} & \mathrm{X}\end{array}$

1.2.2.3 Location and

Positioning

1.2.2.4 Control

1.2.3 Text, style,

and Characters

$\begin{array}{lllllllllll}x & x & x & x & x & x & x & x & x\end{array}$

1.2 .4

Labels 
HUMAN FACTORS

ENGINEERING GUIDELINES

section

Title

MCR SPDS RRSF RRSS EDGC VES ECIS CHSS RTMC

\section{Number}

\begin{tabular}{|c|c|c|c|c|c|c|c|c|c|}
\hline 1.2 .4 .1 & $\begin{array}{l}\text { Data Display: } \\
\text { General }\end{array}$ & $x$ & $\mathrm{X}$ & $\mathrm{X}$ & $\mathrm{x}$ & $\mathrm{X}$ & $\mathrm{X}$ & $\mathrm{x}$ & $\mathrm{x}$ \\
\hline 1.2 .4 .2 & $\begin{array}{l}\text { Scaling, Graphs, } \\
\text { Bar Charts, and }\end{array}$ & $\mathrm{x}$ & $\mathrm{X}$ & $\mathrm{x}$ & $\mathrm{x}$ & $\mathrm{x}$ & $\mathrm{x}$ & $\mathrm{X}$ & $\mathrm{x}$ \\
\hline
\end{tabular}
Histograms

1.2.4.3 Windows

1.2.4.4 Display Control

1.2.4.5 Flow charts

1.2.4.6 Functions Keys

1.2 .4 .7

Pictures,

Drawings, Maps,

and situation

Displays

1.2.4.8 Menus

1.2.4.9 Pie charts

1.2.4.10 Tables

1.2.4.11 Data Entry

1.2.5 Tables and Lists

1.2.6 Data Forms

1.2.7 Mimics

1.2.8 Graphics

1.2.8.1 General

1.2.8.2 Flow Charts

1.2.8.3 Pictures and

Diagrams

$\begin{array}{llllllllll}X & X & X & X & X & x & x & x & x\end{array}$

$\begin{array}{llllllll}X & x & x & x & x & x\end{array}$

$\begin{array}{lllllllll}X & X & x & x & x & x & x\end{array}$

$\begin{array}{llllllllll}x & x & x & x & x & x & x & x & x\end{array}$

$\mathrm{X} X$

$\mathrm{X}$

X 


\section{Number}

1.2 .8 .4 Maps and

$\mathrm{X}$

Situation

$\mathrm{X}$

Displays

1.2.8.5 Instrument

Panels

1.2 .8 .6 Icons

1.2.8.7 Scaling

1.2.8.8 Curves and

Line Graphs

$\mathrm{X} \quad \mathrm{X}$

$\begin{array}{lllll}\mathrm{X} & \mathrm{X} & \mathrm{X} & \mathrm{X}\end{array}$

$1.2 .8 \cdot 9$

Bar/Column Graphs and Histograms

1.2.8.10 Pie Charts

1.2.8.11 Scatterplots

$\begin{array}{llllllllll}\mathrm{X} & \mathrm{X} & \mathrm{X} & \mathrm{X} & \mathrm{X} & \mathrm{X} & \mathrm{X} & \mathrm{X} & \mathrm{X}\end{array}$

$\begin{array}{lllllllll}\mathrm{X} & \mathrm{X} & \mathrm{X} & \mathrm{X} & \mathrm{X} & \mathrm{X} & \mathrm{X} & \mathrm{X} & \mathrm{X}\end{array}$

$\begin{array}{lllllllll} & x & X & x & x & x & x & x\end{array}$

\section{3 coding}

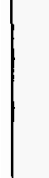

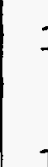
1.

\section{1}




\section{3 .3 .2 Brightness Intensity}

1.3.3.3 Color

1.3.3.4 Flash/Blinking

1.3.3.5 Image Reversal

1.3.3.6 Line

1.3.3.7 Shapes and Symbols

1.3.3.8 Size

1.3 .3 .9 Spatial/Position/ Pattern/Location

$1.3 \cdot 3 \cdot 10$ Texture, Focus, and Motion

2. OPERATOR INPUT

2.1 Entering Information

2.1 .

2.1 .3

2.1 .4

2.1 .5

2.1 .6

2.1 .7

$2 \cdot 1 \cdot 7.1$ General

$\mathrm{x} \quad \mathrm{x}$

$\mathrm{X} \quad \mathrm{X} \quad \mathrm{X}$

$\mathrm{X} \quad \mathrm{X} \quad \mathrm{X}$

$\mathrm{X} \quad \mathrm{X} \quad \mathrm{X}$

$\mathrm{X} \quad \mathrm{X} \quad \mathrm{X}$

$\mathrm{X} \quad \mathrm{X}$

$\mathrm{x} \quad \mathrm{x}$

$\mathrm{x} \quad \mathrm{x}$

$\mathrm{x} \quad \mathrm{x}$

$\mathrm{x} \quad \mathrm{X}$

$\mathrm{x}$

$\mathrm{x}$

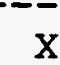

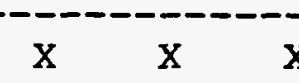

$\mathrm{x} x \mathrm{x}$ $\begin{array}{lllll}x & x & x & x\end{array}$ $\begin{array}{llllll}x & x & x & x & x\end{array}$ $\begin{array}{llllll}x & x & x & x & x\end{array}$ $\begin{array}{llllll}x & x & x & x & x\end{array}$ $\begin{array}{llllll}X & X & X & X & X & X\end{array}$ $\begin{array}{lllllllllll}x & x & x & x & x & x & x\end{array}$ $\begin{array}{lllllll}x & x & x & x & x & x & x\end{array}$ 
HUMAN FACTORB

ENGINEERING GUIDELINES
MCR SPDS RRSF RRSS EDGC VES ECIS CHSS RTMC

section

Title

Number

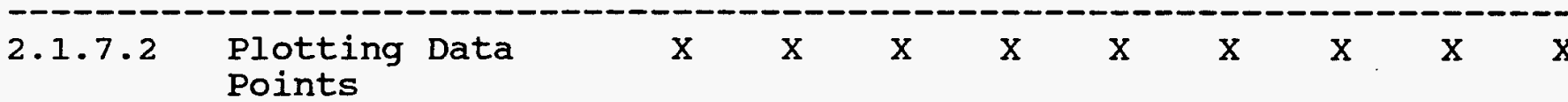

2.1.7.3 Drawing Lines and Figures

2.1 .8

Data Validation

$\mathrm{X}$

$\mathrm{x}$

$\mathrm{x}$

$\mathrm{X}$

2.2 Operator Dialogue

2.2 .1

2.2 .2

2.2 .3

2.2 .4

$2 \cdot 2 \cdot 5$

$2 \cdot 2 \cdot 5.1$

General

Sequence Control

Transaction

Selection

Transaction

Interrupts

Transaction

Dialogue

2.2 .5 .2

$2 \cdot 2 \cdot 5 \cdot 3$

Direct

Manipulation/

Graphic

Interaction

2.2.5.4 Forms

2.2.5.5 Function Keys

2.2.5.6 Macros and

Programmable

Function Keys

2.2.5.7 Menu Selection

$\mathrm{x} \quad \mathrm{x}$

$\begin{array}{lllllllll}X & X & X & X & X & X & X & X & X\end{array}$

$\begin{array}{lllllllll}\mathrm{X} & \mathrm{X} & \mathrm{X} & \mathrm{X} & \mathrm{X} & \mathrm{X} & \mathrm{X} & \mathrm{X} & \mathrm{X}\end{array}$

$\mathrm{X} \quad \mathrm{X} \quad \mathrm{x}$

$\mathrm{x}$

$\begin{array}{llllll}\mathrm{X} & \mathrm{X} & \mathrm{X} & \mathrm{X} & \mathrm{X}\end{array}$ 
HUMAN FACTORS

ENGINEERING GUIDELINES
MCR SPDS RRSF RRSS EDGC VES ECIS CHSS RWMC

section

Title

Number

2.2.5.8 Natural Language $x \quad x \quad x \quad x \quad x \quad x \quad x \quad x \quad x$

$\begin{array}{llllllllllll}2.2 .5 .9 & \text { Query Language } & X & X & X & X & X & X & X & X & X\end{array}$

$\begin{array}{llllllllllll}2.2 .5 .10 & \text { Question and Answer } \mathrm{X} & \mathrm{X} & \mathrm{X} & \mathrm{X} & \mathrm{X} & \mathrm{X} & \mathrm{X} & \mathrm{X} & \mathrm{X}\end{array}$

3. CONTROL/DISPLAY

INTEGRATION

$\begin{array}{llllllllllllll}3.1 & \text { System Response } & T \text { ime } & X & X & X & X & X & X & X & X & X\end{array}$

$\begin{array}{lllllllllllll}3.2 & \text { Input from the User } & x & x & X & X & x & x & x & x & x\end{array}$

3.3 Information

Manipulation

3.3.1 Saving and Exiting $\mathrm{x} \quad \mathrm{x} \quad \mathrm{x}$ Files

3.3.2 Clipboard/

Temporary Editing

$\mathrm{X} \quad \mathrm{X} \quad \mathrm{X}$

Buffer

$\begin{array}{lllll}3.3 .3 & \text { Scrapbook/Excerpt } & X & X & X\end{array}$ File

3.3.4 Retrieval Buffer $X \quad X \quad X$

$\mathrm{x}$

$\mathrm{X}$

3.3.5 Print Que $x \quad x$

3.4 Display Control

$\begin{array}{llllllllllllll}3.4 .1 & \text { General } & X & X & X & X & X & X & X & X & X\end{array}$

$\begin{array}{llllllllllllll}\text { 3.4.2 Display Freeze } & X & X & X & X & x & X & X & X & x\end{array}$

$\begin{array}{llllllllllll}\text { 3.4.3 Display selection } & x & x & x & x & x & x & x & x & x\end{array}$

3.4 .4

Display

Suppression

$\mathrm{x} \quad \mathrm{x} \quad \mathrm{x}$

$\mathrm{X} \quad \mathrm{X}$

3.4 .5

Display Update

$\mathrm{X}$

$\mathrm{X}$

$\mathrm{X}$

$\mathrm{X}$ 
HUMAN FACTORS

ENGINEERING GUIDELINES

\section{section}

Number

-- - - - - - - - - - - -

3.4 .6

Hypertext

3.4 .7

Paging

3.4 .8

scrolling

3.4 .9

Pan and Zoom

3.4 .10

searching

3.4 .11

on-screen

Controls

4. OPERATORS AIDS

4.1 Prompts, Alarms

and Messages

4.1.1 Prompts

4.1 .2

Cautions and

Alarms

$4 \cdot 1 \cdot 3$

System Messages

Operator

$4 \cdot 2$

Guidance

4.2.1 General

4.2 .2

status Information$$
4
$$

.

4

MCR SPDS RRSF RRSS EDGC VES ECIS CHSS RWMC 
HUMAN FACTORS

ENGINEERING GUIDELINES
MCR SPDS RRSF RRSS EDGC VES ECIS CHSS RWMC

section

Title

Number

$\begin{array}{ll}4.2 .7 & \text { On-line } \\ & \text { Assistance }\end{array}$

4.2.7.1 General

$\mathrm{X} \quad \mathrm{X} \quad \mathrm{X}$

4.2.7.2 Help

$\mathrm{X} \quad \mathrm{X} \quad \mathrm{X}$

4.2.7.3 Training

$\mathrm{X} \quad \mathrm{X}$

4.3 Decision Aids

4.3.1 Expert Systems

4.3.1.1 General

$\mathrm{X} \quad \mathrm{X}$

4.3.1.2 Dialogue

$\mathrm{X} \quad \mathrm{X}$

$\mathrm{X}$

4.3.1.3 Planning and

Consultation

$\mathrm{X} x$

$4 \cdot 3 \cdot 1 \cdot 4$

Expert system

Display

$\mathrm{X} \quad \mathrm{X}$

$\mathrm{X}$

4.3.1.5 Certainty Factors $x$

$\mathrm{x}$

4.3.1.6 Explanation

$\mathrm{X} \quad \mathrm{X}$

$\mathrm{X}$

Facilities

$4 \cdot 3 \cdot 2$

Other Decision

Aids

$\begin{array}{lllllllll}\mathrm{X} & \mathrm{X} & \mathrm{X} & \mathrm{X} & \mathrm{X} & \mathrm{X} & \mathrm{X} & \mathrm{X} & \mathrm{X}\end{array}$

5. INTER-OPERATOR

COMMUNICATION

5.I Preparing and sending Messages

$\begin{array}{lllll}5.1 .1 & \text { General } & \text { X } & \text { X } & \text { X } \\ 5.1 .2 & \begin{array}{l}\text { Preparing } \\ \text { Messages }\end{array} & \text { X } & \text { X } & \text { X }\end{array}$


HUMAN FACTORS

ENGINEERING GUIDELINES

\section{Title \\ Section \\ Number}

MCR SPDS RRSF RRSS EDGC VES ECIS CHSS RTMC

\begin{tabular}{|c|c|c|c|c|c|c|c|c|c|c|}
\hline 5.1 .3 & $\begin{array}{l}\text { Addressing } \\
\text { Messages }\end{array}$ & $\mathrm{x}$ & $\mathrm{X}$ & $\mathrm{X}$ & & & & & & \\
\hline 5.1 .4 & $\begin{array}{l}\text { Initiating } \\
\text { Transmission }\end{array}$ & $\mathrm{X}$ & $\mathrm{X}$ & $x$ & & & & & & \\
\hline 5.1 .5 & $\begin{array}{l}\text { Controlling } \\
\text { Transmission }\end{array}$ & $\mathrm{X}$ & $\mathrm{X}$ & $\mathrm{x}$ & & & & & & \\
\hline 5.2 & $\begin{array}{l}\text { Monitoring and } \\
\text { Receiving Messages }\end{array}$ & & & & & & & & & \\
\hline 5.2 .1 & $\begin{array}{l}\text { Receiving } \\
\text { Messages }\end{array}$ & $\mathrm{X}$ & $\mathrm{X}$ & $x$ & & & & & & \\
\hline 6. & $\begin{array}{l}\text { INFORMATION } \\
\text { PROTECTION }\end{array}$ & & & & & & & & & \\
\hline 6.1 & $\begin{array}{l}\text { Error Prevention } \\
\text { and Correction }\end{array}$ & & & & & & & & & \\
\hline 6.1 .1 & $\begin{array}{l}\text { Data Entry/ } \\
\text { Change/Loss }\end{array}$ & $\mathrm{X}$ & $\mathrm{X}$ & $\mathrm{X}$ & $x$ & $\mathrm{X}$ & $\mathrm{X}$ & $\mathrm{X}$ & $x$ & $\mathrm{X}$ \\
\hline 6.2 & Computer security & & & & & & & & & \\
\hline 6.2 .1 & General & $\mathrm{x}$ & & & & & & & & \\
\hline 6.2 .2 & $\begin{array}{l}\text { Operator } \\
\text { Identification }\end{array}$ & $\mathrm{x}$ & $\mathrm{x}$ & $x$ & $x$ & $\mathrm{x}$ & $x$ & $\mathrm{X}$ & $\mathrm{X}$ & $\mathrm{x}$ \\
\hline $6 \cdot 2 \cdot 3$ & Data Access & $\mathrm{X}$ & & & & & & & & \\
\hline 6.2 .4 & Data Transmission & $\mathrm{x}$ & $\mathrm{x}$ & $\mathrm{x}$ & & & & & & \\
\hline 7 & WORKSTATION DESIGN & & & & & & & & & \\
\hline $7.1 \quad I$ & Display Devices & & & & & & & & & \\
\hline 7.1 .1 & $\begin{array}{l}\text { Visual Display } \\
\text { Terminals }\end{array}$ & & & & & & & & & \\
\hline
\end{tabular}


HUMAN FACTORS

ENGINEERING GUIDELINES
MCR SPDS RRSF RRSS EDGC VES ECIS CHSS RWMC

section

Title

Number

7.1.1.1 General

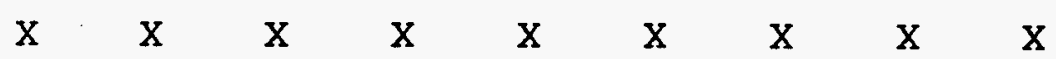

7.1.1.2 CRT

$\begin{array}{llllllllll}X & X & X & X & X & X & X & X & X\end{array}$

7.1.1.3 Liquid Crystal

$\begin{array}{llllllllll}\mathrm{X} & \mathrm{X} & \mathrm{X} & \mathrm{X} & \mathrm{X} & \mathrm{X} & \mathrm{X} & \mathrm{X} & \mathrm{X}\end{array}$

7.1.1.4 Plasma

$\begin{array}{llllllllll}\mathrm{X} & \mathrm{X} & \mathrm{X} & \mathrm{X} & \mathrm{X} & \mathrm{X} & \mathrm{X} & \mathrm{X} & \mathrm{X}\end{array}$

$7.1 \cdot 1 \cdot 5$

Electrochromic

$\mathrm{X} \quad \mathrm{X}$

7.1 .1 .6

Electrophoretic

$\mathrm{X} \quad \mathrm{X} \quad \mathrm{X}$

$\mathrm{X}$

$\mathrm{X}$

$\mathrm{X} \quad \mathrm{X} \quad \mathrm{X} \quad \mathrm{X}$

$7 \cdot 1 \cdot 1 \cdot 7$

Electroluminescent Displays

7.1 .1 .8

Light Emitting

Diodes

7.1 .1 .9

Large Screen

Displays

$\mathrm{X}$

$\mathrm{x} \quad \mathrm{x}$

$\mathrm{X}$

$\mathrm{X}$

$\mathrm{X}$

$\mathrm{X} \quad \mathrm{X}$

$\begin{array}{lllll}\mathrm{X} & \mathrm{X} & \mathrm{X} & \mathrm{X}\end{array}$

7.1 .2

Audio and Voice

Displays

7.1.2.1 Speech

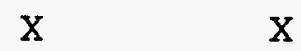

7.1.2.2 Non-Speech

Audio Devices

$\mathrm{X} \quad \mathrm{X} \cdot \mathrm{X}$

$\mathrm{X}$

$7 \cdot 1 \cdot 2$.

Control of

$\mathrm{X} \quad \mathrm{X} \quad \mathrm{X}$

$\mathrm{X}$

Audio Devices

7.1.2.4 Speech

Communication

$\mathrm{X}$

$\mathrm{x}$

$\mathrm{X}$

$\mathrm{X}$

$\mathrm{X} \quad \mathrm{X} \quad \mathrm{X} \quad \mathrm{X}$

Equipment

7.1 .3

Projection

Devices

7.1.3.1 Front Projection $\mathrm{x}$ Devices

$\mathrm{X}$ 


\section{HUMAN FACTORS}

ENGINEERING GUIDELINES

Title

section

MCR SPDS RRSF RRSS EDGC VES ECIS CHSS RTMC

\section{Number}

$\begin{array}{llll}7.1 .3 .2 & \begin{array}{l}\text { Back Projection } \\ \text { Devices }\end{array} & \mathrm{X} & \mathrm{X} \\ 7.1 .3 .3 & \begin{array}{l}\text { Large Screen } \\ \text { Optical } \\ \text { Projection } \\ \text { Devices }\end{array} & \mathrm{X} & \\ 7.1 .4 & \text { Printers } & & \\ 7.1 .4 .1 & \text { General } & \mathrm{X} & \mathrm{X} \\ 7.1 .4 .2 & \text { Dot Matrix } & \mathrm{X} & \mathrm{X} \\ 7.1 .4 .3 & \text { Laser } & \mathrm{X} & \mathrm{X} \\ 7.1 .4 .4 & \text { Daisy Wheel } & \mathrm{X} & \mathrm{X} \\ 7.1 .4 .5 & \text { Thermal } & \mathrm{X} & \mathrm{X} \\ 7.1 .4 .6 & \text { Ink Jet } & \mathrm{X} & \mathrm{X} \\ 7.1 .5 & \text { Plotters } & \mathrm{X} & \mathrm{X}\end{array}$

7.2 Control Devices

7.2.1 Keyboards

$\begin{array}{llllllllllllll}7.2 .1 .1 & \text { General } & X & X & X & X & X & X & X & X & X\end{array}$

Guidelines

for Keyboards

7.2.1.2 Special

Function Keys

7.2.1.3 Displacement Keyboards

7.2.1.4 Membrane Keyboards

\section{$\mathrm{X}$}

$\mathrm{X}$

$\mathrm{X}$

$\mathrm{X}$

$x$

$\mathrm{X}$

$\mathrm{X}$

$\mathrm{X}$

$x$ 
HUMAN FACTORS

ENGINEERING GUIDELINES
MCR SPDS RRSF RRSS EDGC VES ECIS CHSS RWMC

\section{section \\ Number \\ Title}

$7.2 .2 \quad$ Direct

Manipulation

Controls

$\begin{array}{llllllllllllllllllll}\text { 7.2.2.1 General Guidelines } & X & X & X & X & X & X & X & X & X\end{array}$ for Direct Manipulation

Controls

7.2.2.2 X-Y Controllers

$\begin{array}{llllllllllllll}7.2 .2 .2 .1 & \text { Track Balls } & X & X & X & X & X & X & X & X & X\end{array}$

$\begin{array}{lllllllllllllll}7.2 .2 .2 .2 & \text { Mice } & X & X & X & X & X & X & X & X & X\end{array}$

$7.2 .2 .2 .3 \quad$ Joysticks

$\begin{array}{llllllllllllll}7.2 .2 .2 .3 .1 & \text { Force } & X & X & X & X & X & X & X & X & X\end{array}$

(Isometric)

$\begin{array}{lllllllllllllll}7.2 .2 .2 .3 .2 & \text { Displacement } & X & X & X & X & X & X & X & X & X\end{array}$ (Isotonic)

Joysticks

7.2.2.3 Direct Pointing

Controllers

$7.2 \cdot 2 \cdot 3 \cdot 1$

Direct

Pointing

Controller

General

Guidelines

\begin{tabular}{|c|c|c|c|c|c|c|c|c|c|}
\hline 7.2 .2 .3 .2 & Touch Screen & $\mathrm{X}$ & $\mathrm{X}$ & $\mathrm{X}$ & $\mathrm{X}$ & $x$ & $\mathrm{X}$ & $\mathrm{X}$ & $\mathrm{X}$ \\
\hline $7 \cdot 2 \cdot 2 \cdot 3 \cdot 3$ & Light Pen & $\mathrm{X}$ & $\mathrm{X}$ & $\mathrm{X}$ & $\mathrm{x}$ & $\mathrm{x}$ & $\mathrm{x}$ & $\mathrm{x}$ & $\mathrm{X}$ \\
\hline $7.2 \cdot 2 \cdot 3 \cdot 4$ & $\begin{array}{l}\text { Graphic } \\
\text { Tablet-Grid } \\
\text { and Stylus } \\
\text { Devices }\end{array}$ & $\mathrm{X}$ & $\mathrm{x}$ & $\mathrm{x}$ & $\mathrm{x}$ & $\mathrm{X}$ & $\mathrm{x}$ & $\mathrm{x}$ & $\mathrm{x}$ \\
\hline
\end{tabular}


HUMAN FACTORS

ENGINEERING GUIDELINES

section

Number

$7.2 .2 .3 \cdot 5$

Touch Pad

Title

MCR SPDS RRSF RRSS EDGC VES ECIS CHSS RWMC

7.2.2.4 other controllers

$7.2 \cdot 2 \cdot 4 \cdot 1$

General

$\mathrm{X}$

$\mathrm{X}$

$7.2 \cdot 2 \cdot 4 \cdot 2$

Multi-degree

$\mathrm{X}$

of Freedom

Hand

Controllers

$7 \cdot 2 \cdot 2 \cdot 4 \cdot 3$

Glove

$\mathrm{X}$

Controllers

$7 \cdot 2 \cdot 2 \cdot 4 \cdot 4$

Eye

Controllers

$\mathrm{X}$

$7.2 \cdot 2 \cdot 4 \cdot 5$

Head

Movement

$\mathrm{X}$

$\mathrm{X}$

Controllers

7.3 Workstation Configuration

7.3.1 Workstation

Integration

$\begin{array}{lllllllll}\mathrm{X} & \mathrm{X} & \mathrm{X} & \mathrm{X} & \mathrm{X} & \mathrm{X} & \mathrm{X} & \mathrm{X} & \mathrm{X}\end{array}$

7.3.2 Support Devices

$\begin{array}{llllllllll}\mathrm{X} & \mathrm{X} & \mathrm{X} & \mathrm{X} & \mathrm{X} & \mathrm{X} & \mathrm{X} & \mathrm{X} & \mathrm{X}\end{array}$

$7 \cdot 3 \cdot 3$

Workplace

Integration

$\begin{array}{lllllllllll}\mathrm{X} & \mathrm{X} & \mathrm{X} & \mathrm{X} & \mathrm{X} & \mathrm{X} & \mathrm{X} & \mathrm{X} & \mathrm{X}\end{array}$

7.3.4 Environment

7.3.4.1 Glare

7.3.4.2 Static

Electricity

$\begin{array}{ccccccccc}\mathrm{X} & \mathrm{X} & \mathrm{X} & \mathrm{X} & \mathrm{X} & \mathrm{x} & \mathrm{x} & \mathrm{x} & \mathrm{x} \\ \mathrm{X} & \mathrm{X} & \mathrm{x} & \mathrm{x} & \mathrm{x} & \mathrm{x} & \mathrm{x} & \mathrm{x} & \mathrm{x}\end{array}$


APPENDIX F:

NUMBERS AND TITLES OF THE MODIFIED ACRDR GUIDELINES 


\section{TABLE OF CONTENTS}

1.2.2 Data forms

1.2.4.2 Flowcharts

1.3.3 Text, style, Character

1.3.4.2 Scaling, Graphs, Barcharts and Histograms

1.3.4.5 Flowcharts

2.3 .10 On-Screen Controls

4.1.10 On-Line Assistance

4.1.10.1 Help

4.1.10.2 On-Line Training

7.1.1.6 Electrophoretic

7.1.3.4 Daisy wheel

7.1.5.2 Non-speech audio displays

7.1.5.3 Control of audio displays

7.1.5.4 Speech communication equipment

7.2.4.2 Multi-DOF Handcontrollers

SECTION 1
$1 \cdot 1 \cdot 1-1$
Necessary Data Displayed
$1 \cdot 1 \cdot 1-2$
Consolidation of Information
$1.1 \cdot 1-3$
Reserved Screen Areas
$1.1 \cdot 1-4$
Invariant Display Fields
$1 \cdot 1 \cdot 1-5$
Variant Display Fields
$1 \cdot 1 \cdot 1-6$
$1 \cdot 1 \cdot 1-7$
Data Displayed in Usable Form
$1.1 \cdot 1-8$
Data Display Consistent with User Conventions
$1 \cdot 1 \cdot 1-9$
Establishing Display standards
$1 \cdot 1 \cdot 1-10$
Consistent Display Format
$1.1 \cdot 1-11$
$1 \cdot 1 \cdot 1-12$
$1 \cdot 1 \cdot 1-13$
$1 \cdot 1 \cdot 1-14$
$1 \cdot 1 \cdot 1-15$
$1 \cdot 1 \cdot 1-16$
$1 \cdot 1 \cdot 1-17$
$1 \cdot 1 \cdot 1-18$
$1.1 \cdot 1-19$
$1 \cdot 1 \cdot 1-20$
$1.1 \cdot 1-21$
$1.1 \cdot 1-22$
$1.1 \cdot 1-23$
Display Consistent with Entry Requirements
User Control of Data Display
Protection of Displayed Data
Context for Displayed Data
Familiar Wording
Consistent wording
Consistent Wording Across Displays
Consistent Grammatical Structure
Uncluttered Display Screens
Information Density
Screen Packing Density
Display of Information
$1.1 \cdot 1-24$
Hardcopy Request
Date/Time Annotation
$1.1 \cdot 1-25$
$1 \cdot 1 \cdot 1-26$
$1.1 \cdot 1-27$
Display Background
Display Background Contrast
Display Background Color
Frame Identification
$1 \cdot 1 \cdot 1-28$
$1 \cdot 1 \cdot 1-29$
Frame Identifier Demarcation
$1 \cdot 1 \cdot 1-30$
Consistent Format Organization
$1 \cdot 1 \cdot 1-31$
Design to Highlight Differences
Hierarchy of Titles 
$1.1 .1-32$

$1 \cdot 1 \cdot 1-33$

1.1.2-1

1. $1.2-2$

1. $1.2-3$

$1.1 .2-4$

1. $1.2-5$

$1.1 .2-6$

1.1.2-7

1.1.2-8

1.1.2-9

1. $1.2-10$

1.1.2-11

1. 1. 2-12

1. $1.2-13$

1. $1.2-14$

1.1.2-15

$1.1 .2-16$

1. $1.2-17$

1. $1.2-18$

1. 1.2-19

$1 \cdot 1 \cdot 2-20$

$1.1 .3-1$

$1 \cdot 1 \cdot 3-2$

$1.1 .3-3$

$1.1 .3-4$

$1.1 .3-5$

$1.1 \cdot 3-6$

$1 \cdot 1 \cdot 3-7$

$1.1 \cdot 3-8$

$1 \cdot 1 \cdot 3-9$

1. $1.3-10$

$1 \cdot 1 \cdot 3-11$

1. $1.3-12$

1. $1.3-13$

1. $1.3-14$

$1 \cdot 1 \cdot 3-15$

1.1.4.1-1

1.1.4.1-2

$1.1 .4 .1-3$

$1.1 .4 .1-4$

$1.1 .4 .1-5$

1.1.4.2-1

1.1.4.2-2

1.1.4.2-3

1.1. 4.2-4

$1.1 .4 .2-5$

$1 \cdot 1 \cdot 4 \cdot 2-6$

$1.1 \cdot 4 \cdot 2-7$

$1.1 .4 \cdot 2-8$

$1.1 .4 \cdot 2-9$

$1.1 .4 \cdot 2-10$
Distinctive Display Elements

Flexible Design for Data Display

Important Information Displayed First

Minimize Memory Load

Continuous Numbering in Multipage Lists

Labels for Multipage Tables

Annotating Display of Continued Data

Numbering Display Pages

Data Partitioning on Crowded Displays

Related Data on Same Page

Temporal Proximity of Data

Position Reference for Sequential Displays

Temporally Discontinuous Displays

Accessing Information Across Applications

Position within Functional Hierarchy

Navigation Through Functional Hierarchy

Sequential Steps on Multipage Displays

Multitasking Independent Tasks

Multitasking Dependent Tasks

Menu Accessibility

on-Screen Help for continuing

Navigation Messages

Grouping for Data Comparison

Group Data to Support Task Completion

Data Grouped by Sequence of Use

Data Grouped by Function

Data Grouped by Importance

Data Grouped by Frequency

Data Grouped Alphabetically or Chronologically

Demarcation of Groups

Grouping Within High Density Displays

Spacing as a Redundant Demarcation Technique

Combining Dissimilar Data Groups

Within Group Arrangement

Facilitation of Perceptual structure

Spacing to Structure Displays

Group Size

Appropriate Use of Windows

window Functions

Selection of window Functions

Consistent window control

Keeping Track of Open Windows

window Demarcation

window Design

Default window size consistent with content

Default Window size for Scanning Data

Window Default Width

Nondestructive Overlay

Distinction Between window Types

Tiled vs. Layered Windows

Tile Default for Multiple windows

Layered Windows as Default 
1.1.4.2-11 Prioritization of Interactive Windows

1.1.4.2-12 Prioritization of Caution and Warning windows

1.1.4.2-13 Prioritization of Active Windows During Multitasking

1.1.4.3-1 Movable Windows

1.1.4.3-2 Smooth Window Movement

1.1.4.3-3 critical Function Area obscurement

1.1.4.3-4 Moving Windows off Display

1.1.4.3-5 Accessibility to Partially Removed Windows

1.1.4.3-6 Window Opening Methods

1.1.4.3-7 Window Activates Upon Opening

1.1.4.3-8 Independent Control Along Horizontal/Vertical Axis

1.1.4.3-9 User Control Over Window Resizing options

1.1.4.3-10 Largest Allowable window Size

1.1.4.3-11 Smallest Allowable Window Size

1.1.4.3-12 Scrollable Windows

$1.1 \cdot 4 \cdot 3-13$ Closing Windows

1.1.4.3-14 Easy Shifting Among Windows

1.1.4.3-15 Multiple Methods for Switching Between Windows

1.1.4.3-16 organizing Layered windows

1.1.4.3-17 overlapping Tiled windows

1.1.4.3-18 Activating a Previously Opened Window

1.1.4.3-19 Activation of Window Cursor

1.1.4.3-20 Indicate Active Window

1.1.4.3-21 Consistent Control within windows

1.1.4.3-22 Command Entry, Prompts and Message Location

1.1.4.3-23 Keyboard Entry within Active Window

$1.1 .4 \cdot 3-24$ Hidden Windows

1.1.4.3-25 Interacting with closed Windows

1.1.4.3-26 Multi-Modal Window Designation

1.1.4.3-27 User Alert to Prevent Loss of Information

1.1.4.3-28 Alerting User to Information Availability

1.1.4.3-29 Obscurement Necessitating Operator Notification

1.1.4.3-30 User Control of Automatic Updatable Windows

1.1.4.3-31 Retrieval of Window Information

1.1.4.3-32 Management of Multiple Windows During Multitasking

1.1.5-1 Location of Message Areas

1.1.5-2 System vs. User Message Areas

1.1.5-3 Message Area Dimensions

1.1.5-4 Notification of Incomplete Message

1.1.5-5 Message Storage and Retrieval

1.1.5-6 Time-stamp Messages

1.1.5-7 Notification of New Messages

1.1.5-8 Nondisruptive Message Notification

1.1.5-9 Rearrangement of Message Order

1.1.6-1 Consistent Command Area Location

1.1.6-2 Distinctive Command Area

$1.1 \cdot 6-3$

Command Area Located in Window

$1 \cdot 1 \cdot 6-4$

$1.1 \cdot 6-5$

$1 \cdot 1 \cdot 6-6$

$1 \cdot 1 \cdot 6-7$

Accessibility to Command Area

Cursor Location Within Command Area

Command Area Obscurement

1.1.7-1 Time Display 
$1.1 .7-2$

1.1. 7-3

$1 \cdot 1 \cdot 7-4$

$1 \cdot 2 \cdot 1-1$

$1 \cdot 2 \cdot 1-2$

$1.2 .1-3$

$1.2 \cdot 1-4$

$1.2 \cdot 1-5$

$1.2 .1-6$

$1.2 .1-7$

$1.2 \cdot 1-8$

$1.2 .1-9$

1. $2.1-10$

1.2.1-11

1. $2 \cdot 1-12$

1. 2.1-13

1. 2.1-14

1.2.1-15

1. $2.1-16$

1. $2.1-17$

1. $2 \cdot 1-18$

1. $2 \cdot 1-19$

$1.2 \cdot 1-20$

1. $2.1-21$

1.2.1-22

$1.2 .1-23$

$1.2 .1-24$

$1.2 .1-25$

$1.2 .1-26$

1.2.2-1

1.2. 2-2

$1.2 \cdot 2-3$

1. $2 \cdot 2-4$

$1.2 .2-5$

$1.2 \cdot 2-6$

$1 \cdot 2 \cdot 2-7$

$1.2 \cdot 2-8$

$1.2 .2-9$

$1.2 .2-10$

$1 \cdot 2 \cdot 2-11$

$1 \cdot 2 \cdot 2-12$

$1.2 .2-13$

$1 \cdot 2 \cdot 2-14$

1.2.2-15

$1 \cdot 2 \cdot 3-1$

1.2.3-2

$1 \cdot 2 \cdot 3-3$

$1 \cdot 2 \cdot 3-4$

$1.2 \cdot 3-5$

$1.2 \cdot 3-6$

$1.2 \cdot 3-7$

$1 \cdot 2 \cdot 3-8$
Consistent Location

Access to Software Version Number

Removal of General Interest Information

Appropriate Use of Tables

Logical Table Organization

Table Access by Row and Column

Tables Referenced by First Column

Tabular Items Paired for Direct Comparison

Consistent Spacing within Tables

column scanning cues

Row scanning cues

Justification of Alphabetic Data

Justification of Numeric Data

Justification of Numeric Entry

Density of Tables

Character size

Character Font and Aspect Ratio

Leading Zeros

Maintaining Significant zeros

Lists for Related Items

single-column List Format

Vertical List Extension

Marking Multiline Items in a List

Arabic Numerals for Numbered List Items

Logical List ordering

Vertical ordering in Multiple columns

Hierarchic structure for Long Lists

Numbered Items Start with " 1 "

Repeated Elements in Hierarchic Numbering

Appropriate Use of Forms

Visually Distinctive Data Fields

Consistent Format Across Displays

Form Compatible for Data Entry and Display

Consistent Format Within Data Fields

Partitioning Long Data Items

Distinguishing Blanks from Nulls

Comparing Data Fields

Data Form Entry Error

Data Entry Error Acknowledgement

Identification of Entry Field Length

Data Entry Cues

Highlight Active Data Entry Field

Data Form Placeholder Cursor Location

Similar Formats for Data Form and Hardcopy

Mimic Detail

Use of Abstract Symbology

Mimic Line width

Overlapping Lines

Directional Arrowheads

Points of Origin

Mimic Termination Points

Symbolic Component Identifiers 
1.2.3-9 Consistent Use of Symbols

1.2.4.1-1 Graphic Displays: Trends

1.2.4.1-2 Graphic Displays: Data Comparison

1.2.4.1-3 Graphic Displays: Monitoring Data Change

$1 \cdot 2 \cdot 4 \cdot 1-4$ Consistency

1.2.4.1-5 Simplicity

1.2.4.1-6 Emphasis

1.2.4.1-7 Additional Information

1.2.4.1-8 only Necessary Information Displayed

1.2.4.1-9 Highlighting Critical or Abnormal Data

1.2.4.1-10 Reference Index or Baseline

1.2.4.1-11 Text Annotation

1.2.4.1-12 Data Annotation

1.2.4.1-13 Consistent Annotation Format

1.2.4.1-14 Zooming for Display Expansion

1.2.4.1-15 Show Changing Scale

1.2.4.1-16 Show Overview Position of Visible section

1.2.4.1-17 Animation for Dynamic Display

1.2.4.1-18 Highlighting by Animation

1.2.4.1-19 Printing Graphic Displays

1.2.4.1-20 Use of Data Display Codes

1.2.4.1-21 Data Display Code Identification

1.2.4.1-22 Predefined Graphic Formats

1.2.4.1-23 Computer Derivation of Graphic Data

1.2.4.2-1 Appropriate Use of Flowcharts

1.2.4.2-2 Flowcharts to Aid Problem Solving

$1: 2.4 .2-3$ Logical ordering of Steps

1.2.4.2-4 Ordering to Minimize Path Length

1.2.4.2-5 Conventional Path orientation

1.2.4.2-6 Consistent Coding of Elements

1.2.4.2-7 Conventional Use of Arrows

1.2.4.2-8 Highlighting

1.2.4.2-9 Single Decision at Each step

1.2.4.2-10 Logical Ordering of options

$1.2 .4 \cdot 2-11$ Consistent ordering of Options

$1.2 .4 .2-12$ Consistent Wording

1.2.4.2-13 Necessary Information

1.2.4.2-14 Dynamic Flowchart Sizing

1.2.4.2-15 Flowchart symbol set

1.2.4.3-1 Appropriate Use of Pictures

1.2.4.3-2 Appropriate Use of Diagrams

1.2.4.3-3 Linking Sectional Diagrams

1.2.4.3-4 Highlighting

1.2.4.3-5 Rotation

1.2.4.3-6 Aids for Pictorial Analysis

1.2.4.3-7 Spatial Relationships

1.2.4.3-8 Display Only Necessary Information

$1 \cdot 2 \cdot 4 \cdot 3-9$ Dynamic Diagram Sizing

1.2.4.4-1 Appropriate Use of Maps

1.2.4.4-2 Consistent orientation

1.2.4.4-3 Consistent Positioning of Labels

1.2.4.4-4 Area Coding 
1.2.4.4-5 Tonal Codes

$1.2 \cdot 4 \cdot 4-6$ ordered Coding

1.2.4.4-7 Highlighting

1.2.4.4-8 Panning for Flexible Display Framing

1.2.4.4-9 Show Overview Position of Visible section

1.2.4.4-10 Aiding Distance Judgments

1.2.4.4-11 Aids for Analyzing Maps

1.2.4.4-12 Mapping Non-geographic Data

1.2.4.4-13 Situation Displays

1.2.4.4-14 Indicating Data Change

1.2.4.4-15 stable Reference for Changing Data

1.2.4.4-16 Identification of Map Data

1.2.4.4-17 User Selectable orientation

1.2.4.4-18 Qualitative Maps

1.2.4.4-19 Quantitative Maps

1.2.4.5-1 Software-based Instrument Displays

$1 \cdot 2 \cdot 4 \cdot 5-2$ When to Use

1.2.4.5-3 Increasing Scales

1.2.4.5-4 Circular Scales

$1.2 .4 \cdot 5-5$ Location of Zero

1.2.4.5-6 Orientation of Numbers

$1.2 .4 .5-7$ Location of Scale Values

1.2.4.5-8 Pointer orientation

1.2.4.5-9 Pointer Obscurement

1.2.4.5-10 Scale Progression

$1.2 \cdot 4 \cdot 5-11$ Scale Intervals

1.2.4.5-12 Tick Mark Separation

$1.2 .4 .5-13$ Number of Tick Marks

1.2.4.5-14 Display Band Coding

1.2.4.5-15 Usability of Displayed Values

1.2.4.5-16 Digital Displays Level of Accuracy

1.2.4.5-17 Digital Display Range

$1.2 .4 \cdot 5-18$ Rate of Change

1.2.4.5-19 Direction of Change

$1.2 .4 \cdot 5-20$ When to Use Binary Displays

1.2.4.5-21 Binary Display Legends

1.2.4.5-22 Distinguishability of Binary Controls/Displays

$1.2 \cdot 4 \cdot 6-1$ Scaling Conventions

1.2.4.6-2 Indicating Time

1.2.4.6-3 Positive and Negative Values

$1 \cdot 2 \cdot 4 \cdot 6-4$ Consistent Scaling

1.2.4.6-5 Scales consistent with Function

1.2.4.6-6 Linear Scaling

1.2.4.6-7 Scaling in Standard Intervals

1.2.4.6-8 Numeric Scales start at Zero

1.2.4.6-9 Restricted Use of Broken Axes

1.2.4.6-10 Duplicate Axes

1.2.4.6-11 Single Scale only

1.2.4.6-12 Scaling Against a Reference Index

$1.2 \cdot 4 \cdot 6-13$ Multiple Scales

$1 \cdot 2 \cdot 4 \cdot 6-14$ Use of Multiple Scales

1.2.4.6-15 Aids for Scale Interpolation 
1.2.4.6-16 Unobtrusive Grids

1.2.4.6-17 Numbering Grids

1.2.4.6-18 Restricted Use of Three-Dimensional Scaling

1.2.4.6-19 Numerical Scale Value Alignment

1.2.4.6-20 Display of Scale

1.2.4.6-21 Direct Display of Differences

1.2.4.7-1 Appropriate Use of Curves and Line Graphs

1.2.4.7-2 Preference for Graphs over Tables

1.2.4.7-3 Preference for Graphs over Bar Graphs

1.2.4.7-4 Trending Time Intervals

1.2.4.7-5 Safety status Trends

1.2.4.7-6 Multiple Parameters: Identification

1.2.4.7-7 Multiple Parameters: Grouping

1.2.4.7-8 Multiple Trend Lines

1.2.4.7-9 Compatible Ordering in Legends

1.2.4.7-10 Highlighting Multiple Curves

1.2.4.7-11 Line Coding to Distinguish Curves

1.2.4.7-12 Consistent Line Codes

1.2.4.7-13 Broken Lines for Projected Curves

$1.2 .4 \cdot 7-14$ Reference Index

1.2.4.7-15 Repeating Display of Cyclic Data

1.2.4.7-16 Direct Display of Differences

1.2.4.7-17 Surface Charts

1.2.4.7-18 Ordering Data in Surface Charts

1.2.4.7-19 Labeling Surface Charts

1.2.4.7-20 Cumulative Curves

1.2.4.7-21 Interpreting Graphs

1.2.4.7-22 Screen Area of Coverage

$1.2 \cdot 4 \cdot 7-23$ Band Charts

1.2.4.7-24 Linear Profile Chart

1.2.4.7-25 coding Linear Profile Charts

1.2.4.7-26 Labeling Linear Profile Charts

1.2.4.7-27 Linear Profile Pattern Recognition

1.2.4.7-28 Circular Profile Chart

1.2.4.7-29 Labeling Circular Profile

1.2.4.7-30 Coding Circular Profile Displays

1.2.4.7-31 Single Value Line Chart

1.2.4.7-32 Minimize clutter on Single-Value charts

1.2.4.8-1 Appropriate Use of Bar Graphs and Histograms

$1.2 \cdot 4 \cdot 8-2$ Histograms

1.2.4.8-3 stroke Type Charts

1.2.4.8-4 Consistent Orientation of Bars

1.2.4.8-5 Vertical Bar Charts

$1.2 \cdot 4 \cdot 8-6$ Bar spacing

1.2.4.8-7 Reference Index for Normal operations

1.2.4.8-8 Reference Index for Critical Values

1.2.4.8-9 Highlighting

1.2.4.8-10 Paired or Overlapped Bars

1.2.4.8-11 stacked or Segmented Bars

1.2.4.8-12 Ordering Data in Stacked Bars

1.2.4.8-13 Restricted Use of Icons

1.2.4.9-1 Restricted Use of Pie Charts 


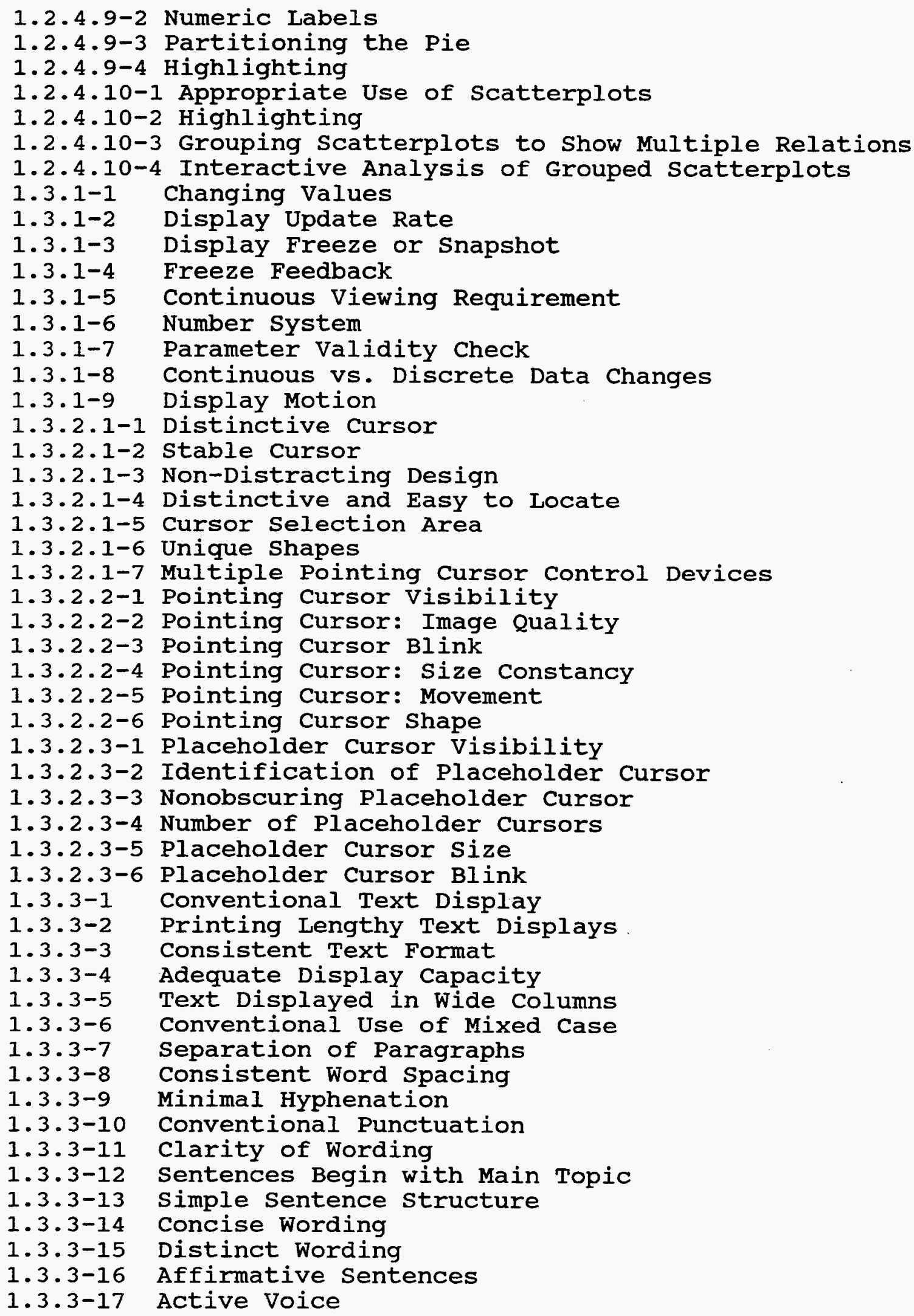


1.3.3-18 Temporal Sequence

1.3.3-19 Justification Options

1.3.3-20 Line Length Options

1.3.3-21 Default Line Length

1.3.3-22 Default Margin Settings

1.3.3-23 Dedicated Function Area

1.3.3-24 Setting Tabs

1.3.3-25 Changing Line spacing

1.3.3-26 combining Text with other Data

1.3.3-27 Placing Figures Near Their Citations

1.3.3-28 Grouping/Demarcating Information

1.3.3-29 Character Height

$1 \cdot 3 \cdot 3-30$

$1 \cdot 3 \cdot 3-31$

$1 \cdot 3 \cdot 3-32$

$1 \cdot 3 \cdot 3-33$

$1 \cdot 3 \cdot 3-34$

$1 \cdot 3 \cdot 3-35$

$1 \cdot 3 \cdot 3-36$

$1 \cdot 3 \cdot 3-37$

$1 \cdot 3 \cdot 3-38$

$1 \cdot 3 \cdot 3-39$

$1 \cdot 3 \cdot 4 \cdot 1-1$

Intercharacter spacing

Character width

Interline spacing

Interline serif spacing

Font style

Distinguishability of Characters

Font styles to Avoid

Figure-Ground contrast

Brightness Ratio

$1 \cdot 3 \cdot 4 \cdot 1-2$

User Selectable Font Size

$1 \cdot 3 \cdot 4 \cdot 1-3$

$1.3 \cdot 4 \cdot 1-4$

$1 \cdot 3 \cdot 4 \cdot 1-5$

$1.3 \cdot 4 \cdot 1-6$

$1 \cdot 3 \cdot 4 \cdot 1-7$

$1 \cdot 3 \cdot 4 \cdot 1-8$

Group Labels

Display Title

Wording of Labels

Labeling User options

Label Contractions and Punctuation

Frame Labels

Label Emphasis

1.3.4.1-9 Meaningfulness

1.3.4.1-10 Proximity to Data Field

1.3.4.1-11 Label Separation

1.3.4.1-12 Consistent Wording of Labels

$1.3 .4 .1-13$ Normal Orientation for Labels

1.3.4.2-1 Axes Labels

1.3.4.2-2 Labeling Single Bars

1.3.4.2-3 Labeling Paired Bars

1.3.4.2-4 Labeling Curves

1.3.4.2-5 Normal orientation for Labels

1.3.4.2-6 Graphical objects

$1.3 \cdot 4 \cdot 3-1$ window Identification

1.3.4.3-2 Multiple Window Identification

1.3.4.3-3 scrollable windows

1.3.4.4-1 Display Identification

1.3.4.4-2 consistent Label Location

1.3.4.4-3 Meaningful Display Labels

$1.3 .4 .4-4$ Paging vs. Scrolling Labels

1.3.4.4-5 Labeling Paging Displays

1.3.4.4-6 Labeling Panning Functions

1.3.4.4-7 Labeling Scrolling Functions

1.3.4.4-8 Labeling Display Freeze 
1.3.4.4-9 Labeling Display Suppression

1.3.4.5-1 Element Labeling

1.3.4.5-2 Process Flow Labels

1.3.4.6-1 Distinctive Labels

1.3.4.6-2 Multifunction Keys

1.3.4.6-3 Disabled Function Keys

1.3.4.7-1 Feature Identification

1.3.4.7-2 Consistent Positioning of Labels

1.3.4.7-3 Symbol Labeling

$1.3 \cdot 4 \cdot 8-1$ Title

1.3.4.8-2 Sub-Group Labels

1.3.4.9-1 Labeling Pie Charts

$1 \cdot 3 \cdot 4 \cdot 9-2$ Numeric Labels

$1 \cdot 3 \cdot 4 \cdot 9-3$ segment Labeling

1.3.4.10-1 Row and column Labels

1.3.4.10-2 Proximity to Columns

1.3.4.10-3 Proximity to Rows

$1 \cdot 3 \cdot 4 \cdot 10-4$ Justification

1.3.4.10-5 Individual Field Labels

1.3.4.10-6 Labeling Units of Measurement

1.3.4.10-7 Multipage Table Labeling

1.3.4.10-8 Scrollable Table Labeling

1.3.4.10-9 Numbered Items Start with "I"

1.3.4.10-10 Repeated Elements in Hierarchic Numbering

1.3.4.11-1 Data Field Definition

1.3.4.11-2 Labeling Units of Measurement

1.3.4.11-3 Justification of Data Field Labels

1.3.4.11-5 Field Labels in Uppercase

1.3.4.11-6 Separation of Character Entry Area and Label

1.3.4.11-7 Justification: Equal Label Length

1.3.4.11-8 Justification: Unequal Label Length

1.3.4.11-9 Location of Group Labels

$1.3 .4 .11-10$ section Headings and Label Indentation

1.3.4.11-11 section Heading Proximity to subordinate Labels

1.3.4.11-12 Data Field Separation

1.3.4.11-13 Separation of Columns

1.3.4.11-14 Multiple Fields without Group Headings

1.3.4.11-15 Multiple Fields With Group Headings

1.3.4.11-16 ENTER Key Labeling

1.3.4.11-17 Protected Labels

1.3.4.11-18 Label Punctuation as Entry Cue

1.3.4.11-19 Data Format Cueing in Labels

1.3.4.11-20 Labeling Units of Measurement

1.3.5-1 Appropriate Use of Icons

$1 \cdot 3 \cdot 5-2$ When Not to Use

1.3.5-3 Icons as Control options

1.3.5-4 Icon Control

1.3.5-5 Cross-mode Standardization

1.3.5-6 Iconic Representation

1.3.5-7 Pictographic Icons

1.3.5-8 Nonpictographic Icons

1.3.5-9 Designs to Avoid 
$1 \cdot 3 \cdot 5-10$

$1.3 \cdot 5-11$

$1 \cdot 3 \cdot 5-12$

$1 \cdot 3 \cdot 5-13$

$1 \cdot 3 \cdot 5-14$

$1.3 \cdot 5-15$

$1.3 \cdot 5-16$

$1.3 \cdot 5-17$

$1.3 \cdot 5-18$

$1.3 \cdot 5-19$

1.3.5-20

1. $4.1-1$

$1.4 .1-2$

$1.4 \cdot 1-3$

$1.4 .1-4$

$1.4 \cdot 1-5$

$1.4 .1-6$

$1.4 \cdot 2 \cdot 1-1$

$1.4 .2 \cdot 1-2$

$1.4 .2 .1-3$

1.4.2.1-4

$1.4 .2 .1-7$

$1.4 \cdot 2 \cdot 1-8$

1.4.2.1-10

Distinguishability

Glossary

Icon Size

Simple Design

Icon Shape

Labeling Icons

Screen Arrangement

Selecting Icons

Moving Icons

origination Point

Restricted Use of Icons

Coding by Highlighting Critical Data

Coding by Data Category

Meaningful Codes

Familiar coding Conventions

Definition of Display Codes

Consistent Coding Across Displays

Minimal Use of Abbreviation

Use of Random Characters

Common Abbreviations

Simple Abbreviation Rule

Dictionary of Abbreviations

Abbreviations Defined in Text

Abbreviations Should be Understandable and Shorter than the Original Word

1.4.2.1-11 When Conventional Abbreviation Does Not Exist

1.4.2.2-1 Alphanumeric Coding

1.4.2.2-2 Consistent Case in Alphabetic coding

1.4.2.2-3 Combining Letters and Numbers

1.4.2.2-4 Short Codes

1.4.2.2-5 Meaningful Alphanumeric codes

1.4.2.3-1 Highlighting With Font Style

1.4.2.3-4 Legibility

1.4.2.3-5 Readability

1.4.2.3-6 Time-insensitive Character Recognition

1.4.2.3-7 Character Height-to-Width Ratio

1.4.2.3-8 Character Format/Aspect Ratio

$1.4 \cdot 2 \cdot 3-9$ Inter-Character Spacing

1.4.2.3-10 Inter-Line Spacing

$1 \cdot 4 \cdot 2 \cdot 3-11$ Inter-Word Spacing

1.4.2.4-3 Easily Recognizable Highlighting

1.4.2.4-6 Flashing

1.4.2.4-8 Minimal Highlighting

1.4.2.5-2 Underlining to Indicate Unusual Values, Errors, Changes

1.4.2.5-4 Underlining Should Not Impact Perception of the Display

1.4.3.1-1 Use of Auditory Coding

1.4.3.1-2 Distinctive Auditory Coding

1.4.3.1-3 Turning off Non-critical Auditory Signals

1.4.3.1-4 Signal When Computer Response Greater than 15 Seconds

1.4.3.1-5 Intermittent Signals

1.4.3.1-9 Computer-Generated Speech output

1.4.3.1-12 Non-duplication of Auditory Signals 
1.4.3.1-13 Frequency of Auditory Signals

1.4.3.1-15 Signal Travel Over $1000 \mathrm{ft}$

1.4.3.1-18 Maintaining Security with Auditory Signaling

$1.4 \cdot 3 \cdot 1-19$ Indicating Who is to Respond

$1 \cdot 4 \cdot 3 \cdot 1-20$ No startle

1.4.3.1-22 Two-stage Signals

1.4.3.1-23 Listening to More than one Channel

1.4.3.1-24 Necessary Information

1.4.3.1-25 Testing Auditory Signals

1.4.3.1-27 Tonal Signals

1.4.3.1-28 Spoken signals

1.4.3.2-1 Limited Use of Brightness coding

1.4.3.2-2 Brightness Inversion

1.4.3.2-3 Brightness Intensity coding

1.4.3.2-11 Highlighting in a List

1.4.3.2-13 Successive Brightening of Graphical Items

1.4.3.3-1 Color Coding for Relative Values

1.4.3.3-2 Color Coding for Data Categories

1.4.3.3-3 Easily Discriminable Colors

1.4.3.3-4 Conservative Use of Color

1.4.3.3-6 Redundant Color coding

1.4.3.3-7 Unique Assignment of Color Codes

1.4.3.3-8 Conventional Assignment of Color Codes

1.4.3.3-9 Brightness and Saturation to Draw Attention

$1 \cdot 4 \cdot 3 \cdot 3-12$ When Not to Use Color Coding

1.4.3.3-13 Limited Color Coding for Group Membership

1.4.3.3-14 Discriminable Color Coding for Group Membership

1.4.3.3-15 Unplanned Patterns from Color coding

1.4.3.3-16 Color Coding on Already Formatted Displays

1.4.3.3-17 Conforming to Already Existing Meanings for a Job

1.4.3.3-18 Indicating the state of the system

1.4.3.3-23 High-Pressure Sodium

1.4.3.3-24 Periodic Adjustment of Color Displays

1.4.3.3-25 Color in Mimic Designs

1.4.3.3-26 Highlighting Related Data

1.4.3.3-27 Color Should Not be Distracting

1.4.3.3-28 Color and Quantitative Values

1.4.3.4-1 Blink coding

1.4.3.4-2 Blinking Marker Symbols

1.4.3.4-3 Optimal Blink Rate

1.4.3.4-6 No Blinking for Attention to Detail or Reading

1.4.3.4-7 User Suppression of Blinking

1.4.3.4-8 Flashing Arrow

1.4.3.4-9 Blink Rate Should Match Operators Scan Rate

1.4.3.4-11 Target Detection Tasks

1.4.3.5-1 Reverse Video

1.4.3.6-2 Coding by Line Length

1.4.3.6-3 Coding by Line Direction

1.4.3.7-2 Standard Symbols

1.4.3.7-5 Shape coding

1.4.3.7-6 Establishing Standards for Shape Coding

1.4.3.7-9 Symbol Heights 
1.4.3.7-11 Clearly Discriminable Shapes

1.4.3.7-12 No Conflicting Information

1.4.3.7-14 Labeling Symbols

$1.4 \cdot 3 \cdot 7-15$ Legends

1.4.3.7-16 More than one Legend

1.4.3.7-17 Minimum of 20 Min of Arc

1.4.3.7-19 Graphical Coding Over Word Messages

1.4.3.7-20 Obvious Meanings of Pictographs

1.4.3.7-21 No Alternating Words and Symbols

1.4.3.7-25 Maximum Viewing Distance/Minimal Ambient Lighting

1.4.3.7-26 Upright Symbols

1.4.3.8-1 Limited Use of Size coding

1.4.3.9-2 Grouping Techniques

1.4.3.9-3 Displays with High Information Density

1.4.3.9-4 Cohesive Groupings

1.4.3.9-5 Spacial Distance for Redundant Coding

1.4.3.9-6 Double-Attribute Item Sharing

1.4.3.10-1 Coding with Texture, Focus, Motion

1.4.3.10-2 Darkest/Lightest Correspond to Extreme Values

1.4.3.10-3 Simple Texture Codes

SECTION 2

$2 \cdot 1 \cdot 1-1$

$2.1 .1-2$

$2 \cdot 1 \cdot 1-3$

$2.1 .1-4$

$2 \cdot 1 \cdot 1-5$

$2.1 .1-6$

$2.1 .1-7$

2.1.1-8

2.1.1-9

$2.1 .1-10$

$2.1 .1-11$

$2 \cdot 1 \cdot 1-12$

$2.1 .1-13$

$2.1 .1-14$

2.1.1-15

$2.1 .1-16$

$2 \cdot 1.1-17$

$2.1 .1-18$

$2.1 .1-19$

$2.1 .1-20$

$2 \cdot 1 \cdot 1-21$

$2.1 .1-22$

$2.1 .1-23$

$2.1 .1-27$

$2.1 .1-28$

2.1.1-29

$2.1 .1-30$

$2.1 .1-31$
Data Entered Only once

Entry via Primary Display

Feedback During Data Entry

Single Method for Entering Data

Consistent Method for Data Change

User-Paced Data Entry

Explicit ENTER Action

Explicit CANCEL Action

Feedback for Completion of Data Entry

Feedback for Repetitive Data Entries

Feedback when Changing Data

Keeping Data Items Short

Partitioning Long Data Items

Optional Abbreviation

Clarifying Unrecognized Abbreviations

Prompting Data Entry

Character Entry via Single Keystroke

Minimal Shift Keying

Upper and Lower Case Equivalent

Decimal Point optional

Leading Zeros optional

Single and Multiple Blanks Equivalent

Aids for Entering Hierarchic Data

Default Values

Defaults for Sequential Entries

User Definition of Default Values

Display of Default Values

Easy Confirmation to Enter Default Values 
2.1.1-32 Temporary Replacement of Default Values

2.1.1-33 Automatic Generation of Routine Data

2.1.1-34 Automatic Computation of Derived Data

2.1.1-35 User Review of Prior Entries

2.1.1-36 Automatic Entry of Redundant Data

2.1.1-37 Automatic Cross-File Updating

2.1.1-38 Flexible Design for Data Entry

2.1.1-39 Editing During Entry

2.1.1-40 Inserting

2.1.1-41 Highlighting

2.1.1-42 Explicit User Actions

2.1.1-43 Validation

2.1.1-44 Input units

2.1.1-45 Compatibility with user skill

$2.1 .1-46$

$2 \cdot 1 \cdot 1-47$

$2 \cdot 1 \cdot 1-48$

$2.1 .1-49$

$2 \cdot 1 \cdot 1-50$

2.1.1-51

$2.1 \cdot 1-52$

Availability of information

Concurrent display

Hierarchical process

User memorization

Data manipulation

$2 \cdot 1 \cdot 2 \cdot 1-1$

Control input data display

$2 \cdot 1 \cdot 2 \cdot 1-3$

Standardized Procedures

Cursor Control - General

$2 \cdot 1 \cdot 2 \cdot 1-4$

Easy Cursor Positioning

$2 \cdot 1 \cdot 2 \cdot 2-1$

Compatible Control of Cursor Movement

$2 \cdot 1 \cdot 2 \cdot 2-2$

Responsive Cursor control

$2 \cdot 1 \cdot 2 \cdot 2-3$

Consistent positioning

$2 \cdot 1 \cdot 2 \cdot 2-4$

$2 \cdot 1 \cdot 2 \cdot 2-5$

Variable Step Size

$2 \cdot 1.2 \cdot 2-6$

Cursor Control at Keyboard

$2.1 .2 \cdot 2-8$

Location of cursor control keys

User Selectable speed

2.1.2.2-9 Direct Manipulation Controls and Cursor Movement

2.1.2.2-11 Confirming Cursor Position

2.1.2.3-1 Automatic Return of Cursor

2.1.2.3-4 Automatic Cursor Placement for Menus

2.1.2.3-5 Cursor Placement for Pointing at options

2.1.2.3-6 Cursor Placement for Keyed Entry of Options

2.1.2.3-7 Cursor Placement Following Error

2.1.2.4-1 Easy Cursor Movement to Data Fields

2.1.2.4-2 Cursor Movement

2.1.2.4-3 Proportional spacing

2.1.2.4-4 Free Cursor Movement

2.1.2.4-5 Cursor Movement by Units of Text

2.1.2.4-6 Tabbing within Rows

2.1.2.4-7 Tabbing within Columns

2.1.2.4-8 Explicit Activation

2.1.2.4-9 Data Entry Independent of Cursor Placement

2.1.2.4-10 Display Format Protection

2.1.2.5-1 Minimal Use of Multiple Cursors

2.1.2.5-3 Distinctive Control of Multiple cursors

2.1.3.1-1 Adequate Display Capacity

2.1.3.1-2 Necessary Data Displayed 
2.1.3.1-3 Control Entries Distinct from Text

2.1.3.1-4 Text Distinct from Annotation

2.1.3.1-5 Text Displayed as Printed

2.1.3.1-6 Format control by User

2.1.3.1-7 Establishing Predefined Formats

2.1.3.1-8 Storing User-Defined Formats

2.1.3.1-9 Natural Units of Text

2.1.3.2-1 Editing Capabilities During Text Entry

2.1.3.2-2 Consistent word spacing

2.1.3.2-3 Hyphenation by Users

2.1.3.2-4 Auditory Signals for Alerting Users

2.1.3.3-1 Editing by Multiple Methods

2.1.3.3-3 Editing Commands

2.1.3.3-4 Reversible Actions

2.1.3.3-5 User Confirmation of Editing Changes

$2 \cdot 1 \cdot 3 \cdot 3-6$ Inserting Text

$2 \cdot 1 \cdot 3 \cdot 3-7$ Replacing Text

2.1.3.3-8 Changing Physical Characteristics of Text

$2 \cdot 1 \cdot 3 \cdot 3-9$ Tabs

$2 \cdot 1 \cdot 3 \cdot 3-10$ Margins

2.1.3.3-11 Control Annotations

$2: 1.3 \cdot 3-12$ selecting Data for Editing

2.1.3.3-13 Highlighting Selected Information

2.1.3.3-14 Minimum Amount of Selectable Data

2.1.3.3-15 Unselecting Information

2.1.3.3-16 Vertical scrolling

2.1.3.3-17 Non-Contiguous Blocks of Text

2.1.3.3-18 Non-Contiguous Graphic objects

2.1.3.3-20 Confirming Actions in DELETE Mode

2.1.3.3-21 Undoing Deletions

2.1.3.3-22 Buffer

$2 \cdot 1 \cdot 3 \cdot 3-23$ Display window

2.1.3.3-24 Horizontal Scrolling

$2 \cdot 1 \cdot 3 \cdot 3-25$ Head-and Foot-of File

2.1.3.3-26 Automatic Pagination Aids

2.1.3.3-27 Pagination

2.1.3.3-28 User Control of Pagination

2.1.3.3-29 Controlling Integrity of Text Units

2.1.3.3-30 Protecting Text During Page Overruns

2.1.3.3-31 Automatic Iine Break

2.1.3.3-32 Program Edit Commands

$2 \cdot 1 \cdot 3 \cdot 4-1$ string search

2.1.3.4-2 Upper and Lower Case Equivalent in Search

2.1.3.4-3 specifying Case in Search

2.1.3.4-4 Global Search and Replace

2.1.3.4-5 Case in Global search and Replace

2.1.3.5-1 Moving Text

2.1.3.5-2 Storing Frequently Used Text

$2.1 .3 .5-3$ Cutting Selected Data

2.1.3.5-4 Placing Cut Data in Compatible Data Files

2.1.3.5-5 Viewing Cut Data

2.1.3.5-6 Placing Cut Data in other Files 
2.1.3.5-7 cutting without a Gap in the Text

2.1.3.5-9 cutting Graphical objects and Areas of Graphical Displays

2.1.3.5-11 Placing Copied Data in Compatible Files

2.1.3.5-12 Viewing Copied Data

2.1.3.5-13 Placing Copied Data in other Files

2.1.3.5-15 Pasting the Same Data More than once

2.1.3.5-16 Pasting Text into a Graphical File and Vice Versa

2.1.3.6-1 Flexible Printing options

2.1.3.6-2 Information on Printing status

$2 \cdot 1 \cdot 4-1$

$2 \cdot 1 \cdot 4-2$

Combined Entry of Related Data

$2.1 .4-3$ Flexible Interrupt

$2 \cdot 1 \cdot 4-4$

$2 \cdot 1 \cdot 4-5$

$2 \cdot 1 \cdot 4-6$

$2 \cdot 1.4-7$ Minimal Use of Delimiters standard Delimiter Character Data Field Labels

$2 \cdot 1.4-10$

$2 \cdot 1 \cdot 4-12$

$2 \cdot 1 \cdot 4-13$

$2 \cdot 1 \cdot 4-14$

$2 \cdot 1 \cdot 4-16$

$2.1 .4-19$

$2 \cdot 1 \cdot 5-1$

$2 \cdot 1 \cdot 5-2$

$2 \cdot 1 \cdot 5-3$

$2 \cdot 1 \cdot 5-4$

$2 \cdot 1 \cdot 5-5$

$2 \cdot 1 \cdot 5-6$

$2 \cdot 1 \cdot 5-7$

$2 \cdot 1 \cdot 5-8$

$2 \cdot 1 \cdot 6-1$

$2 \cdot 1 \cdot 6-2$

$2 \cdot 1 \cdot 6-3$

$2 \cdot 1 \cdot 6-4$

$2 \cdot 1 \cdot 6-5$

$2.1 \cdot 6-6$

$2 \cdot 1 \cdot 6-8$

$2 \cdot 1 \cdot 6-10$

$2 \cdot 1 \cdot 6-11$

$2 \cdot 1 \cdot 6-12$

$2 \cdot 1 \cdot 6-13$

$2 \cdot 1 \cdot 6-14$

$2 \cdot 1 \cdot 6-15$

$2 \cdot 1 \cdot 6-16$

$2 \cdot 1 \cdot 6-18$

$2 \cdot 1 \cdot 7 \cdot 1-1$ Pointing

Grouping Data Fields

Deferring Inputting Data

Variable Length Data Area

Alternative Units of Measurement

Transforming Units of Measurement

Tabbing to Advance to Subsequent Fields

Protected Fields

Keystroke Not Required for Every Character Space

Use of Tabular Displays

Distinctive Labels

Automatic Justification of Entries

Justification of Numeric Entries

Maintaining Significant Zeros

Aiding Entry of Duplicative Data

Row Scanning cues

Significance of Numeric Values

Speech Input

Limited Vocabulary for speech Input

Phonetically Distinct Vocabulary for speech Input

Easy Error Correction for Speech Input

Alternative Entries for speech Input

PAUSE and CONTINUE Options for speech Input

Word Boundaries

Non-Speech Activation

Confidence Rating

Vocabulary Sets

Vocabulary Items

User-Adjustable Rejection Levels

Testing the Recognition of Individual Vocabulary Items

Speaker-Dependent Voice Recognizer

2.1.7.1-2 Distinctive Cursor

2.1.7.1-3 Zooming for Precise Positioning

2.1.7.1-4 Selecting Graphic Elements

2.1.7.1-5 Highlighting Selected Elements

2.1.7.1-6 Changing Position (Translation)

2.1.7.1-7 Deleting Elements 


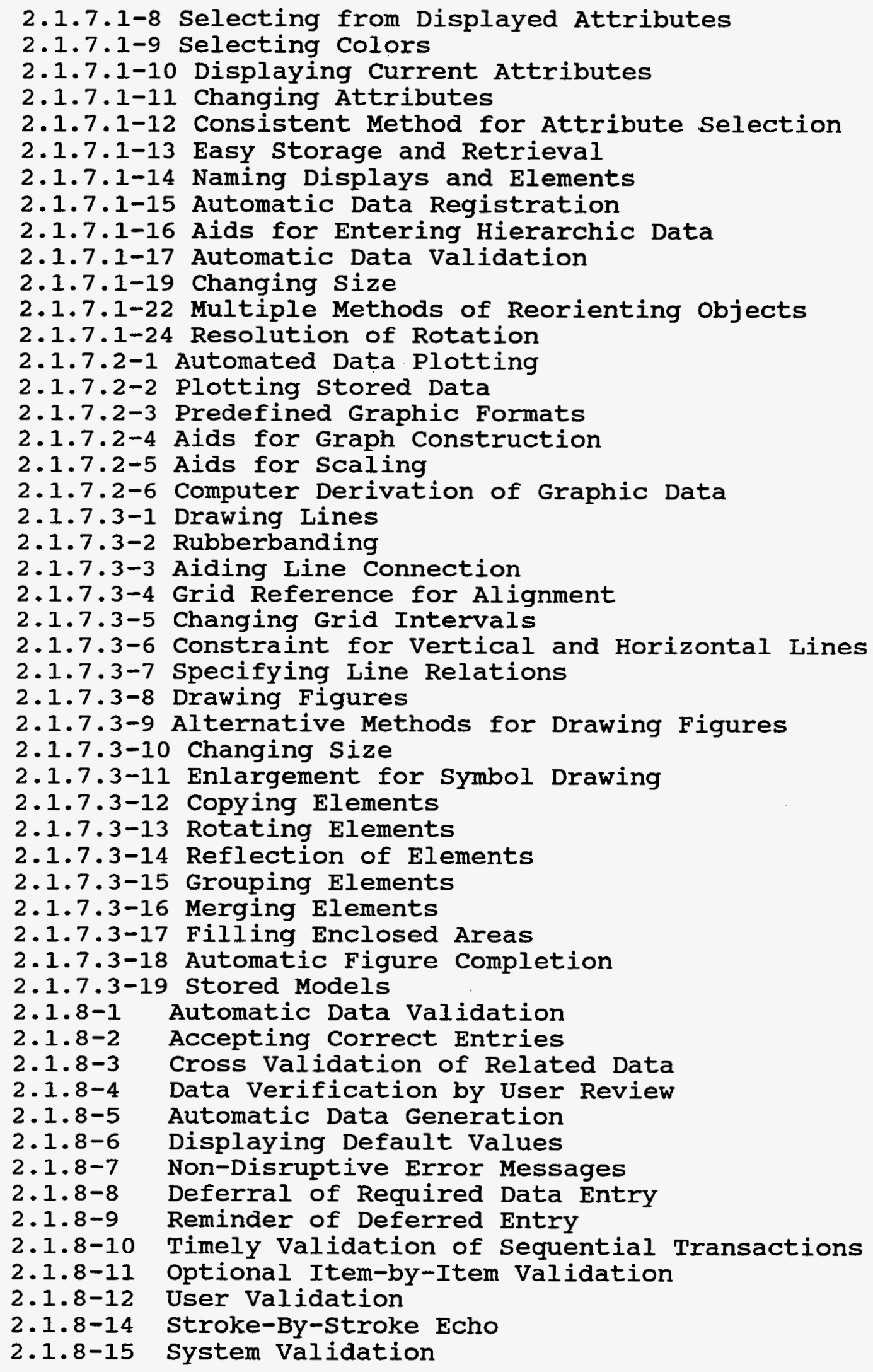


2.1.9.1-1 Consistent Procedures

2.1.9.1-2 Appropriate Ease or Difficulty of User Actions

2.1.9.1-3 Control by Explicit User Action

2.1.9.1-4 Appropriate Response to All Entries

2.1.9.1-5 Prompting Command Correction

2.1.9.2-1 User Review and Editing of Entries

2.1.9.2-2 UNDO to Reverse Control Actions

2.1.9.2-3 Display of Erroneous Entries

2.1.9.2-4 Automated Correction Aid

2.1.9.2-5 Error Message Content

2.1.9.2-6 Spelling Errors

2.1.9.2-7 Immediate Error correction

2.1.9.2-8 Editing Entries After Error Detection

2.1.9.2-9 Explicit Entry of Corrections

2.1.9.2-10 Acknowledging Corrections

2.1.9.2-11 Flexible BACKUP for Error Correction

2.1.9.2-12 Errors in stacked Commands

2.1.9.2-13 Partial Execution of Stacked Commands

2.1.9.3-1 User Confirmation of Destructive Entries

2.1.9.3-2 Separate CONFIRM Action

2.1.9.3-3 Confirmation Message Content

2.1.9.3-4 User Warned of Potential Data Loss

2.1.9.3-5 Verification of Deletion

2.1.9.4-1 Protection from Computer Failure

2.1.9.4-2 Multiple Users

2.1.9.4-3 Protection from Interference by other Users

2.1.9.4-4 Protection from Interrupts

2.1.9.4-5 Segregating Real from simulated Data

2.1.9.4-6 Disabling Unneeded Controls

2.1.9.4-7 Protecting Physical Controls

2.1.9.4-8 Safe Defaults

2.1.9.4-9 Safe Response to Random Inputs

2.1.9.4-10 Explicit Action to Select Destructive Modes

2.1.9.4-11 Feedback for Mode Selection

2.1.9.4-12 Warning Users of Potential Data Loss

2.1.9.4-13 Preventing Data Loss at LOG-OFF

2.1.9.4-14 Protection from Data Change

2.1.9.4-15 Data Entry/Change Transaction Records

2.1.9.4-16 Displaying Data to be Changed

2.1.9.4-17 Distinctive File Names

2.2.1-1 Interactive control

2.2.2-1 Flexible Sequence Control

2.2.2-2 Minimal User Actions

2.2.2-3 Control Matched to User Skill

2.2.2-4 User Initiative in Sequence Control

2.2.2-5 Control by Explicit User Action

2.2.2-6 Consistent User Actions

$2 \cdot 2 \cdot 2-7$

$2.2 .2-8$

$2 \cdot 2 \cdot 2-9$

$2 \cdot 2 \cdot 2-10$

$2 \cdot 2 \cdot 2-11$

Logical Transaction Sequences

Distinctive Display of Control Information

Displayed Context

Consistent Terminology for Sequence Control

Congruent Names for Control Functions 


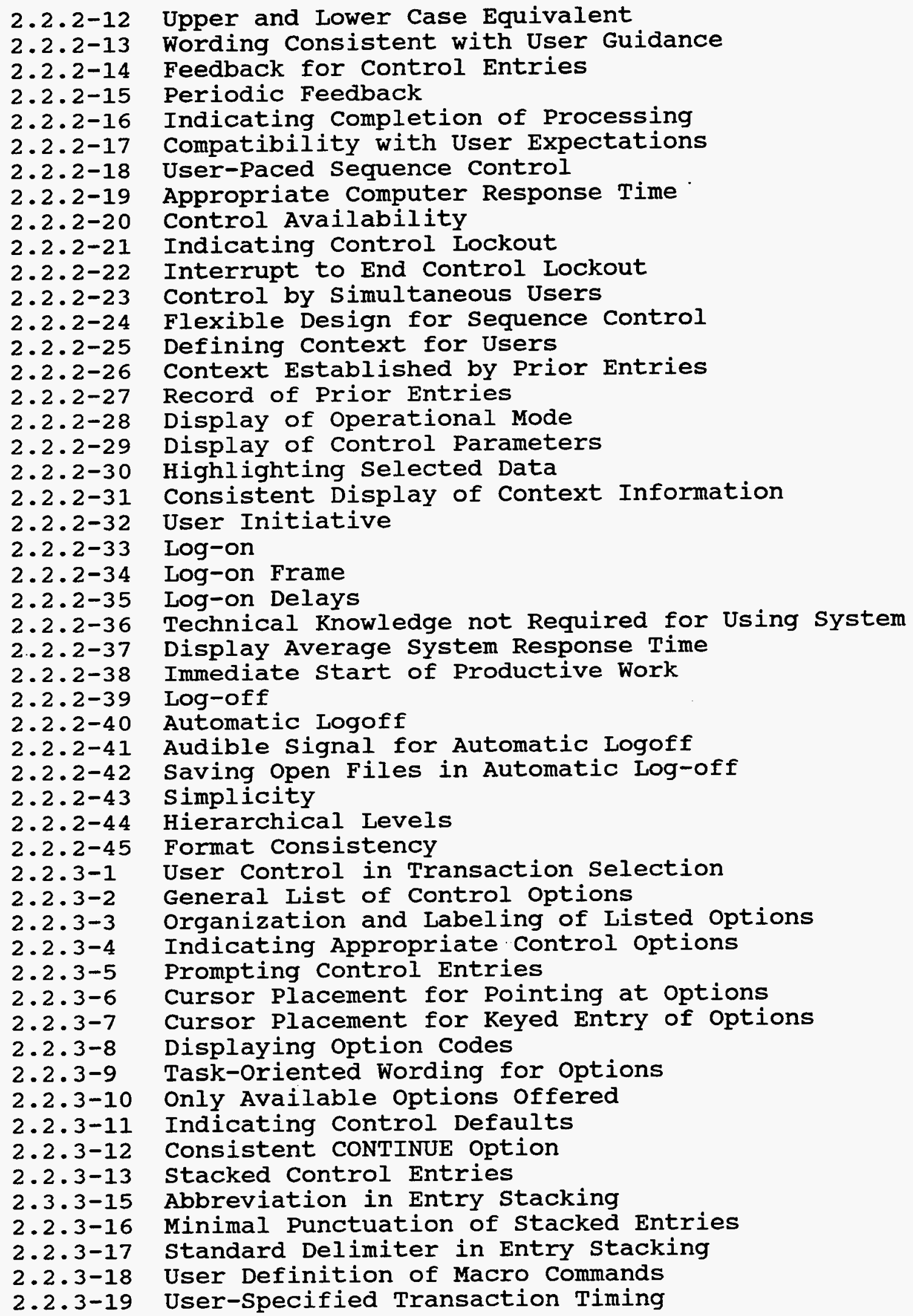


2.2.3-20 Options List/Prompting

2.2.3-21 Provide Further Available Action

2.2.3-22 Minimize Mnemonics, Codes, etc.

2.2.3-23 Computer processing constraints

$2 \cdot 2 \cdot 4-1$

$2.2 \cdot 4-2$

$2 \cdot 2 \cdot 4-3$

$2 \cdot 2 \cdot 4-4$

$2.2 \cdot 4-5$

$2 \cdot 2 \cdot 4-6$

$2.2 \cdot 4-7$

$2 \cdot 2 \cdot 4-8$

$2.2 .4-9$

$2 \cdot 2 \cdot 4-10$

$2 \cdot 2 \cdot 4-11$

$2 \cdot 2 \cdot 4-12$

$2 \cdot 2 \cdot 5 \cdot 1-1$

User Interruption of Transactions

Distinctive Interrupt options

CANCEL Option

BACKUP Option

REVIEW Option

RESTART Option

END Option

PAUSE and CONTINUE Options

$2 \cdot 2 \cdot 5 \cdot 1-2$

$2 \cdot 2 \cdot 5 \cdot 1-3$

Indicating PAUSE status

SUSPEND Option

2.2.5.1-4 Layered Command Language

$2 \cdot 2 \cdot 5 \cdot 1-5$ Meaningful Command Names

$2 \cdot 2 \cdot 5 \cdot 1-6$ Familiar wording

2.2.5.1-7 Consistent Wording of Commands

2.2.5.1-8 Distinctive Meaning for Commands

2.2.5.1-9 Distinctive Spelling for Commands

2.2.5.1-10 User-Assigned Command Names

2.2.5.1-11 User-Requested Prompts

2.2.5.1-12 General List of Commands

$2 \cdot 2 \cdot 5 \cdot 1-13$ Command stacking

2.2.5.1-14 User Definition of Macro Commands

2.2.5.1-15 Minimal Punctuation

2.2.5.1-16 standard Delimiter

2.2.5.1-17 Ignoring Blanks in Command Entry

2.2.5.1-18 Abbreviation of Commands

2.2.5.1-19 standard Techniques for command Editing

2.2.5.1-20 Interpreting Misspelled Commands

2.2.5.1-21 Recognizing Command Synonyms

2.2.5.1-22 Recognizing Alternative Syntax

2.2.5.1-23 Correcting Command Entry Errors

2.2.5.1-24 Replacing Erroneous Commands

2.2.5.1-25 Reviewing Destructive Commands

2.2.5.1-26 Syntactic Complexity

2.2.5.1-27 Guidance Information

2.2.5.1-28 Graphic Examples in Guidance Information

2.2.5.1-29 User Definition of Macro Commands

2.2.5.2-1 Control of Graphic Data

2.2.5.2-2 Graphic Control Aids for Casual Users

$2 \cdot 2 \cdot 5 \cdot 2-3$ Iconic Menus

2.2.5.2-4 Supplementary Verbal Labels

2.2.5.2-5 Direct Manipulation

2.2.5.2-6 Graphic Display of Control Context

2.2.5.2-7 Graphic Display of Control Prompting 
2.2.5.2-8 Selecting and Dragging

$2 \cdot 2 \cdot 5 \cdot 2-9$ Consequences of Dragging

$2 \cdot 2 \cdot 5 \cdot 2-10$ Size of Icons

2.2.5.2-11 Opening an Icon

2.2.5.2-12 Other Primary Features of Direct Manipulation Dialogue

2.2.5.2-14 Feedback for Manipulation of an Icon

2.2.5.2-15 Commands that Cannot be Completed

2.2.5.2-16 When to Use Direct Manipulation

2.2.5.3-1 Form Filling for Data Entry

2.2.5.3-2 Form Filling for Control Entry

2.2.5.3-3 Defaults for Control Entry

2.2.5.4-1 Function Keys for Critical Control Entries

2.2.5.4-2 Function Keys for Frequent Control Entries

2.2.5.4-3 Function Keys for Interim Control Entries

2.2.5.4-4 Distinctive Labeling of Function.Keys

2.2.5.4-5 Labeling Multifunction Keys

2.2.5.4-7 Logical Pairing of Double-Keyed Functions

2.2.5.4-8 Consistent Logic for Double Keying

2.2.5.4-9 Single Activation of Function Keys

2.2.5.4-10 Feedback for Function Key Activation

2.2.5.4-11 Indicating Active Function Keys

2.2.5.4-12 Disabling Unneeded Function Keys

2.2.5.4-14 Consistent Assignment of Function Keys

2.2.5.4-15 Consistent Functions in Different operational Modes

2.2.5.4-16 Easy Return to Base-Level Functions

2.2.5.4-19 Multiple Presses of Function Key

2.2.5.5-1 Restricting User Definable Macros and Programmable Keys

2.2.5.5-2 Syntactic Constraints on Macros

2.2.5.5-3 User Restricted Modifying of Defined Macros

$2.2 .5 .5-4$ No Duplication of Macro Names

$2 \cdot 2 \cdot 5 \cdot 5-5$ Index of Macros

2.2.5.5-6 Communication Among Users About Macros

2.2.5.6-1 Menu Selection

2.2.5.6-2 Single Selection Per Menu

2.2.5.6-3 Single-Column List Format

2.2.5.6-4 Menu Selection by Pointing

$2.2 \cdot 5 \cdot 6-5$ Large Pointing Area for option Selection

2.2.5.6-6 Dual Activation for Pointing

2.2.5.6-7 Menu Selection by Keyed Entry

2.2.5.6-8 Standard Area for code Entry

2.2.5.6-9 Feedback for Menu Selection

2.2.5.6-10 Explanatory Title for Menu

2.2.5.6-11 Menu Options Worded as Commands

2.2.5.6-12 Option Wording Consistent with Command Language

2.2.5.6-13 Letter Codes for Menu Selection

2.2.5.6-14 Consistent Coding of Menu Options

2.2.5.6-15 standard Symbol for Prompting Entry

2.2.5.6-16 Explicit option Display

2.2.5.6-17 Complete Display of Menu Options

2.2.5.6-18 Menu Options Dependent on Context

2.2.5.6-19 Consistent Display of Menu Options

2.2.5.6-20 Menus Distinct from Other Displayed Information 
2.2.5.6-21 Logical Ordering of Menu Options

2.2.5.6-22 Logical Grouping of Menu Options

$2 \cdot 2 \cdot 5 \cdot 6-23$ Logical ordering of Grouped options

2.2.5.6-24 Labeling Grouped Options

2.2.5.6-25 Format Consistency

$2.2 .5 \cdot 6-26$ Hierarchic Menus for sequential selection

$2.2 \cdot 5 \cdot 6-27$ General Menu

2.2.5.6-28 Minimal Steps in Sequential Menu Selection

2.2.5.6-29 Easy selection of Important options

2.2.5.6-30 Indicating Current Position in Menu structure

2.2.5.6-31 Control Options Distinct from Menu Branching

2.2.5.6-32 Consistent Design of Hierarchic Menus

2.2.5.6-33 Return to Higher-Level Menus

2.2.5.6-34 Return to General Menu

2.2.5.6-35 By-Passing Menu Selection with Command Entry

2.2.5.6-36 stacking Menu Selections

$2.2 \cdot 5 \cdot 6-37$ Consistent Location for Menus

$2 \cdot 2 \cdot 5 \cdot 6-40$ Number of Options

$2 \cdot 2 \cdot 5 \cdot 6-41$ No Scrolling in Menus

$2 \cdot 2 \cdot 5 \cdot 6-42$ Permanent Menus

$2 \cdot 2 \cdot 5 \cdot 6-43$ Distinct Subordinate Menus

$2.2 .5 .6-45$ Category Labels on Menu Bar

2.2.5.6-46 Systematic Organization of Items on Menu Bar

2.2.5.6-49 Simultaneous Presentation of Super- and Subordinate Lists

2.2.5.6-50 Permanent Menus Minimized

2.2.5.6-51 User Requested Menus: Pull-Downs and Pop-Ups

2.2.5.6-52 Function of Menu Should Be Evident

2.2.5.6-53 Activation of Pull-down and Pop-Up Menus

2.2.5.6-56 Breadth and Depth of Menu Items

2.2.5.6-57 Visual Representation of Path

2.2.5.6-58 When Menu Items Need Not be Listed

2.2.5.6-62 Non-selection of Conflicting Menu Items

$2 \cdot 2 \cdot 5 \cdot 6-63$ No one Menu Item Menus

2.2.5.6-64 Non-selectable Menu Items

2.2.5.6-65 Indication of Selected Items

2.2.5.6-66 command Completion Feedback

$2 \cdot 2 \cdot 5 \cdot 6-67$ ON/OFF Menu Items

2.2.5.6-68 Selection of ON/OFF Items

2.2.5.6-69 Acknowledgement of Selection from Keyboard

$2 \cdot 2 \cdot 5 \cdot 7-1$ Constrained Natural Language

$2 \cdot 2 \cdot 5 \cdot 8-1$ Query Language

2.2.5.8-2 Natural Organization of Data

2.2.5.8-3 Coherent Representation of Data organization

2.2.5.8-4 Task-Oriented Wording

2.2.5.8-5 Flexible Query Formulation

2.2.5.8-6 Minimal Need for Quantifiers

2.2.5.8-7 Logic to Link Queries

2.2.5.8-8 Linking Sequential Queries

2.2.5.8-9 Confirming Large-Scale Retrieval

2.2.5.9-1 Question-and-Answer Dialogue

2.2.5.9-2 Questions Displayed Singly 


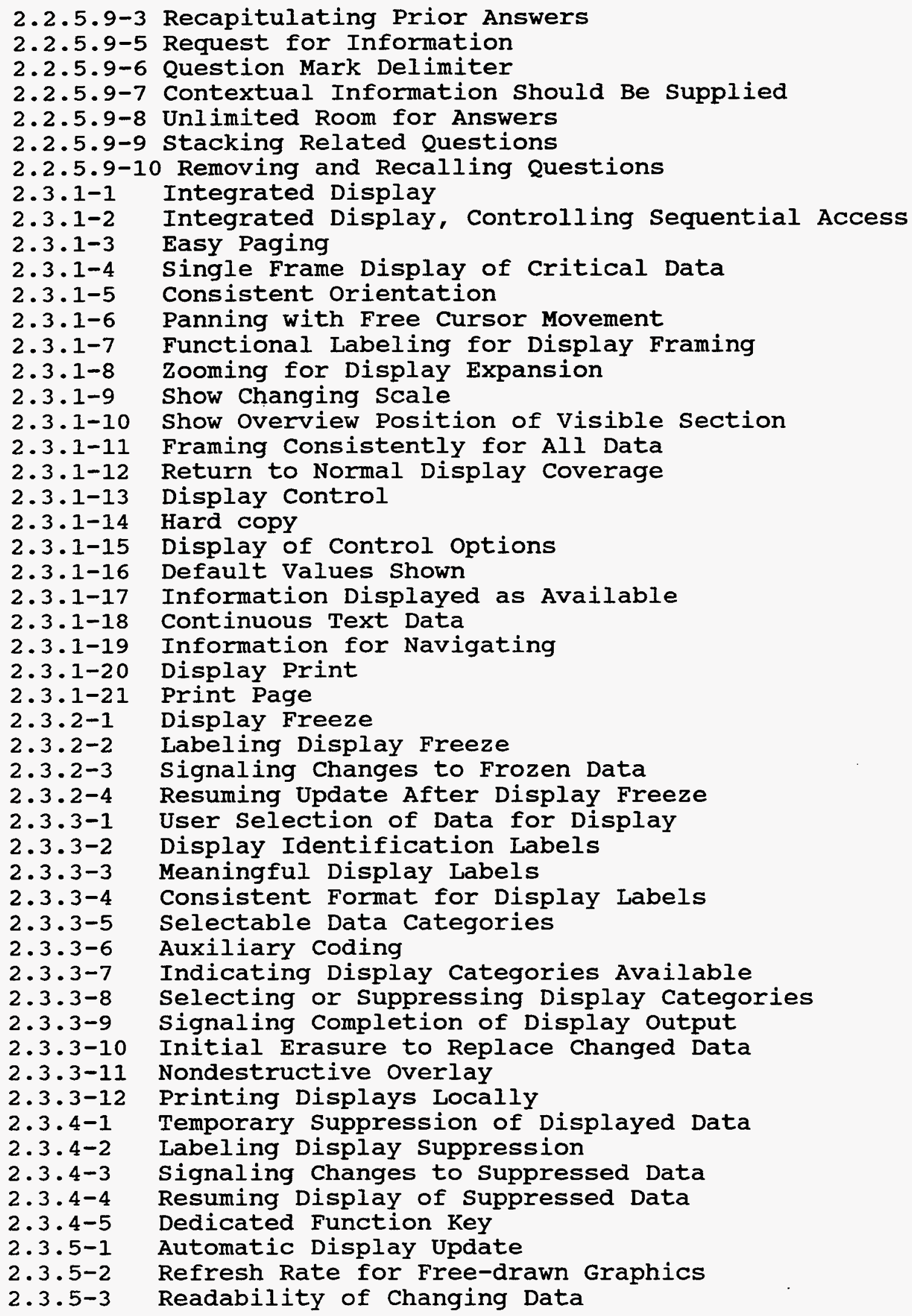


$2 \cdot 3 \cdot 5-4$

$2 \cdot 3 \cdot 6-1$

$2 \cdot 3 \cdot 6-2$

$2 \cdot 3 \cdot 6-3$

$2 \cdot 3 \cdot 6-4$

$2 \cdot 3 \cdot 7-1$

$2 \cdot 3 \cdot 7-2$

$2 \cdot 3 \cdot 7-3$

$2 \cdot 3 \cdot 7-4$

$2 \cdot 3 \cdot 7-5$

$2 \cdot 3 \cdot 7-6$

$2 \cdot 3 \cdot 7-7$

$2 \cdot 3 \cdot 7-8$

$2 \cdot 3 \cdot 7-9$

2.3.7-10

$2 \cdot 3 \cdot 7-11$

$2 \cdot 3 \cdot 7-12$

$2 \cdot 3 \cdot 7-13$

$2 \cdot 3 \cdot 7-14$

$2 \cdot 3 \cdot 7-15$

$2 \cdot 3 \cdot 8-1$

$2 \cdot 3 \cdot 8-2$

$2 \cdot 3 \cdot 8-3$

$2 \cdot 3 \cdot 9-1$

$2 \cdot 3 \cdot 9-2$

$2 \cdot 3 \cdot 9-3$

2. $4.1-1$

$2 \cdot 4 \cdot 1-2$

$2.4 .1-3$

$2 \cdot 4 \cdot 1-4$

$2.4 .1-5$

$2.4 .1-6$

$2 \cdot 4 \cdot 1-7$

$2.4 .1-8$

$2.4 .1-9$

$2 \cdot 4 \cdot 1-10$

2. $4.2-1$

$2.4 .2-2$

$2 \cdot 4 \cdot 2-3$

$2.4 \cdot 2-4$

2. 4 . 3-1

$2 \cdot 4 \cdot 3-2$

$2.4 \cdot 3-3$

$2 \cdot 4 \cdot 3-4$

$2 \cdot 4 \cdot 3-5$

2. $4.4-1$

$2 \cdot 4 \cdot 5-1$

2. 5-1

2. 5-2

$2 \cdot 5-3$

$2 \cdot 5-4$

2. 5-5
Visual Integration of Changing Graphics

Users Having Authoring Tools

Coding Iinked Items

Context-Sensitive Help

Browsing Tools: Question-Answer Dialogue

Paging Controls

Related Data on same Page

Integrated Display

Annotating Display of Continued Data

Numbering Display Pages

Graphic Indication of Scroll Position

Common Display Structure

Scrolling Structures Appear where Appropriate

One structure for Vertical, one for Horizontal Movement

Indicate Absolute and Relative Positions of User

Labeling Scrolling Function

Paging

Paging in one or Multiple Page Increments

Evident Direction of Paging

Discrete Movement of File

Several Different Means of Scrolling

Scroll by Line or Display Unit

Parameters Refer to Data not Window

String Search

Search for Line Numbers

Multiple Methods of Searching

Saving to a Data File

Automatic Saving of a Data File

Exiting a Data File

Protection Against Exiting a File without Saving

Exit with Save

Automatic Backup

Accidentally Replacing a Data File

Distinct Commands for Exit With and without save

Verify Exit with Delete New Inputs

Access of Modified Data After Exit Without Save

Automatic Placement of Cut Data in Buffer

Contents of Temporary Buffer

Default Conditions of Buffer

Access to Contents of Temporary Buffer

Excerpt File

Pasting Data into an Excerpt File

Integrating Data

Cutting or Copying Data From the Excerpt File

Saving the Excerpt File

Retrieval Buffer

Print Queue

Response time consistent with requirements

Fast Response

Fast Acknowledgement of Entry

Response time induced keyboard lockout

Keyboard restoration 
2. 5-6

2. $5-7$

2. $5-8$

2. 5-9

2. 5-10

2. 5-11

$2 \cdot 5-12$

$2 \cdot 5-13$

2. 5-14

$2 \cdot 5-15$

2. 5-16

2. 5-17

2. 5-18

SECTION

3.1

3-2

$3-3$

$3-4$

SECTION

4. 1. 1-1

$4.1 .1-2$

$4 \cdot 1 \cdot 1-3$

$4 \cdot 1.1-4$

$4.1 .1-5$

$4 \cdot 1 \cdot 1-6$

$4.1 .1-7$

4.1.1-8

4.1.1-9

4. $1.1-10$

4.1.1-11

$4.1 \cdot 1-12$

4.1.1-13

4.1.1-14

$4 \cdot 1 \cdot 1-15$

4. $1.1-16$

$4.1 .1-17$

$4 \cdot 1 \cdot 1-18$

4.1.1-19

4. 1. 2-1

$4 \cdot 1 \cdot 2-2$

$4 \cdot 1 \cdot 2-3$

$4 \cdot 1 \cdot 2-4$

$4 \cdot 1 \cdot 2-5$

$4 \cdot 1 \cdot 2-6$

4.1.2-7

Fast Response to Display Request

Data Display Time

Regenerating Changed Data

Processing delay

Indicating Completion of Processing

Appropriate Computer Response Time For User Control

Entries

Error Message Display Time

Response Time to Menu Selections

Response Time to Lightpen Menu Selections

Response Time to Key Activations

Response Time to Cursor Positioning by Lightpen

Variability of Response Time

Maximum system Response Times

\section{3}

Alarm Acknowledgment

Alarm Reset

Special Acknowledgment of Critical Alarms

Alarm settings

4

Standard Display Location for Prompting

Consistent Format for Prompts

Standard Symbol for Prompting Entry

Concise Wording of Prompts

Prompting Data Entry

Standard Symbol for Prompting Entry

Prompting Field Length

Data Format cueing in Labels

Operator-Requested Prompts

Graphic Display of Control Prompting

Prompting control Entries

Prompting Command Correction

Familiar wording

Prompting Entries

Standard Display Location for Prompting

Concise wording of Prompts

Prompting Address Entry

Prompting LOG-ON

Confirmation of Default Values

Redundant Display

Graphical Display

Auditory Signals for Alerting operators

Coding Synthesized Voice Warnings

Distinctive and Consistent Warnings

warning of Threats to Security

Warning Operators of Potential Data Loss 
4. $1.2-8$

4. $1 \cdot 3-1$

4.1.3-2

$4 \cdot 1 \cdot 3-3$

$4 \cdot 1 \cdot 3-4$

4.1. 4-1

4.1.4-2

4.1. 4-3

$4 \cdot 1 \cdot 4-4$

$4 \cdot 1 \cdot 4-5$

$4 \cdot 1 \cdot 4-6$

4.1. 4-7

$4 \cdot 1 \cdot 4-8$

4.1.4-9

4.1.4-10

4.1. . 4-11

4. $1.4-12$

4.1. $4-13$

4. $1.4-14$

4.1.4-15

4. $1.4-16$

$4 \cdot 1 \cdot 4-17$

4. $1.4-18$

4. $1.4-19$

4. $1.4-20$

4.1.4-21

4.1. 4-22

4 . $1.4-23$

4.1. $4-24$

4.1.4-25

4.1. $4-26$

4.1. 4-27

$4 \cdot 1 \cdot 4-28$

$4 \cdot 1 \cdot 5-1$

4.1.5-2

$4 \cdot 1 \cdot 5-3$

4.1.5-4

$4 \cdot 1 \cdot 5-5$

$4 \cdot 1 \cdot 5-6$

$4.1 .5-7$

$4 \cdot 1 \cdot 5-8$

4.1.5-9

$4 \cdot 1 \cdot 5-10$

$4 \cdot 1 \cdot 5-11$

$4 \cdot 1 \cdot 5-12$

$4.1 \cdot 5-13$

4.1.5-14

$4 \cdot 1 \cdot 5-15$

4.1.6-1

4.1.6-2

$4 \cdot 1 \cdot 6-3$

4.1. $6-4$
Time-consuming processes

Signaling Completion of Display output

Feedback for Menu Selection

Feedback for Function Key Activation

Clearly Worded Messages

standard Procedures

Explicit operator Actions

only Necessary Information Displayed

Consistent Display Format

Consistent Format for Operator Guidance

Distinctive Format for operator Guidance

Distinctive Cursors

clear Control Labels

clear Data Labels

Highlighting Critical Operator Guidance

consistent coding Conventions

Familiar coding Conventions

Consistent Wording

Familiar Wording

Task-oriented wording

Wording consistent with control Entry

Speaking Directly to operators

Affirmative statements

Active Voice

Anthropomorphism

Temporal Sequence

Consistent Grammatical structure

Easy Ways to Get Guidance

Speech output

Limited Number of Spoken Messages

Simple Spoken Messages

Distinctive Spoken Warnings

Wording Consistent with operator Guidance

Indicating status

Automatic LOG-ON Display

LOG-ON Feedback

LOG-ON Delay

LOG-ON Failure

Operator Status

Keyboard Lock

Operational Mode

other operators

System Load

Date and Time signals

Consistent status Presentation

Wording of Status Messages

Status Message Alert

Processing Delay

Feedback During Data Entry

Feedback for Completion of Data Entry

Feedback when Changing Data

Feedback for Control Entries 
$4 \cdot 1 \cdot 6-5$

$4 \cdot 1 \cdot 6-6$

4.1. $1 \cdot 6-7$

$4.1 \cdot 6-8$

4.1.6-9

4.1.6-10

4. 1. 6-11

4.1. 6-12

$4 \cdot 1 \cdot 6-13$

$4.1 \cdot 6-14$

$4.1 \cdot 6-15$

4.1. 7-1

4.1.7-2

4.1.7-3

4.1. 7-4

4.1. 7-5

4.1. 7-6

4.1.7-7

4.1.7-8

4.1. 7-9

4.1.7-10

$4 \cdot 1 \cdot 7-11$

$4 \cdot 1 \cdot 7-12$

$4 \cdot 1 \cdot 7-13$

$4 \cdot 1 \cdot 7-14$

4.1.7-15

$4 \cdot 1 \cdot 7-16$

4.1.7-17

4.1. 7-18

4.1. 7-19

4. 1. 7-20

$4 \cdot 1 \cdot 7-21$

4.1.7-22

$4 \cdot 1 \cdot 7-23$

4.1. 7-24

4.1.7-25

$4 \cdot 1 \cdot 8-1$

4.1.8-2

$4.1 .8-3$

$4.1 .8-4$

$4 \cdot 1 \cdot 8-5$

$4 \cdot 1 \cdot 8-6$

$4 \cdot 1 \cdot 8-7$

$4 \cdot 1.8-8$

4.1. 8-9

4.1.8-10

$4.1 .8-11$

4. $1.8-12$

$4 \cdot 1 \cdot 8-13$

$4 \cdot 1 \cdot 8-14$

$4.1 \cdot 8-15$

$4 \cdot 1 \cdot 8-16$
Indicating Completion of Processing

Consistent Feedback

Fast Response

Status Indication During Processing

Feedback for Print Requests

Display Identification

Identifying Multipage Displays

Indicating operational Mode

Indicating option Selection

Indicating Item selection

Feedback for Operator Interrupt

Informative Error Messages

Specific Error Messages

Task-Oriented Error Messages

Advisory Error Messages

Brief Error Messages

Neutral Wording for Error Messages

Multilevel Error Messages

Multiple Error Messages

Indicating Repeated Errors

Non-Disruptive Error Messages

Appropriate Response Time for Error Messages

Documenting Error Messages

Cursor Placement Following Error

Displaying Erroneous Entries

operator Editing of Entry Errors

Removing Error Messages

Cautionary Messages

Operator Confirmation of Destructive Entries

Warning coding

Entry of Corrections

Return to Main Dialogue

Error Message Placement

Distinguishing Among Error Types

Invalid Action

Errors in Stacked Commands

Guidance Information Always Available

Access to Job Aids

General List of Control Options

Logical Menu Structure

Hierarchic Menus

Guidance for OPERATOR GUIDANCE

Transaction-Specific Option Display

Displayed Context

Maintaining Context for Data Entry

Cues for Prompting Data Entry

Consistent Cursor Positioning

on-Line system Guidance

Index of Data

Index of commands

Dictionary of Abbreviations

Definition of Display Codes 
4.1.8-17 Record of Past Transactions

4.1.9-1 Notifying operators

4.1.9-2 Transaction Records

4.1.9-3 Data Access Records

4.1.9-4 Error Records

4.1.9-5 HELP Records

4.1.10.1-1 HELP

4.1.10.1-2 Standard Action to Request HELP

4.1.10.1-3 Task-Oriented HELP

4.1.10.1-4 Clarifying HELP Requests

4.1.10.1-5 synonyms for standard Terminology

4.1.10.1-6 Multilevel HELP

4.1.10.1-7 Browsing HELP

4.1.10.1-8 Return from HELP

4.1.10.1-9 Access to HELP

4.1.10.1-10 Automatic HELP

4.1.10.1-11 HELP Display Format

4.1.10.1-12 HELP Guidance

4.1.10.1-13 HELP Context

4.1.10.1-14 HELP Index

4.1.10.1-15 HELP Security

4.1.10.2-1 On-Line Training

4.2.1.1-1 Basis for Expert System Development

4.2.1.1-2 Representing Causality

4.2.1.1-3 Specify Domains

4.2.1.1-4 Domain Model Contents

4.2.1.1-5 Domain Principle Contents

4.2.1.2-1 Dialog Initiation Flexibility

4.2.1.2-2 Dialog Sequencing Flexibility

4.2.1.2-3 Dialog Modes for Operators

4.2.1.2-4 Rapid Transaction Retrieval

4.2.1.2-5 Information Exchange

4.2.1.2-6 Minimize the Systems Inquire of Operators

4.2.1.2-7 Minimize Operator Request Requirements

4.2.1.3-1 Strategy Planning Provision

4.2.1.3-2 strategy support and selection

4.2.1.3-3 Forward and Backward Chaining support

4.2.1.3-4 Action Simulation Mode Support

4.2.1.3-5 Action Simulation Mode command and Identification

4.2.1.3-6 Interactive Explanation Capability

4.2.1.4-1 Freeze Capability for Dynamic Information

4.2.1.4-2 Status Change Highlights

4.2.1.4-3 Critical Information Alert

4.2.1.4-4 Graphic Representation of Rules

4.2.1.4-5 Graphic Representation of System configuration and Parameters

4.2.1.4-6 Status Display Using Coding Techniques

4.2.1.4-7 Consistency of Coding Techniques

4.2.1.4-8 off-line Printing Capability

4.2.1.5-1 Weighting Certainty Factors

4.2.1.5-2 Priority scheme for weighting

4.2.1.5-3 Provide Weighting Rationale 
4.2.1.5-4 Certainty Factors Representation Capability

4.2.1.5-5 Cumulative certainty Representation

4.2.1.5-6 Use of Decimal coding of Certainty

4.2.1.5-7 Provide Underlying Certainty Judgement Rationale

4.2.1.6-1 Explanation Capability

4.2.1.6-2 Representing Results

4.2.1.6-3 Display of Current Rule

4.2.1.6-4 Rule Recording

4.2.1.6-5 Post Hoc Rule-Event Recall

4.2.1.6-6 Knowledge Base Search to Operator Query

4.2.1.6-7 Inadequate Knowledge Alert

4.2.1.6-8 Respond to Operator Requests

4.2.1.6-9 Explanation Display

4.2.1.6-10 strategy Selection Explanation

4.2.1.6-11 Consistency with Operator Strategies

4.2.1.6-12 Consistent Nomenclature

4.2.1.6-13 Strategy and Process Understanding

4.2.1.6-14 Strategy Explanation

4.2.1.6-15 Explicit Rule Representation

4.2.1.6-16 Rule Exceptions

4.2.1.6-17 Access to Hypothesis ordering Rationale

4.2.1.6-18 Operator Control of Explanation Detail

4.2.1.6-19 Three Levels of Explanation Detail

4.2.1.6-20 Explanation Detail Default

4.2.1.6-21 Explanation by Means-Ends Analysis Systems

4.2.1.6-22 Provide Goodness-of-Fit Estimate

SECTION 5

5. $1-1$

$5.1-2$

$5.1-3$

$5 \cdot 1-4$

$5 \cdot 1-5$

$5.1-6$

$5.1-7$

$5.1-8$

$5.1-9$

$5.1-10$

$5 \cdot 1-11$

$5 \cdot 2-1$

$5.2-2$

$5 \cdot 2-3$

$5.2-4$

$5.2-5$

$5.2-6$

$5.2-7$

$5.2-8$

$5.2-9$

$5 \cdot 2-10$

$5.2-11$
Functional Integration

Interactive Communication

Functional wording

Consistent Procedures

Minimal Memory Load on User

Minimal User Actions

Control by Explicit User Action

Flexible Control of Data Transmission

Interrupt

Flexible Message Filing

Message Highlighting

Message Composition Compatible with Data Entry

User-Designed Message Formats

Unformatted Text

Stored Message Forms

Automatic Message Formatting

Automatic Text Formatting

Data Forms

Tables and Graphics

Flexible Data Specification

Incorporate Existing Files

Incorporate Other Messages 


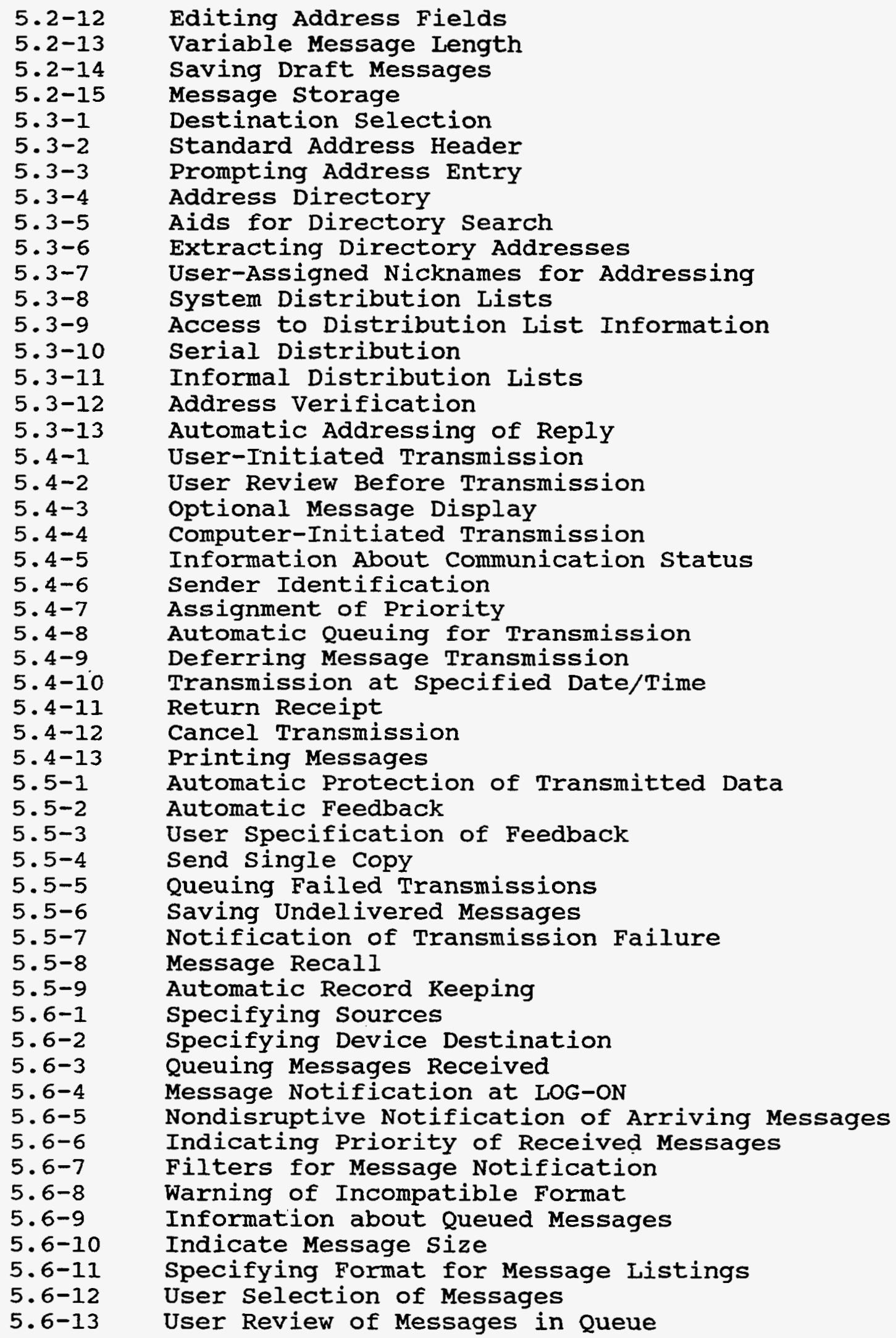


$5 \cdot 6-14$
$5.6-15$
$5 \cdot 6-16$
$5 \cdot 6-17$
$5 \cdot 6-18$
$5.6-19$

SECTION 6

6. 1-1

6. 1-2

6. 2-1

6. 2-2

6. $2-3$

6. 2-4

6. 2-5

6. 2-6

6. 2-7

6. 2-8

6. 2-9

6. 3-1

6. 3-2

6. $3-3$

$6.3-4$

6. 3-5

$6 \cdot 3-6$

$6 \cdot 3-7$

6. 3-8

6. 3-9

6. 3-10

6. 4-1

6. 4-2

6. 4-3

6. 4-4

6. 4-5

6. $4-6$

6. 4-7

Filters for ordering Message Review

Message Review Compatible with Data Display

Labeling Received Messages

Annotating Received Messages

Filters for Message Filing

Discarding Messages

Automated Security Measures

Warning of Threats to Security

Easy LOG-ON

Prompting LOG-ON

User Choice of Passwords

Changing Passwords

Private Entry of Passwords

Limiting Unsuccessful LOG-ON Attempts

Auxiliary Tests to Authenticate User Identity

Continuous Recognition of User Identity

Single Authorization for Data Entry/Change

Single Authorization for Data Access

Displayed Security Classification

Protecting Displayed Data

Indicating "Read-Only" Displays

Protecting Display Formats

Display Suppression for Security

Protecting Printed Data

Automatic Records of Data Access

Encryption

Ensuring Reversible Encryption

Automatic Protection of Transmitted Data

User Review of Data Before Transmission

Encrypting Messages

Saving Transmitted Data Until Receipt is Confirmed

Nondisruptive Notification of Messages Received

Authenticating Message Sources

Printing Messages

Section 7

7.1.1.1-1 Mechanical overlays

7.1.1.2-1 Viewing distance

7.1.1.2-2 Display Luminance

7.1.1.2-3 Luminance control

7.1.1.2-4 Faint Signals

7.1.1.2-5 Ambient illumination

7.1.1.2-6 Display glare

7.1.1.2-7 Illuminance of surrounding area

7.1.1.2-8 Pictorial/Graphic Situation Formats

7.1.1.2-9 Font legibility 
7.1.1.2-10 symbol legibility

7.1.1.2-11 Screen Size

7.1.1.2-12 Choice of Phosphor

7.1.1.2-13 Image continuity

$7 \cdot 1 \cdot 1 \cdot 2-14$ Resolution

$7.1 \cdot 1.2-15$ Contrast

$7.1 .1 .2-16$ Use of Color

$7.1 .1 .2-17$ color coding

7.1.1.2-18 Color Contrast

7.1.1.2-19 Absolute intensity coding

7.1.1.2-20 Relative intensity coding

7.1.1.2-21 Blinking

7.1.1.2-22 Image Linearity

7.1.1.2-23 Geometric stability

7.1.1.2-24 Luminance Uniformity

7.1.1.2-25 Flicker

7.1.1.2-26 Viewing Angle

7.1.1.2-27 Controls

7.1.1.3-1 Liquid Crystal Luminance

7.1.1.7-1 Character Size

7.1.1.8-1 Intensity control

7.1.1.8-2 Color Coding

7.1.1.8-3 Lamp Testing

7.1.1.9-1 Maximum Viewing Distance

7.1.1.9-2 Minimum Viewing Distance

7.1.1.9-3 Interruption of view

7.1.1.9-4 Control of Display

7.1.1.9-5 Information Content

7.1.2.3-1 Seating Area

7.1.2.3-2 Image Luminance

7.1.2.3-3 style of Projected Data

7.1.2.3-4 Size of Projected Characters

7.1.2.3-5 Luminance Ratio

7.1.2.3-6 contrast Polarity

7.1.2.3-7 Alignment

7.1.2.3-8 Keystone Effects

$7 \cdot 1 \cdot 3 \cdot 1-1$ Use

7.1.3.1-2 Visibility

7.1.3.1-3 Contrast

$7 \cdot 1 \cdot 3 \cdot 1-4$ Illumination

7.1.3.1-5 Take-up provision

7.1.3.1-6 Annotation

7.1.3.1-7 Legibility

7.1.3.1-8 Printed tapes

7.1.3.1-9 Indication of Supply of Materials

7.1.3.1-10 Serviceability

7.1.3.1-11 Controls and displays

7.1.4-1 visibility

7.1.4-2 Contrast

7.1.4-3 Take-up device

$7.1 .4-4$ Job Aids

7.1.4-5 Smudging/smearing 
Annotation

$7 \cdot 1 \cdot 4-7$ Control, replenishment and service

$7 \cdot 1 \cdot 5 \cdot 1-1$ Type of voice

$7 \cdot 1 \cdot 5 \cdot 1-2$

$7 \cdot 1 \cdot 5 \cdot 1-3$

Delivery style

7.1.5.1-4 Coding Synthesized Voice warnings

7.1.5.1-5 Speech output

7.1.5.1-6 Limited Number of Spoken Messages

7.1.5.1-7 Simple Spoken Messages

7.1.5.1-8 Distinctive Spoken Warnings

7.1.5.1-9 Intensity of Voice Presentation

7.1.5.1-10 Word Selection

7.1.5.1-11 Nature of signals

7.1.5.1-12 Use of Voice Displays

7.1.5.1-13 Speech processing

7.1.5.1-14 Message content

7.1.5.1-15 Speech Intelligibility

7.1.5.2-1 Audio Coding

7.1.5.2-2 Intensity of Audio Signal

7.1.5.2-3 Frequency of Audio Signal

7.1.5.2-4 Confusible Signals

7.1.5.2-5 Alerting Signal

7.1.5.2-6 Signal type

7.1.5.2-7 False Alarms

7.1.5.2-8 Failure

7.1.5.2-9 Circuit Test

7.1.5.2-10 Use with Several Visual Displays

7.1.5.2-11 Warning Signals

7.1.5.2-12 Nature of Signals

$7 \cdot 1 \cdot 5 \cdot 2-13$ Caution signals

7.1.5.2-14 Relation to Visual Displays

7.1.5.2-15 Alerting capability

7.1.5.2-16 Critical signals

7.1.5.2-17 Action segment

7.1.5.2-18 Compatibility

$7 \cdot 1 \cdot 5 \cdot 2-19$ Masking

7.1.5.2-20 Message categories

7.1.5.3-1 Automatic or manual shut-off

7.1.5.3-2 Automatic reset

7.1.5.3-3 Volume control

$7 \cdot 1 \cdot 5 \cdot 3-4$ Duration

7.1.5.3-5 Duration limitations

7.1.5.4-1 Frequency

7.1.5.4-2 Dynamic Range

7.1.5.4-3 Noise Canceling Microphones

7.1.5.4-4 Pre-emphasis

7.1.5.4-5 Peak-clipping of speech signals

$7.1 .5 .4-6$ Noise shields

7.1.5.4-7 Frequency range

7.1.5.4-8 Loudspeakers for multi-channel monitoring

7.1.5.4-9 Use of de-emphasis

7.1.5.4-10 Headsets 
7.1.5.4-11 comfort

7.1.5.4-12 Hands-free operation

7.1.5.4-13 Accessibility of handsets

7.1.5.4-14 Volume controls

7.1.5.4-15 Squelch control

7.1.5.4-16 Foot-operated controls

7.1.5.4-17 speaker/side tone

7.1.5.4-18 supportive function - audio

7.1.5.4-19 Signal characteristics

7.1.5.4-20 Alarm settings

7.2.1.1-1 Repeat Capability

7.2.1.1-2 Alternate Key Definitions

7.2.1.1-3 Repeat Capability for Cursor Keys

7.2.1.1-4 Cursor control

7.2.1.1-5 Cursor Key Layout

$7.2 .1 .1-6$ Numeric Keypads

7.2.1.1-7 Minimization of Shift Keying

7.2.1.1-8 Overlays

7.2.1.1-9 Key Force

7.2.1.1-10 Multiple-key Rollover

7.2.1.1-11 Key Displacement

7.2.1.1-12 Functional grouping

7.2.1.1-13 Keytop Symbols

$7 \cdot 2 \cdot 1 \cdot 1-14$ Keyboard Surfaces

7.2.1.1-15 Keytop Font

7.2.1.1-16 Keytop Size

$7.2 \cdot 1 \cdot 1-17$ Key spacing

7.2.1.1-18 Push-Button Height

7.2.1.1-19 Key Height

7.2.1.1-20 Keyboard Slope

7.2.1.1-21 slope Adjustment

7.2.1.1-22 Keyboard Thickness

7.2.1.1-23 Inadvertent operation

7.2.1.1-24 Standard Layout

7.2.1.1-25 Keyboard Placement

7.2.1.1-26 Key Nomenclature

7.2.1.1-27 Keying Feedback

7.2.1.1-28 Keyboard Stability

7.2.1.1-29 Keystroke Commands

7.2.1.1-30 Simultaneous Keystrokes

$7.2 \cdot 1 \cdot 2-1$ Repeat

7.2.1.2-2 Inactive Function Keys

7.2.1.2-3 Function Legend

7.2.1.2-4 Standardization

7.2.1.2-5 Functional Consistency

7.2.1.2-6 Availability

7.2.1.2-7 Inactive Keys

7.2.1.2-8 Grouping

7.2.1.2-9 Actuation

7.2.1.2-10 Feedback

7.2.1.2-11 Function labels

7.2.1.3-1 status display 
7.2.1.3-2 Reprogrammable or inactive default functions

7.2.1.3-3 Relabeling

7.2.1.3-4 Shifted Characters

7.2.1.3-5 Easy return to base-level functions

7.2.2.1-1 Control/Display Ratios

7.2.2.1-2 Selectable Tracking Speed

7.2.2.1-3 Selectable Rate Aiding

7.2.2.1-4 Maximum Response Delay Time

7.2.2.1-5 Selectable Inter-Click Interval

7.2.2.1-6 Cursor-Controller Movement Correlation

7.2.2.1-7 Single Monitor/Single Controller Cursor Travel Limits

7.2.2.1-8 Multi Monitor/Multi Controller Cursor Characteristics

7.2.2.1-9 Controller X-Y Movement Requirements

7.2.2.1-10 Selectable Screen Region Size

7.2.2.1-11 Single Controller Input Recognition

7.2.2.1-12 Feedback

7.2.2.2-1 Appropriate Use of Trackball

7.2.2.2-2 Trackball Dynamic Characteristics

7.2.2.2-3 Positive Centering Interface Requirements

7.2.2.2-4 Trackball Dimensions, Resistance and clearance

7.2.2.2-5 Limb Support

7.2.2.3-1 Appropriate Use of Mice

$7.2 \cdot 2 \cdot 3-2$ Mouse Dynamic Characteristics

$7.2 \cdot 2 \cdot 3-3$ Mouse Dimensions and Shape

$7.2 .2 \cdot 3-4$ Use of Mouse by Either Hand

7.2.2.4.1-1 Appropriate Use of Force Joysticks

7.2.2.4.1-2 Hand-Operated Force Joysticks Dynamic Characteristics

7.2.2.4.1-3 Hand-Operated Force Joysticks Dimensions, Resistance, and Clearance

7.2.2.4.1-4 Finger-Operated Force Joystick Dynamic Characteristics

7.2.2.4.1-5 Finger-Operated Force Joystick Dimensions, Resistance, and clearance

7.2.2.4.1-6 Thumb/Fingertip-Operated Force Joystick Dynamic Characteristics

7.2.2.4.1-7 Thumb/Fingertip-operated Force Joystick Dimensions, Resistance and clearance

7.2.2.4.2-1 Appropriate Use of Displacement (Isotonic) Joysticks

7.2.2.4.2-2 Hand-Operated Displacement Joysticks Dynamic Characteristics

7.2.2.4.2-3 Hand-Operated Displacement Joysticks Dimensions, Resistance, and clearance

7.2.2.4.2-4 Finger-operated Displacement Joysticks Dynamic Characteristics

7.2.2.4.2-5 Finger-Operated Displacement Joysticks Dimensions, Resistance, and clearance

7.2.2.4.2-6 Thumbtip/Fingertip-Operated Displacement Joysticks Dynamic Characteristics

7.2.2.4.2-7 Thumbtip/Fingertip-Operated Displacement Joysticks

Dimensions, Resistance, and Clearance

7.2.3.1-1 Controller Placement and Movement

7.2.3.1-2 Direct Pointing Controller Placement Location

7.2.3.2-1 Appropriate Use of Touch-screen Controllers 
7.2.3.2-2 Dimensions and Separation of Touch Zones

7.2.3.2-3 Cursor Characteristics

$7.2 \cdot 3 \cdot 2-4$ Resistance

7.2.3.2-5 Serial Command Response

7.2.3.2-6 Actuation Feedback

7.2.3.2-7 Feedback for Multiple Workstations

7.2.3.2-8 Neutral Tint of Touch Overlays

7.2.3.2-9 Luminance Transmission

7.2.3.3-1 Appropriate Use of a Light Pen

7.2.3.3-2 Dynamic Characteristics

7.2.3.3-3 Dimensions and mounting

7.2.3.3-4 Light Pen Actuation

$7 \cdot 2 \cdot 3 \cdot 3-5$ Feedback

7.2.3.4-1 Appropriate Use of a Graphics Tablet

7.2.3.4-2 Dynamic Characteristics

7.2.3.4-3 Dimensions and Mounting

7.2.4.1-1 Dynamic Characteristics

7.2.4.1-2 Z-Dimension Movement

7.4.1.1-1 Nonreflecting Screen Positioning

7.4.1.1-2 Nonglare VDU Screen Surface

7.4.1.2-1 Static Electricity Humidity control

7.4.1.2-2 Static Electricity Ground Control System 
APPENDIX G:

ACRDR GUIDEIINES FOR CONTROL AND INPUT DEVICES 


\subsection{Control and Input Devices}

\subsubsection{Reyboards}

\subsubsection{General}

7.2.1.1-31 Numeric Keypad Configuration

The configuration of the numeric keypad should be a $3 \times 3+1$ matrix with the zero digit centered on the bottom row.

COMMENT:

ASSESSMENT METHODOLOGY:

SOURCE: MIL-STD-1472D, 1989

CLASSIFICATION: Primary

$* * * * * * * * * *$

\subsubsection{1-32 Numeric Keypad Layout}

The layout of numeric keypads should be either telephone or calculator style.

COMMENT: Research indicates that a slight advantage can be obtained using the telephone arrangement. For control station applications where a premium is not placed on rapid entry of numerical data, either the calculator or telephone arrangement is acceptable. Whichever type of keypad is selected, it should be standardized throughout all control station applications since alternation between layouts degrades performance. ASSESSMENT METHODOLOGY: SOURCE: Gilmore, Gertman, and Blackman, 1989; Salvendy, 1987 CLASSIFICATION: Primary; secondary

7.2.1.1-33 Handedness of the Numeric Keypad The positioning of the numeric keypad should permit easy use for both right- and left-handed operators.

COMMENT: Fast entry of massed numbers usually requires use of the preferred hand. Numeric keypads should thus be mounted either in a separate module from the main keyboard that can be placed on either side of the keyboard, or with two controls, one on each side of the keyboard.

ASSESSMENT METHODOLOGY:

SOURCE: Brown, 1989

CLASSIFICATION: Secondary

$\star \star \star * * \star * * * *$

7.2.1.1-34 Multiple Keyboards

Control station systems containing more than one keyboard should maintain the same configuration for alphanumeric and numeric keys throughout the system.

COMMENT:

ASSESSMENT METHODOLOGY:

SOURCE: MIL-STD-1472D, 1989

CLASSIFICATION : Primary 


\subsubsection{1-35 Other Key Locations}

Frequently used keys which are not part of the typing keyboard, cursor keyboard, or numeric keypad should be placed in the locations in which they are most convenient to use. Keys with potentially destructive consequences should be physically protected with some type of key guard.

COMMENT:

ASSESSMENT METHODOLOGY:

SOURCE: NASA-STD-3000, Rev. A, 1989

CLASSIFICATION: Primary

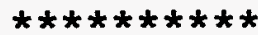

7.2.1.1-36 Keyboard Interlock

A keyboard interlock should exist to prevent the outputs from two or more simultaneously depressed keys from either jamming the print mechanism or outputting an invalid keycode.

COMMENT:

ASSESSMENT METHODOLOGY:

SOURCE: NASA-STD-3000, Rev. A, 1989

CLASSIFICATION: Primary

$\star * \star * * * * * * *$

7.2.1.1-37 Keyboard Control Switches

All commonly used controls associated with keyboard functioning (e.g., on/off) should be readily accessible to the operator.

COMMENT: Both the control and its labeling should be visible to the operator.

ASSESSMENT METHODOLOGY :

SOURCE: NASA-STD-3000, Rev. A, 1989

CLASSIFICATION: Primary

$\star \star \star \star * \star * \star * \star *$

7.2.1.1-38 Keyboard Profile

The keyboard rows should be arranged in either a stepped, dished, sculptured, or flat profile.

COMMENT:

ASSESSMENT METHODOLOGY:

SOURCE: ANSI/HFS 100, 1988

CLASSIFICATION : Primary

$\star \star * \star * * * * * *$

7.2.1.1-39 Cursor Control Key Use

cursor control keys should be used for short, discrete movements of the cursor to character positions.

COMMENT: Cursor movements over long screen distances using cursor control keys are slow. Cursor control keys are usually not effective for control station tasks which require precise positioning, such as graphical input or manipulation tasks.

ASSESSMENT METHODOLOGY:

SOURCE: BrOWn, 1989 
CLASSIFICATION: Secondary

$* * * * * * * * * *$

$7.2 \cdot 1 \cdot 1-40$ Jump Keys

Arrow keys should be used as jump keys.

COMMENT: Arrow keys (tab keys or cursor keys) can be used to expedite cursor selection if they are programmed to cause the cursor to jump to the next (right-arrow) or previous (left-arrow) selectable target.

ASSESSMENT METHODOLOGY:

SOURCE: BrOWn, 1989

CLASSIFICATION: Secondary

$\star \star * * * * * * * *$

7.2.1.1-41 Visual Feedback

The computer screen should provide visual feedback each time a key is activated.

COMMENT:

ASSESSMENT METHODOLOGY:

SOURCE: NASA-STD-3000, ReV. A, 1989

CLASSIFICATION : PrimarY

$\star * * * * * * * * *$

7.2.1.1-42 Keytop Shape

Keys should be indented to fit the shape of the finger tip for ease of location and finger tip placement.

COMMENT: Preferences appear to lean toward keys that are spherically indented as opposed to those having only a cylindrical indentation. The latter are more prevalent on current keyboards in the U.S. and have not been found to adversely affect performance. ASSESSMENT METHODOLOGY:

SOURCE: Helander, 1988

CLASSIFICATION: Tertiary

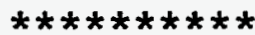

7.2.1.1-43 Key Hysteresis

Hysteresis of the alphanumeric and symbol character keys should be provided.

COMMENT: A key is actuated at the "switch closed" point on the downstroke. Upon release, the switch remains closed until the key travels past the "switch open" point. If the closed and open points occur at the same place, extra keystrokes can be inserted when the typing finger hesitates or is not smooth on the upstroke. This problem is eliminated by hysteresis, which is the travel distance between the switch close and switch open points. That is, the switch remains closed on the upstroke even past the point at which the key was actuated on the downstroke.

ASSESSMENT METHODOLOGY:

SOURCE: Helander, 1988

CLASSIFICATION: Tertiary

$\star \star \star \star \star \star \star \star * * *$ 


\subsubsection{1-44 Buffer Length}

The alphanumeric keyboard should be provided with a large buffer (of at least seven characters).

COMMENT: Keyboards should allow the operator to "type ahead" of the display. This feature is particularly useful when the display is dependent on the response of the control station system. If the operator knows ahead of time what input should be entered next, the delay of the control station system can be avoided by storing keystrokes in a buffer until the system is ready to receive them. ASSESSMENT METHODOLOGY:

SOURCE: Helander, 1988

CLASSIFICATION: Tertiary

$\star \star \star \star * * * * * * * *$

\subsubsection{1-45 Keyboard Height}

The keyboard height should be variable.

COMMENT: The height should include at least one setting wherein the C-row measured at the highest point on the center line of the c-row, measured from the support surface, is less than or equal to $30 \mathrm{~mm}$.

ASSESSMENT METHODOLOGY:

SOURCE: IBM Corporate Standard, 1988

CLASSIFICATION: Tertiary

$* * * * * * * * * *$

\subsubsection{Special Function Keys}

7.2.1.2-12 Fixed Function Key Use

Fixed function keys should be reserved for time-critical, errorcritical, or frequently used control inputs.

COMMENT:

ASSESSMENT METHODOLOGY:

SOURCE: MIL-STD-1472D, 1989

CLASSIFICATION: Primary

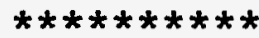

\subsubsection{2-13 Common Functions}

Fixed function keys should be used for universal functions that are likely to be used in a wide variety of control station applications.

COMMENT: Proper selection and use of fixed functions can provide a mechanism for diverse control station applications to perform common functions in the same way. This can simplify learning of new applications and reduce the likelihood of negative transfer, which can occur when different programs require different operator responses to initiate the same control station function. ASSESSMENT METHODOLOGY:

SOURCE: Brown, 1989

CLASSIFICATION: Secondary

$\star \star \star * \star * \star * * *$

7.2.1.2-14 Active Functions 
When some control station functions are only available in certain situations or at certain stages of the dialogue, the fixed function keys which are currently active should be shown.

COMMENT: Examples of highlighted active keys include backlighted keys or small lights such as light-emitting diodes imbedded in the keys. Only those functions that are currently active are lit.

ASSESSMENT METHODOLOGY:

SOURCE: BrOWn, 1989

CLASSIFICATION: Secondary

$* * * * * * * * * *$

7.2.1.2-15 Fixed Function Keys and Alphanumeric Keyboards When fixed function keys are included with an alphanumeric keyboard, the fixed function keys should be physically separate. COMMENT: Multiple-mode keyboards which utilize the same keys for both alphanumerics and control station functions by using shift keys or mode selection controls should be avoided.

ASSESSMENT METHODOLOGY:

SOURCE: Gilmore, Gertman, and Blackman, 1989

CLASSIFICATION: Primary

$\star * \star * * * * \star * *$

7.2.1.2-16 Layout Compatible with Use

The layout of fixed function keys should be compatible with their importance.

COMMENT: Fixed function keys for emergency functions should be given a prominent position and distinctive coding.

ASSESSMENT METHODOLOGY:

SOURCE : ESD-TR-86-278, 1986

CLASSIFICATION: Primary

$* * * * * * * * * *$

7.2.1.2-17 Visual Search and Arm/Hand Movement

The arrangement of the fixed function keys should minimize the amount of visual search and arm/hand movement required to interface with the keys.

COMMENT :

ASSESSMENT METHODOLOGY:

SOURCE: Allen, 1990

CLASSIFICATION: Secondary

$\star \star \star \star \star * * * * * *$

\subsubsection{Variable Function Keys}

7.2.1.3-6 Variable Function Key Application

Variable function keys should be utilized for programmable menu selection and entry of control station functions. They should be provided whenever the key functions may potentially change.

COMMENT:

ASSESSMENT METHODOLOGY:

SOURCE: MIL-STD-1472D, 1989

CLASSIFICATION: Primary 


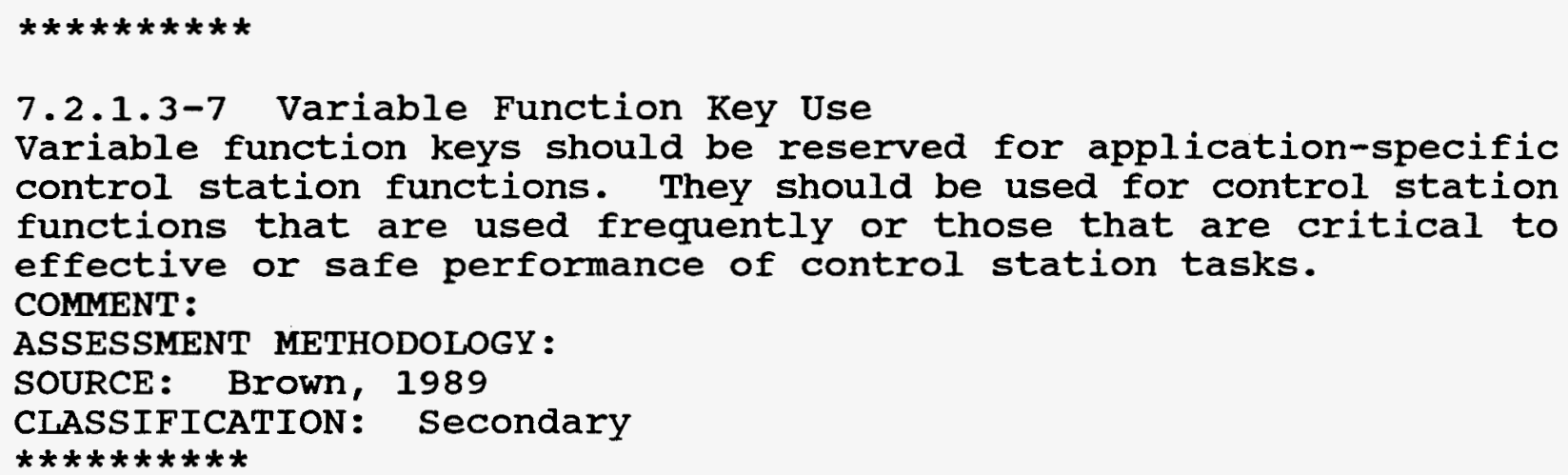
control station functions. They should be used for control station functions that are used frequently or those that are critical to effective or safe performance of control station tasks.

COMMENT:

ASSESSMENT METHODOLOGY :

SOURCE: Brown, 1989

CLASSIFICATION: Secondary

$* * * * * * * * * *$

7.2.1.3-8 Repeat

Variable function keys should not repeat.

COMMENT :

ASSESSMENT METHODOLOGY:

SOURCE: NASA USE 1000, V. 2.1, 1988

CLASSIFICATION: Primary

$\star * * * * * * * * *$

7.2.1.3-9 Consistent Variable Functions once a control station function has been assigned to a given variable function key it should not be reassigned later to a different key.

COMMENT: Throughout the control station system, however, the same key may have to be assigned to different functions as required by the control station tasks to be performed.

ASSESSMENT METHODOLOGY:

SOURCE: Brown, 1989

CLASSIFICATION: Secondary

$* * * * * * * * * *$

7.2.1.3-10 Consistent Functions in Different Operational Modes When a variable function key performs different functions in different operational modes, equivalent or similar functions should be assigned to the same key.

COMMENT: For example, a particular key might be used to confirm data changes in one mode, and confirm message transmission in another. As a negative example, a key labeled RESET should not be used to save data in one mode, dump data in another, and signal task completion in a third.

ASSESSMENT METHODOLOGY:

SOURCE: ESD-TR-86-278, 1986

CLASSIFICATION : Primary

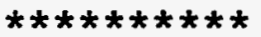

7.2.1.3-11 Unneeded Inactive Variable Function Keys Unneeded variable function keys should be disabled so that no other action occurs upon their depression except an advisory message. COMMENT :

ASSESSMENT METHODOLOGY : 
SOURCE: NASA USE 1000, V. 2.1, 1988

CLASSIFICATION: Primary

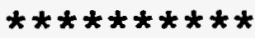

7.2.1.3-12 Variable Function Key Display

Pertinent variable function key assignments should be displayed at all times. The assigned key functions for the variable control station functions should be displayed on each screen.

COMMENT: If some standard control station functions are sometimes inactive, the displayed assignments should show only currently active control station functions or label the temporarily unavailable functions with an "inactive" indicator.

ASSESSMENT METHODOLOGY:

SOURCE: Brown, 1989

CLASSIFICATION: Secondary

$* * * * * * * * * *$

7.2.1.3-13 Variable Function Key Location

When assigning control station functions to a given set of variable function keys, the geometry of the keypad and the spatial relationships among the control station functions should be considered.

COMMENT: In a single row of keys, the end keys, especially the left-most key. are most accessible. In a matrix of keys, the corner keys (especially the top, left key) are more accessible than interior keys. Also spatial relationships among the control station functions can often be reflected in the geometrical relationship of the keys.

ASSESSMENT METHODOLOGY:

SOURCE: Brown, 1989

CLASSIFICATION: Secondary

$\star \star \star \star * * * * * *$

7.2.1.3-14 Operator Defined Key Functions Where possible, experienced operators should be able to define their own variable key functions.

COMMENT: For example, a repetitive transaction sequence, such as FIND - [field value] - REPLACE [field value] - WITH [field value] -SAVE RECORD, may be assigned temporarily to a variable function key.

ASSESSMENT METHODOLOGY :

SOURCE : MIL-HDBK-761A, 1989

CLASSIFICATION : Primary

$* * * * * * * * * *$

7.2.2 Direct Manipulation controls

7.2.2.1 General

7.2.2.1-13 Actuation/Deactuation

A discrete mechanism should be provided on the controller to allow 
the operator to actuate/deactuate the device. COMMENT:

ASSESSMENT METHODOLOGY :

SOURCE : MIL-STD-1472D, 1989

CLASSIFICATION : Primary

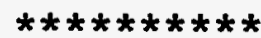

\subsubsection{Trackballs}

\subsubsection{2-6 Handedness}

The positioning of the trackball should permit easy use for both right- and left-handed operators.

COMMENT: Fine cursor control tasks usually require use of the preferred hand. Trackballs should thus be mounted either in a separate module from the keyboard that can be placed on either side of the keyboard, or with two controls, one on each side of the keyboard.

ASSESSMENT METHODOLOGY:

SOURCE: Brown, 1989

CLASSIFICATION: Secondary

$\star * \star \star \star \star * * * * \star$

\subsubsection{2-7 Trackball Location}

Trackball placement should allow efficient use of the device by operators maintaining optimum view of the associated visual display terminal.

COMMENT:

ASSESSMENT METHODOLOGY:

SOURCE: NASA-STD-3000, Rev. A, 1989

CLASSIFICATION: PrimarY

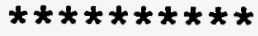

7.2.2.2-8 Trackball/Keyboard Integration

The operator should not have to alternate frequently between the trackball and the keyboard.

COMMENT:

ASSESSMENT METHODOLOGY:

SOURCE: NASA-STD-3000, Rev. A, 1989

CLASSIFICATION: Primary

$\star \star \star \star * * \star * \star * * *$

\subsubsection{Mice}

7.2.2.3-5 Mouse Cursor Control

A mouse should be used for cursor-intensive control station tasks. COMMENT: The mouse is well adapted to control station tasks which require frequent and moderately precise cursor positioning. It provides quick cursor movement across long screen distances. A mouse provides accurate fine resolution cursor positioning. It also allows the table top to support the weight of the operator's arm during prolonged usage, thus minimizing muscular fatigue. Some experimental studies and technology writers have recommended the 
mouse as the most satisfactory general purpose pointing device. ASSESSMENT METHODOLOGY:

SOURCE: BrOWn, 1989

CLASSIFICATION: Secondary

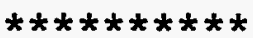

7.2.2.3-6 Mouse-keyboard Switching

Operators should not be required to make frequent changes from keyboard to mouse.

COMMENT: Frequent changes from keyboard to mouse and back interfere with the flow, and thus the efficiency, of keyboard tasks. The operators must reorient their hands to the keyboard after each mouse use.

ASSESSMENT METHODOLOGY:

SOURCE: Brown, 1989

CLASSIFICATION: Secondary

$* * * * * * * * * *$

7.2.2.3-7 Mouse Alternative

The mouse should be used for a large number of targets.

COMMENT: The mouse is an effective pointing and selecting device when there is a potential for a large number of targets from which to select by pointing.

ASSESSMENT METHODOLOGY:

SOURCE: BrOWn, 1989

CLASSIFICATION: Secondary

$\star * \star * * * * * * *$

7.2.2.3-8 Use with Large Targets

The mouse should be used with large targets.

COMMENT: High error rates can occur when the mouse is used with small targets.

ASSESSMENT METHODOLOGY :

SOURCE: NASA-STD-3000, Rev. A, 1989

CLASSIFICATION: PrimarY

$\star * * * * * * * * *$

7.2.2.3-9 Discrete Activation

Where activation switches are required on the mouse, they should be limited to no more than three and the buttons should be operable with a normal grip.

COMMENT:

ASSESSMENT METHODOLOGY:

SOURCE: NASA-STD-3000, Rev. A, 1989

CLASSIFICATION : PrimarY

$\star * * * * * * * * *$

$7.2 \cdot 2 \cdot 3-10$ Mouse Form

The front of the mouse (the end pointing away from the operator) should be lower than the back (or near end). When the mouse has two or more switches, they should be spaced a minimum of 0.75 in (19 $\mathrm{mm}$ ) apart. The connecting cable on the mouse should be pointed 
away from the operator's hand so that it does interfere with the mouse's motion.

COMMENT:

ASSESSMENT METHODOLOGY:

SOURCE: Sherr, $1988^{-}$

CLASSIFICATION: Secondary

$* * * * * * * * * *$

7.2.2.3-11 Finger Tip Use

The mouse should accommodate both one finger and two finger button use.

COMMENT: The mouse should be a finger tip device.

ASSESSMENT METHODOLOGY:

SOURCE: Microsoft, 1988

CLASSIFICATION: Tertiary

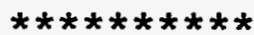

7.2.2.3-12 Tactile Differentiation

If there are two or more buttons on the mouse they should be discriminable by touch.

COMMENT: Tactile feedback increases the ease of locating the buttons.

ASSESSMENT METHODOLOGY:

SOURCE: Microsoft, 1988

CLASSIFICATION: Tertiary

$\star \star \star \star * \star * \star * \star *$

7.2.2.3-13 Activation Surface

A surface which has a texture suited to mouse use and that is conveniently located should be provided when a mouse is to be used. COMMENT :

ASSESSMENT METHODOLOGY:

SOURCE: NASA-STD-3000, Rev. A, 1989

CLASSIFICATION: Primary

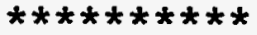

$7 \cdot 2 \cdot 2 \cdot 3-14$ Stowage

The mouse should be removable and/or stowable.

COMMENT:

ASSESSMENT METHODOLOGY:

SOURCE: NASA-STD-3000, Rev. A, 1989

CLASSIFICATION: Primary

$* * * * * * * * * *$

\subsubsection{Joysticks}

\subsection{Force (Isometric) Joysticks}

7.2.2.4.1-8 Handedness

The positioning of the force joystick should permit easy use for both right- and left-handed operators.

COMMENT: Fine cursor control tasks usually require use of the 
preferred hand. Force joysticks should thus be mounted either in a separate module from the keyboard that can be placed on either side of the keyboard, or with two controls, one on each side of the keyboard.

ASSESSMENT METHODOLOGY:

SOURCE: Brown, 1989

CLASSIFICATION: Secondary

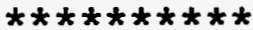

7.2.2.4.1-9 Force Joystick Deflection

The force joystick should deflect minimally in response to applied force, but may deflect perceptibly against a stop at full applied force.

COMMENT:

ASSESSMENT METHODOLOGY :

SOURCE: NASA-STD-3000, Rev. A, 1989

CLASSIFICATION: Primary

$\star * * * * * * * * *$

$7 \cdot 2 \cdot 2 \cdot 4 \cdot 1-10$ option selection

The force joystick should not be used for selection of options. COMMENT :

ASSESSMENT METHODOLOGY:

SOURCE: NASA-STD-3000, Rev. A, 1989

CLASSIFICATION: Primary

$* * * * * * * * * *$

\subsection{Displacement (Isotonic) Joysticks}

$7.2 \cdot 2 \cdot 4 \cdot 2-8$ Handedness

The positioning of the displacement joystick should permit easy use for both right- and left-handed operators.

COMMENT: Fine cursor control tasks usually require use of the preferred hand. Displacement joysticks should thus be mounted either in a separate module from the keyboard that can be placed on either side of the keyboard, or with two controls, one on each side of the keyboard.

ASSESSMENT METHODOLOGY:

SOURCE: Brown, 1989

CLASSIFICATION: Secondary

$* * * * * * * * * *$

7.2.2.4.2-9 Displacement Joystick Placement

The placement of the displacement joystick should allow effective operation when the operator is maintaining an optimum viewing position with respect to the visual display terminal.

COMMENT: The joystick should also be placed so as not to interfere with other controls.

ASSESSMENT METHODOLOGY:

SOURCE: NASA-STD-3000, Rev. A, 1989

CLASSIFICATION: PrimarY

$\star * \star \star \star \star * \star * \star *$ 
$7.2 \cdot 2 \cdot 4 \cdot 2-10$ Control/Display Ratio

The displacement joystick should be large enough such that an adequate control/display ratio will result for positional control. COMMENT:

ASSESSMENT METHODOLOGY :

SOURCE: NASA-STD-3000, Rev. A, 1989

CLASSIFICATION : PrimarY

$\star \star \star \star * \star * \star * * *$

$7 \cdot 2 \cdot 2 \cdot 4 \cdot 2-11$ option selection

The displacement joystick should not be used for selection of options.

COMMENT:

ASSESSMENT METHODOLOGY :

SOURCE: NASA-STD-3000, Rev. A, 1989

CLASSIFICATION: Primary

$\star \star \star \star \star * \star * \star * * \star$

\subsubsection{Direct Pointing controllers}

\subsubsection{General}

7.2.3.1-3 Position Designation

When position designation is the sole or primary means of data entry, as in selection among displayed alternatives, cursor placement by direct pointing rather than incremental stepping or slewing controls should be provided.

COMMENT:

ASSESSMENT METHODOLOGY:

SOURCE: ESD-TR-86-278, 1986

CLASSIFICATION: Primary

$\star \star \star * \star \star * * * * *$

\subsubsection{1-4 Menu Selection}

When menu selection is the primary means of sequence control, and especially if choices must be made from extensive lists of displayed options, option selection by direct pointing should be permitted.

COMMENT: Pointing directly at a displayed option guarantees good display-control compatibility. operators do not have to note associated option codes and enter them by key actions.

ASSESSMENT METHODOLOGY:

SOURCE: ESD-TR-86-278, 1986

CLASSIFICATION : Primary

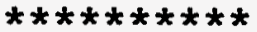

7.2.3.1-5 Selectable Tracking speed

The direct pointing controller tracking speed (control/display ratio) should be operator selectable from a predefined list of alternatives (e.g., slow, 2:1; unenhanced, 1:1; moderate enhancement, 1:2; and high enhancement 1:3), but should have a 
moderate default speed.

COMMENT: The control/display ratios should take into account both screen size and maximum maneuvering displacement.

ASSESSMENT METHODOLOGY:

SOURCE: NASA USE 1000, V. 2.1, 1988

CLASSIFICATION: Primary

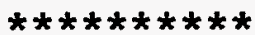

7.2.3.1-6 Selectable Rate Aiding

Rate aiding of the cursor movement (i.e., the speed of follower movement is proportional to the speed of input movement) should be operator selectable on/off.

COMMENT: The default should be not to have rate aiding (zeroorder control-display relationship).

ASSESSMENT METHODOLOGY:

SOURCE: NASA USE 1000, V. 2.1, 1988

CLASSIFICATION: Primary

$* * * * * * * * * *$

7.2.3.1-7 Inadvertent Activation

Selectable screen items or regions should be separated from each other by a sufficient distance to minimize inadvertent activation of adjacent items or regions.

COMMENT:

ASSESSMENT METHODOLOGY:

SOURCE: NASA USE 1000, V. 2.1, 1988

CLASSIFICATION: Primary

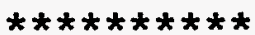

7.2.3.1-8 Maximum Response Delay Time

The delay between the direct pointing controller input and the resulting response on the screen should be less than 0.1 second. COMMENT:

ASSESSMENT METHODOLOGY:

SOURCE: NASA USE 1000, V. 2.1, 1988

CLASSIFICATION : Primary

$\star \star \star * * * * * * * *$

7.2.3.1-9 Single Controller Input Recognition

To avoid inadvertent activation of a selectable display structure, the computer system should accept only one controller input at a time and should recognize a controller input of approximately 0.1 second or greater for selection.

COMMENT :

ASSESSMENT METHODOLOGY:

SOURCE: NASA USE 1000, V. 2.1, 1988

CLASSIFICATION: Primary

$\star \star \star * \star * * * * *$

7.2.3.1-10 Feedback

Visual or auditory feedback (e.g., reverse video, color, or a tone) should be provided to indicate that a controller input has been 
registered.

COMMENT:

ASSESSMENT METHODOLOGY :

SOURCE: NASA USE 1000, V. 2.1, 1988

CLASSIFICATION: Primary

$\star * \star * * * * * * *$

\section{2 .3 .2 Touch Screens}

7.2.3.2-10 Accidental Touch Activation

To avoid accidental activation, two steps should be required to initiate any critical, irreversible, or potentially damaging touch screen action. For example, the operator should first touch the desired action, and then touch an "enter" or "execute" function to initiate the selected activation.

COMMENT: Some touch-screen technologies are susceptible to accidental activation. For example, an optical sensor (infrared) touch screen may be activated by a dropped pencil or sheet of paper. The human-computer interface design can compensate for this by requiring two steps to activate an action. Touch accuracy can also be enhanced by an "enter" function, although speed of input will suffer to some extent.

ASSESSMENT METHODOLOGY:

SOURCE: Brown, 1989

CLASSIFICATION: Secondary

$\star \star \star * \star * * * * * *$

7.2.3.2-11 Simulate Familiar Physical Controls

Touch-screen devices should be programmed to simulate familiar physical controls. For example, menu selections can simulate physical push buttons.

COMMENT: Operator performance is positively influenced if the touch-screen devices are programmed to simulate physical controls. ASSESSMENT METHODOLOGY:

SOURCE: Brown, 1989

CLASSIFICATION: Secondary

$\star * * * * * * * * *$

7.2.3.2-12 Intermittent Inputs

If an installation of a touch-screen device does not permit a mounting scheme which provides arm support during touch screen usage, the role of the touch-screen device should be restricted to short duration, intermittent control station functions.

COMMENT: Touch screen control station implementations often require operators to hold the full weight of their arms without the benefit of supporting surfaces. Prolonged, intensive touch-screen device usage may cause undue muscle strain, impaired performance, and errors.

ASSESSMENT METHODOLOGY:

SOURCE: Brown, 1989

CLASSIFICATION: Secondary 
$7.2 \cdot 3 \cdot 2-13$ Arm Support

If a touch screen is to be used for control station functions which require continuous interaction, its mounting should provide for support of the operator's arm.

COMMENT:

ASSESSMENT METHODOLOGY:

SOURCE: BrOWn, 1989

CLASSIFICATION: Secondary

$* \star * \star * * * * * *$

7.2.3.2-14 Touch-screen Resolution

Touch-screen devices should be used for approximate positioning control station tasks such as simulated push buttons for menu selection.

COMMENT: Touch-screen devices are effective for approximate positioning control station tasks but not for tasks requiring precise positioning tolerances such as graphical input, drawing, and computer-aided design. Some touch-screen technologies have resolution as coarse as one-half inch or more. others have resolution to the pixel in theory, but the size of the operator's finger and the parallax potential of the screen limit the effective resolution to one-quarter inch at best. The obstruction of the operator's view of the display by the hand results in additional interference in precise positioning.

ASSESSMENT METHODOLOGY:

SOURCE: Brown, 1989

CLASSIFICATION: Secondary

$* \star * * * * * * * *$

7.2.3.2-15 Touch Recognition

The computer terminal should recognize an operator's touch in less than $100 \mathrm{milliseconds.}$

COMMENT :

ASSESSMENT METHODOLOGY:

SOURCE: Gilmore, Gertman, and Blackman, 1989

CLASSIFICATION: Primary

$* * * * * * * * * *$

7.2.3.2-16 Touch Area Indication

The touch-sensitive areas of a display should be indicated. COMMENT :

ASSESSMENT METHODOLOGY:

SOURCE: NASA-STD-3000, Rev. A, 1989

CLASSIFICATION: Primary

$\star \star \star \star * \star * \star * * *$

7.2.3.2-17 Touch-sensitive Display/Keyboard Integration

The operator should not have to alternate frequently between the touch display and other computer input devices.

COMMENT :

ASSESSMENT METHODOLOGY:

SOURCE: NASA-STD-3000, Rev. A, 1989 
CLASSIFICATION: Primary

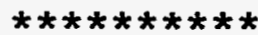

7.2.3.2-18 Parallax

The touch screen should be designed so that parallax problems are minimized.

COMMENT: Parallax occurs when the touch surface or detectors are separated. For all touch-screen technologies, the touch surface will always be slightly above the target due to the glass surface of the display. An overlay separates the finger and the target even more.

ASSESSMENT METHODOLOGY:

SOURCE: Salvendy, 1987; Helander, 1988

CLASSIFICATION: Secondary; tertiary

$* * * * * * * * * *$

7.2.3.2-19 Optical clarity

optical clarity of the touch screen should be maximized.

COMMENT: Optical clarity is of primary importance when an operator uses a touch screen for extended periods of time, since a decrease in display quality can lead to operator strain and fatigue.

ASSESSMENT METHODOLOGY:

SOURCE: Helander, 1988

CLASSIFICATION: Tertiary

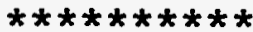

7.2.3.3 Light Pens

7.2.3.3-6 Prolonged Light Pen Use

Prolonged light pen use should be avoided.

COMMENT: Light pen control station implementations seldom provide any support to the operator's arms. This makes the light pen undesirable for control station tasks which would require intensive, continual use of the light pen without frequent opportunities to rest the arm.

ASSESSMENT METHODOLOGY :

SOURCE: Brown, 1989

CLASSIFICATION: Secondary

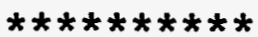

7.2.3.3-7 Light Pen Switching

Computer dialogues should not require operators to alternate between light pen and keyboard entry unnecessarily.

COMMENT: When dialogues that require keyboard entry at some stages permit menu selection by light pen at other stages, use of the light pen should be optional. Operators should be permitted to make selections from the keyboard if they desire. They should not be required to take their hands away from the keyboard, pick up and use the light pen, then put down the light pen and orient themselves on the keyboard.

ASSESSMENT METHODOLOGY :

SOURCE: BrOWn, 1989 
CLASSIFICATION: Secondary

$\star * * * * * * * * *$

7.2.3.3-8 Light Pen Fields

The fields defined as light pen selectable (the poke points) should be as large as possible. At a minimum, all of the text associated with an option should be selectable, not just the option number. COMMENT: The light pen is not accurate as a placement device because of parallax problems and screen curvature. Larger fields help to reduce these problems.

ASSESSMENT METHODOLOGY:

SOURCE: Brown, 1989

CLASSIFICATION: Secondary

$\star \star \star \star \star \star * \star * \star * *$

7.2.3.3-9 Selectable Inter-click Interval

If multiple clicks are required on a light pen selection button, the operator should be able to select the inter-click interval from a predefined list of alternatives.

COMMENT: There should be a moderate default setting.

ASSESSMENT METHODOLOGY:

SOURCE: NASA USE 1000, V. 2.1, 1988

CLASSIFICATION: Primary

$* * * * * * * * * *$

7.2.3.3-10 storage

Light pen storage should be passive on the part of the operator. COMMENT: Once released, the light pen cable should retract to its storage position.

ASSESSMENT METHODOLOGY:

SOURCE: NASA-STD-3000, Rev. A, 1989

CLASSIFICATION: Primary

$\star \star * * * * * * * *$

7.2.3.3-11 Dual Activation

If menu selection is accomplished by use of a light pen, dual activation, in which the first action designates the selected option, followed by a separate second action that makes an explicit control entry, should be provided.

COMMENT: The two actions of cursor placement and entering should be compatible in their design implementation. A dual-action trigger should be provided on the light pen. This guideline for dual activation of pointing assumes that accuracy in selection of control entries is more important than speed. In some applications that may not be true. Interface design involves a trade-off considering the criticality of wrong entries, ease of recovery from wrong entries, and operator convenience in making selections. ASSESSMENT METHODOLOGY :

SOURCE: ESD-TR-86-278， 1986

CLASSIFICATION: Primary

$\star * * * * * * * * *$ 
7.2.3.3-12 Simultaneous Actuation/Deactuation Mechanism Depression Frequently required simultaneous depressions of the light pen actuation/deactuation mechanism should be avoided.

COMMENT: Simultaneous depressions of the light pen actuation/deactuation mechanism may cause slippage and inaccuracy. ASSESSMENT METHODOLOGY:

SOURCE: NASA-STD-3000, Rev. A, 1989

CLASSIFICATION: Primary

$\star * * * * * * * * *$

\subsubsection{Graphic Tablets - Grid and Stylus Devices}

\subsubsection{4-4 Actuation/Deactuation}

A discrete mechanism should be provided on the stylus device to allow the operator to actuate/deactuate the controller.

COMMENT:

ASSESSMENT METHODOLOGY:

SOURCE: MIL-STD-1472D, 1989

CLASSIFICATION: Primary

$\star \star \star \star \star * * * * * *$

7.2.3.4-5 Selectable Inter-click Interval

If multiple clicks are required on a stylus device selection button, the operator should be able to select the inter-click interval from a predefined list of alternatives.

COMMENT: There should be a moderate default setting.

ASSESSMENT METHODOLOGY:

SOURCE: NASA USE 1000, V. 2.1, 1988

CLASSIFICATION: PrimarY

$\star \star \star * \star * * * * *$

7.2.3.4-6 storage of the stylus

The stylus should be storable in a retracted position.

COMMENT: Retraction should be activated automatically when the operator releases the stylus.

ASSESSMENT METHODOLOGY:

SOURCE: NASA-STD-3000, Rev. A, 1989

CLASSIFICATION: Primary

$\star * \star \star \star \star \star \star * * *$

$7 \cdot 2 \cdot 3 \cdot 4-7$ work surface

A work surface that is conveniently located should be provided for the grid when a graphic tablet is to be used.

COMMENT:

ASSESSMENT METHODOLOGY:

SOURCE: NASA-STD-3000, Rev. A, 1989

CLASSIFICATION: PrimarY

$* * * * * * * * * *$

7.2.3.4-8 Operator Fatigue The graphic tablet should be positioned so that the pressure required to operate it does not fatigue the operator. 
COMMENT :

ASSESSMENT METHODOLOGY:

SOURCE: Sherr, 1988

CLASSIFICATION: Secondary

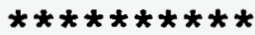

7.2.3.4-9 Physical Characteristics of the stylus

The stylus should be comfortable to hold, light-weight, and easily manipulated.

COMMENT: The size, shape, and balance of the stylus affect an operator's effectiveness.

ASSESSMENT METHODOLOGY:

SOURCE: Sherr, 1988

CLASSIFICATION: Secondary

$\star \star \star * * * \star * \star *$

\subsubsection{Touch Pads}

7.2.3.5-1 Appropriate Use of Touch Pads

Touch pads should be used: for data entry during extremely highstress situations; in instances where operators will be completely inexperienced or will have occasional use of the computer; and where the work space cannot accommodate a keyboard.

COMMENT:

ASSESSMENT METHODOLOGY:

SOURCE: Allen, 1990

CLASSIFICATION: Secondary

$\star \star * * * * * \star * *$

7.2.3.5-2 Design of the Work Space

The work space for the touch pad should be designed so that the physiological fatigue of the operator is minimized.

COMMENT :

ASSESSMENT METHODOLOGY:

SOURCE: Allen, 1990

CLASSIFICATION : Secondary

$\star \star \star \star \star * * * * *$

7.2.3.5-3 Positioning of the Touch Pad

The touch pad should be able to be moved and positioned according to operator preference.

COMMENT :

ASSESSMENT METHODOLOGY:

SOURCE: Helander, 1988

CLASSIFICATION: Tertiary

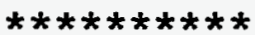

7.2.3.5-4 Fallout/Jitter

Fallout or jitter from the touch pad should be avoided.

COMMENT: Fallout/jitter occurs as the finger is removed from the pad. This happens because the centroid of finger pressure shifts and the display cursor moves in response. 
ASSESSMENT METHODOLOGY :

SOURCE: Helander, 1988

CLASSIFICATION: Tertiary

$\star \star \star * * * * * \star * *$

7.2.3.5-5 Operator Fatigue

The touch pad should be designed so that it does not cause operator fatigue.

COMMENT: The amount of pressure required to activate the touch pad may fatigue the operator. Conversely, fatigue may also occur if operators must hold their hands away from the pad surface to avoid inadvertent touch pad activation.

ASSESSMENT METHODOLOGY:

SOURCE: Helander, 1988

CLASSIFICATION: Tertiary

$\star * * * * * * * * *$

\subsubsection{Other controllers}

\subsubsection{General}

7.2.4.1-3 Applications of $X-Y-Z$ Controllers

The best current applications for the $x-y-z$ controllers are for movement of three-dimensional graphics and proximity operations. COMMENT: Future applications might include movement through hypermedia data bases.

ASSESSMENT METHODOLOGY :

SOURCE: NASA USE 1000, V. 2.1, 1988

CLASSIFICATION: Primary

$\star \star \star \star \star * * * * \star * * *$

7.2.4.1-4 Selectable Tracking speed

The $\mathrm{x}-\mathrm{y}-\mathrm{z}$ controller tracking speed (control/display ratio) should be operator selectable from a predefined list of alternatives (e.g., slow, 2:1; unenhanced, 1:1; moderate enhancement, 1:2; and high enhancement 1:3), but should have a moderate default speed. COMMENT: The control/display ratios should take into account both screen size and maximum maneuvering displacement.

ASSESSMENT METHODOLOGY :

SOURCE: NASA USE 1000, V. 2.1, 1988

CLASSIFICATION: Primary

$\star \star * \star * \star * * * *$

7.2.4.1-5 Selectable Rate Aiding

Rate aiding of the cursor movement (i.e., the speed of follower movement is proportional to the speed of input movement) should be operator selectable on/off.

COMMENT: The default should be not to have rate aiding (zeroorder control-display relationship) .

ASSESSMENT METHODOLOGY:

SOURCE: NASA USE 1000, V. 2.1, 1988 
CLASSIFICATION: Primary

$\star \star * * * * * * * *$

7.2.4.1-6 Maximum Response Delay Time

The delay between the controller input and the resulting response on the screen should be less than 0.1 second.

COMMENT:

ASSESSMENT METHODOLOGY:

SOURCE: NASA USE 1000, V. 2.1, 1988

CLASSIFICATION: Primary

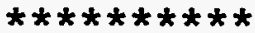

7.2.4.1-7 Single Monitor/Single Controller Cursor Travel Limits In a single monitor/single controller environment, movement of the $x-y-z$ controller should be able to drive the follower only to the edge of the screen, not off the screen.

COMMENT:

ASSESSMENT METHODOLOGY:

SOURCE: NASA USE 1000, V. 2.1, 1988

CLASSIFICATION : Primary

$* * * * * * * * * *$

\subsubsection{Multi-degree of Freedom Hand Controllers}

7.2.4.2-1 Selectable Inter-click Interval

If multiple clicks are required on a multi-degree of freedom hand controller selection button, the operator should be able to select the inter-click interval from a predefined list of alternatives. COMMENT: There should be a moderate default setting.

ASSESSMENT METHODOLOGY:

SOURCE: NASA USE 1000, V. 2.1, 1988

CLASSIFICATION: Primary

$* * * * * * * * * *$

\subsubsection{Glove Controllers}

7.2.4.3-1 Appropriate Use of Glove Controllers

The glove controller uses operator gestures as a basis for input. Glove controllers may be used to point with a large screen display. COMMENT: Glove controllers track the position, orientation, and gestures of the hand. The glove controller allows operators to interact with displayed objects just as they do with real objects: displayed objects can be picked up, twisted, squeezed, thrown, and set down.

ASSESSMENT METHODOLOGY:

SOURCE: Helander, 1988

CLASSIFICATION : Tertiary

$\star \star \star * * \star * \star * *$

7.2.4.4 Eye Controllers

7.2.4.4-1 Appropriate Use of Eye Controllers 
Eye controllers are attractive for item selection and target tracking tasks because they use eye movements inherent in these tasks as the control input.

COMMENT: Eye-controlled input can reduce workload, free the hands to perform other control station tasks, and eliminate the timeconsuming operations of locating, grasping, and moving manual input devices.

ASSESSMENT METHODOLOGY:

SOURCE: Helander, 1988

CLASSIFICATION: Tertiary

$\star \star \star \star \star * \star * \star * * *$

\subsubsection{4-2 Obtrusiveness}

The eye controller equipment should mounted on the operator's head such that it is not obtrusive.

COMMENT:

ASSESSMENT METHODOLOGY :

SOURCE: Sherr, 1988

CLASSIFICATION : Secondary

$* * * * * * * * * *$

\subsubsection{4-3 Locational Feedback}

Locational feedback should be provided to the operator.

COMMENT: Locational feedback can be either continuous, such that the computed point of attention is always shown on the display, or discrete, in which a target is highlighted only when the gaze is near or on the target. Research has found no difference between the two methods in either speed or accuracy of target acquisition. ASSESSMENT METHODOLOGY:

SOURCE: Helander, 1988

CLASSIFICATION: Tertiary

$\star * * * * * * * * *$

7.2.4.4-4 Confirming selections

A conveniently located physical button should be used to designate the selection of an item on which the eye has fixated.

COMMENT:

ASSESSMENT METHODOLOGY :

SOURCE: Helander, 1988

CLASSIFICATION: Tertiary

$\star \star * \star * \star * \star * *$

7.2.4.4-5 Target size

Target sizes for the eye controllers should subtend at least one degree of visual angle.

COMMENT: Eye controllers are not well suited to control station tasks involving small targets because a number of involuntary eye movements take place even while the eye is attempting to fixate on a point and at times the eye's line of sight only approximates the true point of visual attention.

ASSESSMENT METHODOLOGY:

SOURCE: Helander, 1988 
CLASSIFICATION: Tertiary

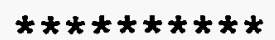


APPENDIX H:

ACRDR GUIDELINES FOR SPECIFIC NUCLEAR OPERATIONS 


\subsection{SPECIFIC NUCLEAR SYSTEYS}

\subsection{Safety Parameter Display systems}

\subsubsection{Purpose and Functions}

\subsection{1-1 Purpose}

The SPDS should provide a concise display of critical plant variables to the control room operators to aid them in rapidly and reliably determining the safety status of the nuclear power plant. COMMENT: Although the SPDS should be operated during normal operations as well as during abnormal conditions, the principal purpose of the SPDS is to aid the control room personnel during abnormal and emergency conditions in determining the safety status of the plant and in assessing whether abnormal conditions warrant corrective action by operators to avoid a degraded core. This can be particularly important during anticipated transients and the initial phase of an accident. This guideline contains five essential elements: concise display, critical plant variables, rapid response, reliable, and conditions when the sPDS should be operational.

ASSESSMENT METHODOLOGY:

SOURCE: NUREG-0737, Supplement 1, 1982; NUREG-1342, 1989

CLASSIFICATION: Secondary

$\star \star * * * * * * * *$

8.1.1-2 Rapid Response

In order for a control room operator to determine the safety status of the plant rapidly, five conditions should exist: (a) the information presented should represent current plant conditions (i.e., real-time data); (b) the information should be sampled at a rate that assures that no meaningful data, or trends in that data, will be missed (i.e., the sample rate should be sufficient to assure that data is of appropriate resolution); (c) the information should be updated on the display often enough to assure that changes in plant status will not be masked or lost by the passage of time (i.e., the update rate should be consistent with, and sufficient to represent, expected variations in plant safety parameters); (d) the information should be rapidly accessible to the operator ( $i . e .$, the SPDS response time should be about 2 to 3 seconds and no greater than about 10 seconds maximum); and (e) the information should be in a simple, easy-to-understand format that can be rapidly comprehended.

COMMENT:

ASSESSMENT METHODOLOGY:

SOURCE: NUREG-1342, 1989

CLASSIFICATION: Secondary

$\star * \star \star * * * \star * \star$

8.1.1-3 Reliability 
The SPDS should be reliable at the system level. Reliability includes two general concepts: (a) reliability -- the degree to which the SPDS will repeatedly produce the same results under identical conditions over time, and (b) validity -- the degree to which the SPDS will produce correct and accurate results that the operator will believe, i.e., rely on.

COMMENT: Acceptable SPDSs are those that are reliable in terms of hardware, software, and operator performance.

ASSESSMENT METHODOLOGY:

SOURCE: NUREG-1342, 1989

CLASSIFICATION: Secondary

$* * * * * * * * * *$

8.1.1-4 Primary Function

The primary function of the SPDS should be to serve as an operator aid in the rapid detection of abnormal conditions by providing a display of plant parameters from which the safety status of operation may be assessed in the control room.

COMMENT: This guideline is satisfied when: (a) the primary spDS display format contains functional information to assist the operator in rapidly evaluating the safety status of the plan; (b) abnormal conditions which impact safety of the plant are easily identified and recognized from the primary SPDS display format; and (c) the SPDS supplements the control room annunciator system when severe plant transients occur.

ASSESSMENT METHODOLOGY:

SOURCE: NUREG-0835, 1981

CLASSIFICATION: Secondary

$\star \star \star \star \star \star * \star * * *$

8.1.1-5 Secondary Functions

The SPDS display system may include other functions that aid operating personnel in evaluating plant status.

COMMENT: The secondary functions are acceptable provided: (a) they do not impair the operator's use of the SPDS in executing the primary function; and (b) the control room operating crew has been trained in the use of the secondary functions.

ASSESSMENT METHODOLOGY:

SOURCE: NUREG-0835, 1981

CLASSIFICATION: Secondary

$\star * * * * * * * * *$

8.1.1-6 Future Functions

The design of the SPDS display system should be flexible to allow for future incorporation of advanced diagnostic concepts and evaluation techniques and systems.

COMMENT: This guideline may be satisfied in designs using a computer-based system when either: (a) the design is expandable to accept new functions; or (b) the design allows for the addition of processors, memories, or additional computers, such as in a distributed network. This guideline may be satisfied by a hardwired system when: (a) the design allows for the addition of 
new displays to the SPDS panel/workspace; and (b) the design allows for the installation of equipment to support the displays. The addition of diagnostic techniques must not compromise the primary function.

ASSESSMENT METHODOLOGY:

SOURCE: NUREG-0835, 1981

CLASSIFICATION: Secondary

$\star \star \star * * * * * * *$

\subsubsection{Data set}

8.1.2-1 Minimum Plant Parameters

The minimum information to be displayed by the SPDS should be sufficient to provide information to plant operators about: (a) reactivity control; (b) reactor core cooling and heat removal from the primary system; (c) reactor coolant system integrity; (d) radioactivity control; and (e) containment conditions.

COMMENT: The specific parameters to be displayed is plant dependent and should be determined by the nuclear plant licensee. ASSESSMENT METHODOLOGY:

SOURCE: NUREG-0835, 1981; NUREG-0737, Supplement 1, 1982

CLASSIFICATION: Secondary

$\star \star * * * * * * * *$

8.1.2-2 Basis of Parameter selection

The basis for selection of the minimum set of parameters in the SPDS primary display should be documented as part of the design. COMMENT:

ASSESSMENT METHODOLOGY:

SOURCE: NUREG-0835, 1981

CLASSIFICATION: SECONdary

$* * * * * * * * * *$

\subsubsection{Data Validation}

8.1.3-1 Real Time Validation

SPDS display data should be validated on a real time basis where practicable.

COMMENT: This guideline is satisfied by: (a) comparing redundant sensor readings prior to the display of the parameter; or (b) using analytical redundancy among different parameters and using models and equations that have been documented and validated. operating regimes where the equations used are not valid should be identified and documented.

ASSESSMENT METHODOLOGY:

SOURCE: NUREG-0835, 1981

CLASSIFICATION : Secondary

$\star \star \star \star \star * \star * \star * * *$

8.1.3-2 Unvalidated Data 
SPDS display data which is unvalidated should be so indicated to operators.

COMMENT:

This guideline is satisfied when:

(a) validated parameters, unvalidated parameters, and invalid data are identified, where practical; (b) validated parameters are coded in a manner whereby they are easily distinguished from unvalidated parameters; (c) coding of invalid data is distinct from the coding of data for which validation is unsuccessful; (d) operating procedures for use of the SPDS provide for the treatment of invalid data and resolution of unsuccessful data validation; and (e) operator training in the use of the SPDS includes practice in dealing with unvalidated data and application of procedures to resolve unsuccessful data validation. Operator knowledge of the validity of data is important in correctly assessing the safety status of the plant.

ASSESSMENT METHODOLOGY:

SOURCE: NUREG-0835, 1981

CLASSIFICATION: Secondary

$\star * * * * * * * * *$

\subsubsection{Display}

\subsubsection{Design Principles}

8.1.4.1-1 Display Format

The SPDS display format should be designed to accepted human factors principles.

COMMENT: The SPDS display should be designed to incorporate accepted human factors principles so that the displayed information can be readily perceived and comprehended by SPDS users. ASSESSMENT METHODOLOGY :

SOURCE: NUREG-0835, 1981; NUREG-0737, Supplement 1, 1982

CLASSIFICATION: Secondary

$\star \star \star * \star * * * * *$

8.1.4.1-2 Display Enhancement

The SPDS display should be enhanced to improve the operator's perception, comprehension, and detection of abnormal operating status significant to safety.

COMMENT: SPDS display enhancement techniques include: display patterns, scaling of displays, identification of displayed parameters, and perceptual aids (e.g., color, symbols and mimics, overlays, setpoints, and blinking and flashing).

ASSESSMENT METHODOLOGY:

SOURCE: NUREG-0835, 1981

CLASSIFICATION: Secondary

$* * * * * * * * * *$

8.1.4.2 Parameters Displayed

8.1.4.2-1 Individual Parameters 
The SPDS primary display should be a continuous indication of individual plant parameters or be composed of a number of measured variables or derived variables.

COMMENT: This guideline is satisfied when: (a) a dedicated display, such as a CRT, with a single primary display format continuously displays the minimum parameter set necessary to assess the safety status of the plant; (b) reduction in size of the primary display format is provided when it is necessary to display secondary information; (c) audio or visual cues are provided on the display to alert a well trained operator to return to the primary. display format while viewing secondary information; or (d) the seismically qualified, concentrated backup display of primary format information is visible to the operator while viewing secondary information on the CRT.

ASSESSMENT METHODOLOGY:

SOURCE: NUREG-0835, 1981

CLASSIFICATION: Secondary

$* * * * * * * * * *$

8.1.4.2-2 Timeliness and Accuracy of Data

Displayed SPDS data should present current and accurate status of the plant.

COMMENT: This guideline is satisfied when: (a) the sampling rate for each parameter is chosen such that there is no meaningful loss of information in the data presented to the operator; (b) the time delay from when the sensor signal is sampled to when it is displayed is no greater than 2 seconds; (c) maintaining the control room SPDS display is given processor priority over display and processing requests from other sources; and (d) each parameter is displayed with an accuracy sufficient for the operator to discriminate between abnormal conditions which impact safety and normal operating conditions.

ASSESSMENT METHODOLOGY:

SOURCE: NUREG-0835, 1981

CLASSIFICATION : Secondary

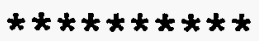

\subsubsection{2-3 Scope of Data}

The SPDS display should be responsive to transient and accident sequences.

COMMENT: This guideline is satisfied when: (a) operator comprehension of a change in the safety status of the plant from the primary SPDS display could be achieved in a matter of seconds. If closure of this task takes several minutes, the design is unacceptable; and (b) the display system correctly portrays the plant process status for all design basis events and events specified by NUREG-0737.

ASSESSMENT METHODOLOGY:

SOURCE: NUREG-0835, 1981

CLASSIFICATION: Secondary

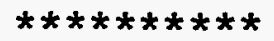


8.1.4.3-1 Parameter Grouping

Parameters should be grouped to enhance operators' assessment of the plant and to assist in making functional comparisons.

COMMENT: This guideline is met when: (a) the minimum set of parameters are presented on the single primary sPDS display format. The minimum set of parameters must be the ones by which the operator evaluates the safety status of the plant; (b) the parameters displayed are grouped so that all are visible to the operator within one field of view; (c) the parameters are sequenced in a logical manner to facilitate operator comparison of parameters in evaluating the safety status of the plant; and (d) the primary display format utilizes patterns and display enhancements.

ASSESSMENT METHODOLOGY:

SOURCE : NUREG-0835, 1981

CLASSIFICATION : Secondary

$\star \star \star \star \star \star \star \star * * * *$

8.1.4.3-2 Pattern and coding Techniques

Pattern and coding techniques should be used to assist operator detection and recognition of unsafe operating conditions.

COMMENT: This guideline can be satisfied by: (a) the use of color coding to indicate the approach to unsafe operation and to indicate unsafe operation; (b) the use of limit marks for each parameter displayed. The limit marks should be representative of operational limits established by technical specifications, process limits, and safety system actuation setpoints, if applicable; or (c) the use of patterns which noticeably distort when an unsafe condition is approached.

ASSESSMENT METHODOLOGY:

SOURCE : NUREG-0835, 1981

CLASSIFICATION : Secondary

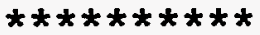

\subsubsection{Additional Data}

8.1.4.4-1 Magnitude and Trend

The SPDS display should be capable of presenting magnitudes and trends of parameters or derived variables. The display of time derivatives in lieu of trends may be acceptable.

COMMENT: This guideline is satisfied when: (a) the primary spDS display format contains the magnitude for all variables being displayed; (b) the primary display format has the capability of indicating trends, or trends of operator selected parameters are available in a secondary display format; and (c) trend data is displayed with sufficient resolution in time and magnitude to ensure that rapidly changing parameters are accurately displayed. The frequency bandwidth of the signal measurement system consisting of sensor, signal processing devices, and trend display device should be broad enough to transmit all meaningful information of the measured parameter or derived variable. The display of time 
derivatives of variables is acceptable only when the derivatives unambiguously reflect the trends in the variables. The algorithm used for time derivatives must be adequate to track oscillating plant variables that mat exist during the design basis events for the plant.

ASSESSMENT METHODOLOGY:

SOURCE: NUREG-0835, 1981

CLASSIFICATION: Secondary

$\star \star \star * * * * * * *$

8.1.4.4-2 Recall Capabilities

The recall of additional data on secondary SPDS formats or displays is desirable.

COMMENT: This guideline is met when: (a) operator requests to the SPDS display system will result in displays of additional data on secondary formats, such as trend data of the safety status parameters; (b) data is available for retrieval and is not lost as a result of an electrical power failure; (c) data stored for retrieval is stored on a secure medium and is available upon demand; and (d) response times to operator requests for information on secondary displays conforms with human factors guidelines for computer response time to operator queries.

ASSESSMENT METHODOLOGY:

SOURCE: NUREG-0835, 1981

CLASSIFICATION : Secondary

$\star * * * * * * * * *$

\subsubsection{Mode of Operation}

8.1.4.5-1 Mode of Plant Operation

The design of the SPDS display should contain a single primary display format for each mode of plant operation.

COMMENT: This guideline is satisfied when the design contains a primary SPDS display format for each mode of plant operation defined by the technical specifications of operation. $A$ common display format composed of the same parameters may be used for several modes of plant operation. However, for any one mode, the SPDS display must contain that minimum set of parameters needed to assess the safety status of the plant.

ASSESSMENT METHODOLOGY:

SOURCE : NUREG-0835, 1981

CLASSIFICATION : Secondary

$\star * * * * * * * * *$

8.1.4.5-2 Display Format Selection

For each plant operating mode, SPDS display formats may either be automatically displayed or manually selected.

COMMENT: This guideline is satisfied when: (a) a manually operated switch or input from an alphanumeric keyboard, touch panel, light pen, cursor, or equivalent interface is provided by the design to allow the operator to adjust the display format for the mode of plant operations; or (b) an automatic display format 
change occurs with a change in the mode of plant operation. Automatic change must be designed so that gradual change due to an abnormal condition is not interpreted as a change in mode of operation. There must also be provisions to indicate to operators that a change in the mode of plant operation has occurred. Provisions must be included for the operator to override automatic change when necessary.

ASSESSMENT METHODOLOGY :

SOURCE: NUREG-0835, 1981

CLASSIFICATION : Secondary

$\star * * * * * * * * *$

\subsubsection{Location and Readability}

8.1.5-1 Display Location

The SPDS should be located in the control room with additional displays provided in the technical support center and emergency operations facility.

COMMENT: This guideline is satisfied when provisions are made for locating the SPDS display and associated controls in the control room, technical support center, and emergency operations facility. ASSESSMENT METHODOLOGY:

SOURCE: NUREG-0835, 1981

CLASSIFICATION: Secondary

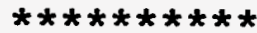

8.1.5-2 Convenient Location and Continuous Display

The SPDS should be located so that it is convenient to the control room operators. It should continuously display information from which the plant safety status can be readily and reliably assessed by control room personnel who are responsible for the avoidance of degraded and damaged core events.

COMMENT: A continuous display is needed for an effective sPDS because it affords the operator almost immediate access to the most important information about plant safety.

ASSESSMENT METHODOLOGY:

SOURCE: NUREG-1342, 1989

CLASSIFICATION : Secondary

$\star \star \star * \star \star \star \star * * *$

8.1.5-3 Control Board

If the SPDS is part of the control board it should be easily recognizable and readable.

COMMENT: This guideline is satisfied when: (a) the SPDS is readily distinguished from other displays on the control board; and (b) the sPDS display conforms to appropriate display readability guidelines.

ASSESSMENT METHODOLOGY:

SOURCE: NUREG-0835, 1981

CIASSIFICATION: Secondary

$\star \star \star * \star * * * * \star$ 
8.1.5-4 Display Readability

The SPDS display should be readable from the emergency station of the senior reactor operator.

COMMENT: This guideline is satisfied when: (a) the SPDS displays design conforms to the appropriate display readability guidelines; (b) the data displayed on the CRTs have acceptably low flicker and noise; (c) alphanumeric characters generated with a $7 \times 9$ dot matrix or larger are preferable; characters with a $5 \times 7$ dot matrix are acceptable, if necessary; (d) density of display is less than 25\% when complex symbology is displayed; (e) for ease of detection, acceptable symbol to background contrast ratio should fall in a range of $3: 1$ to $4: 1$ for all important data; and (f) motion of data displayed on a CRT to prevent screen burnout is at a rate slow enough to avoid distracting the operator.

ASSESSMENT METHODOLOGY :

SOURCE: NUREG-0835, 1981

CLASSIFICATION : Secondary

$\star \star * * * * * * * *$

\subsection{5-5 Display Accessibility}

The SPDS display should be readily accessible and visible to the: shift supervisor, control room senior reactor operator, shift technical advisor, and one reactor operator.

COMMENT: This guideline is satisfied when: (a) physical obstructions do not block a person's filed of view when the person is at the normal work station; (b) if the sPDS is not in the operator's direct field of view at the workstation, a reorientation of his/her field of view allows viewing of the spDs from the workstation; (c) members of the control room operating crew have a physical access to the SPDS from their normal workstation. For example, a short direct walk to the SPDS is acceptable; (d) glare from normal or emergency lighting does not restrict viewing of the SPDS from within the control room. The use of antiglare techniques and devices are acceptable when they are in accord with other human factors criteria; and (e) luminance levels and luminance contrast do not limit viewing from locations throughout the control room.

ASSESSMENT METHODOLOGY:

SOURCE: NUREG-0835, 1981

CLASSIFICATION : Secondary

$\star * * * * * * * * *$

8.1.5-6 Control Accessibility

The SPDS display system should not interfere with the normal movement of the control room operation crew. The display system should not interfere with full visual access to other control room operating systems and displays.

COMMENT: This guideline is satisfied when: (a) the SPDS display system does not obstruct the normal movement of the control room operating crew; and (b) the display system does not interfere with the full visual access to other control room operating systems and displays.

ASSESSMENT METHODOLOGY: 
SOURCE : NUREG-0835, 1981

CLASSIFICATION : Secondary

$\star \star \star \star * * * * * * *$

\subsubsection{Staff}

8.1.6-1 Control Room staff

No additional operating staff other than the normal control room operating staff should be needed for operation of the SPDS display. COMMENT: This guideline is satisfied when: (a) no additional operating staff other than the normal control room operating staff need be added for operation of the SPDS; (b) the operator training program contains instructions on the use of the SPDS; (c) an SPDS user's manual is available for operator reference in the control room; and (d) interaction with an SPDS computer is designed such that training in computer programming is not required.

ASSESSMENT METHODOLOGY:

SOURCE: NUREG-0835, 1981

CLASSIFICATION : Secondary

$\star \star * * * * * * * *$

8.1.6-2 Operator Interaction

Flexibility to allow for interaction by the operator is desirable in the design of the SPDS display designs.

COMMENT: This guideline is satisfied when: (a) the sPDS contains operator interactive devices; (b) the display system positively acknowledges each request that the design allows the operator to make; and (c) system response times to operator request conform to human factors guidelines. Undue time delays in response to a request are unacceptable.

ASSESSMENT METHODOLOGY:

SOURCE : NUREG-0835, 1981

CLASSIFICATION: Secondary

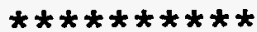

\subsubsection{Procedures}

8.1.7-1 Failure Recognition

The control room operations staff should be provided with sufficient information and criteria for performance of an operability evaluation of the SPDS.

COMMENT: This guideline may be satisfied by: (a) designing a monitoring system in the SPDS display which may be automatic or operator activated; (b) a display of calendar date and time of day with some means of indicating the passage of seconds. The display should be updated only when the SPDS is operating properly so that a static time would indicate a system failure. The data and time should be located in a corner of the display so as not to distract the operator; (c) the operable status of the display system is available upon operator demand; and (d) an equivalent means of 
evaluating display system operability is available.

ASSESSMENT METHODOLOGY:

SOURCE: NUREG-0835, 1981

CLASSIFICATION: Secondary

$\star \star \star \star * * * \star * * *$

8.1.7-2 Technical Specification

A technical specification of operations is required to define compensatory measures for the operator when the SPDS is inoperable. COMMENT: This guideline is satisfied when the technical specification defines acceptable compensatory measure for each function performed by the SPDS. The use of the seismic qualified back-up display, monitored on a frequent basis, may be an acceptable compensatory measure. The same minimum set or comparable set of safety status parameters on the SPDS primary display format should be present on the backup. Also, the backup display must be readily interpretable by the operator.

ASSESSMENT METHODOLOGY:

SOURCE: NUREG-0835, 1981

CLASSIFICATION: Secondary

$\star * * * * * * * * *$

8.1.7-3 Safety Status Procedures

Procedures which describe the timely and correct safety status assessment, when the SPDS is and is not available, should exist. COMMENT :

ASSESSMENT METHODOLOGY:

SOURCE: NUREG-1342, 1989

CLASSIFICATION: Secondary

$\star \star \star * * * * \star \star *$

\subsubsection{Audible Alarms}

8.1.8-1 Audible Notification

When feasible, the SPDS should include some audible notification to alert control room personnel of an unsafe operating condition. COMMENT: This guideline is met when: (a) the SPDS display system emits a distinct audible sound, such as the beeper available on computer terminals, upon detecting an abnormal operating condition; and (b) the SPDS alarm system has provisions to silence, acknowledge, reset, and test these functions, as appropriate. SPDS alarms should be independent of the computerized annunciator system and should not result in the generation of the same audible alarms as the annunciator system.

ASSESSMENT METHODOLOGY:

SOURCE: NUREG-0835, 1981

CLASSIFICATION: Secondary

$\star \star * \star * * * * * *$

\subsubsection{Design Criteria}


8.1.9-1 Functional Qualification

A functional qualification program should be established to demonstrate SPDS operational conformance with the function design criteria.

COMMENT: This guideline is satisfied when: (a) a test plan is available for the SPDS display system. The test plan should define a minimum of one test case for each major functional criterion of the display system. The object of the test case is to illustrate the correct performance of the implemented design; (b) a test report containing the results of the test cases is compiled. All major functional criteria must be tested successfully; (c) all display formats in the SPDS design are tested, including mode dependent formats; (d) a human factors review of the SPDS with results evaluated in accordance with the guidelines in NUREG-0801. The results of this effort are to be documented by the licensee/applicant as part of the control room design review; and (e) a trained control room operating crew can effectively use the SPDS to detect abnormal plant operating conditions which impact safety.

ASSESSMENT METHODOLOGY:

SOURCE: NUREG-0835, 1981

CLASSIFICATION: Secondary

$* * * * * * * * * *$

8.1.9-2 Backup Displays

Displays designated as a seismically qualified backup to the sPDS should be designed to accepted human engineering principles.

COMMENT: This guideline is satisfied when: (a) the back-up displays contain the same minimum set of safety status parameters as presented in the primary display format of the SPDS or an equivalent comparable set of safety status parameters; (b) the back-up display is capable of operating during and following earthquakes to the same degree as control room displays needed to comply with Regulatory Guide 1.97; (c) the needed seismically qualified displays are concentrated into one segment of the control board. Dependence on poorly human-engineered class IE seismically qualified instruments that are scattered throughout the control room is not acceptable; (d) the backup displays, when reviewed as a group, conform with human factors guidelines; and (e) meters on the control board which are part of the SPDS backup display are readily identified and are not likely to be confused with similar meters in the vicinity.

ASSESSMENT METHODOLOGY:

SOURCE: NUREG-0835, 1981

CLASSIFICATION : Secondary

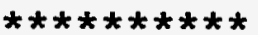

8.1.9-3 Primary Display, Seismically Qualified

Only one SPDS display system should be used for evaluating the safety status of the plant. However, an alternative is to design the overall SPDS function with a primary and a backup display. COMMENT: When the option for a seismically qualified primary SPDS 
display is selected, this option is satisfied when: (a) the design of the primary display conforms to Regulatory Guide 1.97; and (b) the design conforms to the acceptance criteria. ASSESSMENT METHODOLOGY:

SOURCE: NUREG-0835, 1981

CLASSIFICATION: Secondary

$\star \star * * * * * * * *$

\subsection{Computerized Annunciator systems}

\subsubsection{General}

\subsection{1-1 Registration}

The computerized annunciator system should register all of the incoming alarms in the correct chronological sequence.

COMMENT: The alarms should be grouped systematically. They can be classified according to importance (e.g., required safety system functions, disturbances in safety systems or in operational systems, etc.) or plant sections (e.g., nuclear steam supply system, nuclear auxiliaries, balance of plant, etc.).

ASSESSMENT METHODOLOGY:

SOURCE: International Atomic Energy Agency, 1987

CLASSIFICATION: Tertiary

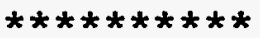

8.2.1-2 Initial Response

The computerized annunciator system should guide the operator's initial response to the deviation.

COMMENT:

ASSESSMENT METHODOLOGY:

SOURCE: Rankin, Rideout, Triggs, and Ames, 1985

CLASSIFICATION: Tertiary

$* * * * * * * * * *$

8.2.1-3 Time to Detect and Assess Deviations

The computerized annunciator system should minimize the time required to detect and assess deviations and to initiate corrective action.

COMMENT: A move to an alarm suppression philosophy should greatly help in the detection and assessment aspect of this guideline. More closely associating the computerized annunciator system with abnormal and emergency procedures would help in the response initiation aspect of the guideline.

ASSESSMENT METHODOLOGY:

SOURCE: Rankin, Rideout, Triggs, and Ames, 1985

CLASSIFICATION: Tertiary

$\star * \star * * * * * * \star$

8.2.1-4 Control station Compatibility

The computerized annunciator system features and concepts should be 
compatible with its control station system.

COMMENT: The computerized annunciator system should be used primarily during normal operations. It may also be utilized during the first few minutes of an abnormal or emergency event to alert, inform, and guide the operator's initial response. The computerized annunciator system should not analyze the deviation and suggest countermeasures beyond guiding the operator to the correct set of procedures.

ASSESSMENT METHODOLOGY:

SOURCE: Rankin, Rideout, Triggs, and Ames, 1985

CLASSIFICATION: Tertiary

$* * * * * * * * * *$

8.2.1-5 Dark-board Concept

The computerized annunciator system should conform to the darkboard concept as much as possible; that is, alarm messages should not be displayed unless there is a real need for the operator to take some sort of corrective action.

COMMENT: The computerized annunciator system should be mode adaptive, that is, what is annunciated should be dependent upon the operating mode of the reactor. Some conditions should be annunciated during certain modes of operation but not others, and the computer annunciator system should take this into account. The system should suppress alarms that follow as a logical consequence of trip or isolation conditions.

ASSESSMENT METHODOLOGY:

SOURCE: Rankin, Rideout, Triggs, and Ames, 1985

CLASSIFICATION: Tertiary

$\star \star \star \star \star \star \star \star \star \star * * *$

8.2.1-6 Operator Memory and Decision Making

The computerized annunciator system should reduce the demands on operator memory and operator decision-making requirements.

COMMENT: The computerized annunciator system should provide information at the higher system/component/level as opposed to the component/signal levels. This can be achieved by making the computerized annunciator system mode adaptive, by incorporating an alarm suppression philosophy following trips, and by including warnings for automatic systems that do not perform correctly following a trip. This guideline can be furthered by developing a computerized annunciator system that is user friendly and gives guidance on what procedures should be used to correct the annunciated condition.

ASSESSMENT METHODOLOGY:

SOURCE: Rankin, Rideout, Triggs, and Ames, 1985

CLASSIFICATION: Tertiary

$\star \star \star \star \star \star * * * * *$

8.2.1-7 Minimizing Distracting Effects

The computerized annunciator system should be designed so as to minimize the distracting effects of the system on other operator control station tasks or functions. 
COMMENT: For example, the computerized annunciator system should be designed so as to minimize the distracting effects of the system on communications. The computerized annunciator system can meet this guideline by presenting information at a high level, with low level information available upon request, and by providing alarm suppression keyed to trip and isolation conditions. The computerized annunciator system can also assist operators by offering more flexible control over the alerting aspects of the computerized system so that the operator is not unnecessarily distracted.

ASSESSMENT METHODOLOGY:

SOURCE: Rankin, Rideout, Triggs, and Ames, 1985

CLASSIFICATION: Tertiary

$\star * * * * * * * * *$

\subsection{1-8 No Prior Computer Training}

The computerized annunciator system should be designed on the assumption that operators have had no prior computer training.

COMMENT: This guideline is met by making the computerized annunciator system user friendly. More specifically the use of menus, cursors, function keys, and touch panels is recommended as the main way for the operator to interact with the computerized annunciator system.

ASSESSMENT METHODOLOGY:

SOURCE: Rankin, Rideout, Triggs, and Ames, 1985

CLASSIFICATION: Tertiary

$* * * * * * * * * *$

\subsubsection{Alarm Display}

8.2.2-1 Mix of VDT and Tile-displayed Warnings

The computerized annunciator system should present some alarms via conventional tiles and other alarms via a VDT.

COMMENT: The only research carried out to confirm the need for some conventional tile warnings has been a survey of operators. However, all operational computerized annunciator systems for which information is available use some conventional tiles because of the more public and information processing benefits of such warnings. ASSESSMENT METHODOLOGY:

SOURCE: Rankin, Rideout, Triggs, and Ames, 1985

CLASSIFICATION: Tertiary

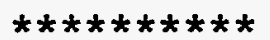

8.2.2-2 Conventional Alarm Tiles

If conventional annunciating tiles are used they should be dedicated to the display of the most critical warning information of which all operators should be made aware.

COMMENT: The primary reason to display the most critical alarms on tiles is that this information should be displayed in a manner that permits all operators to become aware of the problem at once. In addition, tiles can provide important information by virtue of 
their spatial location and by the configuration of a set of annunciating tiles, i.e., operators can recognize familiar patterns of activated tiles as being related to certain types of problems, thus aiding diagnosis.

ASSESSMENT METHODOLOGY :

SOURCE: Rankin, Rideout, Triggs, and Ames, 1985

CLASSIFICATION: Tertiary

$\star \star \star \star \star \star \star * * * * *$

\subsubsection{Alarm Printout}

8.2.3-1 Operator-requested Printout

Printouts by hierarchical alarm group (system, subsystem, component), alarm priority, and alarm chronology should be available on operator request.

COMMENT: Printers are either a principal or secondary interface between the computer system and the operator. Printers can provide a historical record of all parameters monitored by the computer, as well as real-time display, whether or not the data are presented on VDTs.

ASSESSMENT METHODOLOGY:

SOURCE: Banks, Hunter, and Noviski, 1985; EPRI NP-3659, 1984 CLASSIFICATION: Secondary

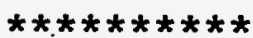

8.2.3-2 Recorded Data

Recorded data on each alarm condition should include the system designation, parameter name and unit of measure, alarm priority, description of condition, time of receipt, and reference to alarm response procedures.

COMMENT:

ASSESSMENT METHODOLOGY:

SOURCE: EPRI NP-3659, 1984

CLASSIFICATION: Secondary

$\star \star * * * * * * * *$

8.2.3-3 Alarm Sequence

Alarm messages should be registered in their order of occurrence. COMMENT:

ASSESSMENT METHODOLOGY:

SOURCE: Banks, Hunter, and Noviski, 1985

CLASSIFICATION: Secondary

$\star * * * * * * * * *$

8.2.3-4 Alarm Discrimination

Alarm messages should be readily distinguishable from other messages.

COMMENT: Alarm messages should provide rapid identification of the nature of the alarm.

ASSESSMENT METHODOLOGY:

SOURCE: Banks, Hunter, and Noviski, 1985 
CLASSIFICATION: Secondary

$* * * * * * * * * * *$

8.2.3-5 Consistent Terminology

Wording in alarm messages should: use terms and abbreviations consistent with other operator interface devices, and where practical the printer alarm messages should be consistent with alarm messages provided by other annunciation devices (e.g., VDTs, window alarm boxes, etc.).

ASSESSMENT METHODOLOGY:

SOURCE: Banks, Hunter, and Noviski, 1985

CLASSIFICATION: Secondary

$* * * * * * * * * *$

\subsubsection{Alerting the operator}

8.2.4-1 System or Process Deviation

The computerized annunciator system should alert the operator to the fact that a control system or process deviation exists.

COMMENT:

ASSESSMENT METHODOLOGY:

SOURCE: Rankin, Rideout, Triggs, and Ames, 1985

CLASSIFICATION: Tertiary

$\star * * * * * * * * *$

8.2.4-2 Reduction of Alerts

The computerized annunciator system should reduce the overall number of discrete visual and aural alerts.

COMMENT: The computerized annunciator system should operate at the system level alarm level and the component level alarm level. It should generate alarms for automatic functions that should follow a trip but do not.

ASSESSMENT METHODOLOGY:

SOURCE: Rankin, Rideout, Triggs, and Ames, 1985

CLASSIFICATION: Tertiary

$* * * * * * * * * *$

8.2.4-3 Conditions for Operator Response

The computerized annunciator system should only generate alarms for conditions for which an operator response is required or is likely to be required.

COMMENT :

ASSESSMENT METHODOLOGY:

SOURCE: Rankin, Rideout, Triggs, and Ames, 1985

CLASSIFICATION: Tertiary

$* * * * * * * * * *$

8.2.4-4 Visual and Aural Signals

A visual signal and an aural signal should be used to indicate the existence of a new VDT displayed alarm.

COMMENT: The aural signal should be easily distinguishable from 
the aural signal associated with the tile-displayed messages. ASSESSMENT METHODOLOGY:

SOURCE: Rankin, Rideout, Triggs, and Ames, 1985

CLASSIFICATION: Tertiary

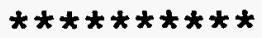

\subsection{4-5 Function Keys}

A separate, dedicated "SILENCE" function key and an "ACKNOWLEDGE" function key should be associated with each VDT station for the purposes of, respectively, silencing the aural signal and acknowledging the presence of an alarm on the VDT by removing the visual alerting feature.

COMMENT: If more than one VDT is used: the SILENCE function key should be used to silence aural signals from any of the VDTs; and the ACKNOWLEDGE function key should only be operable for its specific VDT workstation, or for other VDTs that are displaying the same information. The ACKNOWLEDGE function key should only be able to acknowledge alarm messages when the message is on the screen and has been selected by the operator. That is, the operator must be able to see the message before it can be acknowledged.

ASSESSMENT METHODOLOGY:

SOURCE: Rankin, Rideout, Triggs, and Ames, 1985

CLASSIFICATION : Tertiary

$\star \star \star \star * * * * * *$

8.2.4-6 Signaling When on Another Page

If the operator is not currently on the page where new, unacknowledged alarm messages are entered, some method should be provided for signalling on the current page of information that a new alarm message is available, the priority of the message, and where the alarm can be found.

COMMENT: Access to the page containing the new alarm should require only one operator action.

ASSESSMENT METHODOLOGY:

SOURCE: Rankin, Rideout, Triggs, and Ames, 1985

CLASSIFICATION : Tertiary

$\star * * * * * * * * *$

\subsubsection{Informing the operator}

8.2.5-1 Priority and Nature of the Deviation

The alarm message (whether alphanumeric or graphic) should inform the operator about the priority and the nature of the deviation. COMMENT: The number of priority levels should be held to three or four. Alarm priority can be indicated via color-coding or through the use of the aural signal.

ASSESSMENT METHODOLOGY:

SOURCE: Rankin, Rideout, Triggs, and Ames, 1985

CLASSIFICATION : TertiarY 
8.2.5-2 Message Information

The alarm message should contain, as a minimum, the following:

a good point English language descriptor; (b) the current value of the parameter that is in alarm; (c) the violated set point limit for the triggered alarm; and (d) the severity indicator.

COMMENT:

ASSESSMENT METHODOLOGY:

SOURCE: Rankin, Rideout, Triggs, and Ames, 1985

CLASSIFICATION: Tertiary

$* * * * * * * * * *$

8.2.5-3 Method of Adding Messages

The method of adding new alphanumeric alarm messages to the list of messages should preclude message scrolling.

COMMENT: Alphanumeric alarm messages that overflow the first page of alarm messages should be kept on subsequent alarm pages.

ASSESSMENT METHODOLOGY:

SOURCE: Rankin, Rideout, Triggs, and Ames, 1985

CLASSIFICATION: Tertiary

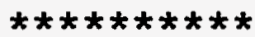

8.2.5-4 Segregation by Alarm Priority

Alphanumeric alarm message lists should be segregated by alarm priority with the highest priority alarms being listed first.

COMMENT: Alarm sources should be prioritized with respect to the severity of consequences associated with delay in recognizing deviant plant conditions and the immediacy of operator response required to mitigate such consequences. Within each alarm priority category, the alarm messages should be listed in chronological order with the most recent messages placed at the top of the stack. ASSESSMENT METHODOLOGY:

SOURCE: EPRI NP-3659, 1984; Rankin, Rideout, Triggs, and Ames, 1985

CLASSIFICATION: Secondary; tertiary

$\star \star \star * * * * * * *$

8.2.5-5 Moving Among Levels

The operator should be able to move easily from system level information to relevant component level information and from component level information to relevant basic sensor alarm information.

COMMENT:

ASSESSMENT METHODOLOGY:

SOURCE: Rankin, Rideout, Triggs, and Ames, 1985

CLASSIFICATION: Tertiary

$\star * * * * * * * * *$

8.2.5-6 Paging

Paging to other alphanumeric alarm messages is considered better than scrolling to other alarm messages if only one of the two techniques is incorporated in the computerized annunciator system. COMMENT: 
ASSESSMENT METHODOLOGY:

SOURCE: Rankin, Rideout, Triggs, and Ames, 1985

CLASSIFICATION: Tertiary

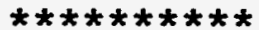

8.2.5-7 Wrap-around Paging

If the operator is viewing the last page of alarm messages and hits the "NEXT PAGE" function key, the computerized annunciator system should take the operator to the first page of alarm messages. If the operator is observing the first page of alarm messages and hits the "PREVIOUS PAGE" function key, the computerized annunciator system should take the operator to the last page of alarm messages. COMMENT:

ASSESSMENT METHODOLOGY:

SOURCE: Rankin, Rideout, Triggs, and Ames, 1985

CLASSIFICATION: Tertiary

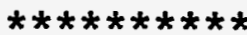

\subsection{5-8 Graphics}

The graphics related to alarm presentation should be such that the graphic for the overall reactor system, for a major subsystem, or for some other sub-subsystem, etc., is wholly contained on one VDT system screen.

COMMENT: Moving to other alarm graphics should be done by paging and not by scrolling. Moving to other alarm graphics should not require typed commands.

ASSESSMENT METHODOLOGY:

SOURCE: Rankin, Rideout, Triggs, and Ames, 1985

CLASSIFICATION: Tertiary

$* * * * * * * * * *$

8.2.5-9 Nuisance Alarms

Nuisance alarms should be controlled using a method where alarm messages are removed from the alarm list or graphics and then restored with re-alarming being prevented.

COMMENT :

ASSESSMENT METHODOLOGY:

SOURCE: Rankin, Rideout, Triggs, and Ames, 1985

CLASSIFICATION: Tertiary

$* * * * * * * * * *$

\subsubsection{Confirming Operator Actions}

8.2.6-1 Timely Feedback

The computerized annunciator system should confirm, in a timely manner, whether the operator's response corrected the deviation. COMMENT:

ASSESSMENT METHODOLOGY :

SOURCE: Rankin, Rideout, Triggs, and Ames, 1985

CLASSIFICATION: Tertiary

$\star * * * * * * * * *$ 
8.2.6-2 Cleared out-of-limit condition

There should be an auditory signal and a visual signal to inform the operator that an annunciated condition has cleared.

COMMENT: The auditory signal should be distinct from the incoming alarm signal and should be self-terminating after a few seconds so that no operator action is needed to silence the signal.

ASSESSMENT METHODOLOGY:

SOURCE: Rankin, Rideout, Triggs, and Ames, 1985

CLASSIFICATION: Tertiary

$\star \star * * * * * * * * *$

8.2.6-3 Reset Action

An explicit reset action should be required to remove the alarm message or indication from the screen.

COMMENT: Since the operator often needs to be aware of the cleared condition, an operator action (i.e., depressing a "RESET" function key) is needed. When the function key is depressed, the message line or indication should clear. In the case of alphanumeric message lists, the list should then automatically be repacked. Also, only cleared alarms that are currently displayed on the screen should be removed when the RESET key is depressed.

ASSESSMENT METHODOLOGY:

SOURCE: Rankin, Rideout, Triggs, and Ames, 1985

CLAASIFICATION: Tertiary

$\star \star \star * * * * * * * *$

8.2.6-4 Out-of-limit to In-limit Condition

The movement from an out-of-limit condition to an in-limit condition should not be displayed as an alarm.

COMMENT :

ASSESSMENT METHODOLOGY :

SOURCE: Rankin, Rideout, Triggs, and Ames, 1985

CLASSIFICATION: Tertiary

$\star \star \star \star \star * \star * \star * * \star *$

\subsection{Nuclear Graphic Displays}

\subsubsection{Color coding}

8.3.1-1 Use of White

The color of white should be used for dynamic valves, dynamic alphanumeric information, and boundaries/outlines.

COMMENT :

ASSESSMENT METHODOLOGY:

SOURCE: Banks, Hunter, and Noviski, 1985; Banks, 1980

CLASSIFICATION: Secondary

$* * * * * * * * * *$

8.3.1-2 Meaning and Use of Yellow

The color of yellow generally means caution. It should be used for 
dynamic alphanumeric information that is of a questionable nature or in a cautionary region, and cautionary regions on graphs. COMMENT :

ASSESSMENT METHODOLOGY :

SOURCE: Banks, Hunter, and Noviski, 1985; Banks, 1980

CLASSIFICATION: Secondary

$\star \star * * * * * * * *$

8.3.1-3 Use of Cyan

The color of cyan should be used for major headings, scales, engineering units, fluid levels, and preferred flow paths on schematic representations.

COMMENT:

ASSESSMENT METHODOLOGY:

SOURCE: Banks, Hunter, and Noviski, 1985; Banks, 1980

CLASSIFICATION : Secondary

$* * * * * * * * * *$

8.3.1-4 Use of Blue

The color of blue should be used for uninstrumented (static) valves, minor headings, valve numbers, component designators, borders, building walls, available but nonpreferred flow paths on schematic representations, and backgrounds

COMMENT:

ASSESSMENT METHODOLOGY:

SOURCE: Banks, Hunter, and Noviski, 1985; Banks, 1980

CLASSIFICATION: Secondary

$* * * * \star * * * * *$

8.3.1-5 Use of Broken BIue

The color of broken blue should be used for unavailable flow paths on schematic representations.

COMMENT:

ASSESSMENT METHODOLOGY:

SOURCE: Banks, Hunter, and Noviski, 1985; Banks, 1980

CLASSIFICATION: Secondary

$\star \star \star \star \star * \star \star * * * *$

8.3.1-6 Meaning and Use of Green

The color of green generally means on, running, and normal. It should be used for on or running state of equipment capable of providing a dynamic input, normal operating regions on graphs, and preferred flow paths -- pumps running.

COMMENT:

ASSESSMENT METHODOLOGY:

SOURCE: Banks, Hunter, and Noviski, 1985; Banks, 1980

CLASSIFICATION: Secondary

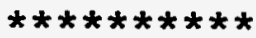

8.3.1-7 Meaning and Use of Red

The color of red generally means not within an acceptable area of operation, and a data or component failure. It should be used for 
emergency warnings, and out of limits or specifications on graphs. COMMENT:

ASSESSMENT METHODOLOGY :

SOURCE: Banks, Hunter, and Noviski, 1985; Banks, 1980

CLASSIFICATION: Secondary

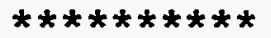

8.3.1-8 Meaning and Use of Magenta

The color of magenta generally means not within an acceptable area of operation (radiation only). It should be used for emergency warnings, and out of limits or specifications COMMENT:

ASSESSMENT METHODOLOGY:

SOURCE: Banks, Hunter, and Noviski, 1985; Banks, 1980

CLASSIFICATION: Secondary

$* * * * * * * * * *$

8.3.1-9 Use of Black

The color of black should be used for background and filler. COMMENT:

ASSESSMENT METHODOLOGY:

SOURCE: Banks, Hunter, and Noviski, 1985; Banks, 1980

CLASSIFICATION: Secondary

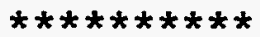




\section{INTERNAL DISTRIBUTION}

1 - 5. R. J. Carter

6. D. N. Fry

7. M. D. Galloway

8. H. E. Knee

9. C. E. Oliver

10. J. C. Schryver

11. R. F. Sincovec

12. P. F. Spelt
13. D. R. Tufano

14. R. E. Uhrig

15. Central Research Library

16. CSMD Reports Office

17. Document Reference Section

18. Laboratory Records-RC

19. ORNL Patent Office

\section{EXTERNAL DISTRIBUTION}

20 - 21. Office of Scientific and Technical Information, P. O. Box 62, Oak Ridge, TN 37831 


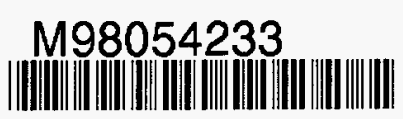

Report Number (14) ORUL/TH--13414

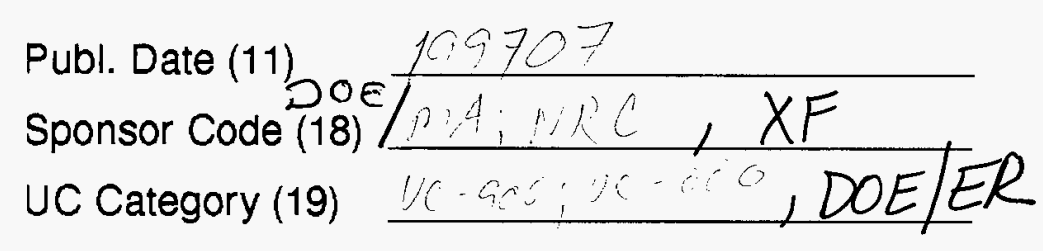

19980707091

DIIC QUALTTY INGPECTIED I 